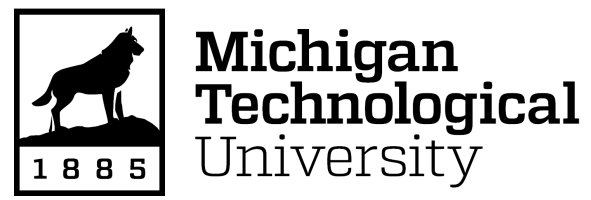

Michigan Technological University Digital Commons @ Michigan Tech

Dissertations, Master's Theses and Master's Reports

2021

\title{
The Motivation To Volunteer: Understanding Volunteer Motivation at United States Industrial Heritage Museums and Organizations
}

Cooper Sheldon

Michigan Technological University, cdsheldo@mtu.edu

Copyright 2021 Cooper Sheldon

Recommended Citation

Sheldon, Cooper, "The Motivation To Volunteer: Understanding Volunteer Motivation at United States Industrial Heritage Museums and Organizations", Open Access Master's Thesis, Michigan Technological University, 2021.

https://doi.org/10.37099/mtu.dc.etdr/1189

Follow this and additional works at: https://digitalcommons.mtu.edu/etdr

Part of the Archaeological Anthropology Commons, and the Museum Studies Commons 
THE MOTIVATION TO VOLUNTEER: UNDERSTANDING VOLUNTEER MOTIVATION AT UNITED STATES INDUSTRIAL HERITAGE MUSEUMS AND ORGANIZATIONS

\author{
By \\ Cooper D. Sheldon
}

\begin{abstract}
A THESIS
Submitted in partial fulfillment of the requirements for the degree of MASTER OF SCIENCE

In Industrial Heritage and Archaeology
\end{abstract}

MICHIGAN TECHNOLOGICAL UNIVERSITY

2021

(C) 2021 Cooper D. Sheldon 
This thesis has been approved in partial fulfillment of the requirements for the Degree of MASTER OF SCIENCE in Industrial Heritage and Archaeology.

\title{
Department of Social Sciences
}

\author{
Thesis Advisor: $\quad$ Dr. Timothy Scarlett \\ Committee Member: Dr. Mark Rhodes \\ Committee Member: Dr. Angie Carter \\ Department Chair: Dr. Hugh Gorman
}




\section{Table of Contents}

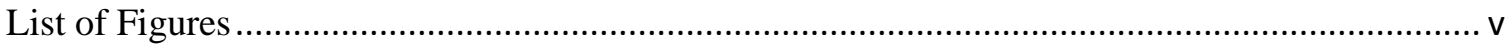

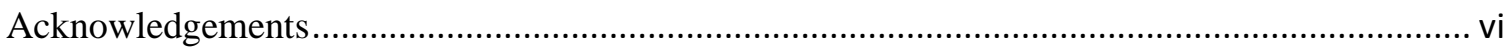

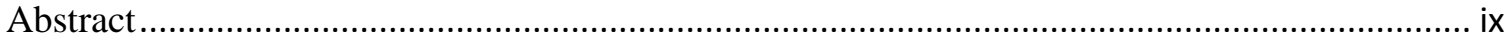

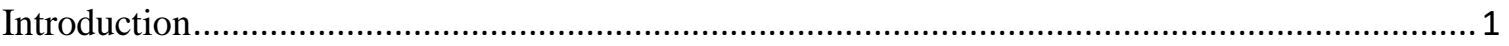

Chapter 1: A Brief History of United States Volunteerism ..................................................... 13

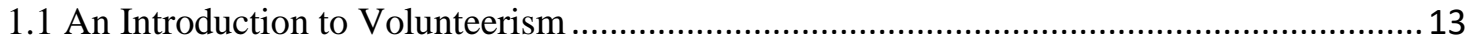

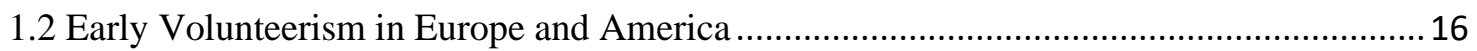

1.3 Contemporary United States Volunteerism: 1960s to 2010s ........................................... 25

Chapter 2: Volunteering and Industrial Heritage Museums and Organizations ............................ 33

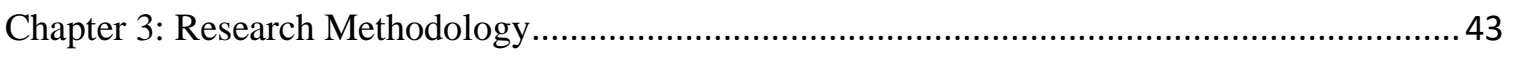

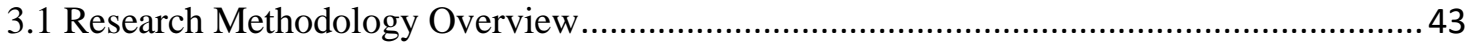

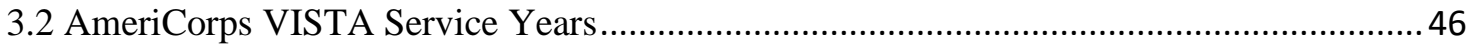

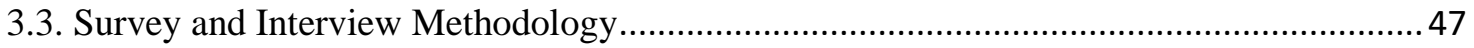

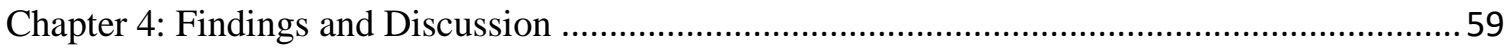

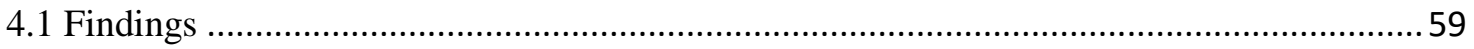

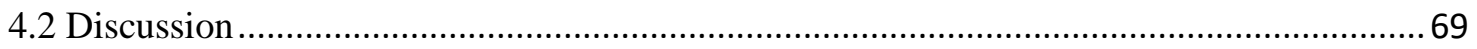

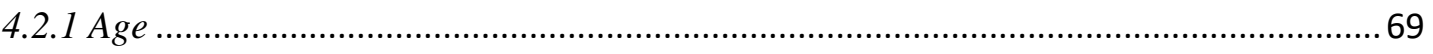

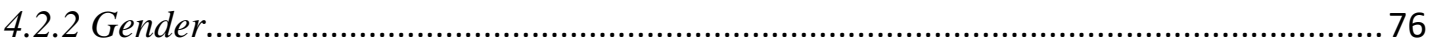

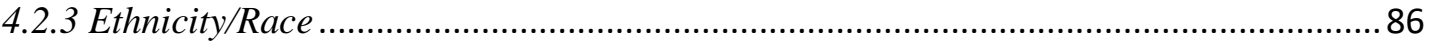

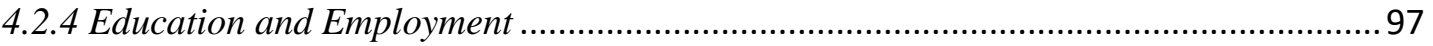

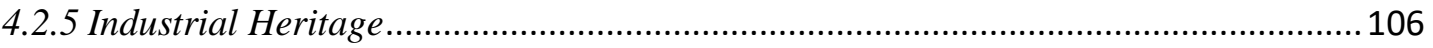

Chapter 5: Future Research, Misgivings, and Conclusion ......................................................117

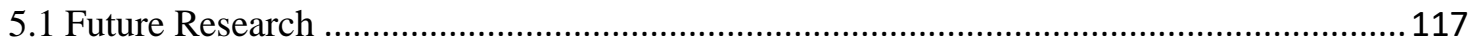

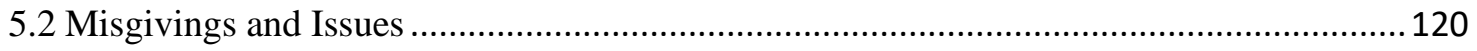

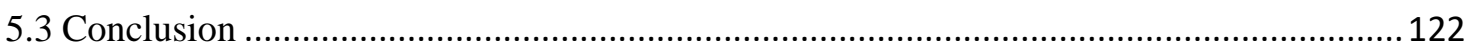

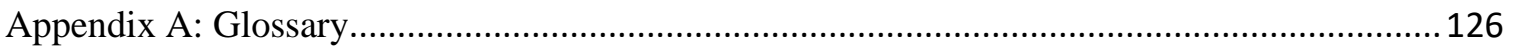

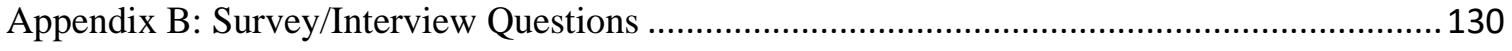

Online Survey for the Appropriate Museum Staff Member .................................................130 
In-Person Semi-Structured Interview Questions.......................................................... 138

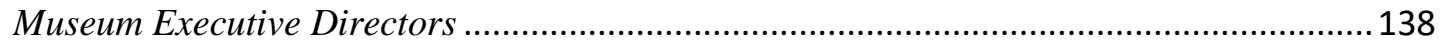

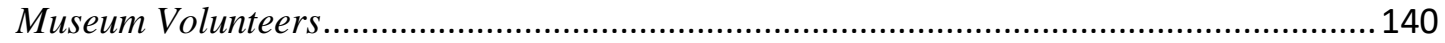

Over-the Phone Semi-Structured Interview Questions .......................................................142

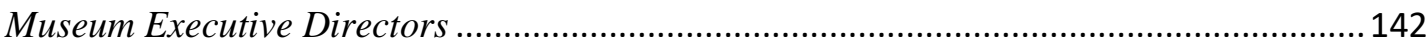

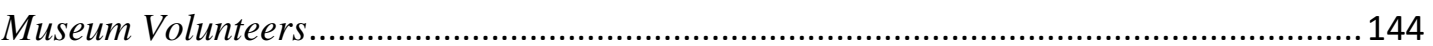

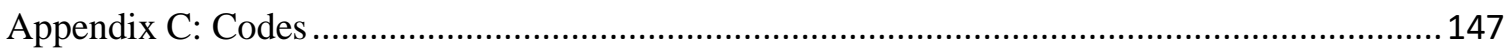

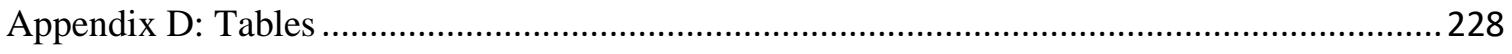

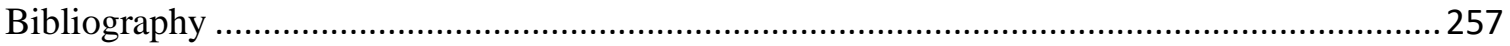




\section{List of Figures}

Figure 1-1. Visual representation of how IHMOs create and perpetuate narratives, and how and where narrative inclusivity can be introduced to the benefit of a wider range of demographics..... 7 


\section{Acknowledgements}

This thesis paper was created out of an interest in volunteering, museums, and industrial heritage; therefore, I would like to thank all those that lead to the production of this piece of academia and the data it contains. Firstly, we have the Michigan Technological University's Social Sciences Departments faculty, staff, and students for their interest and support of my research over the past three and half years. Within the department I would like to give special mention to Dr. Timothy Scarlett, my academic advisor who has worked tirelessly to fine-tune my interests and provide me with guidance when I lack direction or understanding of a concept. In addition to my academic advisor, are the members of my thesis committee, Dr. Angie Carter and Dr. Mark Rhodes. I thank Dr. Angie Carter for her assistance in helping me construct my theoretical concept of volunteerism. I thank Dr. Mark Rhodes for providing me articles on African American narratives within history museums and influencing my research's survey questions. Outside the social sciences department I would like to thank Blair Orr for their part in doing the volumes of paperwork that allowed me to do two service years with AmeriCorps during my studies. While they may not have contributed directly to my research I would also like to thank the various friends I made and college I spent my time discussing my theories with during my time as a student.

During my time as a graduate student, I spent two years as an AmeriCorps member with both years accumulating their own significance in my research. I'd like to thank the Stewards Individual Placement AmeriCorps VISTA program for the 
opportunity to serve communities within disserviced regions of the United States. Within the administration of the AmeriCorps program, I'd like to thank the 2018-2021 East Coast Office staff members. As an AmeriCorps member in Chicago at the Chicago Field Museum and Calumet Collaborative I would like to give special thanks to Madeline Tudor, Sarah Coulter, Mario Longoni, Mark Bouman, Ashley Hodges, the Maginault Family, and all those who supported and/or worked with me during my service year. My second service year as an AmeriCorps member was spent with the Vermont Granite Museum and its executive director Dr. Scott Arthur McLaughlin. Dr. McLaughlin has provided me with guidance since the summer of 2015 and as evidenced by this thesis continues to provide me with his personal experience, academic and workplace resources, and advising as a museum and heritage practitioner.

As part of my research, I called hundreds of museums and emailed hundreds more for data collection, therefore I would be remiss without mentioning my appreciation for those who allowed me to interview them and/or completed one of my surveys. I hope this research can assist in increasing volunteer and interpretation inclusivity within industrial heritage museums.

Outside my academic and workplace support I would like to conclude by acknowledging the greatest supporters in my academic pursuits, my family. Thanks go to my mother and father for allowing me to pursue something that brings me joy and a potential future income; to my brother who kept me entertained in some of my darkest moments; to my grandmother in Vermont who continues to be an inspiration and fountain 
of love; and thanks to all the rest of my family members who show interest in my research and career. 


\begin{abstract}
Industrial Heritage Museums and Organizations (IHMOs) in the United States (US) and their volunteers are underrepresented in the literature on volunteerism. The motivation and demographics of volunteers in IHMOs within the US are examined in this paper. Research into this topic is exploratory and little is known, therefore any hypothesis was based on personal observations as an AmeriCorps VISTA member in a variety of US museums. An online survey was sent out to three hundred and eighty-five museums across the US, along with conducting twelve in-person or over-the-phone interviews with museum practitioners and volunteers. This research found that a majority of IHMO volunteers are sixty years or older, male, white, hold a bachelor's degree, and/or are retired. The results of this research indicate a lack of age, gender, and race/ethnic inclusivity within IHMOs. I provide discussion on how IHMOs may be able to increase volunteer activity through the inclusivity of minority and disserviced groups, as well as how topics, such as industrial heritage, industrialization and de-industrialization, and familial ties play into volunteer motivation.
\end{abstract}




\section{Introduction}

Industrialized communities in the United States (US) preserve and interpret their shared history and heritage through for-profit and nonprofit Industrial Heritage Museums and Organizations (IHMOs). This industrial heritage is interpreted by trained professionals and volunteers in order to develop an appreciation and understanding of industrialization, the daily lives and struggles of the working class, the slowing of industry, and the benefits and repercussions of industry on local communities and environments. Industrial heritage exists within a grey area of history, it is both positive and negative and unifying and segregating, and therefore IHMOs that interpret it can be praised and criticized by local and national communities. A coal mine may be remembered as providing jobs to the local community, but also have a legacy of polluting local streams and causing poor health in its workers. An IHMO telling this story can interpret the industrial heritage as it relates to the company's economic prosperity and/or it can tell a narrative of economic hardship and environmental injustice. IHMOs present and cement industrial heritage narratives, feeding into present power relations within local and regional communities; they can also be used to contradict and provide contrast to pre-conceived notions of industrial heritage, giving voice to the excluded and underrepresented. Whether they are based in the urban metropolis or the rural countryside, most IHMOs need the support of the community to survive and thrive in an ever-changing world (Goddin, 2002; Rhoden, Inseon, \& Rita, 2009). Above all other methods of support is the volunteer, the community member who voluntarily gives their time, energy, and knowledge to keep their local groups, institutions, and organizations 
active and serving the public (Holmes \& Smith, 2009). While conducting my research, academic pieces on IHMO volunteerism and what motivates them was sparce. Academic studies on museum volunteers have been done in the past, but their work is usually centered on natural history museums (Goodland \& McIvorand, 1998) and non-industrial history museums (Holmes et al., 2010; Rowley \& Fullwood, 2017). Specific studies on IHMO volunteerism does not reach past the United Kingdom (Holmes, 1999; Goddin, 2002; Rhoden, Inseon, \& Rita, 2009) and Australia (Lander, 2006), and even then there are only a handful of published pieces to choose from. This gap in information provided me an opportunity to expand on the literature surrounding IHMO volunteerism and benefit IHMOs. With this in mind, I set out to answer the two following questions:

1. What are the motivations that convince US citizens to volunteer at industrial heritage museums and/or organizations?

2. Does the perception and use of industrial heritage at IHMOs motivate Americans to volunteer?

This project collected survey data from IHMOs across the country, as well as over-the-phone and in-person interviews from IHMOs in the Calumet Region of Indiana and Illinois and Central Vermont. Qualitative (grounded theory) and quantitative (descriptive and inferential) data analysis methods, were used to create and support preliminary theories surrounding the motivations of Americans at IHMOs to volunteer. Preliminary codes were developed from the open-response survey questions and transcribed IHMO and volunteer interviews. After their creation, preliminary survey codes were compared to codes derived from interviews in order to establish theoretical 
saturation and compare micro and macro data sets and theories on volunteerism in IHMOs. This thesis and the data collected from the survey and interviews have been sent out to IHMOs that participated in this research, as well as those that expressed interest. It is the author's hope that the information presented will help IHMOs better understand their volunteers' motivations and how industrial heritage can be used as a motivation for volunteering.

To understand volunteerism at IHMOs and how IHMOs and their volunteers present and perceive industrial heritage, I must also ask questions that tie in a volunteer demographic and socioeconomic background, and heritage narratives. Each of these overarching themes is intertwined with concepts such as informal and formal volunteering (Goodland \& McIvor, 1998; Stukas, Snyder, \& Clary, 1999; Langton, 1982; Rowley \& Fullwood, 2017) and intrinsic (altruistic) and extrinsic (egoistic) volunteering motivations (Parker, 1997; Stebbins, 1996; Stukas, Snyder, \& Clary, 1999; Rochester, Paine, and Howlett, 2010). Literature on volunteering with industrial heritage IHMOs is scarce, so to draw a line between what is known and what is not I need to review the concept of volunteer motivation and the overarching themes of volunteerism in the US.

Concepts pertinent to the research being proposed here are informal and formal volunteering (Goodland and McIvor, 1998; Stukas, Snyder, and Clary, 1999; Langton, 1982; Rowley \& Fullwood, 2017) and intrinsic and extrinsic volunteering motivations (Schuermann, 2016; Deci \& Ryan, 1985). The difference between formal and informal volunteering is based on whether the volunteering opportunity is structured through a non-profit organization with set guidelines for volunteers or it is being conducted outside 
of a non-profit for family, friends, or unincorporated groups (Tschirhart, 2005).

Volunteering with IHMOs is a public action with clearly defined guidelines, whereas the act of informal volunteering is less structured and not connected to non-profit organizations. This project focuses on IHMOs and their formal volunteers in order to support IHMOs with industrial heritage conservation and public interpretation through the efforts of their volunteers and staff members, as well as analyze trends in IHMO volunteerism to help IHMOs think through different opportunities for outreach or interpretation, so they can create more inclusive IMHO opportunities for volunteers.

Effective use of volunteer motivations allows IHMOs to both attract enthusiastic and driven volunteers; central to understanding a volunteer's motivation are the concepts of intrinsic and extrinsic motivation. Ryan and Deci (2000) define intrinsic motivation as "performing an activity for its inherent enjoyment or challenge", whereas extrinsic motivation "encourages activities that are done to attain a separable outcome" (pp.71). Why do volunteers spend their time and energy at IHMOs? Do they do it as a form of enjoyment or leisure volunteerism, are they seeking a coveted curator position, or is it somewhere in between? Part of my research sought to understand what combination of intrinsic and extrinsic motivation is most prevalent amongst this project's sample population of IHMOs and their volunteers.

Literature on the concept of volunteerism finds that a population's formal institutional volunteering is based on demographic and socioeconomic themes such as gender (Taniguchi, 2006; Petrzelka \& Mannon, 2006), employment (Tschirhart, 2005; Smith, 1994; Parker, 1997; Holmes, 2006), age and education (Holmes, 2006; Clary \& 
Snyder, 1999; Stukas, Clary, \& Snyder, 1999; Schuermann, 2006), and ethnicity/racial background (Middleton \& Morgan-Hubbard, 2018; Farmer \& Piotrkowski, 2009; Mattis, J. et al., 2004). To have the ability to volunteer with an IHMO, people need excess time and energy that they are not already putting into their family, friends, work, school, and other daily responsibilities. Some may volunteer to bolster their employability via the acquisition of job experience, while others have the experience necessary for employment but are retired and no longer need or want a paying job. Additionally, volunteers may not feel comfortable volunteering in an IHMO based on their ethnic/racial background or gender (Tschirhart, 2005). While some documented trends and suppositions exist as to which demographic and/or socioeconomic group consists of a majority of volunteers within IHMOs (Goddin, 2002; Rhoden, Inseon, \& Rita, 2009), there is very little academic work directed towards the subject to provide a foundation for further speculation. Due to the lack of research and literature on volunteer demographics within IHMOs this project provides insight into this query via a countrywide survey.

Inclusivity in industrial heritage interpretation is key if IHMOs want to both support and be supported by their local and regional communities, be a cultural resource for years to come, and grow their supporters and volunteers. With that said, issues such as inequality, discrimination, a lack of inclusivity, ignorance, sexism, and racism are part of the industrial heritage of the United States. Themes of exclusion, conflict, exploitation, and violence shadow all types of industrial heritage sites, despite some institutions avoiding narratives such as how some plantation museums obscure stories from those they enslaved, how children and women are used as only supportive 
characters or are entirely left out of narratives, or how the health, sovereignty, and culture of Indigenous peoples have continuously been sidelined by industrial corporations and nations in search of natural resources. IHMOs sometimes purposefully avoid or unintentionally neglected the stories of the vulnerable or under-represented communities so they can focus on heroic narratives of great industrial operations. This is increasingly understood to support white supremacy and patriarchal ideology. My study began out of a desire to help support IHMOs and their volunteers, but through my study, I can now show how my study presents a critical need for inclusivity in IHMOs and museums around the US, as well as outline for future research of inequality within the interpretation of industrial heritage.

Throughout this thesis the reader will come across qualitative data related to industrial heritage and demographic variables, such as age, gender, ethnicity/race, education, and employment as they relate to IHMO volunteerism. It is important to note that these categories are not static, they do not only exist within the stories of the past for museum visitors to view from a distance or to pick up and hold, instead, they are current and increasingly relevant to the museums themselves. For age, I have included a discussion on children as volunteers and their representation in an IHMO's narrative. When I discuss gender, I also include a narrative of the first women within museums and their voluntary efforts to carve out different professional positions, gendered in different ways in the communities of museum professionals. My brief review of ethnicity and race in United States industry from the 1700s to the current day is largely about the African American presence, while also touching on other underrepresented or underserved 
groups, such as immigrants and Indigenous peoples and these histories relate to the lack of representation from these communities in IHMO volunteer pools. As for my discussion on education and employment, I provide examples on how a variety of museums utilize local and regional work and education programs to benefit both the museum and those seeking an education and/or work experience. Throughout the history of the US varying ethnic and racial groups have been a part of industrial activity, therefore if IHMOs intentionally or unintentionally fail to include persons from underrepresented groups, they are leaving out the techniques, narratives, and personal experiences of those that lived and toiled the in mines, mills, and marine environs of the US.

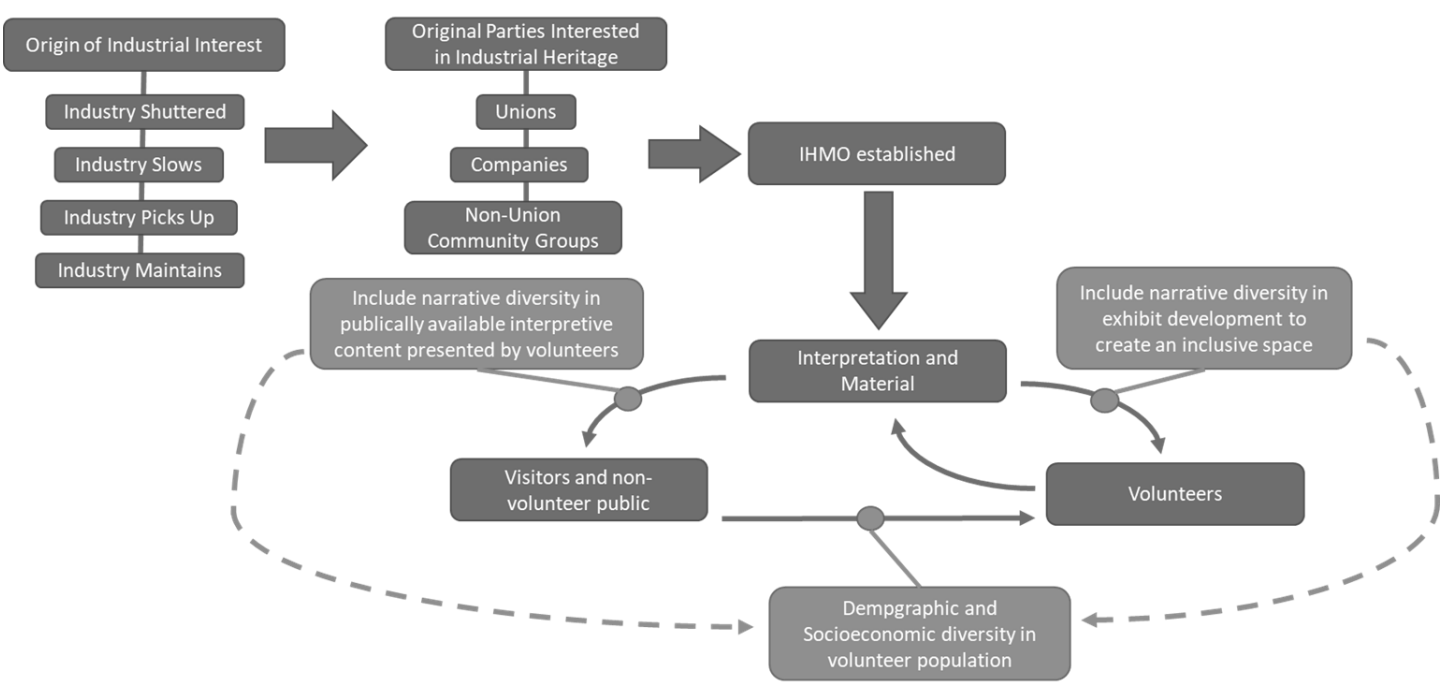

Figure 1-1. Visual representation of how IHMOs create and perpetuate narratives, and how and where narrative inclusivity can be introduced to the benefit of a wider range of demographics.

Figure 1-1 illustrates a view of how IHMOs create and perpetuate narratives. Where does industrial heritage narrative power come from and who holds the power to 
change the narrative in an IHMO? I believe that these questions can be answered by examining a series of topics: the industrial history of an industry/company; where the interest in presenting and preserving industrial heritage is derived and who is pushing for the establishment of an IHMO; and following the origins and supply of funding for an IHMO's creation and ongoing operations. There are four origins of interest narratives that can be leveraged by interested parties to create an IHMO and subsequent exclusionary narratives: Closing, Slowing, Picking Up, and Maintaining. All industries go through these four stages, and not always in a set pattern or order, therefore industrial heritage power narratives are selective. Interested parties utilize specific pieces of an industry's history in order to create an origin narrative and the subsequent power that comes from controlling a heritage narrative. It should be noted that each industrial heritage origin narrative helps develop a sense of place for members of the local community, be it the closing of an industry or an increase in industrial activity. The closing/shuttering of an industry can lead to a romanticized narrative of the way things were, with workers and the surrounding community potentially looking back favorably on a time of stable incomes and lifeways. A sense of place could be created through this narrative, though it is less likely that a community stuck by a closing/shuttering to show a sense of pride, unless that is through solidarity in the face of uncertainty. The power of a closing/shuttering narrative is derived from nostalgia and can be a potent tool, though it may also lose its strength as older generations pass away and social and cultural ideology change. In a similar fashion, the slowing, but not shuttering, of an industry may also lead to a romanticized and dramatic narrative of industrial heritage. Instead of a quick halt to a lifeway from a closing/shuttering, the slowing of industry draws out the mourning 
process and incrementally cuts workers and industrial activity, over time creating a sense of complacency and normalcy. An increase in industrial activity can bring in economic prosperity and work to a community, therefore it may be seen as a positive event in comparison to a decrease in economic certainty. Parties interested in industrial heritage interpretation, or utilizing it to push their own agendas, may see this period of prosperity as an opportunity to establish a power narrative through institutionalizing it in an IHMO. As with the slow increase in industrial activity, the maintaining of an industry over an extended period of time a sense of legacy, place, and pride develops and can transfer into the creation of an IHMO via a union, company, and/or non-union community organization. The narrative power at IHMOs comes from a dialogue between those that show interest in industrial heritage and those with the funding to provide support to interested parties.

Unions, companies, and non-union community groups are the three main interested parties that provide focus and intent in the establishment of an IHMO. While they can provide interest and funding on their own, each interested party can influence the actions and interests of the others. For example, a non-union community organization may be interested in creating an IHMO but not have the capital to do so, therefore they may turn to a contemporary company that might be interested and represented in local or regional industrial history. The two groups would create a partnership and develop an IHMO and interpretive narrative that both agree touches upon agreed upon events, people, industrial techniques, etc. Within this example, I could replace the company with a contemporary or retired workers union. During my time in Chicago as part of the 
research for this thesis I found that due to the presence of industrial activity in the region the partnering of corporate and community organizations allowed for the development, funding, and implementation of IHMO exhibits and activities that interpret the environmental and cultural heritage of the steel industry. Moving from this example, not all partnerships are beneficial and they can lead to the exclusion of narratives in favor of interpretation that feeds into a dominant industrial heritage narrative.

Volunteers are the lifeblood and frontline of the IHMO and therefore contribute to the creation and perpetuation of interpretive content through the development of exhibit content; assisting museum staff and other volunteers with research and community projects; and via giving tours, helping out at public events, and answering the publics' inquiries. Their narrative power comes from their own interpretation of the content available to them at the IHMO and the perspectives and experiences they bring from their demographic background and personal heritage. Volunteers have agency in their interpretation of industrial heritage, though if the IHMOs interpretation aligns with the volunteer's perception of industrial heritage it can potentially perpetuate an exclusionary narrative. A feedback loop is created between the volunteer and IHMO when the IHMO and its volunteer population is lacking in demographic and experiential diversity. The power narrative that was originally installed in the IHMOs interpretation is continuously feed back into the IHMO through the actions of the IHMO staff and volunteers when narrative inclusivity and volunteer diversity isn't included. This loop is only cemented by the inclusion of the visitor, who what they learn and take away from their interaction with the content of the IHMO may become the basis for their understandings of the industry 
and community the IHMO represents. In this power narrative diagram, visitors act as a fresh infusion of volunteers into the volunteer pool at the IHMO. It is at this point in the power diagram that inclusivity and diversity is the easiest to introduce through new volunteers of differing demographic backgrounds, bringing in new ideas, experiences, and perspectives to IHMO interpretation. Similar changes can be made to the industrial heritage narrative power system when IHMO staff and volunteers train new volunteers or retrain older volunteers, when volunteers act as docents, and when volunteers work with staff or other volunteers to produce new interpretive content. It is through these changes to an IHMOs industrial heritage narrative power system that a space can be created in which new volunteers of varying demographic backgrounds feel a sense of belonging and community.

IHMOs have tangible and intangible links to their surrounding communities, moreover, those who touch or focus on industrial heritage have a greater connection to local communities through a sense of place and common heritage. How this heritage is presented, what industries are presented, and the contemporary visibility of these industries on the landscape all play a part in why and how volunteers volunteer, how IHMOs present and interpret industrial heritage, and interact with industrial communities. While heritage tourism literature discusses volunteerism (Rhoden, Inseon, \& Rita, 2009; Lander, 2006; Holmes \& Smith, 2009; Holmes et al. 1999), what is not covered in the literature is the confluence of the topics: industrial heritage, IHMOs, and volunteerism in the US. IHMOs are linked to the past and present in ways that other museums are not, for 
their narratives are the stories of our family members and friends, of small beginnings and tragic loss, and of grit, grime, and ingenuity. 


\section{Chapter 1: A Brief History of United States Volunteerism}

\subsection{An Introduction to Volunteerism}

What is volunteering? Why do people volunteer? Who volunteers? When did the concept of volunteering begin? This chapter will briefly cover the chronological development of volunteering as it moved from $12^{\text {th }}$ century Europe to $21^{\text {st }}$ century America. Since this chapter is being penned in the 21st century, it will be using contemporary volunteerism theory alongside available historical voluntary action concepts presented by available period literature. On that note, what is volunteering, and is it the same as voluntary action and volunteerism? As definitive as one might think volunteering is, the concept of volunteering varies from source to source. A general definition of volunteering, provided by Stebbin's 1996 research on leisure volunteering, is as follows:

"Volunteering may be identified as a help action of an individual that is valued by him or her, and yet is not aimed directly at material gain or mandated or coerced by others. Thus, is the broadest sense, volunteering is an uncoerced helping activity that is engaged in not primarily for financial gain and not by coercion or mandate. It is thereby different in definition from work, slavery, or conscription" (Stebbins, 1996, p. 213)

While this perception of volunteering seems like common sense, there are some contextual pieces of information to consider. Stebbin's (1996) research looked at leisure 
volunteering, meaning, they neglected to account for the possibility that institutions may require their students to volunteer in order to graduate. Moreover, what about those who volunteer to obtain a paid job at a museum or non-profit; do their actions count as altruistic volunteering? As for the difference between volunteering and voluntary action, voluntary action is interchangeable with volunteering. The act of volunteering is complex and no one paper will answer the questions posed at the start of this thesis.

Currently, volunteering has become a national pastime of self-advancement, leisure, and altruistic action. The act of volunteering provides support to individuals and communities across America and various countries across the world. With the introduction of the internet everyone has become closer, and because of this, volunteer opportunities are at the click of the mouse or tap of a finger (Hochbaum, 2015). Fire departments, police forces, libraries, grade schools, youth groups, and museums all run on or are wholly dependent on volunteers from surrounding communities and beyond. Volunteers give their time and energy to these organizations with their own motivations. Current voluntary action literature seeks to understand this concept, with the most inclusive theory being based on multivariate reasons. Stebbins (1996) feels that people volunteer because of pure-altruism, but as Brindle (2015) states, " "we need them to be selfish' in terms of thinking what's in it for them" (Brindle, 2015). Volunteering is not based on pure-altruism, but some form of impure-altruism. This concept being that individuals hope for remuneration at some point in the near or distant future, the benefit to the volunteer and recipient of their help being unknown. In some instances, volunteers are exploited and used as free labor with the promise of career advancement. As will be 
seen when I discuss museum volunteering, volunteer exploitation is not the only issue surrounding the use of volunteerism in a museum setting. Volunteering is a complex phenomenon, and while I may not be able to point to the first voluntary act, I can provide a brief chronological overview of what is currently known.

This brief chronological review will examine how the western view of voluntary action spread throughout Europe and the US. Voluntary action began as a result of religious belief, but by the American Revolution (1765-1783) it was utilized by the patriots in order to grow their militia as they prepared to wage war with the British. After the establishment of the new republic in North America, voluntary action became entangled in the Second Great Awakening (1790-1840) and the first and second Industrial Revolution (1790s-1830s and 1870-1914). By the early $20^{\text {th }}$ century volunteering in America was associated with philanthropic and charity, mutual aid, and communitybased organizations. Amongst the social, economic, and political tumult of the 1950s-70s volunteerism was used by the government to wage a 'war on poverty' and secure America's moral future. From the 1980s onwards, volunteerism broadened to encompass topics such as tourist volunteering, serious leisure, and museum volunteerism. Since there is no literature on industrial heritage museum volunteerism, I will examine what is available from parallel subjects, such as volunteering in museums and heritage railways. Using this chronological approach to examining the development of volunteering, I hope to understand how it was co-opted by different organizations and institutions and how it may be used to benefit industrial heritage museums in the US. 


\subsection{Early Volunteerism in Europe and America}

Organized religion, class-based values, and impure-altruism are the root catalysts that grew into early forms of voluntary action. The western concept of voluntary action came from the development of religious beliefs and political intentions in late Medieval Europe. Around the $12^{\text {th }}$ and $13^{\text {th }}$ century approx. 500 European churches and monasteries acted as hospitals and places of refuge for the poor, sick, and destitute (Brindle, 2015; Hochbaum, 2015). This far back it is hard to discern the motivation behind a solitary volunteer, but Hochbaum (2015) believes that, as with earlier societies, they were social members of society who wanted to help others without the intention of being repaid for their charitable acts. In 1601, the English parliament put forth the English Statute of Charitable Uses which regulated what monetary actions were considered charitable. Under this parliamentary act, the following were considered charitable: providing alms to the poor and orphaned, assisting the sick and downtrodden, supporting young tradesmen, building or establishing public works and organizations, and ransoming captives (U. S. Volunteerism, “no date"a). Jumping forward to the $17^{\text {th }}$ and $18^{\text {th }}$ century, the North American colonies, still under the thumb of the British Empire, developed voluntary action alongside the growing notion of political and religious freedom. In the years leading up to the American Revolutionary War, and for some time afterwards, the Indigenous peoples helped the colonists, but unfortunately the Europeans took advantage of their charity, betrayed them, asserted ownership over the land, and killed more than one-hundred million Indigenous people. The late $17^{\text {th }}$ century found fraternal organizations, social clubs, the Freemasons, and community organizations 
being founded for the direct purpose of mutual-aid, entertainment, and education (U. S. Volunteering, "no date"b).

Beginning in April of 1775, the rebelling colonists utilized the concept of voluntary action as they fought against loyalists and the British military at home and on the battlefield. As will be seen in the 1800s, volunteering was gendered and strictly policed by society, but for now it is poignant to mention that a number of women moved beyond what was seen as their traditional role of supporting and caring for soldiers towards fighting alongside their husbands, sons, and fathers. Enlisted in 1782 under the alias of Robert Shirtliff, Debora Sampson was an example of a woman joining the American Revolutionary War. She served seventeen months with various regiments, eventually being found out after delivering a medical note to her commander in 1783 (Bronski, 2011). Moving from the battlefield and sites of bloodshed into the homestead, Berkin provides that women 'fought' the British through non-consumption, quartering patriot militia in their home, writing satirical plays, and raiding loyalist leaning food stores (Berkin, 1997). A majority of women during the American Revolutionary War joined with their neighbors to fill in for their male relatives in less outwardly significant ways, such as caring for family farms, continuing local businesses, and providing food and clothes for their family; all acts of obligatory volunteerism based on the desire to survive and maintain a semblance of their life from before the war. Approximately six years after the colonists barely survived the war, the newly formed American republic constructed the United States Constitution, giving citizens the right to speak their mind, gather in groups, and worship however they want. Feeding off the latter of these rights 
was the Second Great Awakening, a religious movement that extolled the development of voluntary organizations bent on saving the souls of the republic's citizens through voluntary action against sinful practices.

In the early $19^{\text {th }}$ century, around the same time as the Second Great Awakening various religious and secular voluntary organizations found their footing and began improving the living conditions of the communities around them. During the early decades of America, states were responsible for the welfare of their citizens, but their actions were slow to have an impact; enter privately funded voluntary organizations (Tnnenbaum \& Reisch, 2001). These organizations were philanthropic, and charity based with volunteers providing education, entertainment, political representation, and religious services to its members and the surrounding community. A majority of volunteers and members of these organizations were upper-class women, usually untrained 'proto-socialworkers' who wanted to "help poor individuals through moral persuasion and personal example" (Tnnenbaum \& Reisch, 2001). One such organization called the Mount Vernon Ladies Association (MVLA), charted by the state of Georgia in 1856, was a completely volunteer run organization of elite southern white women who wished to leverage their socially constructed and engendered 'role' as caregivers and guardians to preserve Mount Vernon (Brandt, 2016). With the purchase of Mount Vernon in 1859 the MVLA became the first women's historic preservation organization. In the following decades and centuries, similar organizations, such as the Colonial Dames of America, Daughters of the Confederacy, Daughters of the Utah Pioneers, and Daughters of the American Revolution would take part in similar acts of preservation. Outside the MVLA and other 
women's associations, groups like the American Temperance Society (1826), American Anti-Slavery Society (1833), Boston Society for the Preservation of Pauperism (1835), and the YMCA (1844), tried to address economic, social, and political issues surrounding poverty, immigration, and urbanization. When the American Civil War broke out in 1861, both sides were reliant on the charitable and philanthropic organizations that had cropped up prior to the fighting. As seen with the American Revolutionary War, husbands, brothers, and sons were either coerced or volunteered to fight for their respective sides of the conflict while their wives, sisters, and daughters acted as support (Rosenburg, 2013). Whether religiously or secularly leaning, motivated by wartime patriotism, or based on altruistic attitudes, volunteering played a pivotal role in the development of $18^{\text {th }}$ and $19^{\text {th }}$ century America.

At the end of the $19^{\text {th }}$ century, volunteering had already been co-opted for the support of war and community development, so as the $20^{\text {th }}$ century appeared on the horizon the second industrial revolution took hold and with-it voluntary actions defined by charitable and philanthropic organizations. Charity and philanthropic organizations are the focus of the period's volunteerism literature, with authors critically analyzing the actions of charities and praising the patronage of businesses, while forgetting to mention the hands-on volunteers (Bishop, 1902; Devine, 1913; Wines, 1898). In agreement with period writers, Rosenburg (2001) and Hochbaum (2015) believe the early $20^{\text {th }}$ century to be the birth of organizationally based voluntary action due to the establishment of voluntary and membership-driven organizations such as the Volunteers of America (1896), Rotary Club (1905), Kiwanis (1915), and the Lions Club (1916). Organized 
charities and community groups were beneficial because they provided the means of funding and hierarchy to men and women who had "varying gifts and acquisitions" that "can inspire goodness and graciousness in other men and women" (Bishop, 1902, p. 596). In the $20^{\text {th }}$ century, philanthropies and charities relied on voluntary donations of money or labor and were considered private voluntary organizations that acted as social welfare for the poor and destitute. Volunteering, as it is today, serves both sides of the political spectrum. It could be used by organizations like the Ku Klux Klan (1865) to disempower ethnic, racial, and societal minorities or it could be used to oppose lynching, influence economic and political reform, and promote African American and women's suffrage (U. S. Volunteerism, "no date"d). Not singularly existing on any one side of an issue, volunteerism had just as much strength as it does in the contemporary.

The late 1800 s, full of voluntary and membership-based private organizations, was a breeding ground of advocates for social change, such as Upton Sinclair (18781968), Jane Adams (1860-1935), and Jacob Riis (1849-1914). As the latter of this 'altruistic' advocate group, Jacob Riis used his photos to bring the New York slums to the city's townhouses. Through his photographs of tenement life in the 1880s and 1890s, Jacob Riis advocated for social reform, this advocacy originating from a place of 'altruism' and interest in the destitute members of New York's urban slums. By the 1890s, Riis's tenement reform advocacy became more of a lecture circuit, traveling outside the city to provide edutainment to members of society with money to spare. While his photos remain some of the most well-known, critics provide that his work was not wholly altruistic, instead, his motivations leaned towards fame and recognition by co- 
opting photographic journalism (Gurock, 1981; Swienty, 2008). Between the 1890s and 1910s, Riis voluntary action went from being centered on saving the souls of the poor and destitute to advocating for changes in tenement construction. As I have provided thus far, the development of volunteerism as a concept is a communal affair, but also not wholly equal. Bishop (1902) and Wines (1898), in comparison to Riis, are smaller figures, of whom little is known about. It is through their published works and contributions to charity and philanthropic themed literature that they have not been forgotten about, whereas Riis has whole museum exhibits dedicated to his photography (Jacob Riis: How the Other Half Lives, National Endowment for the Humanities). While the commonality and support of 'muckrakers' and social advocates like Riis grew, so too did religious leaning charities.

Of the voluntary organizations and institutions being subtly used by businesses and upper-class individuals, schools, libraries, social agencies, colleges, and museums seem to be the most affected. DiMaggio (1986) provides that museums in the early $20^{\text {th }}$ century could have been used to enlighten the public and shape their values in a way that benefits the wealthy. Museums required volunteers to support them with both labor and economic donations and membership, thus as these volunteer-run organizations became more professional the less volunteers were allowed to do. Extending off the idea of unselfishness, sociologist Bogardus (1882-1973) argued for the use of the term 'Unselfish Service'. At its core, unselfish service is a "habit of thinking first of the welfare of [others]" and "of reacting first from a standpoint of public welfare" (Bogardus, 1923, p. 101). This focus on helping others without benefit to one's self may seem utopian, but he 
proposes that with humans "even [their] inherited traits are largely products of group survival; and hence the habit of responding to group needs (unselfish service) is simply a normal trend in the individual's growth" (Bogardus, 1923, p. 102).

Writing during a time of uncertainty and hardship, Benjamin (1932) and Burns (1932) relay that voluntary action does not halt just because the economy was in one of the largest depressions in US history. From what Benjamin (1932), Devine (1913), and Wines (1898) have hinted at, family agencies or social work was moving up in the ranks of "helpful" services meant to alleviate the economic and social ills of society. Benjamin (1932) felt that supportive voluntary action tactics were changing from giving monetary donations to the needy, to meeting their social needs, stating that "it is a wasteful use of a good case worker's time to give or try to give case-work services to a family whose only desire and need is relief' (p. 138). While his statement does not call for charities to stop the practice of giving money out to the poor, it does relay that they are thinking that social and emotional support during times of crisis may be better suited to mend the wounds of economic devastation. In a similar fashion, Burns's (1932) believed that instead of blaming each other for unemployment and making no headway on the issue, communities should agree that it was a collective issue and proceed to have the government, public services, and municipalities provide help or relief. During the Great Depression (1929-1939), Benjamin's (1932) research found that “one of the significant factors emerging from the situation [Great Depression] is the "rediscovery" of the volunteer by family societies" (p. 136). Both Benjamin (1932) and Burns (1932) indicate that volunteers were held as a positive factor that resulted from the social, economic, and 
political turmoil of World War I (1914-1918) and the Great Depression. Whether their notion that family agencies 'rediscovered' volunteering is valid or not, their research makes clear that voluntary organizations and communities were experiencing an influx of (potentially male) volunteers (Benjamin, 1932; Burns, 1932). Burns (1932) believed that the previously mentioned selfishness in volunteering was "obsolete", stating that (in the context of supporting US soldiers) "we [United States community members] did not feel that we were in any sense the superiors, or benefactors" (p. 463). The mention of 'benefactors' brings up a concept not brought up by previous authors, the idea that a volunteer is gaining something from their service and not just gaining that (noneconomically redeemable) warm feeling in their heart. Akin to Bogardus (1923) and Devine's (1913) critique of volunteer motivations is Burns (1932) belief that a volunteer's motivation is based on local and national economic and industrial conditions. Contrasting Benjamins (1932) outwardly positive views on volunteering, Burns (1932) is deductive and concerns himself with the underlying motivation of volunteers during the Great Depression and World War I. To Burns, advocacy within the voluntary action theory can be dissected and separated into three 'social devices': economic (unemployment), social (depression), and political (involvement in the war). These three social devices can be found throughout the world, playing their roles in war, economic devastation, and peace times. Ultimately, Burns (1932) concluding that volunteering is a socially developed mentality of self-aggrandizement, "gratuity of supererogation", and self-indulgence. In a way volunteering was used not to help the community or society at large but the individual's ego and social worth (p. 463). The beliefs and values Benjamin (1932) and Burns (1932) hold towards volunteerism reflect the contradicting themes 
behind volunteering, the grey area that exists between advocating for social, political, and economic action through volunteerism, and why people volunteer.

While World War II raged in the European theater, volunteers back in the America continued to support their communities and advocate for social, political, and economic change. In conducting research on volunteerism during this tumultuous period in US and world history, there was a plethora of voluntary action literature concerning soldiers; because of this I chose to focus on volunteers on the US Homefront. At this point in US military history women were now serving overseas as soldiers, medics, mechanics, and a variety of other positions. Back in America, men and women who stayed back to provide support and hold down the country worked and volunteered with the intention of helping their friends and relatives in the European theater as well as their local community. While women volunteers were still forced into playing the role of supporter and caregiver, his inclusion of women indicates that they were beginning to move out of the shadows of their male counterparts and into the spotlight. Based on research into voluntary action during the 1940 s, volunteering developed a rigid management structure that utilized volunteer motivation to advocate on the organization's behalf, a slight increase in formal volunteering by women, and a plea for community oriented informal volunteering movement. With the end of the Second World War and the dramatic social changes of the $60 \mathrm{~s}$ and $70 \mathrm{~s}$, volunteering will see a resurgence that seeps into the economic, social, and political fabric of private and public organizations across America. 


\subsection{Contemporary United States Volunteerism: 1960s to 2010s}

On Wednesday, January $8^{\text {th }}, 1964$ President Lyndon B. Johnson, proposed the Equal Opportunities Act during his State of the Union address, officially starting the 'War on Poverty'. Throughout the 1960s and 70s United States (US) voluntary action literature had a resurgence due to social, political, and economic ills, such as the Watergate scandal (1972-74), the Assassination of JFK (1963), the Red Scare (1950s), the Vietnam War (1955-75), and the Hippie movement (1960s). While the term 'volunteerism' was used throughout the early 1900s it began a steady escalation in the 1960s (Google Ngram Viewer, Volunteerism). After the turn of the $20^{\text {th }}$ century volunteerism became something of a national pastime, with vacationers traveling to far off locals to 'support' South African communities and students taking years at a time to volunteer with governmentally funded organizations. From the 1960 s to the late 2010 s the application of formal and informal volunteerism branched out to take root in subjects like anthropology, economics, environmental studies, gender and women's studies, and history. Within these branched sub-themes of volunteerism is the concept of industrial heritage museum volunteerism. Instead of laying the literature in chronological order it makes sense to examine each concept within volunteerism on its own. While the purpose of this paper was to draw a line between volunteerism and industrial heritage in museums, it is pertinent that I interweave the topics with similar sub-themes of contemporary volunteerism. It should also be noted that this segment's discussion of volunteerism is not centered around historical events, instead it concerns the application and theoretical differences of 'who volunteers and for what reason'. 
Volunteering is not organized, there are innumerable private and public and informal and formal not-for-profits and non-profit organizations in the $21^{\text {st }}$ century. Moreover, the same could be said about the $20^{\text {th }}$ century, because of this the late $20^{\text {th }}$ and early $21^{\text {st }}$ century of voluntary literature can be examined based on theoretical paradigms and thematic categories. After conducting a literature review of voluntary action, Rochester, Paine, and Howlett (2010) posit that there are three paradigms that constitute volunteerism: 'non-profit', 'civic society', and 'leisure'. The idea of paradigms in volunteering is novel but useful in categorizing voluntary action, therefore I will use Rochester, Paine, and Howlett (2010) as a jumping point to examine the literary positions of other authors and their theoretical examinations of volunteering. Non-profit volunteerism is seen by Rochester, Paine, and Howlett (2010) as the dominant paradigm due to its longevity and pervasiveness in literature and $20^{\text {th }}$ and $21^{\text {st }}$ century volunteering (Carson, 1999; Lander, 2006; Martin, 1925; Sweetland, 1943).

Individuals who volunteer with non-profits are motivated by a sense of altruism where they care for others, alleviate poverty, support the destitute, and develop social welfare. Organizations that fall within this paradigm are usually highly organized, have paid staff members, and volunteers are recruited, selected, and trained for specific tasks (Rochester, Paine, \& Howlett, 2010). Highly organized and large-scale museums in urban areas, such as The Chicago Field Museum, The Smithsonian, and state museums would fall under this paradigm. The second volunteering paradigm, 'civic society', as outlined by Rochester, Paine, and Howlett (2010) has volunteers motivated by the possibility of self-help, mutual assistance, and social, economic, and political improvement. Common 
to this paradigm is a lack of altruism, charity (Jordan, 1916), and philanthropy (Burns, 1932); although the concept of impure altruism may be applied to this paradigm. Organizations that situate themselves within this 'advocacy' paradigm are mostly grassroots associations with their entire staff consisting of volunteers (Sweetland, 1943). 'Civic' (Cause-Serving) volunteering is portrayed by Parker (1997) as seeking to "meet the needs of another without reward"; the cause being political, religious, moral, etc. (p. 5). This paradigm exists in all levels of the US political continuum, making it a possible answer to issues concerning the lack of governmental assistance on societal issues. Leisure volunteering is the third paradigm, where people are motivated by personal interests and enthusiasm in a subject, the acquisition of information, personal experience, and/or skill in a subject or career field out of curiosity or future benefit. Similar to Rochester, Paine, and Howlett (2010), Parker views leisure volunteering as “giving one’s time and energy not primarily to help others altruistically, not to help oneself in a market situation, not to help a cause in which one believes, but primarily to have a leisure experience" (p. 5). Adding to the concept of leisure volunteerism is 'serious leisure', which is itself contradictory in that its self-interestedness overshadows possible altruistic actions (Stebins, 1996). Serious leisure usually involves volunteering to benefit one's career or hobby, such as volunteering with a heritage railway or industrial heritage museum. Outside of the three paradigms are the concepts of market and pure-altruistic volunteering. Market volunteering is defined by Parker (1997) as giving "something 'freely', but with the ulterior motive that you expect something in return, eventually if not immediately". This form of volunteering is the most prevalent and is theorized as being the base of volunteering. While the three paradigms do cover a majority of voluntary 
organizations and volunteer motivations, they do not consider individuals and organizations that may exist in two or all three paradigms at once; that's where Rochester, Paine, and Howlet's (2010) four paradigm hybrids come into use. These four hybrid groups of the three paradigms of volunteering are service-civic, civic-leisure, leisure-service, and a service-civic-leisure. Instead of a volunteer's motivation being determined through mono or bivariates, these hybrids can be arranged to encompass multi-variate volunteer motivations.

Out of concern for the future values, morals, and ideals of its citizens, the United States (US) government and non-governmental organizations developed programs to support 'new volunteerism'. In 1973 the national volunteer service programs were developed, one of which went on to become the Volunteer In Service to America (VISTA) program. Currently the VISTA program is part of a larger organization called the Corporation for National and Community Service, of which provides funding for organizations that wish to obtain the efforts of gap-year volunteers (year-long volunteers). As found with the development of organizations like VISTA, Langston (1988) believes that the development of these programs was to create "active involvement of voluntary associations in the revitalization of American cities" (p. 3). Stkas, Snyder, and Clary's (1999) examination of how students in US high schools may respond to being required to complete a set number of hours volunteering in the surrounding community suggests that it is not uncommon for an organization or institutions to use volunteering as an educational or management tool. Their research found that requiring students to volunteer undermines their future behavioral intentions to 
volunteer due to a lack of interested or time (Stkas, Snyder, \& Clary, 1999). On a similar note, societal influences in an individual's environment can also subliminally coerce an individual to or not to volunteer. The 'blame' for negativity surrounding the act of volunteering should not be placed on one central institution, instead it should be focused on the contextual clues surrounding the volunteer and the institution they volunteer with. Volunteerism in US industrial heritage museums may follow a similar case where volunteers are motivated by social groups, academic requirements, or familiar ties. The act of volunteering, as recognized by Langston, holds a sense of catharsis that developed as a social tonic meant to dull the pain felt from societal wounds inflicted by the Vietnam War, Watergate scandal, theological uncertainty, etc. This volunteer catharsis is defined by Langston (1988) as "a process of expressing strong emotions in order to restore a healthy sense of balance in the human soul" (p. 4). The social guilt and disgust this catharsis aimed alleviate did not fix the social, economic, and political issues in society, but it did influence the perception that the new volunteerism was some form of moral crusade or 'corrective' force. Adding nuance to this movement, Langston (1988) provides that advocacy for social change was defined as subjective and prophetic, with the prior meaning "proposals which have a direct and relatively exclusive benefit to the advocating institution", the latter "proposals concerned with correcting unjust conditions in society and which will have little or no direct benefit to the institution" (p. 7). These distinctions play into the question of 'why volunteer and for what reason' as volunteering with any organization (industrial heritage museum or otherwise) can have a multitude of social meanings, such as supporting an industry or helping to educate visitors on environmental pollution. Langston provides researchers with historical background in the development 
of the volunteerism and non-profit craze that continues to populate a space once was filled by philanthropic and charity-based organizations in the early 1900s.

Key to the late $20^{\text {th }}$ and early $21^{\text {st }}$ century concept of volunteerism is what determines participation and who is considered a volunteer. Smith's (1994) literature review of volunteer participation outlines five possible determinants: Context, Social Background, Personality, Attitude, and Situation. Instead of three general paradigms of volunteerism (Rochester, Paine, \& Howlett, 2010), these determinants allow for the examination of singular volunteers and their motivation to volunteer. The benefit in examining more than one determinant allows the researcher to view means of volunteering from various angles, sometimes even producing outcomes contrary to previously conducted studies. While academic journals written in the early $20^{\text {th }}$ century managed to skim the surface of who participates in volunteering opportunities (Martin, 1925; Piper, 1941), they neglected to mention who 'counts' as a volunteer. Research conducted by voluntary action scholars Tschirhart (2006) and Stkas, Snyder, and Clary (1999) on company management and educational requirements state that the voluntary actions of individuals within institutional or business systems may be required to volunteer in order to maintain company or education status. This begs the question as to 'what qualifies an action to be considered volunteering?'. Carson (1999) believes that using the words like 'amateur' to describe the efforts of volunteers is demeaning; moreover, some volunteers are retired professionals. What then should it be called? Petrzelka and Mannon's (2006) ethnographic examination of gendered volunteering in rural Ohio considers volunteering to be contextual and that in rural areas it should be seen 
as economic survival. In the community Petrzeklka and Mannon (2006) conducted their participant observation, it was evident that outside of survival the community members were motivated to 'volunteer' because it allows them to serve others and provides them with social interaction. The community members in Petrzeklka and Mannon's (2006) research meet each of Smith's (1994) participant determination categories. Still, should this be considered volunteering, economic survival, or serious leisure? In his own words, Carson (1999) describes the complexity of defining volunteering, stating that it "is recognized as a cultural activity that is conditioned by multiple factors including ethnic traditions, religious beliefs, and legal regulations" (p. 68). This detention of volunteering still lacks a solidity; instead, it provides an amorphous and dynamic concept of voluntary action. Who is considered a volunteer is then relegated to the systems in which it is utilized, such as US corporations and educational institutions.

Early $20^{\text {th }}$ century US voluntary research tends to discuss larger organizational structures (Bishop 1902; Burns, 1932) and volunteer motivations, but lacks the perspective that not everyone can, or does, volunteer in the same way. Moreover, who can and does volunteer is linked to formal and informal volunteering. Informal volunteering ranges from helping family members to shoveling the snow off an elderly neighbor's walkway, whereas formal volunteering mainly concerns organized groupbased volunteering. Acting on a community's industrial heritage is at the crossroads of informal and formal voluntary action because the volunteer can both support the community without organization and benefit how others view the industrial heritage through museum exhibits and programs. Based on current research I can only speculate 
on the motivations behind museum and industrial heritage volunteerism in the US, therefore, to develop some understanding of the subject and how it answers the question “who volunteers and for what reason' I need to briefly examine the literature surrounding industrial heritage and museum volunteering outside America. 


\section{Chapter 2: Volunteering and Industrial Heritage Museums and Organizations}

While volunteering in the United States includes a variety of museum and heritage organization opportunities, from conducting tours of historic homes and teaching kids about natural sciences to preserving historic structures and collecting oral histories from local senior citizens, it lacks voluntary action literature on the convergence of the two. Contemporary museums, or the concept of them, cannot exist without the support of local communities. In the past, private collections of artifacts were collected and curated by individuals, now, public and private museums have become hybridized. Be it private, public, or a hybrid of the two, museums in the countries like the US, United Kingdom (UK), and Australia rely on volunteers for support. Due to a lack of literature on industrial heritage volunteering in the US, I will draw case studies and research from the UK and Australia. It is by combining the literature and perspectives from industrial heritage organizations and museums and applying it to museums in America that I can begin to develop literature surrounding US industrial heritage museum and organization (IHMO) volunteerism.

Before I discuss industrial heritage volunteering in the UK and Australia, I need to briefly cover the topic of museum volunteering. Museums can be managed by forprofit, non-profit, and not-for-profit organizations, but for this literature review, I will be focused on their non-profit variation. I chose to examine non-profit IHMOs because they are either completely volunteer run or have a mix of paid staff and volunteers. The use of 
volunteers in the museums allows for the sharing of formal and informal forms of knowledge, the education of future curators and heritage practitioners, and the inclusion of local community members. Knowledge in of itself is useful to the continuation of the contemporary, for, as Csikszentmihalyi and Hermanson (1996) states, "it would be difficult to see how a species as dependent on learning as we are could have survived if we did not find the process of making sense of our environment pleasurably rewarding" (p. 67). Knowledge is power, and "if [volunteer management] is done well, a huge resource of interested, concerned and lively people can help to educate others and simultaneously educate themselves" (Goodland \& McIvor, 1998, p. 2). Rowley and Fullwood (2017) conducted in-person interviews with volunteer management staff members and voluntary focus groups with museum volunteers, ultimately finding that "informal learning was...the principle vehicle for the acquisition of knowledge by volunteers" (p. 856). When discussing informal and formal volunteer opportunities, nonmuseum volunteering research (Carson, 1999; Petrzelka \& Mannon, 2006; Stukas, Snyer, \& Clary, 1999; Tschirhart, 2005) does not mention knowledge transference. Museums are dependent on the "consumption" of knowledge, not only by volunteers, but by visitors; following this perspective, volunteers can be seen as merchants of knowledge and the public their prospective buyers or clients. This view of volunteerism may seem bleak and reductive, but Goodland and McIvor (1998) make note that voluntary actions are multivariate and almost intersectional in their motivational complexity. Goodland and McIvor (1998) provide that a major motivation to voluntary action is based on the idea of the ego and that people discover satisfaction for presenting knowledge to others can become enticing, therefore volunteers may continue in order to gain a form of superiority 
over others based on the acquisition and dealing of knowledge. For my research, this view confirms what previous research has recovered, that, in at least one theory of volunteer motivation, volunteers use time and their actions as social capital or as a bargaining chip (Holmes, 1999, 2006; Rowley \& Fullwood, 2017) in the crossroads of economic and social spheres; objects and the intangible knowledge that follows them become positional goods. The volunteer sells and is sold a good of the temporal variety.

Museums, other than being spaces of voluntary knowledge transference, play host to visitors (guests) from outside the local community. A reductionist view of museums provide that they are essentially tourist traps where members of the surrounding community (hosts) come to act out and fulfill their motivations to volunteer and where people from outside the community come to glimpse at what the surrounding communities want to show to outsiders (Rowley \& Fullwood, 2017). I believe that they while that reductionist view of museums has some valid points, mainly concerning the role of volunteers, the IHMO is more of a cultural resource to be used by visitors and volunteers. Volunteers at these museums act as the mouthpiece of the community, sharing the narrative depicted at the museum with their own personal flare thrown in to make interactions and interpretations of heritage one-of-a-kind. Holmes et al.'s (2010) research places the concepts of guest and host volunteering into the context of leisure volunteering (Parker, 1997; Rochester, Paine, \& Howlet, 2010; Stebbins, 1994) and tourism volunteering. In order to parse the difference between guest and host Smith et al. (2005) provides four dimensions of tourism volunteering: setting, time commitment, level of obligation, and remuneration. These dimensions, when applied to a museum setting, 
find that tourist volunteers may be given opportunities that required less intimate knowledge of the museums subject matter. Volunteers, no matter their familiarity with the artifacts and museum staff, are significant to the museum industry in that they provide support and community for the museum and injecting institutions with life and new perspectives on well-worn topics and issues.

Museums and their staff are not static, staff members move forward with their career or onto other museum jobs, therefore there will always be a need for young museum professionals and interested community members. In the museum industry it is almost a requirement to have volunteered in a museum if you want to be hired as a staff member (Merritt, 2016). Undergraduate and graduate students volunteer at museums in order to gain experience in their career field, turning museums into a vast training ground for future museum professionals. Even if an interested volunteer does not choose to go into the field of museum studies, they still use the knowledge they gained to benefit their future actions and influence whatever career path they choose. While volunteers are beneficial to the ecology of the museum, the surrounding community, and the volunteers themselves, the concept of volunteering in a museum setting has some drawbacks.

Volunteering in a museum may be exciting to a young professional, interested community member, or tourist, but it can have serious ethical issues, such as economic and social inequality and volunteer exploitation. As of April 11, 2019, one hour of volunteering is similar to $\$ 25.43$, with a total of sixty-three million people volunteering a combined eight billion hours of time in the US alone (Independent Sector Releases New Value of Volunteer Time of \$25.43 Per Hour, 2019). While these estimates are based on 
data provided by organizations that offer formal volunteering opportunities, it lacks the number of informal volunteer hours. Individuals that have more personal obligations, such as caring for family members, holding multiple jobs, and attending school are less likely to volunteer, whereas those with less obligations and responsibilities may spend more time volunteering. If the goal of the volunteer is to gain experience so that they can gain a paid position at a museum then, based on their social, economic, and racial background, they might have a long road ahead of them. Overt segregation in museums no longer happens, instead it is subtle and prevents people from volunteering based on their social connections, economic wealth, and education (Holmes, 2006). Pearce (1993) presents, from their own literature review on volunteer motivation, that those with a higher degree of education, income, occupational status, and social standing are more likely to volunteer than those without these demographic attributes. In some situations, such as volunteering to conserve artifacts or give guided tours, potential volunteers may not be allowed to volunteer because they lack the 'proper' educational requirements (Holmes, 2006). In a study of friend organizations in UK museums, Prestwich (1983) found that museum executives were concerned that the utilization of friend groups and volunteers would eventually replace paid museum professionals. While the 'friends of the museum' groups were, on average, older, wealthier, socially connected, and college educated, museum volunteers were pictured as being relegated to grunt work. Based on this study it seems that volunteers were not trusted to do anything without the consent and direct supervision of a staff member or 'Friend of the Museum' member. It seems that even if someone were able to beat the inequality within the museum industry, gain 
some credit in the museum, and be given a volunteer position, they would still be the equivalent of a school child being guided by an omnipresent and overbearing teacher.

The second major issue that exists in museum volunteering involves the mismanagement and exploitation of volunteers. With the increase of public interest came a simultaneous increase in the volume of volunteers. This influx led to changes in volunteer management and the concern that volunteers would take the jobs of paid staff members (Rochester, Paine, \& Howlett, 2010). Instead of looking into how and why volunteers were 'stealing' museum positions from museum professionals, Holmes (1999) conducted a study on the exploitation of volunteers seeking careers in the museum industry. They questioned "how useful is work experience gained outside of a [museum] study programme?" and "Is [museum volunteering] valuable experiential learning or simply exploitation by an under-resourced sector?" (Holmes, 1999, p. 241). At the conclusion of the research Holmes found that the motivations behind volunteering change from volunteer to volunteer, but for younger and inexperienced museum professionals, volunteering might be seen as gaining experience in order to elevate themselves into a paid position. The issue behind this reasonable pathway towards a career in the museum industry is based on the inordinate economic resources young professionals funnel into the pursuit of a paid museum position. Holmes (1999) outlines three goals that need to be reached before a volunteer can obtain a paid position: “(1) Independent volunteering to gain a place on a postgraduate museum programme. (2) An unpaid work placement as part of postgraduate museum program. (3) After completing a postgraduate museum programme of study they may have to continue to volunteer independently to gain 
additional skills and experience in order to find paid work.” (p. 246). These findings suggest that in order to gain a position at a museum they might be required to become economically in-debt or reliant on a non-traditional form of support such as relatives, loans, or state support. As museums branch out into differing fields of subject matter, museums centered and inclusive of industrial heritage may offer inclusive volunteer positions due to its connection to the topics of labor and industrialization.

Industrial heritage museums in urban and rural geographical regions across the US, speak of industrial heritage narratives told through voluntary community interpretation. As a part of my research design, I chose to survey non-profit industrial heritage museums because of the role volunteers have in the institution's management and interpretation of industrial heritage. In the US, IHMOs range from exhibiting the process of smelting iron ore to be used in the production of railway ties to the use of those ties in the expansion of railroads and commerce across the United States in the $19^{\text {th }}$ century. A discussion on volunteering and the management of volunteers is lacking in the literature surrounding these industrial heritage museums is, as a result I will examine it in the context of the UK and Australia.

Occurring between the 1750s and 1840s, the European industrial revolution led to the development of massive industrial factories, canal systems and railways, and urban communities. After the Second World War and the near destruction of many industrial sites across Europe, and the spread of a service economy, individuals concerned with the preservation of these sites banded together and began to advocate for their protection and interpretation. Key to this movement towards protection, preservation, and interpretation 
was the efforts of volunteers and volunteer-based organizations. As of the $21^{\text {st }}$ century, organizations like the European Route of Industrial Heritage (ERIH) and European Heritage Volunteers (EHV) have developed networks of volunteers and industrial heritage museums. The EVH website's homepage provides that "the understanding and the public appreciation of technical heritage strongly differs between the particular European countries - some countries have a very strong and living tradition in preserving technical and industrial heritage meanwhile in some other countries that is not at all the case and the interest for technical heritage is limited only on a very small circle of enthusiasts." (Industrial Heritage, European Heritage Volunteers). This statement indicates that volunteering with an IHMO may be related to its geographical placement and the strength and opacity of local heritage. As we have found with studies focused on the application of volunteerism at museums, volunteers enjoying their experience can bolster a sense of community in and around the museum. With the connection of industrial heritage to labor and hands-on activity in mining, manufacturing, and agriculture, volunteering can be seen as a bridge between historical narratives and contemporary issues. Reflecting this concept on an international level, EHV states that "international volunteering at technical heritage sites can help to create bridges between those different traditions and approaches, at the same time creating more public attention for technical heritage sites and supporting the local enthusiasts in their efforts to conserve and to restore a specific technical heritage site." (Industrial Heritage, European Heritage Volunteers). 
Of the few works on industrial heritage volunteering in the UK, a majority discuss volunteer motivations of heritage railway volunteers (Goddin, 2002; Rhoden, Inseon, \& Rita, 2009). Goddin's (2002) research on volunteer motivations at two UK heritage railways, found that leisure volunteering is the dominant motivation for volunteers, with a slightly lower theme being the comradery between staff and volunteers. Studies on volunteer motivation in US museums found that motivation is based on similar values, with younger museum professionals motivated by the prospect of future career opportunities. Contrary to museums in the US, Rhoden, Inseon, and Rita (2009) found that volunteers did not seek out the heritage railway to gain experience for employment or advancement in careers, more, they did so in order to have a social group, relax, teach, and change pace. The data collected by Rhoden, Inseon, and Rita (2009) indicates that these motivations could be leveraged to retain volunteers through targeting specific age groups and gender orientations in the UK volunteer pool. Understanding who volunteers and for what reason can not only help the industrial museum attract volunteers, but it can also help the volunteers transfer their personalized knowledge of the industry in question. Moreover, Rhoden, Inseon, and Rita's (2009) research shows that heritage railway volunteers are predominantly older males who want to volunteer in a hands-on role. Historically speaking the railway industry was predominantly made of male workers, however Rhoden, Inseon, and Rita's (2009) identified that women who volunteered tended to spend more time supporting the management of the heritage railway through fundraising and less hands-on volunteering. This finding reflects the gendered spheres present in industrial heritage volunteerism. Both research projects included the volunteer motivations of males while failing to address the motivations of female volunteers. 
Volunteering is a persistent part of industrial heritage museums, as these spaces highlight the heritage of the innumerous individuals who gave their sweat, blood, and tears to carve out a livelihood in US urban centers, farms, and mining and logging camps. 


\section{Chapter 3: Research Methodology}

\subsection{Research Methodology Overview}

This project used the constructivist angle of grounded theory methodology (Charmaz 2014) to collect and analyze data pertaining to IHMO volunteerism. Prior to conducting my research my research was reviewed by the MTU IRB board and found exempt because the survey and research poses little to no risk to the research participants. Coded transcripts of in-person and over-the-phone interviews of IHMO executive directors and volunteers were compared to survey derived qualitative data from IHMOs (Jacob, S., \& Furgerson, S., 2012; Miles, Huberman, \& Saldaña, 2013; Charmaz, 2014). Interviews were collected from IHMOs in two industrial regions: The Calumet Region and Central Vermont. These regions were chosen based on my personal experience at both regions as part of Michigan Technological Universities (MTU) Open-Source Mining/Volunteer In Service To America (OSM/VISTA) Industrial Archaeology Master's program. While the interviews aimed to collect micro-level data concerning the industrial heritage volunteering at each region, a macro-level survey was sent out to three-hundred-and-eighty-two IHMOs. There are three reasons as to why a macro-level account of IHMO volunteerism is needed; a micro-level account would only speak to a small convenience population and not the various types of industrial heritage present across the US, a macro-level examination would produce more quantitative data on volunteer demographics and socioeconomics, IHMO volunteer management, and industrial heritage interpretation could be collected from a larger population pool. Micro- 
level accounts through interviews were significant to the project because they are more open ended, therefore they had a higher chance of eliciting qualitative data pertaining to IHMO volunteer motivation. Due to the sheer number of museums in the United States, a survey sample population was thematically chosen based on five conditions:

1. Museums had to have an internet presence, via their own website, a webpage or that of a governmental entity, and/or community organization.

2. Museum websites or pages had to have contact information such as an email address, phone number, or contact form.

3. Museums had to be registered as non-profits within the US.

4. Museums had to have a link on their website or webpage that provides information related to becoming a volunteer.

5. Museums had to discuss industrial heritage in their exhibits, document and artifact collections, public education, and conservation, preservation, and interpretation of their collections and property.

Initial searches for IHMOs were conducted by searching through websites, such as Wikipedia $\odot$ and MuseumsUSA $\odot$. After searching through both websites, between one and fifteen IHMOs per state were used as a representative survey population. Initial searches found that some states in America had fewer IHMOs than others, therefore some states have fewer representative IHMOs in the initial pre-survey sample population. However, it was assumed that of the three-hundred-and-eighty-two IHMOs included in the pre-survey sample population, only twenty to thirty percent would respond and 
complete the emailed survey. Both qualitative and quantitative survey questions were derived from a lack of answers to said questions in the literature, common demographic questions described by researchers in the literature, and suggestions by Michigan Technological University faculty members and students who pre-tested the survey instrument. While the survey questions were meant specifically for executive directors, volunteer managers, or individuals with knowledge of both the IHMO's volunteers and any industrial heritage presented by exhibits, collections and property, and public education efforts, the interview questions were crafted for both volunteers and museum professionals. Quantitative volunteer interview questions were altered slightly from those presented to museum practitioners to collect data on a volunteer's demographic and socioeconomic background, while the qualitative questions were to be open ended and sought to illuminate the deeper meanings behind volunteer motivation and personal perceptions of industrial heritage. In order to provide context for the data collected and theories presented by this research, I provided personal accounts and experiences as an AmeriCorps VISTA member at IHMOs in Chicago, Illinois, the Calumet Region, and Barre, Vermont. During this research (Summer 2019-Fall 2020), a worldwide COVID-19 pandemic temporarily closed a majority of museums and volunteer organizations around the globe. Due to the subject matter of this research, COVID-19 changed the originally proposed survey and interview population, the likelihood of survey responses, and how interviews were conducted. The impacts of this pandemic on IHMO volunteer motivation will be touched on in a later chapter. It is hoped that by combining experienced narratives, research results, and personal accounts that this research can provide United States IHMOs a better understanding of volunteer motivation. 


\subsection{AmeriCorps VISTA Service Years}

As part of my research, I spent two years as an AmeriCorps VISTA member, one year in Chicago (2018-2019), the other in Vermont (2020-2021). Stewards AmeriCorps VISTA, is a national service program within Conservation Legacy, working and engaging with communities across the country to benefit the environment. Michigan Technological University, along with various other universities across the country have service year programs that allow students hands-on implementation of their education, while gaining experience and paying less for tuition. The Open-Source Mining/Volunteer In Service To America (OSM/VSTA) Industrial Archaeology Master’s program “partner with local groups to help communities build the capacity to manage economic redevelopment, cultivate environmental stewardship, and explore models of community revitalization" (Office of Surface Mining VISTA Master's Programs, MTU). AmeriCorps VISTAs volunteer as part of "non-profit organizations and state and federal agencies [to] build capacity within communities across the country" with service programs ranging from community driven land revitalization and gardening groups for youth to developing museum exhibits and local heritage preservation (AmeriCorps VISTA Program, Stewards Individual Placement Program). The aim of serving two years with AmeriCorps VISTA was to provide my research with anecdotal evidence and loosely defined participant observation. My first service year was with the Chicago Field Museum and Calumet Collaborative, whereas my second and current (2020) service year is with the Vermont Granite Museum. While no formal research notes were taken during my service years, 
contacts and friendships were made with volunteers and trained professionals that provided me with readily available and willing interview participants for my thesis.

\subsection{Survey and Interview Methodology}

This thesis contributes to literature related to volunteering at US industrial heritage museums and organizations (IHMOs). Grounded theory methodology (Charmaz 2014) was used in the survey and interview data collection and examination during this project. In line with this projects research, Grounded Theory Methodology has been used to understand the motivations of older volunteers (Brown et al., 2011), those interested in transcribing ancient Chinese scrolls (Zhang et al., 2018), and millennial college students (Schuermann, 2016). In each of these projects the researcher used interviews to get at the motivations of their volunteer sample population. This thesis deviates from past volunteer motivation research through its use of surveying as a form of data collection methodology instead of primarily interviews. There were five reasons that using a survey in tandem with interviewing the staff of IHMOs and volunteers was methodologically beneficial to this project's goal to develop theories surrounding volunteer motivation at IHMOs.

1. By combining data collection methods, I collected data from a variety of industrial categories instead of only two or three convenient regions of America.

2. Time provided by conducting interviews, gave survey respondents more time and flexibility to respond, therefore they were more willing to complete and turn in the survey. 
3. A digital survey provided a mixture of qualitative and quantitative data that was already transcribed and required little to no formatting before conducting data analysis.

4. IHMO directors provided the digital survey with quantitative and qualitative data that a volunteer taking the survey may not have at hand.

5. Contact information for IHMO volunteers are not usually presented on social media, websites, and related internet pages, whereas a director's or IHMOs support staff's information is either linked to a IHMO's contact page or they are the one to respond to emails and phone calls.

The closest project of this type within recent literature comes from two works conducted and published in the UK. Mattingly (1993) focused on history museums and IHMO volunteers across the UK via a combination of mail and in-person survey data collection, while the other survey conducted in-person interviews and surveys centered on a single UK heritage railway and how the volunteers were managed. Questions presented in the digital survey were created by referencing Mattingly (1993), Holmes (1999), and Dillman et al. (2007), gaps in the literature, and questions proposed by faculty members and students at Michigan Technological University. The online survey platform Google Forms@ was used to create the survey, which was then attached to emails sent out to students and faculty members at Michigan Technological Universities (MTU) Social Sciences department with a background or interest in museum studies, industrial history, and survey development. Responses from this test survey were taken into account and used to create survey questions that would be used in the initial wave of 
surveys sent out to three-hundred-and-eighty-two IHMOs. While the survey was being developed and tested, a sample survey population of IHMOs was decided based on the aforementioned survey population criteria. Without an up-to-date listing of IHMOs a list had to be created using Wikipedia $\odot$ and MuseumsUSA@. Wikipedia already had a rudimentary list of museums and organizations that had some connection to industrial heritage, therefore a more precise definition of what an industrial heritage museum entailed was created.

Many of the museums or organizations chosen from Wikipedia $\bigcirc$ and Museum Directory@ for this research not only discussed industrial heritage, but also a wide variety of local or regional non-industrial topics, therefore four categories were created based on the narrative focus of the museum or organization: "Single Industry Centered Narrative IHMO”, “Single Industry Inclusive Narrative IHMO”, "Multi-Industry Centered Narrative IHMO", and "Multi-Industry Inclusive Narrative IHMO" (See Appendix A for Glossary). Additionally, while looking over the US census rubric on what is considered an urban or rural area, it was decided that instead of the three categories of urban, urban cluster, and rural, the category of 'rural space' would be created and implemented, as well as the alteration of population requirements for the original three. These and other definitions used as categories for concepts surrounding IHMOs were presented to colleagues and staff members at MTU's Department of Social Science in order to fine tune how they would be used in this research. In addition to collecting information on the pre-survey sample populations' industrial narrative and urbanity/rurality, this survey also collected website and social media accounts and contact information. All collected pre- 
survey data was placed into a Google Sheets ${ }^{\circledR}$ document on the data cloud program Google Drive ${ }^{\odot}$ to have its contents readily available at any computer with an internet connection.

During the pre-survey data collection, a boilerplate email was constructed from internet sources and used for contacting each IHMO chosen for the survey sample population. These emails asked receivers if they would like to be a participant in a research project by laying out what the project aimed to accomplish, the responsibilities of the respondent, and my contact information. Instead of sending the emails in one large mass email, each email was personalized with either the museum's name or the appropriate staff member and a sentence as to why their perspective is important to the project. While sending out a mass email would be time efficient, there was a chance the respondents email account would flag it as spam before they had a chance to view or respond to the email. By constructing a boilerplate email and inserting the names and identifier information for each IHMO into the email, it was hoped that there would be a higher response rate. The boilerplate emails were not based on past research examples and underwent review by faculty members at MTU's Department of Social Sciences with a background in survey design and public inclusion before being sent to the pre-survey sample population. All data collection and analysis methods were examined and approved of by MTU's Internal Research Board (IRB) prior to emailing potential study participants the online survey and conducting in-person and over the phone interviews. Originally projected to be sent out in the Fall of 2019, the emailing process was postponed until after the seasonal holidays (November-January), giving IHMOs and their 
volunteers a chance to resume routine. Two weeks were given for IHMOs to respond to the survey participation inquiry. If the IHMO did not respond within the first two weeks, then they were called over the phone. Once a month had passed and no contact had come from the IHMO, they were placed on a list of IHMOs to no-longer contact. IHMOs that replied were provided with a link to the Google Forms@ survey. As with the test survey, when a respondent filled out and submitted the form I was notified, and the responding IHMOs email address was collected. If an IHMO showed interest in being a participant but did not submit the survey within two weeks of the initial receiving date, they were reminded via email about their initial show of interest. IHMOs that show interest but never responded were placed on a list to not-contact but were noted that they showed initial interest. In February of 2020, the COVID-19 pandemic swept throughout the world, dramatically effecting what museums were open, and therefore what museums could be reached for the survey. At the time of writing this thesis (October 2020), the COVID-19 pandemic has only been curtailed, allowing all manner of businesses, institutions, organization, and the like to either open at a reduced capacity or not at all. It is possible that due to this unforeseen circumstance many museums and organizations did not respond to this project's survey request and a concerted effort was made to reach approx. one-hundred museums. As mentioned previously, it was expected that only twenty to thirty percent of the IHMOs chosen for the pre-survey sample population would respond or participate. While only twenty-six of the participating IHMOs were completely volunteer run, it begs the question, how many would have participated if the COVID-19 pandemic hadn't temporarily closed as many museums as it did. 
In partial accordance with the grounded theory methodology of qualitative data collection and analysis, the survey data was coded and used as examples for the coding of the interview transcripts (Miles, Huberman, \& Saldaña, 2013; Charmaz, 2014). Due to the interview data collection process taking longer than the survey process, comparisons between the two data sets happened sporadically over the course of the data collection and analysis period. Qualitative data collected during the survey was subjected to initial, focused, and axial coding. Initial coding of the qualitative survey data occurred via a lineby-line analysis, which developed into focused coding; an incident-by-incident coding of survey results. Axial coding came into play when grouping the codes into categories. Codes developed from the survey were given theoretical validation via their frequency; the higher the frequency of a single code, the more likely it was to develop into a theory. This frequency count method was used for every question throughout survey and interviews. Since this project was my master's thesis, I was the only coder of the collected data.

While the project's survey depends on a great deal of qualitative data, quantitative data is still present and influential to the overall outcome (Charmaz, 1996; Schuermann, 2016; Groen et al., 2017). Quantitative results from the survey were filtered through a combination of descriptive and inferential data analysis methods (Miles, Huberman, \& Saldaña, 2013; Groen et al., 2017). Descriptive data analysis produces visual data sets, such as approx. how many volunteers serve each IHMO. Inferential data analysis makes predictions and generalizes larger data sets based on sample populations, such as generalizing about volunteer motivations in IHMOs without surveying every IHMO in 
the US. Quantitative data was analyzed apart from the qualitative but was combined and used as supporting data during the data analysis. After the descriptive data analysis was finished, the qualitative data was subjected to an inferential data analysis.

In addition to the survey sample population, fifteen IHMOs were chosen prior to the COVID-19 pandemic. Consent to be interviewed was given orally by the museum executive or volunteer prior to being interviewed and has been typed out in the interview transcripts. Due to the COVID-19 pandemic, seven of those IHMOs could not be reached, leaving the interview sample population at seven; six in the Chicago and Calumet Region and one in Vermont. Additionally, of the IHMOs that were interviewed, only two (The Vermont Granite Museum and Cedar Lake Historical Association and Museum) were able to provide volunteers for an interview. The only interviews conducted in-person rather than over-the-phone were in early February or late June of 2020 at the Vermont Granite Museum in Barre, Vermont. At its conclusion, two over-thephone and two in-person volunteer interviews were conducted, while nine over-the-phone and one in-person IHMO staff interviews were recorded. The interview process in this project used semi-structured interviews and grounded theory methods for data collection and analysis (Jacob \& Furgerson, 2012). Transcriptions from the interviews were constantly compared to question-by-question transcripts of qualitative questions collected from the IHMO survey. The following is an overview of the interview population selection and data analysis process:

1. IHMOs in the project's chosen region were contacted via a pre-developed email that outlines the research project and asks them for their participation. 
2. IHMOs choose two or more volunteers that were interested in being interviewed.

3. Participating IHMOs and volunteers were emailed a list of questions that will be covered in either an over-the-phone or an in-person semi-structured interview.

4. All interviews took place at the convenience of the IHMOs staff member or volunteer's schedule.

5. Interviews were transcribed by the interviewer onto a Microsoft Word $\odot$ document.

6. Transcripts were broken down and coded via a grounded theory method of data analysis. During this data analysis process, interview codes were compared to codes developed from the digital survey in order to reach theoretical saturation.

7. Theories derived from the constructivist grounded theory method were given support from the qualitative data collected by the online survey.

8. Audio files related to the interview process were deleted and the transcripts were saved so as to both protect the anonymity of the interviewee and to be used for future research projects.

Sites chosen for the over-the-phone and in-person interviews were done so based on convenience sampling and academic connections. Each site fell into the aforementioned survey qualifications and was either within the Calumet Region of Illinois and Indiana, or Central Vermont. The following pre-COVID-19 pandemic list of sample interview 
IHMOs were chosen based on their connection to my time as an AmeriCorps VISTA member:

1. The Chicago Field Museum's Science Action Center

2. The Pullman National Monument

3. The Historic Pullman Visitors Information Center

4. The Blue Island Historical Society and Museum

5. The Southeast Chicago Historical Society and Museum

6. The Calumet Heritage Partnership

7. The Cedar Lake Historical Society and Museum

8. The Porter County Museum

9. The Barker Mansion

10. The Westchester Township History Museum

11. The Vermont Granite Museum and Stone Arts School

12. The Vermont Historical Museum

13. The Vermont Historical Society

14. The Billings Farm and Museum

15. The American Precision Museum

Of the IHMOs emailed, only the following eight would be interviewed: 


\section{The Chicago Field Museum's Science Action Center}

2. The Blue Island Historical Society and Museum

3. The Southeast Chicago Historical Society and Museum

4. The Calumet Heritage Partnership

5. The Cedar Lake Historical Society and Museum

6. The Porter County Museum

7. The Barker Mansion

8. The Vermont Granite Museum and Stone Arts School

Each IHMO was contacted via email. The email itself was like the online survey email to IHMOs. Its body was a boilerplate email with personalization based their position and institution. Due to the holiday season (December-January), IHMOs were busy with planning and preparing holiday programs, therefore some IHMOs did not respond right away, because of this a week was given before a second email was sent. IHMOs that expressed interest were provided the interview questions and asked to choose two or more volunteers that would be interested in being interviewed for the project. There were no qualifications for the IHMO executives when selecting volunteers, and it was assumed that those being interviewed were interested in sharing their personal experiences and perspectives on industrial heritage. Due to a lack of response, potentially in part from the COVID-19 pandemic, only four of the originally projected thirty volunteers were interviewed over the course of the project. 
The interview questions differ from the digital survey questions in that there were two versions of the interview questions, one for the volunteers and one for the IHMO executive director or equivalent staff member. Before the interview began, all interviewees were read an explanation of the project, how the data would be used, and asked if they give consent to have their perspectives recorded and used in the project. The interviews lasted between thirty minutes and one hour, only ending if the interviewee lost interest, the interview questions were exhausted, or the interviewee did not wish to continue. At the conclusion of the interview, the interviewee was given an alias so as to protect their confidentiality in the case a quote or section of their interview was included in this paper.

In line with the grounded theory method of qualitative data analysis, all interviews were transcribed and coded in order to uncover trends related to the motivations of IHMOs volunteers (Corbin \& Strauss, 2008; Schuermann, 2016). Due to the online survey data collection and analysis process taking less time to compile and analyze than the semi-structured interview process, comparisons between the two data sets happened sporadically over the course of the data collection and analysis period. Qualitative data collected during the interviewing process was compared to codes developed during the analysis of survey responses (Scott \& Medaugh, 2017). Unlike the coding that took place in the survey data analysis there were fewer codes, the interview codes were broke into two groups, one for IHMO staff responses and one for volunteer responses. The frequency count of codes from survey and interview questions were combined to create total frequency counts for each code. Combining survey and 
interview codes was chosen due to the relatively small number of interviews with IHMO staff members and the similarity of a question's subject matter. Codes developed from the volunteer interviews were not included due to the small size of the sample population. The IHMO survey and interviews total frequency counts were used to create theories tied to each question's subject matter.

At the conclusion of this project, survey participants will receive an electronic copy of the thesis and the raw data used to draw the conclusions and suggestions posited in the discussion sections. It is hoped that the dissemination of this research, as well as how this research was conducted will provide IHMOs and future researchers insight into the subject of volunteer motivation. The following section will lay out the results of this project and discuss the findings so that museums, organizations, and researchers alike will be provided with suggestions as to why people are motivated to volunteer and to what level industrial heritage plays a role. 


\section{Chapter 4: Findings and Discussion}

This chapter will provide a mix of findings and discussions on the data collected prior to, and after, this project's online survey and in-person/over-the-phone interviews with United States industrial heritage museum and/or organization (IHMO) staff members. Following the results, I aim to provide discussions linking my findings with statistical information from published research, anecdotal evidence from volunteers, and personal experiences from my time as an AmeriCorps VISTA member in Chicago, Illinois and Barre, Vermont.

\subsection{Findings}

In this section I will cover the findings from the IHMO online survey and overthe-phone interviews with IHMOs. All interview questions asked were open-ended, with the responses being coded to either match or add to the pre-developed multiple-choice options or post-survey and interview codes. Results were reached by combining the findings of both the online survey and the over-the-phone interviews. Throughout this section each questions results presentation will differ slightly, some will outline the resulting majority, while others will cover their highest frequency/count responses. The results to the questions not touched upon in the findings section will be included in the discussion section or can be found in Appendix B at the back of this paper.

Question \#1, “[W]hat age is the majority of your volunteers?”, found that a majority of IHMO volunteers are 60 years or older (80\% or 90:113) (Table 1). All 113 IHMOs 
responded to Question \#1, giving it a 100\% response rate. This question was multiplechoice with four age groups: 13-20 y/o, 21-39 y/o, 40-59 y/o, and $60 \mathrm{y} / \mathrm{o}$ and up.

Question \#2, "[W]hat gender is the majority of your volunteers?", found that most IHMO volunteers are male (50\% or 57:109), seconded by female IHMO volunteers (39\% or 44:109) (

Table 2). A total of 109:113 IHMOs responded to Question \#2, giving it a 96\% response rate. While all of the interviewed IHMOs responded to this question, only 101 surveyed IHMOs responded. This question was multiple-choice with three options ("Male", "Female", and "Other") for the online IHMO survey, while the over-the-phone IHMO interviews were open ended. Due to the uncertainty, balanced volunteer pools, or ability to be more flexible in the IHMO interview responses, the code "Male/Female Split" was included as a post-survey option during the coding process so that the online survey and interviews could be combined and analyzed as one data set.

Question \#3, “[W]hat race or ethnicity are the majority of your volunteers?", found that a majority of IHMO volunteers are white (97\% or 108:111) (Table 3). A total of 111:113 IHMOs responded to Question \#3, giving it a 98\% response rate. While all of the interviewed IHMOs responded to this question, 103 surveyed IHMOs responded. This question was multiple-choice with seven options ("Asian”, "Black/African", "White", "Hispanic/Latinx", "Native American", "Pacific Islander", and "Prefer Not to Answer") 
for the online IHMO survey, while the over-the-phone IHMO interviews were openended.

The results of Question \#4, "[W] hat education level is the majority of your volunteers?", indicate that a majority of IHMOs volunteers have a Bachelor's Degree (55\% or 62:111) (Table 4). A total of 111:113 IHMOs responded to Question \#4, giving it a 98\% response rate. While all of the interviewed IHMOs responded to this question, 103 surveyed IHMOs responded. This question was multiple-choice with 12 options, one of which allowed IHMO survey respondents to provide an open-ended response. Of the 111 responses, 18 were coded to match the existing 11 options, with the code "Widely Varied" being added as a post-survey option.

Question \#5, “[W]hat employment status is the majority of your volunteers?", revealed that the majority of IHMO volunteers are retired (80\% or 90:111) (Table 5). A total of 111:113 IHMOs responded to Question \#5, giving it a 98\% response rate. In contrast to previous questions, seven interviewed and 104 surveyed IHMOs responded. This question was multiple-choice with nine options, one of which allowed for IHMO survey respondent to provide an open-ended response. Of the 111 responses, 14 were coded to match the existing 11 pre-determined options, with two codes ("Varied" and "Unable to Work”) being added as post-survey options.

Question \#8, “[H]ow many staff members does your museum currently employ?”, found that most IHMOs employ 1-3 staff members (34\% or 38:112), followed closely by IHMOs with 4-9 staff members (27\% or 31:112), and those with no staff members (23\% or 26:112) (Table 7). A total of 111:113 IHMOs responded to Question \#8, giving it a 
$98 \%$ response rate. Of the 111 IHMOs that responded, eight were from interviewed IHMOs and 103 from the IHMO online survey. This question was multiple-choice with four options ("0 Staff Members", "1-3 Staff Members”, "4-9 Staff Members”, "10+ Staff Members") for the online IHMO survey, while the over-the-phone IHMO interviews were open-ended.

The results of Question \#9, “[A]pprox. how many active volunteers volunteer at your museum?", indicate that the majority of IHMOs have 1-10 volunteers (36\% or 41:111), followed by IHMOs with 11-25 volunteers (27\% or 30:111), and those with 50 or more volunteers (26\% or 29:111) (Table 8). A total of 112:113 IHMOs responded to Question \#9, giving it a $99 \%$ response rate. Of the 112 IHMOs that responded, eight were from interviewed IHMOs and 104 from surveyed IHMOs. This question was multiple-choice with four options (“1-10 Volunteers”, “11-25 Volunteers”, “26-49 Volunteers”, “50 + Volunteers") for the online IHMO survey, while the over-the-phone IHMO interviews were open-ended.

Question \#13, “[W] hat do volunteers do at your museum?", revealed that the majority of volunteers in IHMOs help at special events/programing (79\% or 89:112), followed by being docents ( $79 \%$ or $88: 112)$, giving tours $(77 \%$ or $86: 112)$, volunteering in collections management (68\% or $76: 112)$, and doing maintenance (63\% or $71: 112)$ (Table 12$)$. A total of 112:113 IHMOs responded to Question \#13, giving it a 99\% response rate. Of the 112 IHMOs that responded, eight were from interviewed IHMOs and 104 from the surveyed IHMOs. This question was multiple-choice with 18 options, one of which allowed the respondent to provide an open-ended response for the online IHMO survey. 
Of the 112 responses, 23 were coded to match the existing 17 options, with the code "Finances" being added as a post-survey option.

Question \#18, "[D]o your volunteers receive any non-salary benefits and/or rewards at the museum?", found that a majority of IHMO volunteers receive some form of nonsalary benefit or reward for volunteering (60\% or 67:112) (Table 17). A total of 112:113 IHMOs responded to Question \#18, giving it a 99\% response rate. Of the 112 IHMOs that responded, eight were from interviewed IHMOs and 104 from the surveyed IHMOs. This question was polar (Yes or No) for the IHMO online survey, while the over-thephone IHMO interviews were open-ended.

The results of Question \#19, “[W]hat are they?" (in relation to the previous question (\#18) on volunteer benefits/rewards), indicate that the following are the top five nonsalary benefits or rewards for volunteering with IHMOs: volunteer only social gatherings (49\% or 34:69), volunteer appreciation events (39\% or 27:69), free admission to the IHMO's programs/events/special events (29\% or 20:69), non-monetary volunteer appreciation awards (20.3\% or 14:69), free admission to the IHMO site (16\% or 11:69) (Table 18). A total of 69 IHMOs responded to Question \#19, giving it a $61 \%$ response rate. Of the $69 \mathrm{IHMOs}$ that responded, six were from interviewed IHMOs and 63 from surveyed IHMOs. Since this question was open-ended, the 69 responses were coded, creating 22 individual codes. Based on the combined code frequency count of both the surveyed and interviewed IHMOs.

Question \#20, "[H]ow involved is the surrounding community with the museum and its administration?", found that most communities surrounding IHMOs are actively involved 
in its administration and volunteer efforts (37\% or 39:106) (Table 19). A total of 106:113 IHMOs responded to Question \#20, giving it a 94\% response rate. Of the 106 IHMOs that responded, eight were from interviewed IHMOs and 98 from surveyed IHMOs. Since this question was open-ended, the 106 responses were coded, creating four codes: "Community is Actively Involved", "Community is Moderately Involved", "Community is Minimally Involved", and "Uncertain".

Question \#21 asked "[W]hat do you think are the motivations behind your volunteers to volunteer?", the result of which indicates that most IHMO volunteers are motivated to volunteer because of a sense of belonging ( $26 \%$ or $29: 111)$, an interest in history ( $23 \%$ or 26:111), or the IHMOs industrial assets (22\% or 24:111) (Table 20). A total of 111:113 IHMOs responded to Question \#21, giving it a $98 \%$ response rate. While all of the interviewed IHMOs responded to this question, 103 surveyed IHMOs responded. Since this question was open-ended, the 111 responses were coded, creating 30 individual codes.

The results of Question \#23, “[W]hat does industrial heritage mean to you?", show that most IHMOs perceive industrial heritage as the history of industry (18\% or 19:106) (Table 21). A total of 106:113 IHMOs responded to Question \#23, giving it a 94\% response rate. Of the 106 IHMOs that responded, eight were from interviewed IHMOs and 98 from surveyed IHMOs. Responses were split into three groups ("General”, "Specific", and "Mixed") based on the generality or specificity of how they attribute meaning to industrial heritage. From the 106 responding IHMOs I found that most view industrial heritage in a general way (58\% or 62:106). Eighty-six codes were developed 
from the responses, each being placed in either the "General" or "Specific" category. Of the 85 codes, the "General" group contains 51 codes, while "Specific" group has 34 codes.

Question \#25, “[W]hat industries are represented in the collections and exhibits at your museum?", found that the majority of IHMOs include some element manufacturing (55\% or $61: 110)$ in their collections and exhibits, followed by agriculture (39\% or $43: 110)$, transportation ( $38 \%$ or $42: 110)$, and mining (23\% or $25: 110$ ) (Table 22$)$. A total of 110:113 IHMOs responded to Question \#25, giving it a 97\% response rate. Of the 110 IHMOs that responded, eight were from interviewed IHMOs and 102 from surveyed IHMOs. Since this question was open-ended, the 110 responses were coded, creating 15 individual codes.

In relation to Question \#25 of the IHMO online survey, I found that $48 \%$ have a single industry centered narrative (50:105), 24\% have a multi-industry inclusive narrative (25:105), $15 \%$ have a multi-industry centered narrative (16:105), and $13 \%$ have a single industry inclusive narrative (14:105) (Table 23). In order to come these results, I examined the industrial heritage narratives presented by the various IHMO on their websites and social media accounts. Before collecting the data four narrative categories were created: "Single Industry Centered Narrative IHMO”, "Single Industry Inclusive Narrative IHMO", "Multi-Industry Centered Narrative IHMO”, and “Multi-Industry Inclusive Narrative IHMO”.

Question \#26 of the IHMO online survey and over-the-phone IHMO interviews asked "[A]re the industry(s) represented in your museum still operating?", the results of which 
find that a majority of the industry(s) represented in the participating IHMOs are still operating (69\% or $75: 108)$ (Table 24$)$. Combining the results of both the online survey and the over-the-phone interviews a total of 108:113 IHMOs responded to Question \#26, giving it a 94\% response rate. Of the 108 IHMOs that responded, eight were from interviewed IHMOS and 100 from surveyed IHMOs. This question was polar (Yes or No) for the IHMO online survey, while the over-the-phone IHMO interviews were openended.

Question \#27 asked “[H]ow many of your volunteers have worked in the industry(s) represented at the museum?", the results of which show that most IHMOs have 1-3 volunteers that have worked in the industry(s) represented at the IHMO (32\% or 36:110) (Table 25). A total of 110:113 IHMOs responded to Question \#27, giving it a 97\% response rate. Of the 110 IHMOs that responded, eight were from interviewed IHMOs and 102 from surveyed IHMOs. This question was multiple-choice with four options (“0 Volunteers”, “1-3 Volunteers”, “4-9 Volunteers”, and "10+ Volunteers”), for the online IHMO survey, while the over-the-phone IHMO interviews were open-ended.

The results of Question \#28, “[H]ow many of your volunteers currently work in the industry(s) represented at the museum?", indicate that that a majority of IHMOs have no volunteers currently working in the industry(s) represented at their IHMO (63\% or 71:110) (Table 26). A total of 110:113 IHMOs responded to Question \#28, giving it a $97 \%$ response rate. Of the 110 IHMOs that responded, eight were from interviewed IHMOs and 102 from surveyed IHMOs. This question was multiple-choice with four 
options ("0 Volunteers", "1-3 Volunteers", “4-9 Volunteers", and "10+ Volunteers"), for the online IHMO survey, while the over-the-phone IHMO interviews were open-ended. Question \#29, asked " $[\mathrm{H}]$ ow many of your volunteers have familial connections to the industry(s) represented at your museum?", indicates that most IHMOs have ten or more volunteers (35\% or $40: 106)$ that have some form of familial tie to the industry(s) being represented at their IHMO (Table 27). A total of 106:113 IHMOs responded to Question \#29, giving it a $93.8 \%$ response rate. Of the 106 IHMOs that responded, seven were from interviewed IHMOs and 99 from surveyed IHMOs. This question was multiple-choice with four options ("0 Volunteers", "1-3 Volunteers", "4-9 Volunteers", and "10+ Volunteers"), for the online IHMO survey, while the over-the-phone IHMO interviews were open-ended.

Question \#30, “[D]o you consider your museum to be urban, rural, or somewhere inbetween?", found that many of the IHMOs find themselves to be geographically "Somewhere In-Between" urban and rural areas (47\% or 52:111) (Table 28). A total of 111:113 IHMOs responded to Question \#30, giving it a 98.2\% response rate. Of the 111 IHMOs that responded, eight were from interviewed IHMOs and 103 from surveyed IHMOs. This question was multiple-choice with three options ("Rural", "Somewhere InBetween", and "Urban"), for the online IHMO survey, while the over-the-phone IHMO interviews were open-ended. Of the 111 responses, eight were coded to match the existing options, with the code "All of the above" being added as a post-survey option.

In relation to Question \#30 of the IHMO online survey, I found that $46 \%$ are situated in a rural area (48:105), 29\% in an urban area (30:105), 17\% in a rural space (18:105), and 
$9 \%$ in urban clusters $(9: 105)$ (Table 29). In order to come to this result, I examined the participating IHMOs geographic level of urbanity and rurality, via population levels. Before collecting the data, I created four categories: "Rural Area", "Rural Space", "Urban Cluster", and "Urban Area" (See Appendix A for Glossary).

Question \#32 asked "[D]o volunteers at your museum have opportunities for hands on interaction with industrial heritage?" the results of which indicate that a majority of IHMOs volunteers have opportunities for hands on interaction with industrial heritage (78\% or 85:109) (Table 30). A total of 109:113 IHMOs responded to Question \#32, giving it a $96 \%$ response rate. Of the 109 IHMOs that responded, eight were from interviewed IHMOs and 101 from surveyed IHMOs. This question was polar (Yes or No) for the IHMO online survey, while the over-the-phone IHMO interviews were openended.

Question \#33, “[I]f yes, how?" (in relation to Question \#32), found that the operation of IHMO equipment is the hands-on interaction with industrial heritage that most IHMOs provide their volunteers ( $25 \%$ or $22: 87$ ), followed by the demonstration of IHMO equipment (22\% or 19:87) (Table 31). A total of 87 IHMOs responded to Question \#33, giving it a $77 \%$ response rate. Of the 87 IHMOs that responded, 7 were from interviewed IHMOS and 80 from the IHMO online survey. Since this question was open-ended, the 87 responses were coded, creating 24 individual codes.

Question \#36 asked, “[D]oes your museum discuss the impacts of deindustrialization?”, the results of which show that most IHMOs do not discuss the impacts deindustrialization (54\% or 59:109) (Table 32). A total of 109:113 IHMOs responded to Question \#36, 
giving it a $96 \%$ response rate. Of the 109 IHMOs that responded, eight were from interviewed IHMOS and 101 from surveyed IHMOs. This question was polar (Yes or No) for the IHMO online survey, while the over-the-phone IHMO interviews were openended.

Question \#37, “[I]f yes, how?”, (in relation to Question \#36) found that the themes of a decline of industry (32\% or 16:50) and a period of transition (28\% or 14:50) are used by IHMOs to discuss the topic of deindustrialization (Table 33). A total of 50:113 IHMOs responded to Question \#37, giving it a 44\% response rate. Of the 50 IHMOs that responded, four were from interviewed IHMOS and 46 from surveyed IHMOs. Due to this question being open-response, 14 codes were developed from the 50 responses.

\subsection{Discussion}

In this section I will be discussing the findings from the survey and interviews that relate to volunteer motivations at US industrial heritage museums or organizations (IHMOs). To provide support in this discussion, I will provide examples from my interviews with IHMO volunteers and staff members, as well as scholarly sources, national statistics, and personal anecdotes from my time as an AmeriCorps VISTA in Chicago, Illinois and Barre, Vermont.

\subsubsection{Age}

When discussing age, its common to place people into societal groups, such as children, teens, adults, middle-age, elderly, and/or generational groups like the greatest generation, baby boomers, generation $\mathrm{X}$ and Z, Millennials, and so on. Thinking in terms 
of industrial heritage, all these age groupings have experienced industrialization and deindustrialization in some form, be it that they worked in a factory, or passed by it as it slipped into abandonment. A focus of my discussion in this section will be based on the inclusion of children and teens into the interpretive narratives presented by IHMOs, not only as volunteers, but also as subjects of interpretation. IHMOs allow for volunteers to shape how visitors and other volunteers interact and perceive industrial heritage, therefore what age groups volunteer becomes an important factor in furthering a IHMOs mission, their public standing, and contribution to local and/or regional industrial heritage. Findings from this research project indicate a variety of options to answer how age might impact who volunteers and their motivations to do so.

First on the volunteer age agenda is to examine how the findings from this research project compare to other studies of general volunteerism and museum volunteerism. In 1993, Mattingly completed a report on museums and art galleries in the UK in order to understand volunteer motivation and demographics. Of the surveyed museums and art galleries, twenty percent responded that most of their volunteers were sixty-one years or older (Mattingly, 1993). Then in 1998 another study was conducted by the UK National Center for Volunteering, where it was found that forty-three percent of surveyed museums and art galleries had volunteers who were mostly sixty-one years or older (Holmes, 1999). Now, both of these studies are from the UK, over a decade old, and include art galleries in their survey populations. The research outlined and discussed in this paper focuses on the US, is relevant to 2019 standards, and focus on museums and organizations with an industrial heritage narrative or component in their collections, 
interpretation, or overall theme. While the differences are blaringly obvious, there is still a trend to be found; most museum volunteers are older individuals. In 2016 the US Bureau for Labor Statistics (USBLS) published that people between the ages of thirtyfive and fifty-four were most likely to volunteer (28\%) (US Bureau of Labor Statistics, 2016). The difference between the studies conducted in the UK in the 1990s and my research in 2020 to the USBLS findings is based on the survey size and level of focus. Their survey sample population was a whopping sixty-three million people, whereas mine was one-hundred and three IHMOs; their focus was general volunteering in the US, whereas mine was volunteering done in IHMOs. I decided to preface this discussion on the effect of age on volunteering to point out that museums, especially ones dealing with industrial heritage or history acquire a stereotype where mainly older individuals volunteer. What I aim to show readers is that while my findings do suggest older individuals are the majority of volunteers at IHMOs there is ample reasons for this and that younger individuals can and do volunteer, but their motivations may be slightly different from that of their older counterparts.

IHMOs are places where visitors come to engage with the heritage being interpreted there, visitors perceive heritage based on their own backgrounds and those being presented by the IHMO and its volunteers. An issue within the museum and art gallery community is the lack of younger volunteers (Schwartz, 2005). When I talk about 'younger' volunteers I am talking about those between the ages of thirteen and thirtynine. Based on my research, IHMOs are lacking in these younger volunteers; in contrast, it appears IHMOs are densely populated by volunteers sixty years or older (Table 1). Due 
to the general research focus of this project, little data was collected on younger IHMO volunteers; because of this, all suggestions will be based on scholarly material, personal perceptions and interpretation of the survey and interview results. In discussing a lack of younger volunteers, the Cedar Lake Historical Association Museum's director stated, "We are trying to actively engage younger volunteers and we haven't figured out how to do that... we have been trying to more actively recruit younger volunteers... we have four volunteers total that work and they are all fifty and under, so that's my youngest group, but even then we're talking, the youngest person is in their 30s". In a similar fashion, the South East Chicago Historical Society had this to say, "All the industrial stuff that goes on, all the museums are the same way, they're all desperate for people to come and visit them, desperate to have people come and volunteer more, ya know, it's just the way it is because it's an old demographic, we're trying to get younger volunteers." It is their goal, as well as many others, to make their IHMO more attractive to younger audiences via outreach, accommodation, and inclusion. Due to a lack of younger volunteers, over time these IHMOs and others just like them may experience a shortage of volunteers. To potentially remedy this through the use of volunteer motivation, an IHMO may want to use industrial assets to create hands-on experiences and include younger volunteers in the exhibit and interpretation process.

Narrating heritage through the use of interpretation is the norm at IHMOs, though how and by whom these interpretive pieces and exhibits are constructed by can vary. Scwartz (2005) posits that increasing the presence of work done by younger volunteers and including community youth may, over time, increase the interest of younger 
individuals in museums. It was found that word-of-mouth was the most popular way that IHMOs recruit volunteers, therefore, if a younger individual enjoys their experience they may be more likely to talk about it with others and recruit friends and peers (Scwartz, 2005). This recruitment tactic leans into the most popular form of motivation, the sense of belonging. If a younger volunteer feels like they belong as member of the museum community, they will be more likely to volunteer. In addition to potentially gaining a younger volunteer base, the younger volunteers would be exposed to local and/or regional industrial heritage. Younger volunteers also bring to the table new views on traditional material, using their experiences as molds to create new exhibit material, shape interpretation, and potentially gain an appreciation for industrial heritage. In addition to a sense of belonging, it was found that IHMO volunteers were motivated by their access to museum and/or organizational assets and industrial machinery (Table 20). IHMOs are in a position to provide hands-on interaction with the heritage narratives represented through their exhibits, programs, collections, and interpretive material. Based on the industrial heritage narrative being represented, these hands-on interpretive pieces can range from being able to descend into a structurally sound mine, mill lumber, and weave yarn, to handle equipment, interact with collections, and forge material. From the author's personal experience at the Vermont Granite Museum, demonstrating how a tool was used while the visitor holds it is in of itself enough of a motivation to continue to volunteer. Understanding their place within the fabric of industrial activity in the United States may also spark interest in children and teens, an interest that may develop into the act of volunteering. 
Children and teens play a pivotal role in the development of industry within the United States, therefore an increase in the inclusion of their story in IHMO interpretation may lead to increasing their interest in IHMO exhibits, presentations, and activities. Agricultural work was the original space in which children labored. Children were taught how to tend the farm and animals so that the land could be either passed onto them or so that when they get old enough, they would have the skills to find work elsewhere. Today, children in rural communities (such as the ones I grew up in) who live on farms regularly learn how to use farming machinery, care for animals, and tend to a variety of crops. These children and teens, unlike those in the 1800s, have far greater agency if they chose to leave the agricultural industry to pursue another job or career path. In the 1800 s, child labor became a point of contention between northern and southern states. Southern states pointed to child labor in the north as immoral and degrading, whereas reformers in the north pointed towards slavery as being morally objectionable (Wood, 2020). In 1924, an amendment was added to the constitution that regulated the labor of people under the age of eighteen, though it was not ratified and upheld by all (then forty-nine) states until 1938 (Donovan \& Shimabukuro, 2016). Though childhood labor in the United States was and is severely restricted and regulated, in 2012 it was found that "nearly 500,000 children as young as six harvest up to twenty-five percent of all crops in the United States" (York, 2012). Childhood labor within industry, no matter their temporal or spatial place in industrial history, should be included in the industrial heritage narrative of IHMOs. By providing interpretation on children in HIMOs, contemporary child and teen visitors can connect with a narrative that is, to many, foreign and surprising. While my research was 
unable to collect interviews and survey data on children and teen volunteers in IHMOs, it does have an abundance of older volunteers.

Over eighty percent of the IHMOs who participated in this research project provided that their primary volunteer age demographic were sixty-five years and older. While there is research supporting the mental and physical benefits of volunteering for older individuals (Mayo Clinic, 2017), and there were a few IHMOs that provided that as the motivations behind their volunteers, it is argued by this paper's author that part of the reason an older age demographic is so popular is linked to a tie between age and lived industrial experiences. The projects survey found that seventy-six percent of the IHMOs have at least one volunteer who at some point worked in the industries represented at the IHMO. It is not hard to imagine that those who once worked in industry would spend their later years sharing stories and seeking out a sense of belonging with familiar sights and surroundings. Turns out that twenty-six percent of IHMOs stated that their volunteers were motivated to volunteer based on their want of a sense of belonging. This "sense of belonging" continues to be a theme in motivation throughout my research, giving credence to the idea that a museum is a community and that people have a need to be validated and be around others with similar interests, views, and experiences. Sharing these experiences is another motivation identified in this research, with a total of fifteen percent. Even though it is a small percentage, when looking at how many IHMOs allow their volunteers to act as docents and tour guides (76.8\% tours and $78.6 \%$ docenting) another picture is revealed. When interviewing volunteers at the Vermont Granite Museum, one interviewee who currently works in the granite industry brought up that 
many of the volunteers that spend time there grew up in the surrounding community, "our culture in this area is interesting and people have grown up, some of the volunteers I know from years past have grown and matured in this town, so these things have meaning for them, and they will find interesting tidbits along the way that will reward their efforts." Their statement sounded familiar, for when interviewing the South East Historical Society, they stated "they [their volunteers] all either live now or have lived in the area that we represent with our museum". Older volunteers, from my research are motivated by the desire to share with younger individuals or anyone willing to listen, their personal experiences with industry, as well as those of their family and friends, educate future generations about past industrial activity, and find community in familiarity. It is not too much of a leap to postulate that these older volunteers have lived through more ebbs and flows in industry and based on their age, they may have also experienced the total collapses of some industries. These older volunteers have lived through far more than can be written down on paper, interpreted in an exhibit, or recorded in a single interview, therefore their presence at any IHMO is similar to having a living breathing piece of industrial heritage.

\subsubsection{Gender}

In 2016 the US Bureau for Labor Statistics (USBLS) publicized their volunteerism findings from 2015. This document stated that twenty-eight percent of surveyed males volunteered, whereas twenty-seven-point-eight percent females volunteered (US Bureau of Labor Statistics, 2016). In 2017 the Corporation for National and Community Service released that twenty-seven percent of males' volunteer and 
thirty-four percent of females' volunteer. While these percentages might seem small, consider it this way, nearly seventy-seven million US citizens volunteered in 2016 (CNCS, 2017). Holmes in 1998 published an article where they provided that of the onehundred-and-eighty-eight UK based museums they surveyed fifty-one percent stated that fifty percent or more of their volunteer pool consisted of female volunteers (Holmes, 1998). While conducting research I surveyed one-hundred-and-thirteen IHMOs, the results of which showed that fifty percent of IHMOs consisted of primarily (fifty percent or more) male volunteers, while only thirty-nine percent had primarily female volunteers. Of the remaining eleven percent, six percent responded that they had neither male nor female as their primary volunteer, instead they chose "Other". It is also probable that the few IHMO who chose "Other" did so because some didn't know what it meant, or they checked it just as an error. Regardless, before I further discuss my findings that my research was focused on finding the majority of volunteers and is not representative of every volunteer in each surveyed IHMOs, therefore it may be that there are almost just as many individuals representing themselves as female as male, or non-binary individuals. Another point to mention is that all the surveys I draw from for this research include the categories of male, female, and non-binary. During the course of this section, I will give mention to genders such as man, woman, and non-binary. I may also mention biological orientations such as male, female, and transgender. While I will not have time to tackle the confluence of gendered and biological orientations within IHMOs within this paper, my research constitutes gendered orientations as socially constructed, while biological orientation is based on anatomy. This is not to say that the two do not mix and create new avenues for individual and group self-expression. But I digress. Industrial heritage is 
tangible and intangible, visible on the landscape and inside a museum's collections, and passed down through stories and techniques by those who practiced them. While women worked in industrial settings throughout the industrial history of the United States, such as in the home, in cotton mills, on assembly lines, and in munition factories, men are remembered more for their predominance in the resource extraction and heavy manufacturing industries. Industry is seen by many as being a workplace dominated and curated by males, while other narratives are pushed to the back of the drawer because women are overshadowed by an androcentric and masculine remembering of the United States industrial past. Is this then why more men volunteer at IHMOs? How do museum professionals motivate more female, gender-neutral, and other various gender individuals to volunteer at IHMOs?

The first Nineteenth century US museums contained spaces and positions that allowed women to volunteer and work alongside their male counterparts, while certain jobs or roles within museums have been differently feminized or masculinized over time. Art museums were usually seen as primarily feminine spaces, while history and natural history museums were masculine ( Baldwin \& Ackerson, 2017). In 1905 Agnes Mongan became the first female curator, presiding over the Fogg Museum (art museum) at Harvard University (Sorensen, L., n.d.). As for the first US historical museum curator, that moniker goes to the women of the Mount Vernon Ladies' Association (MVLA) in the 1850s (Brandt, 2016). The MVLA was founded by Ann Pamela Cunningham and given a charter by the state of Georgia in 1856 (Brandt, 2016). With the dedication of the MVLA, Mount Vernon became the first preserved house museum, setting an example for 
other women's historic preservation organizations such as the Colonial Dames of America, Daughters of the Confederacy, Daughters of the Utah Pioneers, and Daughters of the American Revolution following in the decades and centuries to follow. Important to this narrative is the efforts of volunteers to congregate, organize, lobby, purchase, define, and preserve the home of the first President of the United States. As I will cover in later sections, gender plays an integral part in volunteering within museums, deciding who is allowed to volunteer and what they are allowed to do. Their efforts, along with most women between the 1800s and the first world war were not seen as 'professional', instead they were regarded as amateurs, unprofessional, and cheap labor (Hill, 2016). Nineteenth and early twentieth century feminine 'roles' were reinforced through museums, with women being given jobs that required skillful handwork, communication, and childcaring, instead of curating, field work, or anything construed as 'gentlemanly' or masculine. Wealthy women donated material to public museums, while those without the social or economic capital volunteered their time. As with other 'cultured' past times and professions, an economic and social barrier bared men and women alike from volunteering and working in the museum field. Hill (2016) points out that the position of museum educator was the entry point in which women entered the museum field as professionals. Since then, women have made ground, for in 2019 the American Alliance of Museum's stated that women make up forty-nine-point-five percent of museum workers (AAM, 2019). Baldwin and Ackerson (2017) found that sixty-two percent of the respondents to their survey on equality and inclusiveness in the museum workplace relayed that were witness to gender discrimination on the job (Baldwin \& Ackerson, 2017; Gender Equity in Museums Movement, 2018). It is a troubling notion that a 
museums staff and faculty and their visitors and volunteers are still subject to outdated social values, sexism, and discrimination. It is this discrimination that is at the core of my argument for gender inclusivity in IHMOs, for as Middleton and Morgan-Hubbard (2018) present, "museums should be places where museum staff and visitors are safe and comfortable being their complete selves" (174).

While contemporary women are gaining equality for their hard work and determination, their progress rests on the back of others. We see the vestige of women within industry in America during the 1800s through the cottage industry or "put-out system”. This system had families produced goods in their homes, such as cotton, farm produce, leather, etc., to be sold at local markets (History Crunch, 2017). Prior to 1900, twenty percent of white women above fourteen years old had a job outside of the home. Some women chose to work or had to do so to provide for their family, while others were domestic workers. In the case of African American women, it was about three times more likely that they had a job outside of the home (Kessler, 2018). Employers went as far as enacting labor restrictions on women in the workforce because they were seen as fragile and meant to be in the home and not in the workplace. All this happened prior to the Second US Industrial Revolution (1870-1914) where the cottage industry and women alike moved to urban areas for potentially better opportunities. At this time men had far better economic opportunities than women, leading many to become housewives, work as servants or maids, or choose to be cotton mill girls. Certain industries looked for women who had no families and responsibilities, such as mill towns like the Lowell Cotton Mills. It was in these mill towns where women were given "training" to become better wives 
(Kessler, 2018). Women were constantly placed into workforce positions that were seen as supportive, such as nurse, typist, servant, maid, caretaker, etc. It was not their choice to enter into these positions as, from a young age, they were inducted into an androcentric culture where men were the "breadwinners" and women were "other" or "lesser than" (Funk \& Pashkevich, 2020: Romano \& Papastefanaki, 2020). During the First and Second World War's women flocked to the workforce where their husbands, fathers, and brothers had been before they were sent to off to fight. It is at this time that women created labor unions, though at a disadvantage due to the temporary nature of their position as placeholders for their male counterparts (Kessler, 2018). At the conclusion of war, most women were forced out of their new place in the workforce to make way for returning soldiers, while some fought to keep their positions. This was also around the same time women were moving into higher positions in industry, such as conducting Union Pacific railroads and working in the Chicago Steel Mills (Union Pacific, 2017). Even in current workplace settings, the uncontrolled gender pay gap for women in 2020 is eighty-one cents for every dollar earned by a man (PayScale, 2020). What I have outlined is a very brief and selective history of woman's labor issues, but with this knowledge I can now discuss why women are not represented nearly as much as men in IHMOs.

IHMOs, based on my research, tended to have more male than female volunteers. While examples like the Union Pacific Railroad Museum's Move over Men exhibit, or the American Labor Museum's Women Who Dare to Inspire exhibit talk primarily of women in their respected industries, IHMOs need more inclusivity in heritage interpretation 
amongst different genders in order to close the volunteer gender gap. As outlined by Funk and Pashkevich (2020) in their research on androcentric heritage marketing, men are given the spotlight, while women, children, and minorities are side characters who are only mentioned because they play a role in the lives of men. Men were seen as robust individuals that could operate heavy technology without severe damage to themselves, because of this, most heavy machinery was tailored to be operated by men (Taska, 2019). As previously mentioned, girls who grew up in the US, prior to and during the First and Second Industrial Revolution, were buffeted by androcentric practices, such as training girls to cook and clean, care for and teach children, and be an obedient wife. Social norms were self-regulating, therefore, unless they needed the money to care for their family or wanted extra income, most white women did not enter the workforce in large numbers until men were at war (Funk \& Pashkevich, 2019). If an IHMO can change the narrative that is continuously perpetuated by the androcentric interpretation, then they can accomplish two things: narrative inclusivity and the creation of an inclusive environment for volunteers. By creating an inclusive narrative, women who worked in the industries represented may be more likely to come forward with their stories now that they see their experiences as valid industrial heritage. As seen in my research, a sense of belonging and the act of sharing experiences lie in the top five reasons individuals are motivated to volunteer with IHMOs. Additionally, having more narrative inclusivity opens up the opportunity for more exhibits, programming/events, and grants focused on institutions with gender inclusive practices. Heritage, as is discussed by Archer, Cooper, and Ruhanen (2012) and Funk and Pashkevich (2020) is both a resource as well as a product that can be crafted, branded, sold, and re-sold; therefore, it is up to the IHMOs, their staff, 
and volunteers to decide on their intended audience. It is hoped that IHMOs choose the path of inclusivity, as in comparison to other museum themes, industrial heritage is close enough to the present that people are still experiencing industrialization and deindustrialization.

In addition to the arguments provided on inclusivity for women in IHMOs I found a number of useful comparisons between gender and volunteer tasks, gender and community involvement, and gender and volunteer motivation. When examining the relationship between the gender majority at participating IHMOs, and what volunteer tasks these volunteers completed, I found that when an IHMO relied upon a majority of female volunteers, those volunteers completed tasks related to hospitality fifteen percent more often than those IHMOs with a majority of male volunteers (Table $38 \&$ 39). I can not determine whether women were assigned these volunteer tasks of if they chose more frequently than men to serve in roles that relate to hospitality. It is an unfortunate theme in this analysis that there was not nearly enough data relating to persons with non-binary, non-CIS gender identities to examine these questions further, though this lack of data alone may reflect a lack of representation of GBLTQIA in IHMOs or that survey participants were not comfortable discussing detailed personal information.

It is clear that a high percentage of female volunteers at an IHMO correlates with strong and active participation by members of the surrounding community. When males make up the majority of volunteers, there seems to be less involvement by local community members (Table $40 \& 41$ ). In examining volunteers' ages, the survey found that an overwhelming majority of volunteers were sixty years and over. Oder women 
therefore seem to be more active or outwardly visible in the IHMO and surrounding community than men. IHMOs could use this information to leverage tailored volunteer opportunities to engage more women (of all ages) in positions and activities that stimulate involvement by/with the surrounding communities.

Men and women reported different motivations as volunteers within IHMOs. Of the motivations, a volunteer's sense of belonging, the IHMOs industrial assets, the volunteer's interest in history, a volunteer's interest in local history all had a ten to twenty percent difference between gender groups, from majority male to majority female volunteer communities (Table $42 \& 43$ ). Female-volunteer majority IHMOs were seventeen percent more likely to state that their volunteers were motivated by a sense of belonging than that of male-volunteer majority IHMOs.

These motivational differences are noteworthy in the context of gender and community involvement. In addition to the higher level of local community involvement found among female-majority volunteer groups, twenty-three percent of IHMOs with a female-volunteer majority reported that their volunteers were motivated by an interest in local history. This is fourteen percent higher than that of male-volunteer majority IHMOs. It appears that IHMOs with a female-volunteer majority might feel a greater connection with both the surrounding community and among the institutions' volunteers. As for male-volunteer majority IHMOs they tend to have more volunteers motivated by a general interest in history and the IHMOs industrial assets. Out of the IHMOs with a male-volunteer majority and a motivation to volunteer based on an IHMOs industrial assets almost sixty-seven percent of the IHMOs were based around an industrial narrative 
of transportation such as railroads, locomotives, and/or shipping. In comparison, only twenty five percent of female-volunteer majority IHMOs with volunteers motivated by its industrial assets had a narrative based on transportation. Based on these comparisons, IHMOs could leverage new understandings of the motivational patterns provided in this research to design programming that will attract more diverse community of volunteers based on their interests and sense of belonging and community.

The findings from this project also point towards a small percentage of IHMOs that either were unsure what to present as their gender majority or their majority were individuals who do not identify with conventional gender norms. There is very little in the way of demographic information on non-binary gendered volunteers in IHMOs, though there are some pieces on non-binary museum exhibits and representations in select museums. In 2019 the Exploratorium in San Francisco opened up the exhibit called "Self-Made: Exploring You in a World of We" that "offered ways to explore how identity is constructed personally, socially, and structurally" (Alexander \& Herring, 2020). While their exhibit did not directly discuss demographics of volunteers, they did provide fodder for discussions in IHMOs. Middleton and Morgan-Hubbard (2018) provide that in seeking to write an article they found that women of color and trans and queer individual "are especially burdened by caregiving responsibilities, time and financial restrictions" that prevent them from potentially pursuing (among others) careers in the museum field and advocating for systematic change in museums and other institutions. The same can be said for the inclusion of non-binary, trans, queer, women, and other minority individuals and groups within the interpretive plans for IHMOs, for if 
an institution lacks the time and energy to put towards the creation of an inclusive narrative then it will be harder for them to do so. Though, while it may be hard to find representative non-binary individuals or anecdotes in industrial history, any effort will be better than completely ignoring their presence in history. Volunteers, no matter their gender should feel comfortable spending their time at an IHMO. Not only is it important for IHMOs to be inclusive of age and gender, but also in terms of ethnicity and racial background.

\subsubsection{Ethnicity/Race}

Are US industrial heritage museums or organizations (IHMOs) inclusive? Do they tell the stories of minority populations in a way that explains how they fit into the industrial tapestry of our nation? And could inclusivity in IHMO interpretation be used to recruit racially and ethnically diverse volunteer groups? While the first two questions will be touched upon, the latter is the focus of this discussion on the confluence of IHMOs, their volunteers, and the themes of race and ethnicity. The 2016 US Bureau of Labor Statistics (USBLS) report on volunteerism found that white volunteers were the most prominent amongst all racial groups (26\%) (United States Bureau of Labor Statistics, 2016). Similarly, my research found that ninety-seven percent of responding IHMOs volunteers were primarily white. Comparing my findings to that of the 2008 Survey of Public Participation in the Arts (SPPA), I found that seventy-nine percent of all visitors to museums/art galleries were white (American Alliance of Museums, 2009). While this last survey was based on visitors to museums, correlations can be drawn from those who visit and those who volunteer based on their interests, therefore it is posited that demographics 
with high visitation percentages would also be the most likely to volunteer. Using all three surveys it is blaringly obvious that whites are the most probable visitor and volunteer to museums, though what about all the other US Census Bureau defined groups? The same USBLS study found that of the majority-minority volunteer groups African Americans represented nineteen percent, Asians eighteen percent, and Hispanics fifteen percent (United States Bureau of Labor Statistics, 2016). Only three percent of the IHMOs in my research responded with something other than white; specifically, two percent choosing "Prefer Not to Answer" and one percent leaving the question "Unanswered". Sadly, the results of the SPPA also show that of the visitors to museums/art galleries six percent were African American, nine percent were Hispanic, and seven percent were listed as "Other" (American Association of Museums, 2009). Even though the USBLS survey was a general survey of volunteerism across the country, it still paints a grim picture in terms of inclusivity for museums, especially IHMOs. Now it should be brought up again that my research focused on the majority and not every volunteer at each IHMOs, therefore there are likely many persons of color who volunteer that are unrepresented by my research. Though it is an unfortunate result that persons of color were not focused on, my research still brings up a valid point, IHMOs need (where possible) to become more racially and ethnically inclusive.

In a 2020 Slate article, Haigney explains different circumstances in which current volunteer docents may need more training on discussing race with visitors. In my experience serving museums as an AmeriCorps VISTA member in Chicago and New England, there is an overwhelming number of white volunteers who do everything from 
give tours, to help in programming, and work on collections. The Haigney provides a nice perspective on this that made me chuckle "As one museum education employee who has worked at New York's Museum of Modern Art said, "It's not totally this, but mostly, it's an army of privileged old white women"' (Haigney, 2020). The notion that someone has free time to give to a museum or art gallery speaks to a form of socioeconomic privilege where those with the extra capital and time can go and volunteer without major economic repercussions. This is also true of visiting museums, for, unless one is a member of a museum, or has a relative or friend at a museum there is an entrance fee. As mentioned previously, those who visit museums most frequently have the highest probability of becoming volunteers themselves. With this in mind, a 2009 AAM report outlines the racial and ethnic demographics of museum goers and the future of museums, providing four explanations as to why minority groups do not visit museums as much as whites:

- "historically-grounded cultural barriers to participation that make museums feel intimidating and exclusionary to many people"

- "the lack of specialized knowledge and a cultivated aesthetic taste ("cultural capital") to understand and appreciate what are perceived by many as elite art forms, especially in art museums"

- "no strong tradition of museum-going habits, whether these were fostered in childhood or other family experience and tradition" 
- "the influence of social networks to encourage museum-going rather than other leisure activities - i.e., if none of your friends go to museums, you don't go either"

(American Association of Museums 2009, p. 13)

Of these reasons, I would like to focus on the first, which provides that there is a historical component as to why minority groups do not visit, and potentially volunteer at museums. In order to understand why IHMOs are greatly affected by this explanation, I must examine the relationships between industry and historically minority groups.

As with women, children, and the 'poor', minorities during industrialization and subsequent de-industrialization events had it rough. The following is a brief history of African American and other minority groups within America during periods of industrialization and de-industrialization. Prior to, and after, the first shots of the Revolutionary War in 1776 Africans were forcibly transported to the colonies and placed into slavery. In bringing them to the colonies, they introduced new techniques for planting and harvesting of rice and cotton (among other produce) and new methods of cooking (Trotter, 2000). It is also during this time that Indigenous Peoples from North and South America were being forced into labor or used to kick-start various industries, such as the tobacco, fur, and sugar industry, otherwise known as the primitive accumulation of capital (Arnesen, 2002; Trotter, 2000; Marx et al. 1990). The first US Industrial Revolution occurred from the 1790s to the early 1800s, with enslaved Africans being forced to work in the cotton fields, enslaved Mexican forced to mine and labor in the South and South West, Indigenous Peoples being removed from their ancestral land 
due to the prospect of gold (and later coal and uranium), and a general mistreatment and subjugation of minority populations. Industry was growing and many, particularly those who were poor, women, and/or persons of color were subject to sexism, racism, or classism in one way or another. Between 1740 and 1834, many southern states passed laws, such as the Anti-Negro Act of 1740, that made it illegal for enslaved people to learn to read and write (Konadu, 2010; PBS, 2004). This legal obstacle prevented free Africans and other minority groups from patenting inventions and gaining societal standing via education. In addition to the common view of enslaved African laboring in cotton fields, Trotter (2000) provides that they also worked in the lumber, naval, textile, tobacco, and railroad industries. Arnesen's (2002) book on African American railroad workers provides a view into the opportunity offered to newly freed enslaved people, as well as the racial and gendered injustices that befell them in the very same industry. African Americans and immigrants from countries like Asia, Europe, and Mexico were given jobs that ensured the railroad or railcars were tended to, such as grading railroad beds, acting as porters, and laying tracks (Arnesen, 2002). It was also at this time (early 1900s) that African Americans and other minority groups began to find jobs in factories, though not without strife and struggle. During the Reconstruction Era of the South, factory owners began a smear campaign against their former laborers by stating that they were ill fit for factory work. Some even going as far as saying that "the whirring of the machines would put blacks to sleep" (Trotter, 2000, p. 21). Of course, this was not the case, but it was part of a larger movement to put a stranglehold on people considered "other". For example, Hunter (1998) discusses a societal tug and pull between African American washer women and their wealthy employers and the newly formed African American elite in 
Georgia during the late 1800s and early 1900s. In order to survive, and in some cases thrive, African American washer women used social groups, mutual aid societies, and dancing "sinfully" to express themselves (Hunter, 1998). Employers and the African American elite rejected these groups and smeared washer women, labeling them as heathens and restricting employment unless they lived on site and refrained from dancing (Hunter, 1998). Slowly minority populations gained more civil rights (though not uniformly across the US), which also allowed them to pursue career paths outside agriculture and private service.

With the US's entrance into the First World War and restrictions on immigration, no longer was there a steady stream of immigrants, therefore businesses began begrudgingly welcoming minority populations into factories (Arnesen, 2002). Railroads, while subjugating African Americans and immigrant groups to rampant racism and sexism, still provided workers with some modicum of financial freedom and choice. Those who worked in the railroad industry and other increasingly available jobs took the racism and sexism and held their tongue as they now had a reliable income source that they could use to change their own living situation, without being dependent on landholders. Anthropologists, heritage, historical geography, and political science (to name a few) scholars' debate as to whether this freedom from slavery was actual 'freedom' or if it was the continuation of the plantation system, but on a larger and more systematic and subtle level that that of the southern plantations (Hunter, 1998; Hoelscher, 2003; McKittrick, 2011; Featherston, 2016; Carter et al., 2011; Littler, 2008). The Pullman Company took advantage of this surplus of laborers and in 1914 the Pullman 
Company had approx. six-thousand African Americans on their pay role, doubling in the decades to follow (Arnesen, 2002). The Pullman Company employed both African Americans and a variety of immigrants in its factories and sleeper and dining cars. While the Pullman Company has its own metaphorical 'closet of skeletons', it provided African's and immigrants a glimmer of hope at economic stability in a time of uncertainty. Another notable employer of African Americans and immigrants were Ford Automobile Factories. Ford's factories gave African Americans jobs where they were on somewhat similar standings as other workers, these and other factory jobs were seen as badges of honor (Trotter, 2000, p. 21). Though that piece of information should not overshadow the fact that Henry Ford was a white supremacist and anti-Semite (Lee, 1980; Willis, 2016). A combination of a variety of factors, two of which being a world war and its subsequent lack of white laborer and the slow change of social values surrounding racism allowed for African Americans, Indigenous groups, and immigrants greater economic freedom, as well as new trials.

With new avenues open to African Americans and other minority groups, so too came mass migrations of ethnic and racial groups, as well as the systematic abuse of such groups at the hands of the government and natural resource hungry companies. African American women also gained footholds in industries like paper, glass, leather, iron, food packing, and railroad/railcar companies. At the same time as holding down these factory positions, African American women were still subject to traditional gendered norms of the time such as child rearing and housekeeping. Hunter (1998) provides that the creation of mutual aid societies helped alleviate some of the stress and turmoil, with African 
American families and individuals helping each other out when times were tough, though in some cases this just was not enough, as some looked to greener pastures for economic prosperity. During the Great Depression, many African American families were forced to migrate to survive. As Marsh provides, in an article on her father's accounts of northwestern migration during the Great Depression, he migrated for three reasons; the crop prices fell; "strict racial segregation [was] enforced by Jim Crow laws and practices, which...kept workers in low-wage jobs with poor working conditions; and [there was] demand for lumber from western states" (Marsh, 2015, p. 500). On a more recent note, in 2019 Curley published an article on the moral economies of Navajo Coal workers, where there was discussion of extending a coal mining permit for the tribe. As of early 2020 , the very coal mine the tribe was seeking to obtain an extension on was shutdown, leaving their local economy in uncertain straights (Vanderpool, 2020). In the late 1940s, the United States Atomic Energy Commission (AEC) established uranium mines on Indigenous peoples reservations, leading to the employment of Indigenous peoples to mine 'radioactive' uranium (Brugge \& Gobble, 2002). In the 1950s the link between rapidly increasing reports of lung cancer by miners was acknowledged, but regulations only appeared on legislators' desks in the late 1960s. Indigenous communities, like the ones mentioned above, have a deeply troubling history with being exploited by governments and companies in order to reap the benefits of a local workforce and low wages. While Indigenous peoples were employed on reservation lands, many chose to leave in the search of economic prosperity. Many African Americans, Latin Americans, Indigenous peoples, and ethnic minorities found more than work in urban areas like Chicago, Pittsburg, Los Angeles, and New York City; they also experienced racially 
charged inequality, community, the potential for education, and above all, survival. It is hoped that in time, the workforce and jobs in all professions will become increasingly diverse and inclusive, so as not to repeat the atrocities of racial and ethnic segregation and discrimination.

With the history surrounding the inequalities of industrial work, how now do IHMOs make reparations and increase the diversity in their volunteer population? The research conducted for this paper focused on motivation, therefore I will begin by acknowledging what happened, speaking to the personal stories of those who lived through it. While working on the Calumet Voices, National Stories exhibit in Chicago, I regularly discussed with museum professionals and volunteers on how to approach and include the overarching narrative of minority populations in the steel industry, Pullman Car Works, and other industries present in the late 1800s all the way up to the late 1900s. We chose to discuss the efforts of the Tuskegee Airmen, the experiences of African American and Latin American workers in the steel industry, and the ethnic diversity and struggles of the Pullman Car Works employees. While Chicago was, and is still, known for its racial and ethnic diversity, Vermont is not, or at least not racially. The Vermont Granite Museum discusses the granite industry within Vermont, the history of which is whitewashed, focusing on European and Canadian immigrants and Vermonters. This does not go without saying that there were no accounts of African American, Indigenous peoples, and other minorities in the granite industry workforce of Vermont, they just happen to be harder to find. If I move my examination of ethnic inclusion within IHMOs to the southern portion of the US, one might find a completely different level of 
inclusion. In my research I chose to include plantations as sites of industrial heritage because of their reputation as being sites of large-scale cotton cultivation. It is my opinion that the enslaved Africans who toiled in the fields, within the plantation manor house, and on the grounds are part of a plantation's industrial heritage. Therefore, it may be understandable to readers that when I came across Eichstedt and Small's (2002) findings on how slavery is presented at plantation museums in Virginia, Georgia, and Louisiana I was shocked. Eichstedt and Small (2002) found that twenty-seven percent of the plantation museum's they surveyed included an interpretation narrative that discussed the trials and tribulations of enslaved Africans. Carter et al. (2011) includes Eichstedt and Small's work in their discussion of plantations and the memorialization of narratives that exclude the voices of enslaved Africans. Their research affirmed the findings of Eichstedt and Small in that some plantation museums choose to place the narrative of a plantation owner over that of the individuals who produced the owner's wealth. Hoelscher's (2003) work examines the Natchez Pageant's concerning display of confederate heritage, while discussing the pageant members lack of concern about the legacy and history of slavery and the implications it has for local African American communities. As with the past examples, dominant narratives of whiteness and glamor gloss over the injustices committed by the very people the pageant members are placing on a metaphorical and physical pedestal (Hoelscher, 2003; Smith, 2006). It is the exclusion or lack of knowledge of the personal, individual, and intimate narratives of producers within IHMOs that makes me believe that more research and consideration in creating exhibits and heritage interpretation. In representing the stories, accounts, and details of producers, workers, and the enslaved, as well as their place in the shared industrial heritage of each 
industrial region IHMOs increase the potential that underrepresented groups may be more comfortable with volunteering and sharing their perspective, histories, and experiences. Based on the AAM's 2010 report, visitors, and by extension, volunteers, with familial ties or experiences in racial segregation and exclusion, may visit and/or volunteer with IHMOs less than that of whites. This historical trend is not something that can and should be changed, instead it needs to be represented and acknowledged so then future generations learn about it and make better decisions about race and ethnic inclusivity in industry and their individual lives.

While working on this project, I interviewed staff members from various IHMOs, some of which provided their perspective on racial and ethnic issues engrained in recruiting and retaining volunteers. When asked about demographics at the Chicago Field Museum, a museum practitioner, and past supervisor mentioned that they felt that they were not doing enough to bring in the diversity that they hoped they would with their volunteer program:

"I mean, it's interesting because compared to a rural area, where you are, or a more rural area than one of the five largest metropolitan areas in the county, which is where I am, like I said before, while we don't achieve the goal of matching the demographics of our city, and that's a failure on our part, we still have more diversity that allot of other areas would have, and that doesn't just mean Latinos and African Americans, which we do have some of, just not in the portions we should, we also have Asians, and we have a fairly large Jewish contingent in our, volunteer group, over the years." 
Looking back on this interview, I realize that the more urban an IHMO, or any museum, is the wider a range of diversity they will attract. In Chicago, there are industrial neighborhoods more diverse than many small towns in America, but the stories of minority groups are not readily told in rural museums nearly as much. Now, before some IHMOs out there get angry at this statement, I should also mention that museums usually only have a limited space to present what they have in their collections, and even then there may be little preserved material relating to minority groups. When looking back at the interviews and surveys, one of the interviewed and three of the surveyed IHMOs mentioned racial or ethnic diversity, with only one pointing out an issue surrounding racial/ethnic inclusivity amongst the volunteer groups. Again, if we (and by "we" I refer to IHMO practitioners) are seeking to diversify their volunteer population, we should begin by acknowledging the various ethnic and racial groups that make up our shared industrial heritage. In addition to understanding the racial and ethnic issues surrounding volunteer motivation at IHMOs, there is also a need to understand how an individual's education plays a role.

\subsubsection{Education and Employment}

Education and employment are both critical demographics for my research and in most cases one feeds into the other. In 2017, the USBLS found that "among persons age 25 and over, 38.8 percent of college graduates with a bachelor's degree and higher volunteered compared with 26.5 percent of persons with some college or an associate's degree, 15.6 percent of high school graduates, and 8.1 percent of those with less than a high school diploma" (US Bureau for Labor Statistics, 2017). The natural take away from 
these findings is that those with an education are more apt to volunteer than those without. As a degree holding volunteer, I fit into the higher percentile group; although, I would be remiss without mentioning that the USBLS study was based on formal acts of volunteering and not those done informally (See Chapter 1 for more on this).

Volunteering with an IHMO is a formal act of volunteering, therefore the USBLS study can be used as a comparison. My own research found that fifty-five percent of surveyed IHMOs responded that a majority of their volunteers hold a Bachelor's Degree (Table 4). As for levels of employment in my research, I found that eighty percent of the surveyed IHMOs responded that a majority of their volunteers were retired. While the USBLS study does not specifically mention the statistics of retired volunteers, they do provide their results for those unemployed, as well as those with full and part-time employment: "among the employed, 27.2 percent volunteered...by comparison, 23.3 percent of unemployed persons and 21.4 percent of those not in the labor force volunteered. Persons employed part time were more likely than full-time workers to have participated in volunteer activities--31.1 percent versus 26.3 percent" (US Bureau for Labor Statistics, 2017). The research I carried out, while vastly different in population size and purpose, provides corroborating evidence indicating that those with more free time on their hands are more apt to volunteer than those with a full-time job. It seems that those with a higher education and a retirement are better situated to volunteer than those with one or neither of the provided characteristics. How does education and employment, on their own or in tandem, play in the motivations of people to volunteer at IHMOs? To answer this question, I have included in this section a discussion how state unemployment stipulations play into IHMO volunteerism, how museum related careers or higher 
education influences an individual's potential to volunteer, and how a person's career in an industrial field influences their potential to volunteer at IHMOs.

While serving as an AmeriCorps VISTA member at the Vermont Granite Museum (VGM) in Barre, Vermont, I was impressed by the number of volunteers that came in on a weekly basis. Interviewing the director, I came to realize that part of the museum's volunteer population was actually those seeking benefits from unemployment, "I work with case managers of the Vermont Department of Labor [Workforce Development Program] to train unemployed residents of Central Vermont." Within this program are branch programs such as the 'Returnship Program', 'Learn IT 2 Work', and the 'Senior Community Service Employment Program'. During their time at the museum, they were trained and then tasked to work on exhibit development, research projects, museum maintenance, and collections management. These individuals had no formal training in museum studies but were provided skills by the museum that they could then use to find employment. Additionally, they are given state unemployment benefits if they $\log$ a certain number of hours per week. In the surveying of one hundred and thirteen IHMOs, the VGM was the only one to mention this method of volunteer recruitment and management. Based on a study conducted by the Corporation for National and Community Service (CNCS) in 2013, volunteering is associated with a twenty-seven percent higher chance in finding employment (Spera et al., 2013). While my research found none of the IHMOs to have a volunteer population of primarily adult unemployed individuals, my experience at the VGM shows that there are definitely IHMOs out there that have volunteers who are currently unemployed. Outside of the unemployed, the 
VGM also works with the Washington Criminal Division of the Vermont Judiciary to offer community service projects to adolescents that need to complete community service hours, the Vermont Department of Disabilities, Aging, and the Independent Livings Division of Vocational Rehabilitation to provide skill training and experience to some of their patients, and the Vermont Department of Human Services' Economic Services Division program 'Reach Up'. While the restorative justice program is centered on younger individuals, the mental health program volunteers range from early 20 s to late 30s. Based on Stkas, Snyder, and Clary's (1999) study on the mandatory volunteering of youth in schools, by requiring an individual to volunteer at a young age they are then more likely to volunteer throughout their life. By tapping into local and regional programs based on reform, skill training, and assistance, IHMOs, like the VGM, can increase their volunteer population, support members of the community who need assistance, and be a force for local change.

In general, museums, just like many public non-profit organizations need volunteers to run, grow, and support the local community. Volunteers in a museum setting outnumber staff members seven to one, therefore it is useful to inquire as to how many volunteers and staff members are at the IHMOs surveyed and interviewed during my project (AAM, 2019). About thirty-three percent of the interviewed and surveyed IHMOs have between one and three staff members, whereas $36 \%$ have between one and ten volunteers. As we increase the number of staff members, so too does the number of volunteers. Fifteen percent of the IHMOs interviewed and surveyed have more than ten staff members, though twenty-six percent have more than fifty volunteers. While staff 
members are paid a salary or hourly wage, volunteers are paid via the benefits/rewards they gain from the museum, service training, and personal motivation-based benefits. It is important to note that IHMOs, just like other museums, survive and thrive by way of community support. During my time at the Chicago Field Museum, Vermont Granite Museum, and at various local municipal museums, I have observed that those who volunteer tend to be people with science backgrounds, pursuing a higher education, or have a higher education and need something to do in retirement. Additionally, during these volunteering experiences, I realized that very few individuals who have a full-time job volunteer at IHMOs. While not all IHMOs follow this trend, the volunteer populations of eleven IHMOs in my study are made up of primarily full time or "Employed for Wages" (Table 5). Notable to mention in the context of this finding is that, while small in comparison to those who are retired and volunteer at IHMOs, the volunteer population of two surveyed IHMOs are made of primarily students. It is this student population that I will now focus on.

Throughout my time in Chicago, I spoke with volunteering high schoolers, undergraduates, and graduates as to why they volunteer. Their responses and motivations were the same as mine, practical experience. Since most of the data I collected lacked the perspective of the high schooler, the college student, or graduate, I will be turning to the interview responses from IHMO directors and staff members. One of my supervisors and a researcher at the Chicago Field Museum, mentioned in an interview that their interns are "interested in career fields like anthropology, archaeology, environmental studies, sustainability, which is emerging as a topic, a major that one could study in college." On 
a phone interview with my contact at the Porter County Museum (POCO), Indiana, they stated that "when it comes to students, sometimes it's just that they want to get practical work experiences or they want to, it could be service hours for maybe like an honor society or church or extracurricular assignment." Looking at the motivations of surveyed IHMO volunteers, eleven percent were motivated due to a desired to learn or gain experience, fifteen percent by their want to teach or share, and twenty-six percent by a sense of belonging. As a graduate student, these three aspects, being able to learn, teach, and be surrounded by peers, are key when I am looking for a volunteer opportunity. Moreover, the task people are given as a volunteer are also a factor of motivation. IHMOs that listen to what volunteers have to say and want to take away from their experiences, as well as what they expect, will gain them loyal and long-lasting volunteers. In general, seventy-nine percent of IHMO volunteers spend their time helping host special events/programs. Though this is a general percentage, my interview with the POCO indicated that younger individuals and students may be more likely to volunteer with IHMOs during special events/programs, "we also had something called "up late" at the POCO muse, that featured live music and artist and businesspeople in booths. That got a lot of younger people in the museum, younger than and more than expected." Based on the proximity to a college, university, or city/town's downtown, an IHMO's program may attract college age individuals, younger professionals, and locals interested in an areas culture and arts. Another aspect of volunteer motivation is how they were initially told or came to know about the possibility of volunteering. While fifty-seven percent of the IHMOs responded that word of mouth was a method they used for volunteer recruitment, only seven percent mentioned reaching out to local universities. This 
percentage is surprisingly low considering that most volunteers at formal institutions have a higher education (US Bureau for Labor Statistics, 2017). By seeking out students pursuing a higher education, IHMOs not only get volunteers with more specialized skill sets, but they also help younger volunteers develop these skills and gain on-the-job experience.

One method used by some museums to garner more volunteers is through the use of an AmeriCorps member. These individuals are similar to volunteers in that they are there to volunteer; however, they are funded by the Corporation for National and Community Service (CNCS) and a partnering organization for a year of service. As an AmeriCorps VISTA member I have spent twenty-two months serving museums and other heritage organizations, and during my time each organization has helped me develop as a professional while also getting support from a volunteer that needs far less training and can potentially train others. During my interview, the POCO's director mentioned that, "in the past, we have gone through AmeriCorps and they basically assign a volunteer coordinator to the museum, their role is to attract volunteers. I was actually in this position at one point." Motivation for AmeriCorps VISTA members vary as much as any other volunteer, though a benefit is that they get an education award at the end of their service; therefore, they may be more likely to be motivated to learn and gain experience. Straddling the line between volunteering and employment, AmeriCorps members are given a stipend of one-hundred-and-ten percent the poverty rate of the area they are serving so they can afford housing during their service. 
Based on the 2017 USBLS study about sixty-three million US citizens volunteered in 2016, of that twenty-six percent were adults with full-time jobs (US Bureau for Labor Statistics, 2017). In comparison with the USBLS study, my research found that only ten percent are employed for wages; where then are all the volunteers with full-time jobs when it comes to my research? Answer: they are probably busy. Working forty or more hours a week, attending school, and trying to maintain some semblance of a social life is hard. Most of the time, volunteering on the weekends or in the evenings is the only option. In Chicago, I volunteered as part of my service year, while also helping out local museums that were trying to find their footing. Before graduate school, I worked in the food industry, with my off time being spent at my local historical society doing archival and being a tour guide. Employment levels in IHMO volunteers vary, for example, when I was interviewing the volunteer director of the Cedar Lake Historical Association (CLHA) they mentioned that "we have 4 volunteers total that work and they are all 50 and under, so that's my youngest group, but even then we're talking, the youngest person is in their 30s." From the age of seven, my parents were involved in my towns Boy Scout Troop because I was a member of the organization. Although they still worked forty-hour weeks, they made time to volunteer. I include this personal anecdote because it adds to the idea that even though they may be overworked and tired, people with full-time jobs still volunteer and are motivated to do so by the same desires and needs as other volunteers. Another example, provided by a former president of the Calumet Heritage Partnership, explained the motivations of professors to volunteer, "when you're a professor you do your teaching, your research, and then your kinda community service/community engagement things. And you actually do get sorta 
credits towards tenure and towards your advancement, depending on where you are, but that can be the case and so engaging as a volunteer in an organization can help on that side of things." Their interview feeds back into the idea of incentivized, mandatory, or required volunteering. Volunteering, for those within higher education, becomes part of the position, their motivation to continue becomes bundled up in their research, students' projects, and role as an educator and community member.

IHMOs focus on the heritage of an industry, the history of technology, the site of industrial activity, events that shook the world, and the techniques and methods people used to manufacture goods or extract resources from the earth. It is this latter of the group that I intend to discuss next, for while IHMO volunteers present and interpret industry, there are those that lived and continue to experience it in the workplace. Thirty-two percent of the IHMOs surveyed provided that one to three of their volunteers once worked in the industries represented in their IHMO, while sixty-three percent responded that none of their volunteers currently work in the industries represented in their IHMO (Table 26). What motivates these veterans of industry to spend their free time at IHMOs? To answer the former of these questions I need to point out that eighty percent of IHMO volunteers are retired. After retiring from the industry, no longer seeing the same things day after day, talking with people who they worked with for so long, the idea of being able to relive and grab hold of that nostalgic past in an IHMO may sound attractive. The same motivations apply in this case, a sense of belonging, an interest in history, and the IHMOs industrial assets (Table 20). While checking in on some of the IHMOs that had emailed to confirm their participation in my research, I managed to catch the director of a 
railroad IHMO in Kentucky. During our conversation, they mentioned that they used to work on the rails, as did their father, and it was this connection that led them to establish the IHMO and act as its director. In Chicago, I was privileged enough to go to a Steelworker Organization of Active Retirees (SOAR) meeting, where I sat down with a number of retirees who were happy to see a young face take interest in their stories. It was at this meeting that I understood something, these men and women were proud of their connections to the steel industry, their built brotherhoods and sisterhoods, and the communities they lived and still live in. While only a couple of the SOAR members at that meeting spent time at the South East Chicago Historical Society, it was the interaction with these living figures of industrial heritage that made the experience notable. Looking over all the conversations, interviews, survey results, and personal experiences with industrial heritage, I find that what motivates these retired and still working individuals above all else is a sense of where they have been, what they have done, and a desire deep down to share it with those that will listen.

\subsubsection{Industrial Heritage}

The purpose of this study was to understand volunteer motivation in IHMOs. During the course of my research, I found that I also needed to understand how people understood industrial heritage and its use as motivation for community involvement and how IHMOs discussed industrialization and deindustrialization. As I reviewed the responses from the survey, I split people's understandings of industrial heritage into three groups: general, mixed, and specific. Fifty-one codes were developed to group the onehundred-and-thirteen individual perceptions of industrial heritage, with a majority being 
labeled as "general" (Table 21). General perceptions of industrial heritage tended to focus on overarching concepts, such as the history of industry or technology, people and physical remains, and industrial artifacts. Specific perceptions of industrial heritage used specific examples from their own experiences, while mixed are perceptions that blend specific and general concepts. It seems that respondents used general concepts of industry more than specific or mixed ones. The most mentioned general concepts of industrial heritage were "history of industry", "people", "physical remains", "history of technology", and "industrial artifacts". When I presented the idea of industrial heritage to visitors of the Vermont Granite Museum (VGM), they connected it back to the industrial revolution, 1920s, or in rare circumstances, their parents or grandparents' experiences. Heritage is a personal concept, and everyone has a slightly different understanding, therefore the same can be said about industrial heritage. While there were concepts in my analysis of the survey and interview results that crossed and compounded, such as "history of industry", there were still fifty-one codes that represent a continuum of personal understandings of industrial heritage. As I cannot review all fifty-one codes in this discussion, I leave it to readers to examine them and see how they compare to their personal understanding of industrial heritage (Table 21).

From the research I drew a few correlations that connect back to the age of volunteers within IHMOs. It turns out that the understandings of industrial heritage may be linked to age, for IHMOs with a majority of younger volunteers tend to have more general understandings of industrial heritage as compared to IHMOs whose volunteer communities are older on average (Table $43 \& 44$ ). Those IHMOs with a majority of 
their volunteers aged more than sixty years were thirteen percent more likely to discuss industrial heritage using specific experiences, events, places, and people than IHMOs with a majority of their volunteer pool aged below fifty-nine years. IHMOs whose mission or programming discuss general concepts of industrial heritage may have a wider and more inclusive appeal to wider audiences. Conversely, IHMOs that discuss or present specific elements of industrial heritage may better interpret themes at local or regional levels, therefore providing visitors and volunteers with a focused industrial narrative. Each personal perception of industrial heritage is valid and IHMOs can utilize these perceptions to elicit support and involvement from the surrounding community.

Community involvement is key in keeping an IHMO operational, for they supply the volunteers, the funding, the visitorship, and interest. I was delighted to find that thirty-six percent felt that the community surrounding them was actively involved in their IHMO. To support this finding, I have included some statement from a couple of the interviewed IHMOs:

"Very...they provide most of our funding, donated services and goods, archival collections, and are the labor force of the museum." - VGM

"The community is pretty involved and we're at the city center, people can rent this space and use it for their own events" - Barker Mansion

"I would say pretty involved. We try to involve different aspects of the Porter County Community in all our programs" - POCO 
Each of these sites is located within or close to the center of the community or fairly close, offering programs to visitors that are put on by volunteers from the local community, and have a mission to advance the community as well as share and inform people of the history of the area.

When examining the comparison between population density and community activity in IHMOs I found that rural areas are more apt to have minimal volunteer involvement than urban areas (Table 45). It was also apparent that IHMOs run completely by volunteers tend to lack active community support, which seemed counterintuitive, but as IHMOs hire staff members there is an increase in community support (Table 46, 47, 48, \& 49). This may be due to the focus that staff members bring to non-profits, where their job rides on supporting, maintaining, and growing of the IHMO and its volunteer and community interest and support. The most active communities were those found 'somewhere-in-between' urban and rural (Table 50). In the case of the VGM, the community surrounding it elicits help from individuals who have lived there their entire lives, worked in the granite industry, or see volunteering as an opportunity to make a difference.

On the opposite end of the spectrum are sites that responded, saying that the surrounding community is minimally involved. At thirty-one percent some of these IHMOs felt that the local community does not know they exist, that they do not really do much, and that their volunteer population is almost non-existent. One of the IHMOs I interviewed had this to say on the topic, "It's hit or miss, the number one question is "oh there is a museum in town, I did not even know that"'. In this case, near the end of the 
interview the director told me that they were going to be re-branding as a way to elicit more support from the surrounding community. A big issue that comes from a lack of community support is the possibility that the site will lose its volunteer base, move what collections they can to other sites, and shutter the IHMO. One such interview response spells out this fear, "it seems to me when I talk to people from other organizations, most other organizations, they're worried about what's going to happen to their collections after this group of volunteers that are there like dies or can't do what they do anymore and we don't have that issue at all, we have more and more younger people getting involved so it's a, we're in a good spot." It is this IHMO and twenty-three others that were grouped into the "community is moderately involved" category. Based on their responses, I grouped the community support for their IHMOs were somewhere between active and minimally involved, or growing, but not quite to where they want to be. A few sites were uncertain about their stance in the community, and during our interview they provided me with a perspective I had not thought to examine:

"So that's a long story and I'll cover it as quickly as I can. We're on the museum campus next to downtown Chicago. We have been a field trip destination for all of Chicago area for a long time, a tourist destination for a long time, but there's even a degree to which the Downton area has only emerged as a residential neighborhood in the city within the last 10 or 15 years and before that it was a working district that went dark after hours. So we don't have a true kind of relationship to an immediate neighborhood. This realization of a flagship international museums do not, 
are not conscious of and do not have a strong relationship with their immediate neighborhoods. And even at times don't have strong relationships to their city that they're in, is actually what led to the creation of the entire science action center."

While the Chicago Field Museum and its Keller Science Action Center are not primarily IHMOs, the latter does involve itself in the creation of a National Heritage Area in the Calumet Region. In speaking with one of my interviewees, they pointed out that "the Calumet Heritage Partnership is eager to preserve that particular collection of industrial heritage out of the objects, records and so forth,... we continue to try and articulate the relationship between the industrial heritage of the Calumet region, as the calumet region itself tries to seek a more sustainable future." Just like other National Heritage Area initiatives (e.g., the Silos and Smokestacks National Heritage Area and the Augusta Canal National Heritage Area), the Calumet National Heritage Area would utilize the industrial and environmental heritage of the region to support community involvement and increase tourism (NPS, 2019). It is this and other efforts to preserve history and heritage, educate visitors and community members, and learn from the past that stimulates a response in people familiar with the region. Utilizing industrial heritage does not need to grow into a National Heritage Area initiative, instead it can be as simple as how one recruits volunteers, interacts with the public, and connects with local industry. In thirty-five percent of the surveyed IHMOs, ten or more of their volunteers have a familial connection to the industry being represented at the IHMO. At the VGM, a majority of the older volunteers had fathers, uncles, and brothers who worked in the granite industry. A 
similar example can be found at the South East Chicago Historical Society, where many of their volunteers used to work at the local steel mills before either the plant shut down or the volunteer retired. Both of these examples have something else in common, both the granite industry and the steel industry are still operational in their respective regions. Based on my research, sixty-nine percent of the industries represented in the surveyed IHMOs are still operational, giving IHMOs an opportunity to create partnerships with these industries in order to develop educational programming, co-sponsor events, and elicit support from past and present employees. While I have discussed how industrial heritage can be used to support the development of a sense of heritage pride in the surrounding community, what has not been touched on is how the concepts of industrialization and de-industrialization are presented at IHMOs.

Originally, I did not intend on asking about industrialization and deindustrialization, but after an early discussion with my graduate committee, I was convinced to include it in my research. I provide this insight into the planning of what questions to ask in the projects survey because it shows that when discussing industrial heritage, one would assume that the museum or organization being surveyed or interviewed would represent at least some form of industry. In choosing which museum or organization to reach out to and survey, I examined each sites webpage, their online collections (if available), and social media presence to identify themes of industrial heritage. You can imagine my surprise when after collecting the survey responses and conducting the interviews, eighteen percent did not discuss industrialization and fiftyfour percent did not discuss de-industrialization. Industrialization is a physical and social 
cultural process that occurs when a group or population of individuals apply scientific and technological advancements to increase the production of goods and services. An physical example of this would be the dramatic construction of factories in Chicago during the late 1800 s and early 1900 s, whereas a social example would be the movement and mixing of cultures as immigrant and migrant populations converged on urban areas and urban clusters in search of economic stability and employment. As a process, industrialization continues to this day, though at a slower pace in locals which have already experienced industrialization. Similarly, de-industrialization is a physical and social cultural process, though instead of the expansion of industry, de-industrialization is marked by the movement, closing, or shoring up local or regional industry. Physically this could look like a company relocating and selling off their property to interested parties. Socially, de-industrialization may mean a worker looses their job or is given the choice to move. Instead of effecting only the worker, de-industrialization could cause the disruption of a community's economic lifeline and a transition to a new lifeway. Both industrialization and de-industrialization can also lead to positive and negative lasting changes in the local and regional environment.

When IHMO operate in areas where the industries represented in their collections or exhibits are still operating, they tend to focus on different heritage narratives. IHMOs with their represented industries no longer operating are twenty percent more likely to discuss anthropogenic landscape change than those museums or organizations whose industries were still operating (Table $51 \& 52$ ). I believe that IHMOs that represent shuttered industries are more open to discussing the negative effects of industrialization 
on the landscape since they can explain the entire context of how the landscape was potentially irrevocably changed, often for the worse. By contrast, IHMOs that have represented industries still operating may be getting funding from active companies or employees and have no interest in studying and representing detrimental landscape changes. In addition, IHMOs with their represented industries still in operation were more likely to discuss the growth of industry than IHMOs with their represented industries no longer in operation. This is also probably due to the romanticization and glorification of industries still extant and providing local jobs and support in the surrounding community.

No matter the state of the industries represented by the IHMOs, respondents reported common rates of narratives related to deindustrialization, having less than one percent of difference, making the interpretation difficult without more data (Table $53 \&$ 54). While the above examination of de-industrialization and the operating status of represented industries may be difficult to parse, I found that the age of an IHMOs volunteer may have an impact on how they understand industrial heritage. The results of my comparison between age and understanding of de-industrialization showed that IHMOs with a majority of volunteers aged between thirteen and thirty-nine were almost twenty-nine percent more likely than those with a volunteer majority aged sixty years or older to discuss de-industrialization using the concept of transition (Table 55). This may be due to younger generations seeing de-industrialization in a more positive light through the introduction of new businesses, a change in social and/or cultural attitudes, and/or the diversification of economic opportunities. 
Since it would have added more time to complete the project, I chose not to reach out to those that did not discuss industrialization and/or de-industrialization. Because most, if not all, of my interviewees mentioned something about the impacts of industrialization, I am still left perplexed why those few IHMOs did not discuss the impacts of industrialization. I chalked it up to either the question was not worded correctly and confused some respondents, or I personally judged their institutions inclusion of industrial heritage incorrectly. Regardless the reason, industrialization has impacted every part of America, and touched everyone at some point in their life, therefore I believe it has a place in IHMOs. Based on my projects findings the most popular way that IHMOs discuss the impacts of industrialization are the "Introduction of Technological Innovations” (34\%), "Specific Local Industry” (29\%), “Anthropogenic Landscape Change" (22\%), "General Local Industry" (20\%), and "Growth of Industry" (16\%). These findings suggest that industrialization is inexplicably linked with the concepts of landscape change, technology, local industry, and growth. However, while these concepts can be positive, they can also turn disastrous for the people, environment, and future of a region. Pollution, industrial disasters, sickness, unethical monopolization, and de-forestation are some of the general negative landscape and local population impacts. Economic growth, new and more efficient modes of planting and growing produce, and personal stories of progress all make up the positive side of the impacts of industrialization. With industrialization, so to came the downturn, movement, and/or transition of a region's industry. A little more than half of the surveyed IHMOs discussed de-industrialization, with the most popular impacts being "decline of industry" (32\%), "transition" (26\%), "introduction of technological innovations" (16\%), "labor issues" 115 
$(16 \%)$, and "local/regional populations" (14\%). While "decline of industry" is a common explanation of the impacts of de-industrialization, "transition" is more of a concept under which both de-industrialization and industrialization fall within. The same can be said for the "introduction of technological innovations", as it can provoke labor issues, fluctuations in a region's population, the movement of industrial hubs, and the change in production methods. Each of the impacts of industrialization and de-industrializations feed into visitor and local group and personal understandings and perceptions of industrial heritage. Volunteers of IHMOs help collect, preserve, and interpret the impacts of industrialization and de-industrialization. While their motivations are the focus of this study, how they understand and interact with industrial heritage is just as important. Industrial heritage helps US citizens understand how although the impacts of industry in industrialized and de-industrialized regions can be seen through crumbling facades, polluted and scared landscapes, and the graves of its workforce. Industrial Heritage can also explain how industries changed the way America manufactured and produced goods, spawned inventions that changed history, and helped bring together millions of people from all over the world. 


\section{Chapter 5: Future Research, Misgivings, and Conclusion}

\subsection{Future Research}

With all that I have done and found during my research, there are still (and most likely will always be) avenues for understanding people's motivation to volunteer with industrial heritage museums and organizations (IHMOs). This research has opened up my eyes to parallel research topics that intertwine themselves with this project's theme, such as, volunteering to survive, community and sense of place, virtual volunteerism, and postCOVID-19 elderly volunteering. Petrzelka and Mannon's (2006) article on volunteerism in rural small-town America provided that volunteering may be construed as a method of keeping small town America alive through tourism. Industrial heritage has been leveraged in the past to promote tourism in areas effected by de-industrialization, therefore conducting a study on the motivations of people to volunteer with small town IHMOs may provide other IHMOs with tips on how to leverage industrial heritage and volunteerism to support their local economy and sense of community. Volunteers act as the front lines when it comes to interpreting industrial heritage for the public, thus it might be relevant to understand the connection between IHMO volunteers, narrative perception, and sense of place. My proposed future research is similar to Funk and Pashkevich's (2020) article as it includes the examination of how people perceive and propagate narratives within industrial heritage landscapes. Minus the androcentric undertones of the material provided by some IHMOs (Funk \& Pashkevich's, 2020), marketing material aimed at volunteer recruitment that includes diverse and inclusive 
narratives may propagate diverse and inclusive views and perspectives on long standing industrial heritage narratives. If IHMOs can better understanding how people approach and perceive themselves in relation to industrial heritage landscapes then IHMOs can better market and design their volunteer program, community events, and heritage interpretation. Based on my research, one of the primary motivations of people to volunteer at IHMOs is the sense of belonging they have when volunteering. For elderly individuals, possibly those who are retired, used to being social outside of the home, or living on their own, volunteering helps their mental health (Mayo Health Clinic, 2017). The world currently (2020) lives in a state of apprehension and fear over COVID-19, with the most vulnerable individuals being the young and elderly. Eighty percent of the IHMOs surveyed responded that a majority of their volunteers are elderly. What then does that mean for elderly IHMO volunteers in a pandemic world? In order to keep immunocompromised and at-risk volunteers safe, I propose that research be done on how IHMOs can motivate people to volunteer who cannot physically be at the IHMO. With more and more people volunteering on their own time from home or work through internet connections (Amichai-Hamburger, 2008; Ihm, 2017), this research would also feed into understanding the motivations of people to volunteer digitally with IHMOs.

While time constraints and other responsibilities currently prevent me from revisiting and reworking my research design, there are a few alterations I would make that could be applied in order to focus the project's subject matter, increase its breadth, and/or make it more applicable to specific audiences. To start off, instead of focusing on a scattering of IHMOs from across the United States, the survey could be conducted in 
regions well known for their relationship with industrial activity and subsequent deindustrialization. Instead of metaphorically shooting a shotgun at a map of IHMOs in America and using those points as random sampled points, this method would focus in on already known regions where IHMOs are more apt to exist. Piggybacking off this change in the research design, future research could compare these regions to examine levels of community support and volunteerism. Identified regions of greater community support and volunteerism would then be examined further to understand what in their industrial heritage narrative, marketing design and efforts, and/or organizational structure are catalysts for positive change. Another option, though harder for me personally to accomplish is the copying of my research design and applying it to other countries with intimate histories steeped in industrial heritage, such as the UK, China, Russia, and Germany. Extending this research beyond America could be done via surveys, internet video conference interviews, and/or with a collaborating overseas researcher, with the latter being preferred because of reflexivity when it comes to personal experiences and national identity. Other changes to this project's research design could include conducting a phone survey where the researcher would ask a single qualitative question and the rest of the survey questions would be delivered electronically and/or interviewing primarily volunteers at a smaller number of IHMOs. I do not lay claim to these projects, instead I simply provide them as a way to help future researchers seek out relatively untouched research topics and to advance the wealth of knowledge associated with volunteer motivation as it relates to IHMOs. 


\subsection{Misgivings and Issues}

In addition to the future research suggested above, I would be remiss without mentioning the misgivings and failings of my own research design and its implementation. While sending out participation emails to IHMOs, I realized that my predeveloped method of choosing which site to include and which to ignore was not going to allow for an equal distribution across each state (Table 36). Begrudgingly, I made a note on this error instead of going back and addressing it. Originally, while searching through each state, I found that there were very few museums or organizations that dealt specifically with industrial heritage, therefore I needed to expand the definition to encompass those that included industrial heritage, but did not focus on it. By broadening what could be construed as an IHMO, I fell victim to personal bias in choosing which museums or organizations to include in my research. Small town museums and those with a general purpose of displaying local heritage fell through the cracks and were less likely to be chosen due to their generality; that being said, a few did get included because of their inclusion of an industrial heritage narrative.

Another issue within the umbrella of who to survey and not-to-survey came down to single (or very few) industrial heritage narratives in certain states. For example, if you only surveyed transportation and mining IHMOs in Colorado then look at Vermont and find no transportation or mining IHMOs your results will be skewed towards transportation and mining narrative IHMOs. As I learned more about volunteer motivation and examined the collected data my project changed from a comparison of volunteer motivation between urbanity and rurality, to volunteer motivation and its 
confluence with industrial heritage. As was mentioned in the findings chapter, urban and rural individuals volunteer for the same reason; therefore, there is not a difference in motivation, instead there is a slight difference in the number of visitors and volunteers. This was the second misgiving with my research, one that could not have been rectified at the onset, but one that needed to be uncovered and incorporated into later phases of research.

Another critical aspect arose as I analyzed my survey data. I have primarily examined demographic attributes (such as age, gender, ethnicity, etc.) on its own. I did not undertake detailed analysis of multi demographic groupings (ex: age + gender + ethnicity). This does not change the overall significance of my findings, for the demographic group with the highest percentage of the total one-hundred and thirteen IHMOs is still retired, elderly, white males holding at least a bachelor's degree. Retired, elderly, white females with a bachelor's degree were within a single percentage point of males in the similar demographic group (Table 54). The relationship between these groups will require more study and critical assessment through future surveys to ensure that this data collection is representative. It is also very clear that members of other demographic categories or intersectional identifies are not prevalent as volunteers at IHMOs, which are dominated by elderly, white, educated, and retired individuals.

The fourth issue, one that was unexpected, was the outbreak of COVID-19 across the globe. Thankfully, when the pandemic hit America, I had already collected the majority of my over-the-phone executive director or volunteer manager interviews; this was not the case for my volunteer interviews. With the temporary closure of most 
museums, the responses to my inquiries about participation dried up and so too did the possibility of interviewing volunteers. In the end, I only managed to interview four volunteers, whereas I had planned on interviewing two to three volunteers from each site. It was originally hoped that I could obtain survey results from at least half of the threehundred-and-eighty-two museums contacted via email, but due to COVID or some other unforeseen factor, I ended up with one-hundred-and-five surveyed and eight interviewed IHMOs. Though it is less than thirty percent, the total inquiry emails send out, the research was still able to provide a snapshot of volunteer demographics and motivations in IHMOs.

\subsection{Conclusion}

One summer day at the Vermont Granite Museum, back in 2015, I had a discussion with an older volunteer, this individual had just started volunteering there and from the looks of it, he was well into his retirement from the granite industry. Our chat lasted a few minutes, and at a lull in the conversation, he asked "what makes you want to volunteer here?". Taken aback by this, I responded as I always had to questions like this, that I wanted to work in museums and loved it in Vermont. That response got a chuckle out of him, before he began to tell me about his relation to the industry and why he volunteered, "I spend my time here because I got nothing else to do, and there's stories here to be told by people like you and I". Not until I began writing this thesis did I remember our conversation, though I have regretfully forgotten his name or what his relationship was to the granite industry. Just like the hundreds of thousands of quarrymen, laborers, teamsters, and sculptors in the granite industry, the results of his 
labor still stand prominently while his identity has been hidden by the passage of time and neglect.

I decided to preface my conclusion with the above memory because it reflects what IHMO volunteers represent, how IHMOs and their volunteers play a part in representing the stories of people living and deceased, and the various motivations of volunteers at different stages in their life. Originally, when outlining this project, I was asked by my advisor, "How is this research going to contribute and, why should people care about what you're doing?". Now that this project is coming to a close, I can say for certain that this project was not just designed to answer the question of why people are motivated to volunteer, but also to provide dialogue on the lack of inclusivity in industrial heritage narratives and collect data that could be of use to IHMOs that might not have the resources to conduct a similar study. It is to this end that the data collected from my research and this paper will be electronically delivered to the IHMOs that assisted me in my research by showing interest, participating in an interview, or completing my survey. It was not altruism that sparked this research but a deep care for industrial heritage and the people living and passed that poured their lives into the work they did, be it the coal mines in Pennsylvania or the logging in the Pacific Northwest.

From its formal appearance in charities in $12^{\text {th }}$ century Europe to the War on Poverty (1964) in the US, the concept of volunteering has been altered and warped to match the ideology and desires of religion (Tnnenbaum \& Reisch, 2001; Devine, 1913; Wines, 1898), political groups (Rosenburg, 2013), and social crusaders (Bishop, 1902; Gurock, 1981; Swienty, 2008; Bogardus, 1923) (sometimes all three at once). The roots 
of volunteering do not belong to one ethnic group, race, country, or group, because it is both something ethereal and deeply personal to each person. Even though the definition of what it means to be a volunteer is murky, the core function is to be helpful to someone or something (Stebbins, 1996). During the Revolutionary War, Civil War, WWI and II, and the Vietnam War, volunteers flocked to support the soldiers and maintain a sense of normalcy on the Homefront. Women voluntarily entered into the industrial workforce during WWI and II (Kessler, 2018), only to be coerced to leave once the war concluded. African Americans and other minorities hit hard by the Great Depression (1929-1939) helped one another in urban and rural communities to survive and find work (Trotter 2000; Marsh 2015). These informal acts of volunteering kept people alive, helped develop community and a sense of belonging, and provided them with hope of a future of equality and inclusivity. During the tumultuous period of social and political change in America in the 1960s and early 70s, volunteerism as a field of study flourished, laying the theoretical and ideological foundation for books and articles published in the past 30 years. Current volunteer motivation research themes include (but are not limited to) volunteerism as leisure, as survival, as self-improvement, and as civic duty. These and other themes allow museum professionals to understand how to recruit, train, and understand the motives behind their volunteers.

IHMOs are different than most museums and heritage organizations in that the individuals who worked (or continue to work) in the industries represented by interpretation, in exhibit and programming content, and by the myriad of artifacts and documents, may be alive to share their stories and experiences. My research provides that 
not only do a majority of IHMOs have volunteers who at one point worked in industry, but there are some that have volunteer who actively work in industry. While older, educated, white, and retired males make up the majority for volunteers at IHMOs, this paper suggests the inclusion of industrial heritage narratives with more women, nonbinary individuals, African Americans, Latin Americans, Asian Americans, and other underrepresented minorities and ethnic groups. I provided discussion on how education and employment levels make it hard for people to volunteer. And I highlighted how volunteer motivation is key to recruiting, supporting, and retaining volunteers at IHMOs. People volunteer at IHMOs by a sense of belonging, the intimate experience of interacting with machines and industry, and the general enjoyment of learning and sharing knowledge. Without the volunteer, these sites, silos, and sanctuaries of human and machine would lack the experiential spark that continues to protect and propagate industrial heritage so that it is not forgotten and made irrelevant in our daily lives. 


\section{Appendix A: Glossary}

Industrial Heritage: For the purpose of this study Industrial Heritage constitutes the tangible and intangible memories, values, lifeways, narratives, and history of past and present communities interwoven with capitalism through mass manufacturing, production, and fabrication of materials, goods, and products. This representation includes the technological manipulation and subjugation of natural resources such as animals, plants, and humans for the express purpose of capital and resources accumulation over time.

Industrial Heritage Museum/Organization (IHMO): For the purpose of this study an Industrial Heritage Museum/Organization will be synonymous with industrial museums/organizations and indicate a museum/organization that represents the tangible and intangible history, past and present communities, and heritage surrounding the mass manufacturing, production, extraction, mining, construction, and use of technology, architecture, landscape, and material for the purpose of capital accumulation over time. This representation includes the visualization of technological manipulation and subjugation of natural resources such as environments, animals, plants, and humans for the express purpose of capital and resources accumulation over time through artifact and document collections, exhibits, educational programing, preservation, and organizational structuring via mission and collection statements, community inclusion, etc.

Multi-Industry Centered Narrative Museum: For the purpose of this study the term MultiIndustry Centered Narrative Museum will refer to museums that focus or center on 126 
multiple industries (Mining and Quarrying, Energy and Manufacturing, etc.) in the creation of the narrative that ties together its heritage, exhibits, collections, and public education.

Multi-Industry Inclusive Narrative Museum: For the purpose of this study the term MultiIndustry Narrative Museum will refer to museums that are inclusive of the impact of multiple industries in the creation of the narrative that ties together its heritage, exhibits, collections, and public education.

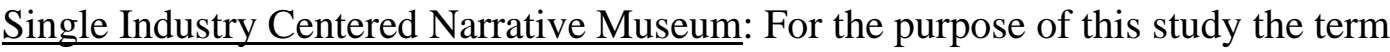
Single Industry Centered Narrative Museum will, when in the context of museums, refer to museums that focus or center on a single industry (Mining, Manufacturing, Energy, etc.) in the creation of the narrative that ties together its heritage, exhibits, collections, and public education.

Single Industry Inclusive Narrative Museum: For the purpose of this study the term Single Industry Inclusive Narrative Museum will refer to museums that are inclusive of the impact of a single industry in the creation of the narrative that ties together its heritage, exhibits, collections, and public education.

Rural Area: "what is not urban — that is, after defining individual urban areas, rural is what is left." (Ratcliffe et al., 2016, p. 1)

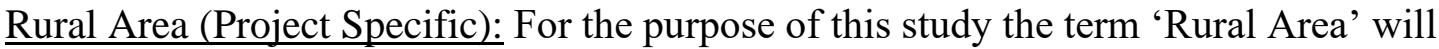
constitute any developed environment outside an urban human settlement that is within 
the boundaries of a city, town, village, or homestead with a population equal to or below $10,000$.

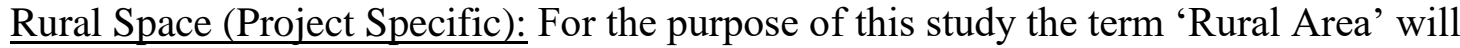
constitute any developed environment outside an urban human settlement that is within the boundaries of a city or town with a population equal to or between 10,001 and 30,000 .

Urban Cluster (Project Specific): For the purpose of this study the term Urban Cluster will constitute any developed environment and human settlement that is within the boundaries of a city or town with a population equal to or between 30,001 and 49,999.

Urbanized Areas: Areas with 50,000 or more people (Ratcliffe et al., 2016, p. 3)

Urban Clusters: Areas with at least 2,500 but fewer than 50,000 people. (Ratcliffe et al., 2016, p. 3)

Urban (Project Specific): For the purpose of this study the term Urban will constitute any developed environment and human settlement that is within the boundaries of a metropolis, city, or town with a population equal to or above 50,000 .

Volunteer: For the purpose of this study Volunteer constitutes the individual in the act of volunteering.

Volunteering: For the purpose of this study Volunteering constitutes the informal or formal willful or coerced voluntary actions of an individual through spending time and energy for another individual, group, association, etc. for personal, public, and/or 
individual, group, association, etc. Volunteering includes unpaid internships, charity work, advocacy, and civic duty.

Volunteerism: For the purpose of this study Volunteerism constitutes the overall act or series of actions and reactions that come with volunteering as singular individual for another individual, as part of a civic duty, and/or as a member of an organization, association, group etc. 


\section{Appendix B: Survey/Interview Questions}

\section{Online Survey for the Appropriate Museum Staff Member}

Thank you for agreeing to complete the following survey. The data from this survey will be aggregated with data from other museum volunteers from across the country and used to understand volunteerism in industrial heritage museums across the United States. You were chosen to complete this survey because (explain).

This survey is broken into three sections: Volunteer Demographics, Volunteer Management, and Industrial Heritage and Volunteering. Completing the survey can take from 20 to $45 \mathrm{~min}$ based on how much you are willing to share. Your participation is optional; if you come to a question you don't feel comfortable answering, you may skip it or come back to it later. If you provide an email, we will provide you with the results of the survey once it's been completed.

If you have any questions, please contact Cooper Sheldon, MS student in Industrial Heritage at Michigan Tech University, cdsheldo@ mtu.edu, (315)-529-0394. Again, thank you and have a great day.

1. What is the name of your museum?

a. (Open Ended)

Volunteer Demographics: The following questions will ask you about the average demographic of active volunteers at your museum.

2. What age is the majority of your volunteers?
a. 1 - 12 years of age
b. 13 - 20 years of age
c. 21 - 39 years of age
d. 40 - 59 years of age
e. $60+$ years of age

3. What gender is the majority of your volunteers?
a. Male
b. Female
c. (other) 
4. What race or ethnicity are the majority of your volunteers?
a. Asian
b. Black/African
c. White
d. Hispanic/Latinx
e. Native American
f. Pacific Islander
g. Prefer not to answer
h. (Open Ended)

5. What education level is the majority of your volunteers?
a. No schooling completed
b. Nursery school to 8th grade
c. Some high school, no diploma
d. High school graduate, diploma, or the equivalent (for example: GED)
e. Some college credit, no degree
f. Trade/technical/vocational training
g. Associate degree
h. Bachelor's degree
i. Master's degree
j. Professional degree
k. Doctorate degree
1. (Open Ended)

6. What employment status is the majority of your volunteers?
a. Employed for wages
b. Self-employed
c. Out of work and looking for work
d. Out of work but not currently looking for work 
e. Homemaker

f. Full-Time Student

g. Part-Time Student

h. Military

i. Retired

j. Unable to work

7. What marital status is the majority of your volunteers?
a. Married
b. Widowed
c. Divorced
d. Separated
e. In a domestic partnership, or civil union
f. Single, but cohabiting with a significant other
g. Single, never married

8. Is there any demographic information that stands out about your volunteers that you think would be useful to the research being conducted?
a. (Open Ended)

Volunteer Management: The following questions will ask you about the organizational management of volunteers at your museum.

9. How many staff members does your museum currently employ?
a. 0
b. $1-3$
c. 4-9
d. $10+$

10. Approx. how many active volunteers volunteer at your museum?
a. $1-10$
b. $11-25$
c. $26-49$ 
d. $50+$

11. Do you recruit volunteers?
a. Yes
b. No

12. How do you recruit volunteers?
a. (Open Ended)

13. When did volunteers first start volunteering at your museum?
a. $1900 \mathrm{~s}$
b. $1910 \mathrm{~s}$
c. $1920 \mathrm{~s}$
d. $1930 \mathrm{~s}$
e. $1940 \mathrm{~s}$
f. $1950 \mathrm{~s}$
g. $1960 \mathrm{~s}$
h. $1970 \mathrm{~s}$
i. $1980 \mathrm{~s}$
j. $1990 \mathrm{~s}$
k. 2000s
1. $2010 \mathrm{~s}$

14. What do volunteers do at your museum?
a. Collections Management
b. Exhibits
c. Fundraising
d. Hospitality
e. Maintenance
f. Newsletter
g. Public Relations 
h. Membership

i. Office Assistant

j. Research Library

k. Special Events/Programs

1. Marketing

m. Docent

n. Museum Store Assistant

o. Tours

p. Web Design and Social Media

q. Volunteer Management

r. Other

15. Do you have a museum volunteer manager?
a. Yes
b. No
c. Other

16. Who is the volunteer manager?
a. Paid Employee
b. Volunteer
c. (Other)

17. Do you offer training for new volunteers and volunteers interested in new opportunities?
a. Yes
b. No

18. Who conducts the training?
a. Paid Employee
b. Volunteer
c. (Other) 
19. Do your volunteers receive any non-salary benefits and/or rewards at the museum?
a. Yes
b. No

20. What are they?
a. (Open Ended)

21. How involved is the surrounding community with the museum and its administration?

a. (Open Ended)

22. What do you think are the motivations behind your volunteers to volunteer?

a. (Open Ended)

23. Anything else you'd like to share?

a. (Open Ended)

Industrial Heritage and Volunteering: The following questions will ask you about industrial heritage and the volunteers at the museum.

24. What does industrial heritage mean to you?

a. (Open Ended)

25. Based on this meaning do you believe that your museum focuses on industrial heritage or briefly represents it through your collections, exhibits, outreach, and mission statement?
a. Yes
b. No

26. What industries are represented in the collections and exhibits at your museum?

a. (Open Ended)

27. Are the industry(s) represented in your museum still operating?
a. Yes
b. No

28. How many of your volunteers have worked in the industry(s) represented at the museum?
a. 0 

b. 1-3
c. 4-9
d. $10+$

29. How many of your volunteers currently work in the industry(s) represented the museum?
a. 0
b. 1-3
c. 4-9
d. $10+$

30. How many of your volunteers have familial connections to the industry(s) represented at your museum?
a. 0
b. 1-3
c. 4-9
d. $10+$

31. Do you consider your museum to be urban, rural, or somewhere in-between?
a. Urban
b. Somewhere In-Between
c. Rural

32. Why?
a. (Open Ended)

33. Do volunteers at your museum have opportunities for hands on interaction with industrial heritage?
a. Yes
b. No

34. If yes, how?
a. (Open Ended)

35. Does your museum discuss the impacts of industrialization? 
a. Yes

b. No

36. If yes, how?

a. (Open Ended)

37. Does your museum discuss the impacts of de-industrialization?

a. Yes

b. No

38. If yes, how?

a. (Open Ended)

39. Anything else you'd like to share?

a. (Open Ended) 


\section{In-Person Semi-Structured Interview Questions}

\section{Museum Executive Directors}

Thank you for agreeing to be interviewed for this project. The data from this survey will be aggregated with data from other museums from across the country and used to understand volunteerism in industrial heritage museums across the United States. You were chosen to complete this survey because (explain).

This survey is broken into three sections: Volunteer Demographics, Volunteer Management, and Industrial Heritage and Volunteering. Completing the survey can take from 30 minutes to 1 hour based on how much you are willing to share. Your participation is optional; if we come to a question you don't feel comfortable answering, you may ask to skip it.

Before we begin, I need to get an oral confirmation that this interview is being done completely of your free will and that you understand the following: we will not use your name in this research, you will be given an alias if we are to directly refer to something you mention in the course of this interview, and that you can refrain from answering any of the questions posed. Are you still willing to proceed?

The following are demographic questions.

1 . What age is the majority of your volunteers?

2. What gender is the majority of your volunteers?

3. What race or ethnicity are the majority of your volunteers?

4. What education level is the majority of your volunteers?

5 . What employment status is the majority of your volunteers?

6. What marital status is the majority of your volunteers?

7. Is there any demographic information that stands out about your volunteers that you think would be useful to the research being conducted?

The following questions will ask you about the organizational management of volunteers at your museum.

8. How many staff members does your museum currently employ?

9. Approx. how many active volunteers volunteer at your museum? 
10. Do you recruit volunteers?

11. How do you recruit volunteers?

12. When did volunteers first start volunteering at your museum?

13. What do volunteers do at your museum?

14. Do you have a museum volunteer manager?

15. Who is the volunteer manager?

16. Do you offer training for new volunteers and volunteers interested in new opportunities?

17. Who conducts the training?

18. Do your volunteers receive any non-salary benefits and/or rewards at the museum?

19. What are they?

20. How involved is the surrounding community with the museum and its administration?

21. What do you think are the motivations behind your volunteers to volunteer?

22. Anything else you'd like to share?

The following questions will ask you about industrial heritage and the volunteers at the museum.

23. What does industrial heritage mean to you?

24. Based on this meaning do you believe that your museum focuses on industrial heritage or briefly represents it through your collections, exhibits, outreach, and mission statement?

25. What industries are represented in the collections and exhibits at your museum?

26. Are the industry(s) represented in your museum still operating?

27. How many of your volunteers have worked in the industry(s) represented at the museum?

28. How many of your volunteers currently work in the industry(s) represented at the museum?

29. How many of your volunteers have familial connections to the industry(s) represented at your museum?

30. Do you consider your museum to be urban, rural, or somewhere in-between? 
31. Why?

32. Do volunteers at your museum have opportunities for hands on interaction with industrial heritage?

33. If yes, how?

34. Does your museum discuss the impacts of industrialization?

35. If yes, how?

36. Does your museum discuss the impacts of de-industrialization?

37. If yes, how?

38. Anything else you'd like to share?

\section{Museum Volunteers}

Thank you for agreeing to be interviewed for this project. The data from this interview will be aggregated with data from other museum volunteers from across the country and used to understand volunteerism in industrial heritage museums across the United States. You were chosen for this interview because (explain).

This interview is broken into three sections: Volunteer Demographics, Volunteer Management, and Industrial Heritage and Volunteering. The interview can take from 30 minutes to 1 hour based on how much you are willing to share. Your participation is optional; if we come to a question you don't feel comfortable answering, you may ask to skip it.

Before we begin, I need to get an oral confirmation that this interview is being done completely of your free will and that you understand the following: we will not use your name in this research, you will be given an alias if we are to directly refer to something you mention in the course of this interview, and that you can refrain from answering any of the questions posed. Are you still willing to proceed?

The following are demographic questions.

1. What's your age?

2. What's your gender?

3. What's your ethnicity?

4. What's your level of education?

5. What's your employment status? 
6. What's your marital status?

The following are volunteer management questions.

7. When did you start volunteering at the museum?

8. Why did you begin volunteering at the museum?

9. Why do you continue to do so?

10. What do you do at the museum?

11. Approx. how often do you volunteer at the museum?

12. Do you volunteer anywhere else?

13. Does the museum provide benefits, rewards, or incentives to you and/or other volunteers?

14. If so, what are they?

15. If not, why do you think it doesn't?

16. Why do you think other volunteers volunteer at the museum?

17. How do volunteers find out about potential volunteer opportunities at the museum?

18. Did they offer you training when you began volunteering?

19. Who does the training?

20. Have you taken any additional training?

21. For what?

22. Anything else you'd like to share?

The following questions will ask you about industrial heritage and the volunteers at the museum.

23. What does industrial heritage mean to you?

24. Based on this meaning do you believe that the museum focuses on industrial heritage or briefly represents it through your collections, exhibits, outreach, and mission statement?

25. What industries are represented in the collections and exhibits at the museum?

26. Are the industry(s) represented in the museum still operating?

27. Do you currently work in the industry(s) represented at the museum? 
28. If yes, what do you do?

29. Have you worked in the industry(s) represented at the museum?

30. If yes, what did you do?

31. Do you have familial connections to the industry(s) represented at the museum?

32. If yes, what connections?

33. Do you consider your museum to be urban, rural, or somewhere in-between?

34. Why?

35. Do volunteers at the museum have opportunities for hands on interaction with industrial heritage?

36. If yes, how?

37. Does the museum discuss the impacts of industrialization?

38. If yes, how?

39. Does your museum discuss the impacts of de-industrialization?

40. If yes, how?

41. Anything else you'd like to share?

\section{Over-the Phone Semi-Structured Interview Questions}

\section{Museum Executive Directors}

Thank you for agreeing to be interviewed for this project. The data from this survey will be aggregated with data from other museum volunteers from across the country and used to understand volunteerism in industrial heritage museums across the United States. You were chosen to complete this survey because (explain).

This survey is broken into three sections: Volunteer Demographics, Volunteer Management, and Industrial Heritage and Volunteering. Completing the survey can take from 30 minutes to 1 hour based on how much you are willing to share. Your participation is optional; if we come to a question you don't feel comfortable answering, you may ask to skip it.

Before we begin, I need to get an oral confirmation that this interview is being done completely of your free will and that you understand the following: we will not use your 
name in this research, you will be given an alias if we are to directly refer to something you mention in the course of this interview, and that you can refrain from answering any of the questions posed. Are you still willing to proceed?

The following are demographic questions.

1. What age is the majority of your volunteers?

2. What gender is the majority of your volunteers?

3. What race or ethnicity are the majority of your volunteers?

4. What education level is the majority of your volunteers?

5 . What employment status is the majority of your volunteers?

6 . What marital status is the majority of your volunteers?

7. Is there any demographic information that stands out about your volunteers that you think would be useful to the research being conducted?

The following questions will ask you about the organizational management of volunteers at your museum.

8. How many staff members does your museum currently employ?

9. Approx. how many active volunteers volunteer at your museum?

10. Do you recruit volunteers?

11. How do you recruit volunteers?

12. When did volunteers first start volunteering at your museum?

13. What do volunteers do at your museum?

14. Do you have a museum volunteer manager?

15 . Who is the volunteer manager?

16. Do you offer training for new volunteers and volunteers interested in new opportunities?

17. Who conducts the training?

18. Do your volunteers receive any non-salary benefits and/or rewards at the museum?

19. What are they?

20. How involved is the surrounding community with the museum and its administration?

21. What do you think are the motivations behind your volunteers to volunteer? 
22. Anything else you'd like to share?

The following questions will ask you about industrial heritage and the volunteers at the museum.

23. What does industrial heritage mean to you?

24. Based on this meaning do you believe that your museum focuses on industrial heritage or briefly represents it through your collections, exhibits, outreach, and mission statement?

25. What industries are represented in the collections and exhibits at your museum?

26. Are the industry(s) represented in your museum still operating?

27. How many of your volunteers have worked in the industry(s) represented at the museum?

28. How many of your volunteers currently work in the industry(s) represented at the museum?

29. How many of your volunteers have familial connections to the industry(s) represented at your museum?

30. Do you consider your museum to be urban, rural, or somewhere in-between?

31. Why?

32. Do volunteers at your museum have opportunities for hands on interaction with industrial heritage?

33. If yes, how?

34. Does your museum discuss the impacts of industrialization?

35. If yes, how?

36. Does your museum discuss the impacts of de-industrialization?

37. If yes, how?

38. Anything else you'd like to share?

\section{Museum Volunteers}

Thank you for agreeing to be interviewed for this project. The data from this interview will be aggregated with data from other museum volunteers from across the country and 
used to understand volunteerism in industrial heritage museums across the United States. You were chosen for this interview because (explain).

This interview is broken into three sections: Volunteer Demographics, Volunteer Management, and Industrial Heritage and Volunteering. The interview can take from 30 minutes to 1 hour based on how much you are willing to share. Your participation is optional; if we come to a question you don't feel comfortable answering, you may ask to skip it.

Before we begin, I need to get an oral confirmation that this interview is being done completely of your free will and that you understand the following: we will not use your name in this research, you will be given an alias if we are to directly refer to something you mention in the course of this interview, and that you can refrain from answering any of the questions posed. Are you still willing to proceed?

The following are demographic questions.

1. What's your age?

2. What's your gender?

3. What's your ethnicity?

4. What's your level of education?

5. What's your employment status?

6. What's your marital status?

The following are volunteer management questions.

7. When did you start volunteering at the museum?

8. Why did you begin volunteering at the museum?

9. Why do you continue to do so?

10. What do you do at the museum?

11. Approx. how often do you volunteer at the museum?

12. Do you volunteer anywhere else?

13. Does the museum provide benefits, rewards, or incentives to you and/or other volunteers?

14. If so, what are they?

15. If not, why do you think it doesn't?

16. Why do you think other volunteers volunteer at the museum? 
17. How do volunteers find out about potential volunteer opportunities at the museum?

18. Did they offer you training when you began volunteering?

19. Who does the training?

20. Have you taken any additional training?

21. For what?

22. Anything else you'd like to share?

The following questions will ask you about industrial heritage and the volunteers at the museum.

23. What does industrial heritage mean to you?

24. Based on this meaning do you believe that the museum focuses on industrial heritage or briefly represents it through your collections, exhibits, outreach, and mission statement?

25. What industries are represented in the collections and exhibits at the museum?

26. Are the industry(s) represented in the museum still operating?

27. Do you currently work in the industry(s) represented at the museum?

28. If yes, what do you do?

29. Have you worked in the industry(s) represented at the museum?

30. If yes, what did you do?

31. Do you have familial connections to the industry(s) represented at the museum?

32. If yes, what connections?

33. Do you consider your museum to be urban, rural, or somewhere in-between?

34. Why?

35. Do volunteers at the museum have opportunities for hands on interaction with industrial heritage?

36. If yes, how?

37. Does the museum discuss the impacts of industrialization?

38. If yes, how?

39. Does your museum discuss the impacts of de-industrialization? 
40. If yes, how?

41. Anything else you'd like to share?

\section{Appendix C: Codes}

Online Survey Response Codes, Question \#12: How do you recruit volunteers?

\begin{tabular}{|c|c|c|c|}
\hline Code & Examples from Survey & Code Meaning & $\begin{array}{l}\text { Code } \\
\text { Frequency }\end{array}$ \\
\hline $\begin{array}{l}\text { Ask current } \\
\text { volunteers }\end{array}$ & $\begin{array}{l}\text { vetted by board, usually friends } \\
\text { of the board that are recently } \\
\text { retired; asking current } \\
\text { volunteers; through existing } \\
\text { volunteers }\end{array}$ & $\begin{array}{l}\text { IHMO volunteers } \\
\text { are asked to ask } \\
\text { their family, friends, } \\
\text { and acquaintances. }\end{array}$ & 13 \\
\hline $\begin{array}{l}\text { Contacts } \\
\text { Local } \\
\text { Universities }\end{array}$ & $\begin{array}{l}\text { we have history/education } \\
\text { departments at local universities } \\
\text { send out volunteer notices; } \\
\text { partnerships with universities }\end{array}$ & $\begin{array}{l}\text { IHMO contacts } \\
\text { local universities to } \\
\text { stir up interest in } \\
\text { museum } \\
\text { volunteering }\end{array}$ & 6 \\
\hline Emailing & email; email blast & $\begin{array}{l}\text { IHMO emails } \\
\text { interested parties } \\
\text { with information on } \\
\text { volunteering } \\
\text { opportunities }\end{array}$ & 9 \\
\hline $\begin{array}{l}\text { Host Public } \\
\text { Meeting }\end{array}$ & meetings; & $\begin{array}{l}\text { IHMO opens board } \\
\text { or museum } \\
\text { volunteer meetings } \\
\text { to the public }\end{array}$ & 3 \\
\hline $\begin{array}{l}\text { IHMO's } \\
\text { professional } \\
\text { notoriety }\end{array}$ & $\begin{array}{l}\text { some degree by virtue of our } \\
\text { notoriety in our field of } \\
\text { preservation. }\end{array}$ & $\begin{array}{l}\text { IHMO is notorious } \\
\text { in the museum field } \\
\text { (or related field) for } \\
\text { their programs, } \\
\text { collections, staff. } \\
\text { etc. }\end{array}$ & 4 \\
\hline
\end{tabular}




\begin{tabular}{|c|c|c|c|}
\hline $\begin{array}{l}\text { Community } \\
\text { Events }\end{array}$ & $\begin{array}{l}\text { we also participate in } \\
\text { community events }\end{array}$ & $\begin{array}{l}\text { IHMO joins in on } \\
\text { local community } \\
\text { events through } \\
\text { information desks, } \\
\text { speakings, etc. }\end{array}$ & 5 \\
\hline $\begin{array}{l}\text { Recruitment } \\
\text { Drives }\end{array}$ & $\begin{array}{l}\text { community outreach, friend- } \\
\text { raising efforts, visitor } \\
\text { solicitation/recruitment. }\end{array}$ & $\begin{array}{l}\text { Museum hosts } \\
\text { recruitment drives } \\
\text { for specific } \\
\text { purposes, programs, } \\
\text { or events at the } \\
\text { museum }\end{array}$ & 1 \\
\hline $\begin{array}{l}\text { Volunteer } \\
\text { Fairs }\end{array}$ & $\begin{array}{l}\text { volunteer fairs: we distribute } \\
\text { volunteer applications at our } \\
\text { kiosk }\end{array}$ & $\begin{array}{l}\text { IHMO } \\
\text { staff/volunteers } \\
\text { attends volunteering } \\
\text { fairs }\end{array}$ & 6 \\
\hline $\begin{array}{l}\text { Posters, } \\
\text { Flyers, } \\
\text { Signs, } \\
\text { Newsletters, } \\
\text { and Ad } \\
\text { Prints }\end{array}$ & $\begin{array}{l}\text { paid print ads; newsprint; flyers; } \\
\text { posters; signage at the museum; } \\
\text { eNewsletter }\end{array}$ & $\begin{array}{l}\text { IHMO pays for the } \\
\text { printing of Ads in } \\
\text { local papers; hands } \\
\text { out flyers; puts up a } \\
\text { poster(s) and/or } \\
\text { sign(s); mails or } \\
\text { emails a newsletter } \\
\text { to volunteers and } \\
\text { interested } \\
\text { individuals }\end{array}$ & 34 \\
\hline $\begin{array}{l}\text { Third Party } \\
\text { Website }\end{array}$ & $\begin{array}{l}\text { VolunteerMatch; online } \\
\text { postings; Google Ads; local } \\
\text { volunteer consortium website }\end{array}$ & $\begin{array}{l}\text { IHMO posts } \\
\text { volunteering } \\
\text { information on a } \\
\text { website that's not } \\
\text { their own or a } \\
\text { volunteering } \\
\text { database }\end{array}$ & 12 \\
\hline $\begin{array}{l}\text { Hosts public } \\
\text { program }\end{array}$ & $\begin{array}{l}\text { we host four steam ups a year } \\
\text { and actively engage our visitors } \\
\text { to participate; we hold events for } \\
\text { the public which often attracts }\end{array}$ & $\begin{array}{l}\text { IHMO hosts a } \\
\text { public program at } \\
\text { the museum or a } \\
\text { local venue }\end{array}$ & 13 \\
\hline
\end{tabular}




\begin{tabular}{|c|c|c|c|}
\hline & $\begin{array}{l}\text { people to volunteer; community } \\
\text { outreach }\end{array}$ & & \\
\hline $\begin{array}{l}\text { IHMO } \\
\text { reaches out } \\
\text { to other } \\
\text { organizations }\end{array}$ & $\begin{array}{l}\text { requests to certain organizations; } \\
\text { churches \& other organizations }\end{array}$ & $\begin{array}{l}\text { IHMO reaches out } \\
\text { to the other } \\
\text { organizations with } \\
\text { similar goals and } \\
\text { missions to recruit } \\
\text { new volunteers }\end{array}$ & 10 \\
\hline $\begin{array}{l}\text { Public } \\
\text { Service } \\
\text { Announceme } \\
\text { nts }\end{array}$ & public service announcements & $\begin{array}{l}\text { IHMO sends out a } \\
\text { public service } \\
\text { announcement }\end{array}$ & 2 \\
\hline Social Media & Facebook & $\begin{array}{l}\text { IHMO } \\
\text { staff/volunteer posts } \\
\text { on social media }\end{array}$ & 28 \\
\hline $\begin{array}{l}\text { IHMO's } \\
\text { Staff Attends } \\
\text { Networking }\end{array}$ & networking opportunities & $\begin{array}{l}\text { IHMO Staff } \\
\text { member or } \\
\text { volunteers attend a } \\
\text { networking event }\end{array}$ & 1 \\
\hline $\begin{array}{l}\text { IHMO's } \\
\text { Website }\end{array}$ & $\begin{array}{l}\text { through our website; application } \\
\text { available on our website; online } \\
\text { postings }\end{array}$ & $\begin{array}{l}\text { IHMO personal } \\
\text { website promotes } \\
\text { volunteering and } \\
\text { includes } \\
\text { information on } \\
\text { volunteering }\end{array}$ & 19 \\
\hline Too general & $\begin{array}{l}\text { advertising; recruitment; } \\
\text { individually; media }\end{array}$ & $\begin{array}{l}\text { Too general to be } \\
\text { coded }\end{array}$ & 1 \\
\hline $\begin{array}{l}\text { Visitor to } \\
\text { IHM/O } \\
\text { become } \\
\text { Interested }\end{array}$ & $\begin{array}{l}\text { most are from tours; visitor } \\
\text { education; respond to visitor } \\
\text { inquiries; respond to those } \\
\text { expressing interest. directly } \\
\text { asking people who come to the } \\
\text { museum; we distribute volunteer } \\
\text { applications at our kiosk; walk- } \\
\text { ins }\end{array}$ & $\begin{array}{l}\text { Visitors visiting the } \\
\text { IHMO become } \\
\text { interested in } \\
\text { volunteering }\end{array}$ & 18 \\
\hline
\end{tabular}




\begin{tabular}{|l|l|l|l|}
\begin{tabular}{|l|l|} 
Word-of- \\
Mouth
\end{tabular} & $\begin{array}{l}\text { in our small community, word- } \\
\text { of-mouth; contacts; other } \\
\text { volunteers }\end{array}$ & $\begin{array}{l}\text { People tell others } \\
\text { about volunteering } \\
\text { at the IHMO and } \\
\text { they become } \\
\text { interested and } \\
\text { volunteer } \\
\text { themselves }\end{array}$ & 48 \\
& & \\
\hline
\end{tabular}

Online Survey Response Codes, Question \#20: What are they? (Volunteer Benefits/Rewards)

\begin{tabular}{|c|c|c|}
\hline Code & Examples from Survey & Code Frequency \\
\hline $\begin{array}{l}\text { Free Admission to the } \\
\text { IHMO's } \\
\text { programs/events/special } \\
\text { events }\end{array}$ & $\begin{array}{l}\text { free admission to member only } \\
\text { events; free admission to certain } \\
\text { museum events; free admission to } \\
\text { special events based on hours } \\
\text { volunteered; invitations to member- } \\
\text { only events }\end{array}$ & 19 \\
\hline $\begin{array}{l}\text { Volunteer Appreciation } \\
\text { Events }\end{array}$ & $\begin{array}{l}\text { recognition during National } \\
\text { Volunteer Appreciation Week; } \\
\text { annual meeting recognition; annual } \\
\text { appreciation lunch; recognition at } \\
\text { annual volunteer awards night; } \\
\text { weekly volunteers get birthday } \\
\text { parties. }\end{array}$ & 25 \\
\hline Gift Store Discount & gift store discount & 16 \\
\hline $\begin{array}{l}\text { Non-Monetary } \\
\text { Volunteer Appreciation } \\
\text { Awards }\end{array}$ & $\begin{array}{l}\text { event volunteers get 'bling'--a } \\
\text { handmade token.; lots of hand- } \\
\text { written thank you notes (sometimes } \\
\text { accompanied by candy).; name } \\
\text { recognition on trail signs }\end{array}$ & 11 \\
\hline $\begin{array}{l}\text { Volunteer only Social } \\
\text { Gathering }\end{array}$ & $\begin{array}{l}\text { end of the season get together; field } \\
\text { trips; organized enrichment outings; } \\
\text { volunteer-only social functions; } \\
\text { weekly fellowship; any food left } \\
\text { over from events; free water and } \\
\text { "snacks" while they are working }\end{array}$ & 31 \\
\hline
\end{tabular}




\begin{tabular}{|c|c|c|}
\hline & $\begin{array}{l}\text { their shift driving the tractor over } \\
\text { the causeway or being a docent for } \\
\text { the tug or the museum; }\end{array}$ & \\
\hline $\begin{array}{l}\text { Volunteer Involvement } \\
\text { Trinket from the IHMO }\end{array}$ & $\begin{array}{l}\text { free event materials; T-Shirts; free } \\
\text { museum magnet; weekly volunteers } \\
\text { get hats, }\end{array}$ & 9 \\
\hline $\begin{array}{l}\text { Free IHMO } \\
\text { Membership }\end{array}$ & $\begin{array}{l}\text { free annual membership for } 50 \text { or } \\
\text { more volunteer hours in a year; free } \\
\text { membership after serving } 25 \text { hours } \\
\text { each year. }\end{array}$ & 7 \\
\hline $\begin{array}{l}\text { Free Admission to the } \\
\text { IHMO and/or Site }\end{array}$ & $\begin{array}{l}\text { entry into our historic sites; free } \\
\text { admission; reciprocal pass } \\
\text { privileges; free admission for family } \\
\text { and friends; free museum admission } \\
\text { to the volunteer and their immediate } \\
\text { family; volunteers to bring } 24 \text { guests } \\
\text { (2/month) at no charge. }\end{array}$ & 10 \\
\hline $\begin{array}{l}\text { Free Use of the IHMO's } \\
\text { Assets }\end{array}$ & $\begin{array}{l}\text { free use research center; lab access; } \\
\text { use of watercraft; occasional use of } \\
\text { workshop. }\end{array}$ & 5 \\
\hline $\begin{array}{l}\text { Discounts to the } \\
\text { IHMO's } \\
\text { programs/events/special } \\
\text { events }\end{array}$ & $\begin{array}{l}\text { discounts to public programs and } \\
\text { special events; program discounts; } \\
\text { stipend for tours }\end{array}$ & 4 \\
\hline $\begin{array}{l}\text { Discounted IHMO } \\
\text { Membership }\end{array}$ & discounted membership & 3 \\
\hline Use of IHMOs Venues & $\begin{array}{l}\text { discounts on room rentals; free hall } \\
\text { rental with } 50 \text { hours of volunteering; } \\
\text { meet with others once a month with } \\
\text { no charge for room rental }\end{array}$ & 3 \\
\hline Free Parking & free parking & 2 \\
\hline $\begin{array}{l}\text { Involvement in the } \\
\text { IHMO's Administration }\end{array}$ & $\begin{array}{l}\text { meetings for the docents so that they } \\
\text { can voice their concerns and }\end{array}$ & 2 \\
\hline
\end{tabular}




\begin{tabular}{|l|l|l|}
\hline & $\begin{array}{l}\text { opinions; voting rights (to elect } \\
\text { board members), }\end{array}$ & \\
\hline $\begin{array}{l}\text { Monetary Volunteer } \\
\text { Appreciation Award }\end{array}$ & $\begin{array}{l}\text { gift card; gift cards for local } \\
\text { businesses }\end{array}$ & 2 \\
\hline Ability to Volunteer & ability to volunteer & 1 \\
\hline $\begin{array}{l}\text { Discounts to local } \\
\text { restaurants and } \\
\text { attractions }\end{array}$ & $\begin{array}{l}\text { discounts to local restaurants and } \\
\text { attractions }\end{array}$ & 1 \\
\hline $\begin{array}{l}\text { Free Family/Friends } \\
\text { Admission to other } \\
\text { Museums }\end{array}$ & $\begin{array}{l}\text { family pass to get into other } \\
\text { museums }\end{array}$ & 1 \\
\hline $\begin{array}{l}\text { IHMO Volunteer and } \\
\text { Member Newsletter }\end{array}$ & newsletter & 1 \\
\hline Travel Stipend & travel stipend & 1 \\
\hline Volunteer Name Tag & volunteer name tag & 1 \\
\hline
\end{tabular}

Online Survey Response Codes, Question \#21: How involved is the surrounding community with the museum and its administration?

\begin{tabular}{|l|l|l|}
\hline Code & Examples from Survey & Code Frequency \\
\hline $\begin{array}{l}\text { Community is } \\
\text { Actively } \\
\text { Involved }\end{array}$ & $\begin{array}{l}\text { we are well integrated in the community; } \\
\text { community is extremely interested in the } \\
\text { museum activities; very involved; community } \\
\text { is very supportive of the organization with a } \\
\text { broad range of members and financial backers; } \\
\text { getting better all the time }\end{array}$ & 36 \\
\hline $\begin{array}{l}\text { Community is } \\
\text { Moderately } \\
\text { Involved }\end{array}$ & $\begin{array}{l}\text { in a small rural community of less than 5,000, } \\
\text { we have 80 volunteers, 1.6\% of our } \\
\text { community; moderate; not as much with } \\
\text { administration aspects, but definitely with } \\
\text { support and interest in bringing folks there } \\
\text { from out of town, etc. }\end{array}$ & 21 \\
\hline
\end{tabular}




\begin{tabular}{|l|l|l|}
\hline $\begin{array}{l}\text { Community is } \\
\text { Involved }\end{array}$ & $\begin{array}{l}\text { involvement has gone down significantly; the } \\
\text { community is not involved a great deal; hands } \\
\text { off; we get visitors, but they are not regulars; } \\
\text { almost no involvement from surrounding } \\
\text { community; the immediate surrounding } \\
\text { neighborhood is uninvolved; the public's } \\
\text { awareness of our organization is not good }\end{array}$ & 30 \\
\hline Uncertain & $\begin{array}{l}\text { many locals attend our steam ups and being } \\
\text { their friends and family; broad question; varies; } \\
\text { equal parts what you put in; too vague a } \\
\text { question to answer }\end{array}$ & 11 \\
\hline
\end{tabular}

Online Survey Response Codes, Question \#22: What do you think are the motivations behind your volunteers to volunteer?

\begin{tabular}{|c|c|c|}
\hline Code & Examples from Survey & $\begin{array}{l}\text { Code } \\
\text { Frequency }\end{array}$ \\
\hline Experience/Learning & $\begin{array}{l}\text { experience for resume; seeking to learn; learn } \\
\text { skills; class credit; they are lifelong learners; } \\
\text { acquiring new transferrable skills; mental } \\
\text { stimulation; place with many opportunities to } \\
\text { develop new skills learn and research; fulfillment } \\
\text { of various community service requirements }\end{array}$ & 7 \\
\hline $\begin{array}{l}\text { Local Community } \\
\text { Pride }\end{array}$ & pride in community; local pride & 3 \\
\hline $\begin{array}{l}\text { A Sense of } \\
\text { Belonging }\end{array}$ & $\begin{array}{l}\text { a sense of belonging to our museum family; sense } \\
\text { of community with other volunteers; sense of } \\
\text { community; social activity; the society is a main } \\
\text { pillar of the community; socialize; desire to be } \\
\text { involved; socialization; the friendships that they } \\
\text { have made with other volunteers and staff over } \\
\text { the years; wanting a social experience; volunteers } \\
\text { love to restore machinery and have a club; a } \\
\text { desire to be a part of it; relationships with other } \\
\text { volunteers, staff and board; being involved in } \\
\text { their local community; wanting to be involved in } \\
\text { community; social relationships; we are a family; }\end{array}$ & 27 \\
\hline
\end{tabular}




\begin{tabular}{|c|c|c|}
\hline & $\begin{array}{l}\text { they like the fact that we have a volunteer council } \\
\text { with officers and monthly meetings; a desire for } \\
\text { social engagement or peer pressure; camaraderie; } \\
\text { value the social aspects of volunteering.; they like } \\
\text { socializing with each other and getting out of the } \\
\text { house; ant to be involved in something; }\end{array}$ & \\
\hline Local Heritage Pride & pride in our heritage; love of the island & 2 \\
\hline Pride in IHMO & $\begin{array}{l}\text { pride in museum; volunteers want to take pride in } \\
\text { the museum; we listen to them, we ask for their } \\
\text { opinions and feedback and we pay attention to } \\
\text { what they have to say; dedication to the museum; } \\
\text { a sense of pride that this museum has such a rich } \\
\text { history in the development of the area }\end{array}$ & 5 \\
\hline $\begin{array}{l}\text { Help Local } \\
\text { Community }\end{array}$ & $\begin{array}{l}\text { volunteers want to help the local community; the } \\
\text { role of the museum important in the life of the } \\
\text { community; tourism is one of the last major } \\
\text { industries in the county; the society is a main } \\
\text { pillar of the community; give back to the } \\
\text { community; trying to promote the area; being } \\
\text { involved in their local community }\end{array}$ & 8 \\
\hline Fulfilling Work & $\begin{array}{l}\text { they find their work fulfilling; interesting work; } \\
\text { the personal satisfaction resulting from } \\
\text { volunteerism }\end{array}$ & 4 \\
\hline Interest in History & $\begin{array}{l}\text { interested in history; love of history; passion for } \\
\text { history; deep colonial history; they love history; } \\
\text { enjoy history; a keen interest in history; passion } \\
\text { for history }\end{array}$ & 22 \\
\hline Like the IHMO & $\begin{array}{l}\text { like the museum; their love of the museum; } \\
\text { people really love the museum; an institution they } \\
\text { admire }\end{array}$ & 8 \\
\hline $\begin{array}{l}\text { Interest in Local } \\
\text { History }\end{array}$ & $\begin{array}{l}\text { interest in local history; interested in local } \\
\text { history; they want to get to know the local } \\
\text { history; interest in history, especial of local } \\
\text { settlement life; love of the area's history; } \\
\text { engaging history of the museum; they like to }\end{array}$ & 16 \\
\hline
\end{tabular}




\begin{tabular}{|c|c|c|}
\hline & $\begin{array}{l}\text { share stories about local history; enthusiasm for } \\
\text { local history; individuals who value the history or } \\
\text { our region }\end{array}$ & \\
\hline Personal Heritage & $\begin{array}{l}\text { volunteers often have a personal connection to } \\
\text { former employees; personal connection; they are } \\
\text { proud of their heritage; they have a personal } \\
\text { connection to the maritime world; a personal } \\
\text { connection to the industry and related trades; their } \\
\text { families part in it; volunteers usually have a } \\
\text { connection to the regions past }\end{array}$ & 9 \\
\hline Preservation & $\begin{array}{l}\text { feel like the museum is part of their heritage that } \\
\text { they want to preserve; retired skilled craftsman } \\
\text { who want to help save a historic foundry; many } \\
\text { also are interested in our historical preservation } \\
\text { activities; saving important history; preserving a } \\
\text { significant part of our nation's industrial heritage; } \\
\text { desire to preserve; an appreciation and interest in } \\
\text { industrial archeology; keeping the old ways new } \\
\text { again. }\end{array}$ & 12 \\
\hline Looking for Purpose & $\begin{array}{l}\text { looking for something to do; to have "something" } \\
\text { to do; boredom; volunteers who want to stay } \\
\text { busy, active and contribute; more time to spare } \\
\text { for volunteerism in retirement; wanting to be } \\
\text { useful; wanting a purpose with their free time; } \\
\text { need to stay active and engaged; people who are } \\
\text { looking for something to do to fill an hour or two } \\
\text { a week }\end{array}$ & 12 \\
\hline Beneficial to Health & most volunteers are disabled; keep mentally sharp & 2 \\
\hline $\begin{array}{l}\text { Cross organizational } \\
\text { support }\end{array}$ & $\begin{array}{l}\text { most of our volunteers do so because it will get } \\
\text { the word out about their establishment and our } \\
\text { staff will also volunteer at their events }\end{array}$ & 1 \\
\hline $\begin{array}{l}\text { Previous } \\
\text { experiences }\end{array}$ & $\begin{array}{l}\text { technical (professional) connection; retired } \\
\text { skilled craftsman who want to help save a historic } \\
\text { foundry; professional interest; they have a } \\
\text { personal connection to the maritime world; } \\
\text { previous experience related to museum themes; }\end{array}$ & 8 \\
\hline
\end{tabular}




\begin{tabular}{|c|c|c|}
\hline & $\begin{array}{l}\text { personal connection to the industry and related } \\
\text { trades; nostalgia }\end{array}$ & \\
\hline Industrial Assets & $\begin{array}{l}\text { repairing tractors; love of trains is usually } \\
\text { foremost; Love of trains; helping animals; Most } \\
\text { of them are looking to participate in a largely } \\
\text { extinct industrial world; sharing their skills; } \\
\text { building; volunteers love to restore machinery; } \\
\text { interest in the collection; they're interested in } \\
\text { railroads; some like working behind the scenes } \\
\text { with primary source documents and/or helping us } \\
\text { digitize these documents; volunteers first became } \\
\text { involved during construction of schooners in our } \\
\text { shipyard or the adjoining shipyard; interest in the } \\
\text { materials / project; passion for trains; most get a } \\
\text { lot of pleasure out of watching children who } \\
\text { frequently experience their first train ride with us; } \\
\text { research about different artifact and displays; } \\
\text { learn how things were done in the past.; fan of } \\
\text { antiques or trains or trolleys; exhibits (railroads, } \\
\text { Civil War, local history); fan of antiques or trains } \\
\text { or trolleys }\end{array}$ & 22 \\
\hline Personal Projects & work on their own projects. & 1 \\
\hline IHMO's Events & $\begin{array}{l}\text { interest in special events; desire to be involved in } \\
\text { museum activities; event volunteers tend to be } \\
\text { people who have come for years and love the } \\
\text { place }\end{array}$ & 4 \\
\hline Industry & $\begin{array}{l}\text { Interest in mining; feel of how lumber mills like } \\
\text { ours; especially industrial/worker aspects; } \\
\text { familiar with the various industries and } \\
\text { businesses represented in the collection; they love } \\
\text { print; celebrate the contributions of working } \\
\text { people, the Labor Movement, and immigrants. }\end{array}$ & 12 \\
\hline Training & quick turn-around on answering and training. & 1 \\
\hline Location & small location; great location & 2 \\
\hline
\end{tabular}




\begin{tabular}{|c|c|c|}
\hline General Support & $\begin{array}{l}\text { to make a better experience for others; help the } \\
\text { museum; desire to help; opportunity to engage in } \\
\text { something they're really interested in; a desire to } \\
\text { see the museum succeed; contribute; want to } \\
\text { support the Museum; enjoy giving back; } \\
\text { philanthropy; they want to be helpful to an } \\
\text { organization they care about; a desire to "give } \\
\text { back" (especially in the case of younger } \\
\text { volunteers); fundraising }\end{array}$ & 17 \\
\hline Teaching/Sharing & $\begin{array}{l}\text { educating visitors; working with kids; sharing } \\
\text { that passion with others; proud of their heritage } \\
\text { and want to share it; they like to teach children; } \\
\text { increase accessibility to the information; the } \\
\text { ability to continue to use their vast knowledge in } \\
\text { a charitable way; enjoy working with our visitors } \\
\text { inc. school children.; they enjoy meeting visitors } \\
\text { from around the world }\end{array}$ & 14 \\
\hline $\begin{array}{l}\text { IHMO's } \\
\text { Mission/Goals }\end{array}$ & $\begin{array}{l}\text { one is sharing in the goal of our museum; care } \\
\text { about our cause; vision for growth; They believe } \\
\text { in what we do; they like the mission of the } \\
\text { museum; find our mission important to share; are } \\
\text { motivated by the mission of the museum }\end{array}$ & 9 \\
\hline Personal Pride & getting their name in the paper; & 1 \\
\hline
\end{tabular}

Online Survey Response Codes, Question \#24: What does industrial heritage mean to you?

\begin{tabular}{|l|l|l|l|}
\hline Code & Examples from Survey & Code Meaning & $\begin{array}{l}\text { Code } \\
\text { Frequency }\end{array}$ \\
\hline $\begin{array}{l}\text { G-Bridge Between the } \\
\text { Past and Present }\end{array}$ & N/A & $\begin{array}{l}\text { Industrial } \\
\text { heritage is } \\
\text { what connects } \\
\text { us to the lives } \\
\text { of those who } \\
\text { lived before us }\end{array}$ & 1 \\
\hline G-Artwork & N/A & $\begin{array}{l}\text { The } \\
\text { preservation, }\end{array}$ & 1 \\
\hline
\end{tabular}




\begin{tabular}{|c|c|c|c|}
\hline & & $\begin{array}{l}\text { collection, or } \\
\text { remembrance } \\
\text { of things, } \\
\text { works of art, } \\
\text { and ideas both } \\
\text { tangible and } \\
\text { intangible } \\
\text { related to } \\
\text { industrial } \\
\text { communities, } \\
\text { societies, } \\
\text { production, } \\
\text { and } \\
\text { transportation. }\end{array}$ & \\
\hline $\begin{array}{l}\text { G-Celebration of } \\
\text { Industrial Heritage }\end{array}$ & $\begin{array}{l}\text { The celebration of historic } \\
\text { enterprises; Industrial } \\
\text { heritage means celebrating a } \\
\text { once critical part of the } \\
\text { national economy that has } \\
\text { now been largely out sourced } \\
\text { to other countries and } \\
\text { overwhelmed by a white- } \\
\text { collar service economy.; } \\
\text { recognition and exploration of } \\
\text { the key role that industry (and } \\
\text { the people who worked there) } \\
\text { had in the development of our } \\
\text { communities }\end{array}$ & N/A & 3 \\
\hline $\begin{array}{l}\text { G-Cultural History of } \\
\text { Industry }\end{array}$ & $\begin{array}{l}\text { The cultural and } \\
\text { technological history of a } \\
\text { particular industry. }\end{array}$ & N/A & 1 \\
\hline G-Economic Decline & $\begin{array}{l}\text { History of mining, economic } \\
\text { decline, scale of work }\end{array}$ & N/A & 1 \\
\hline G-Industry & $\begin{array}{l}\text { A history of the following } \\
\text { commercial activities, } \\
\text { especially when they played a } \\
\text { significant role in a location's } \\
\text { economy: manufacturing new }\end{array}$ & N/A & 14 \\
\hline
\end{tabular}




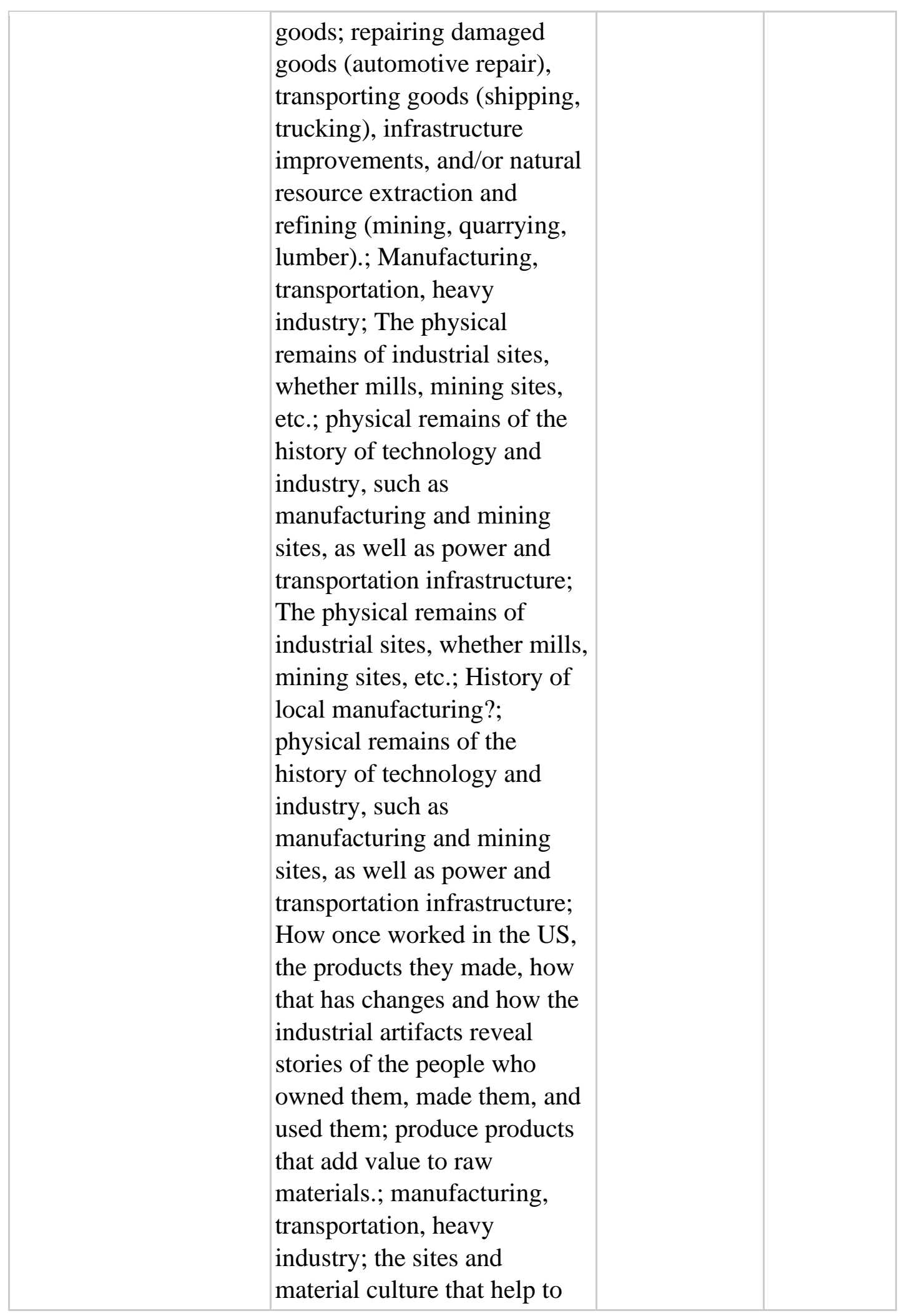




\begin{tabular}{|c|c|c|c|}
\hline & $\begin{array}{l}\text { tell the story of our } \\
\text { manufacturing past }\end{array}$ & & \\
\hline G-Equipment & $\begin{array}{l}\text { The surviving memories, } \\
\text { knowledge, equipment and } \\
\text { sites of trades and processes }\end{array}$ & N/A & 1 \\
\hline $\begin{array}{l}\text { G-Hands on } \\
\text { Learning/Teaching }\end{array}$ & $\begin{array}{l}\text { Teaching (including physical } \\
\text { demonstration); Preserving } \\
\text { the tools, records, artifacts, } \\
\text { structures, and historic site of } \\
\text { an industry, and utilizing } \\
\text { these assets to educate } \\
\text { visitors and students about the } \\
\text { industry within its cultural } \\
\text { context. }\end{array}$ & N/A & 3 \\
\hline $\begin{array}{l}\text { G-History of } \\
\text { Engineering }\end{array}$ & $\begin{array}{l}\text { The preservation and } \\
\text { interpretation of artifacts, } \\
\text { stories, and places related to } \\
\text { the history of engineering. }\end{array}$ & N/A & 1 \\
\hline G-History of Invention & $\begin{array}{l}\text { History of invention, } \\
\text { innovation, manufacturing }\end{array}$ & N/A & 1 \\
\hline G-History of Industry & $\begin{array}{l}\text { The history of industry; } \\
\text { history of industrial } \\
\text { technology; History of past } \\
\text { industry; Physical remains of } \\
\text { the history of technology and } \\
\text { industry.; history of tech, } \\
\text { power, transportation, and } \\
\text { industry; The history of } \\
\text { industry in a town or } \\
\text { community; The history and } \\
\text { artifacts associated with } \\
\text { industry and work.; The } \\
\text { history of industry in America } \\
\text { in different sectors.; The } \\
\text { history of industry; It's } \\
\text { remembering where an } \\
\text { industry began and how that }\end{array}$ & N/A & 23 \\
\hline
\end{tabular}




\begin{tabular}{|c|c|c|c|}
\hline & $\begin{array}{l}\text { affected the area.; History of } \\
\text { mining, factories and the } \\
\text { people associated with them; } \\
\text { History of mining, factories } \\
\text { and the people associated } \\
\text { with them; history of mining, } \\
\text { economic decline, scale of } \\
\text { work; Industrial Heritage is } \\
\text { the interpretation of tradition } \\
\text { or history of manufacturing, } \\
\text { the skills involved in making } \\
\text { things, the people \& } \\
\text { businesses that manufacture } \\
\text { items and the products } \\
\text { themselves.; The preservation } \\
\text { and interpretation of artifacts, } \\
\text { stories, and places related to } \\
\text { the history of technology, } \\
\text { manufacturing, and } \\
\text { engineering. }\end{array}$ & & \\
\hline G-History of Power & $\begin{array}{l}\text { history of tech, power, } \\
\text { transportation, and industry }\end{array}$ & N/A & 1 \\
\hline $\begin{array}{l}\text { G-History of } \\
\text { Technology }\end{array}$ & $\begin{array}{l}\text { The history of technology; } \\
\text { history of industrial } \\
\text { technology; Physical remains } \\
\text { of the history of technology } \\
\text { and industry; history of tech, } \\
\text { power, transportation, and } \\
\text { industry; The cultural and } \\
\text { technological history of a } \\
\text { particular industry.; The } \\
\text { preservation and } \\
\text { interpretation of artifacts, } \\
\text { stories, and places related to } \\
\text { the history of technology, } \\
\text { manufacturing, and } \\
\text { engineering; The history of } \\
\text { technology, the machinery it }\end{array}$ & N/A & 11 \\
\hline
\end{tabular}




\begin{tabular}{|c|c|c|c|}
\hline & $\begin{array}{l}\text { produced, and its effect on } \\
\text { society. }\end{array}$ & & \\
\hline $\begin{array}{l}\text { G-History of } \\
\text { Transportation }\end{array}$ & $\begin{array}{l}\text { The history of tech, power, } \\
\text { transportation, and industry }\end{array}$ & N/A & 1 \\
\hline G-History of Labor & $\begin{array}{l}\text { I am assuming the history of } \\
\text { the "working man". }\end{array}$ & N/A & 1 \\
\hline G-Immigration & $\begin{array}{l}\text { History of industry, including } \\
\text { entrepreneurship, innovation, } \\
\text { the workforce, immigration, } \\
\text { and organized labor. }\end{array}$ & N/A & 1 \\
\hline G-Organized Labor & $\begin{array}{l}\text { History of industry, including } \\
\text { entrepreneurship, innovation, } \\
\text { the workforce, immigration, } \\
\text { and organized labor. }\end{array}$ & N/A & 1 \\
\hline G-Workforce & $\begin{array}{l}\text { History of industry, including } \\
\text { entrepreneurship, innovation, } \\
\text { the workforce, immigration, } \\
\text { and organized labor. }\end{array}$ & N/A & 1 \\
\hline G-Industrial Artifacts & $\begin{array}{l}\text { artifacts from past industry.; } \\
\text { artifacts and memories from } \\
\text { the history of local industry } \\
\text { rise and fall; how once } \\
\text { worked in the US, the } \\
\text { products they made, how that } \\
\text { has changes and how the } \\
\text { industrial artifacts reveal } \\
\text { stories of the people who } \\
\text { owned them, made them, and } \\
\text { used them; the history and } \\
\text { artifacts associated with } \\
\text { industry and work.; the } \\
\text { preservation and } \\
\text { interpretation of artifacts, } \\
\text { stories, and places related to } \\
\text { the history of technology, } \\
\text { manufacturing, and }\end{array}$ & N/A & 7 \\
\hline
\end{tabular}




\begin{tabular}{|c|c|c|c|}
\hline & $\begin{array}{l}\text { engineering.; the sites and } \\
\text { material culture that help to } \\
\text { tell the story of our } \\
\text { manufacturing past; industrial } \\
\text { heritage includes all of the } \\
\text { social and material culture } \\
\text { directly or indirectly related } \\
\text { to the people engaged in the } \\
\text { creation of infrastructure and } \\
\text { the production and } \\
\text { distribution of raw materials, } \\
\text { objects, and energy }\end{array}$ & & \\
\hline $\begin{array}{l}\text { G-Industry as } \\
\text { Influencing Society }\end{array}$ & $\begin{array}{l}\text { The history of technology, the } \\
\text { machinery it produced, and its } \\
\text { effect on society. }\end{array}$ & N/A & 1 \\
\hline G-Trade/Commerce & $\begin{array}{l}\text { our nation's heritage as it } \\
\text { relates to trade, } \\
\text { manufacturing, certain } \\
\text { industries including fish } \\
\text { culture, dairy, ranching, } \\
\text { farming, textiles, etc.; history } \\
\text { of industry, including } \\
\text { entrepreneurship, innovation, } \\
\text { the workforce, immigration, } \\
\text { and organized labor.; the } \\
\text { surviving memories, } \\
\text { knowledge, equipment and } \\
\text { sites of trades and processes }\end{array}$ & N/A & 3 \\
\hline G-Industrialization & $\begin{array}{l}\text { Heritage from the industrial } \\
\text { period, i, e mills etc.; } \\
\text { remaining built environment } \\
\text { from a previous era }\end{array}$ & N/A & 2 \\
\hline G-Social Culture & $\begin{array}{l}\text { industrial heritage includes all } \\
\text { of the social and material } \\
\text { culture directly or indirectly } \\
\text { related to the people engaged } \\
\text { in the creation of } \\
\text { infrastructure and the }\end{array}$ & N/A & 1 \\
\hline
\end{tabular}




\begin{tabular}{|c|c|c|c|}
\hline & $\begin{array}{l}\text { production and distribution of } \\
\text { raw materials, objects, and } \\
\text { energy }\end{array}$ & & \\
\hline $\begin{array}{l}\text { G-Industry as World } \\
\text { Shaping }\end{array}$ & $\begin{array}{l}\text { How the American Industrial } \\
\text { Revolution affected the lives } \\
\text { of millions of people across } \\
\text { the world and through the } \\
\text { centuries right up to us here } \\
\text { today.; the innovations of the } \\
\text { industrial era are world } \\
\text { changing; impact on the } \\
\text { people, their lives, their } \\
\text { community, and the world. }\end{array}$ & N/A & 3 \\
\hline $\begin{array}{l}\text { G-Industrial } \\
\text { Methods/Processes }\end{array}$ & $\begin{array}{l}\text { operations; about historical } \\
\text { industrial methods }\end{array}$ & N/A & 2 \\
\hline $\begin{array}{l}\text { G-Industry as Shaping } \\
\text { Community }\end{array}$ & $\begin{array}{l}\text { Recognition and exploration } \\
\text { of the key role that industry } \\
\text { (and the people who worked } \\
\text { there) had in the development } \\
\text { of our communities; impact } \\
\text { on the people, their lives, } \\
\text { their community, and the } \\
\text { world; The history of industry } \\
\text { in a town or community; } \\
\text { Industrial heritage is the root } \\
\text { of a community's identity. It } \\
\text { is the foundation of an } \\
\text { economy, a way of life, and a } \\
\text { common thread that binds } \\
\text { neighbors and community } \\
\text { together. }\end{array}$ & N/A & 3 \\
\hline $\begin{array}{l}\text { G-Industry as Defining } \\
\text { Region }\end{array}$ & $\begin{array}{l}\text { The type of industry that } \\
\text { defines a region }\end{array}$ & N/A & 1 \\
\hline $\begin{array}{l}\text { G-Industry as } \\
\text { Impacting Region }\end{array}$ & $\begin{array}{l}\text { It means acknowledgment of } \\
\text { the impact of local industry } \\
\text { on the development, } \\
\text { economy, and culture of a }\end{array}$ & N/A & 2 \\
\hline
\end{tabular}




\begin{tabular}{|c|c|c|c|}
\hline & $\begin{array}{l}\text { region; It's remembering } \\
\text { where an industry began and } \\
\text { how that affected the area. }\end{array}$ & & \\
\hline $\begin{array}{l}\text { G-Industry as Nation } \\
\text { Altering }\end{array}$ & $\begin{array}{l}\text { history of industry is vast in } \\
\text { America, the changes during } \\
\text { war times to peace time }\end{array}$ & N/A & 1 \\
\hline $\begin{array}{l}\text { G-Industry as Nation } \\
\text { Shaping }\end{array}$ & $\begin{array}{l}\text { I feel it is the history of how } \\
\text { industry built and shaped our } \\
\text { country; American industry is } \\
\text { one of the most important } \\
\text { aspects of how America } \\
\text { became what it is today, and } \\
\text { its developments have } \\
\text { influenced all of our everyday } \\
\text { lives; the industrial Heritage } \\
\text { of the United States is crucial } \\
\text { to the understanding of } \\
\text { American History in general. } \\
\text { It is the roots of everything } \\
\text { that made our country } \\
\text { prosperous and secure.; a } \\
\text { history that played a } \\
\text { significant role in the } \\
\text { development of the country; } \\
\text { It is the foundation of } \\
\text { America's existence and } \\
\text { salvation }\end{array}$ & N/A & 4 \\
\hline $\begin{array}{l}\text { G-Industry as Shaping } \\
\text { Cultural Landscape }\end{array}$ & $\begin{array}{l}\text { A look into the historical } \\
\text { importance on how industries } \\
\text { shaped the cultural } \\
\text { landscape.; The type of } \\
\text { industry that defines a region } \\
\text { and shapes its current society } \\
\text { and landscape }\end{array}$ & N/A & 1 \\
\hline G-Infrastructure & $\begin{array}{l}\text { A history of the following } \\
\text { commercial activities, } \\
\text { especially when they played a } \\
\text { significant role in a location's }\end{array}$ & N/A & 5 \\
\hline
\end{tabular}




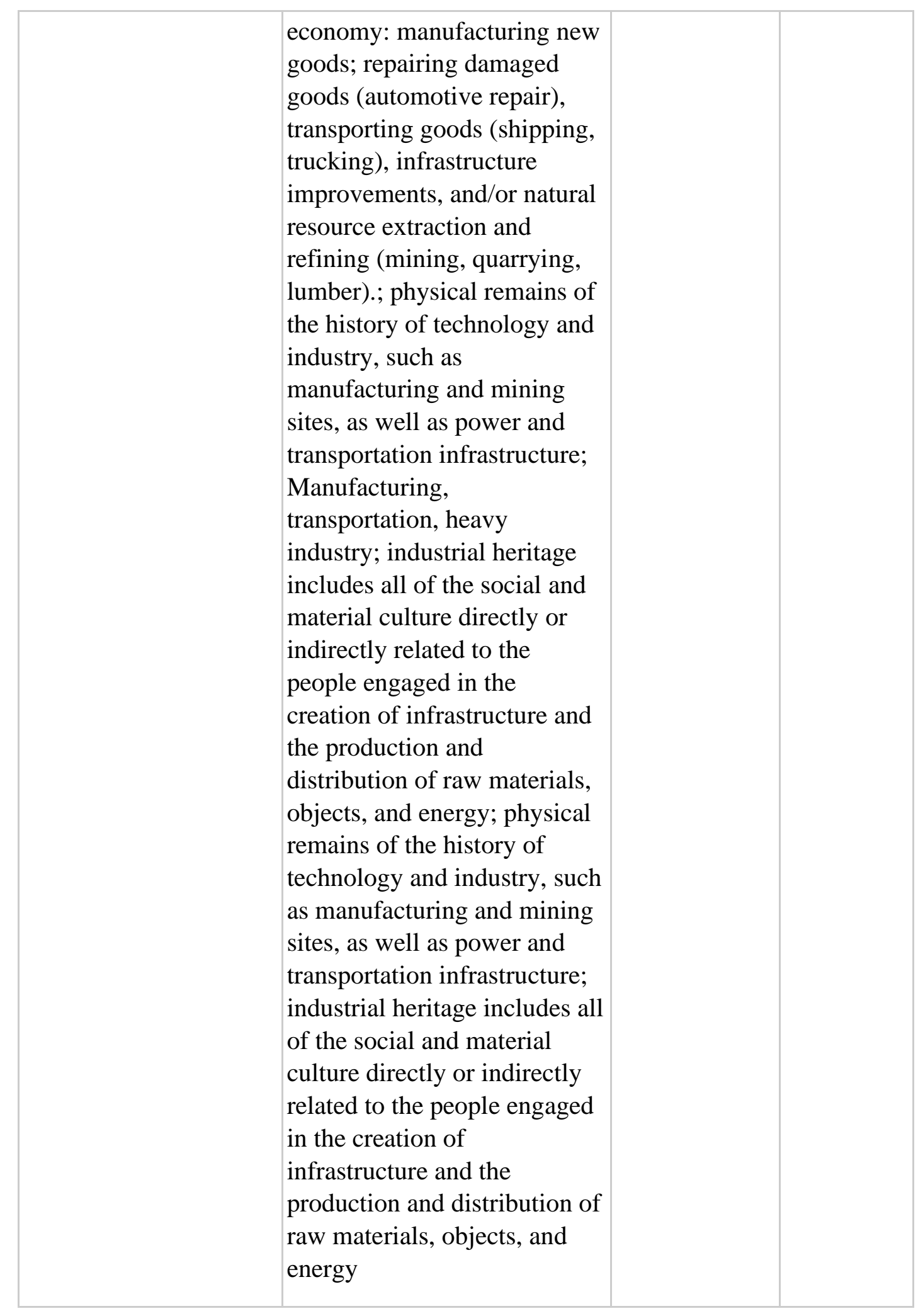




\begin{tabular}{|c|c|c|c|}
\hline G-Interpretation & $\begin{array}{l}\text { The interpretation of historic } \\
\text { enterprises; Preserving and } \\
\text { interpreting the legacy of } \\
\text { industry; Industrial Heritage } \\
\text { is the interpretation of } \\
\text { tradition or history of } \\
\text { manufacturing, the skills } \\
\text { involved in making things, } \\
\text { the people \& businesses that } \\
\text { manufacture items and the } \\
\text { products themselves.; The } \\
\text { preservation and } \\
\text { interpretation of artifacts, } \\
\text { stories, and places related to } \\
\text { the history of technology, } \\
\text { manufacturing, and } \\
\text { engineering. }\end{array}$ & N/A & 4 \\
\hline G-Local Industry & $\begin{array}{l}\text { Artifacts and memories from } \\
\text { the history of local industry } \\
\text { rise and fall; The history of } \\
\text { industry in a town or } \\
\text { community; Historical } \\
\text { industry that was vital to the } \\
\text { area; It means } \\
\text { acknowledgment of the } \\
\text { impact of local industry on } \\
\text { the development, economy, } \\
\text { and culture of a region.; } \\
\text { Industrial heritage is the root } \\
\text { of a community's identity. It } \\
\text { is the foundation of an } \\
\text { economy, a way of life, and a } \\
\text { common thread that binds } \\
\text { neighbors and community } \\
\text { together. }\end{array}$ & N/A & 7 \\
\hline G-Machinery & $\begin{array}{l}\text { Something that is machine } \\
\text { related; study of the } \\
\text { mechanical devices } \\
\text { developed; The history of }\end{array}$ & N/A & 4 \\
\hline
\end{tabular}




\begin{tabular}{|c|c|c|c|}
\hline & $\begin{array}{l}\text { technology, the machinery it } \\
\text { produced, and its effect on } \\
\text { society. }\end{array}$ & & \\
\hline G-Remembrance & $\begin{array}{l}\text { The preservation, collection, } \\
\text { or remembrance of things, } \\
\text { works of art, and ideas both } \\
\text { tangible and intangible related } \\
\text { to industrial communities, } \\
\text { societies, production, and } \\
\text { transportation.; Bring back } \\
\text { memories of bygone } \\
\text { business.; artifacts and } \\
\text { memories from the history of } \\
\text { local industry rise and fall; } \\
\text { The surviving memories, } \\
\text { knowledge, equipment and } \\
\text { sites of trades and processes }\end{array}$ & N/A & 3 \\
\hline G-Past Creates Present & $\begin{array}{l}\text { It is our past which has } \\
\text { created our present. }\end{array}$ & N/A & 1 \\
\hline G-Past Shapes Present & $\begin{array}{l}\text { Understanding and } \\
\text { appreciating how } \\
\text { industrialization has shaped } \\
\text { our lives; Just what it says. } \\
\text { These are the things that } \\
\text { provided the physical support } \\
\text { for our way of life. }\end{array}$ & N/A & 5 \\
\hline $\begin{array}{l}\text { G-Past Influence the } \\
\text { Future }\end{array}$ & $\begin{array}{l}\text { Industrial heritage means } \\
\text { learning from our past to } \\
\text { make the future. }\end{array}$ & N/A & 2 \\
\hline G-People & $\begin{array}{l}\text { For industrial heritage, I get } \\
\text { more excited about the } \\
\text { people; lives of those who } \\
\text { lived before us, how they } \\
\text { lived; the stories of the people } \\
\text { who worked in and around } \\
\text { industry.; impact on the } \\
\text { people, their lives, their }\end{array}$ & N/A & 10 \\
\hline
\end{tabular}




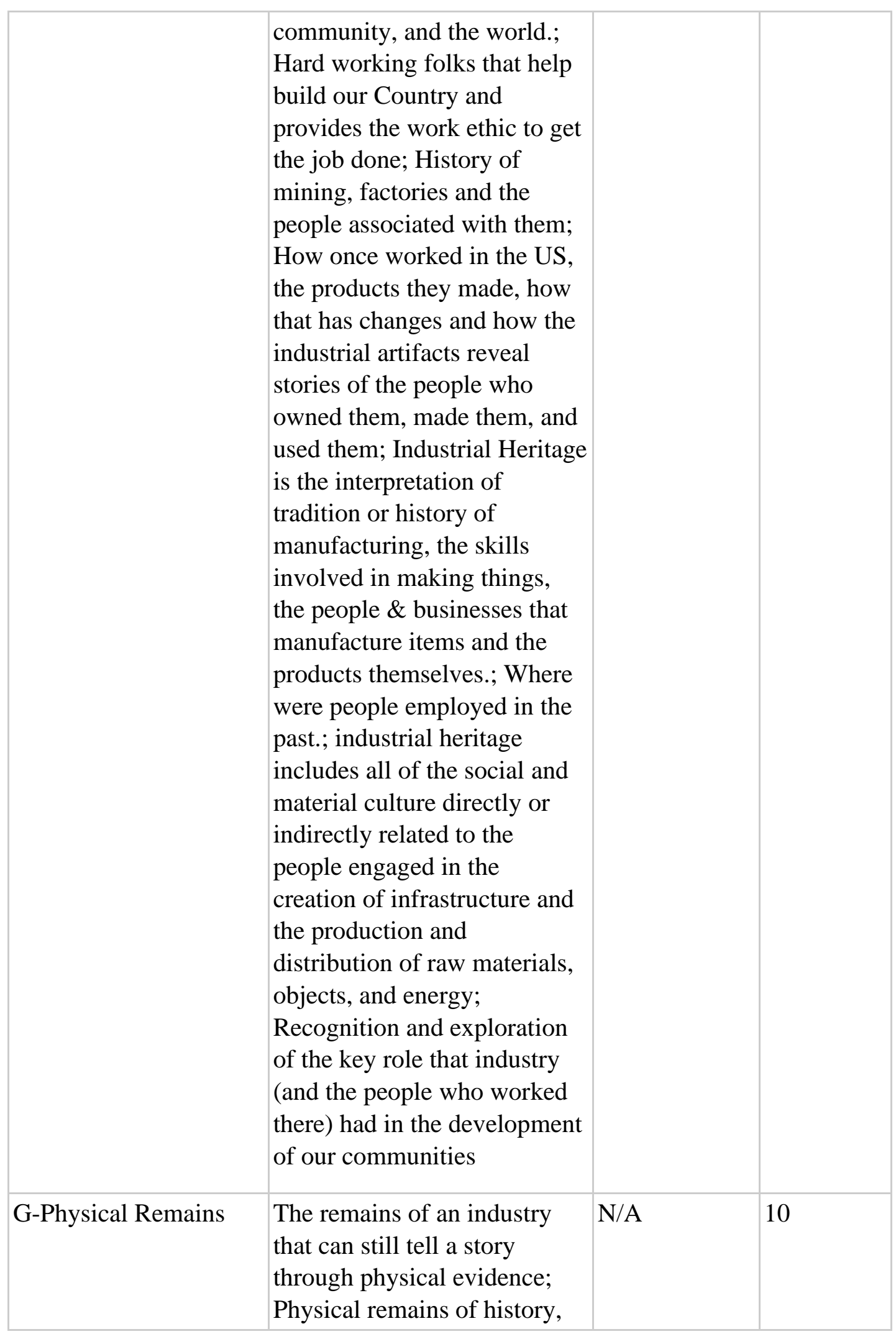




\begin{tabular}{|c|c|c|c|}
\hline & $\begin{array}{l}\text { technology, and industry.; } \\
\text { The physical remains of } \\
\text { industrial sites, whether mills, } \\
\text { mining sites, etc.; Physical } \\
\text { remains of the history of } \\
\text { technology and industry.; the } \\
\text { sites and material culture that } \\
\text { help to tell the story of our } \\
\text { manufacturing past; The } \\
\text { remaining built environment }\end{array}$ & & \\
\hline G-Preservation & $\begin{array}{l}\text { Preserving the history of } \\
\text { previous industrial sites; } \\
\text { Preserving the history of } \\
\text { industrial technology, } \\
\text { operations, and the stories of } \\
\text { the people who worked in and } \\
\text { around industry; The } \\
\text { preservation of historic } \\
\text { enterprises; Preserving and } \\
\text { interpreting the legacy of } \\
\text { industry; Preserving the tools, } \\
\text { records, artifacts, structures, } \\
\text { and historic site of an } \\
\text { industry, and utilizing these } \\
\text { assets to educate visitors and } \\
\text { students about the industry } \\
\text { within its cultural context.; } \\
\text { The preservation and } \\
\text { interpretation of artifacts, } \\
\text { stories, and places related to } \\
\text { the history of technology, } \\
\text { manufacturing, and } \\
\text { engineering. }\end{array}$ & N/A & 7 \\
\hline G-Repairing Goods & repairing goods & N/A & 1 \\
\hline G-Salvation & $\begin{array}{l}\text { It is the foundation of } \\
\text { America's existence and } \\
\text { salvation }\end{array}$ & N/A & 1 \\
\hline
\end{tabular}




\begin{tabular}{|c|c|c|c|}
\hline G-Scale of Work & $\begin{array}{l}\text { history of mining, economic } \\
\text { decline, scale of work }\end{array}$ & N/A & 1 \\
\hline $\begin{array}{l}\text { G- } \\
\text { Tangibility/Intangibility }\end{array}$ & $\begin{array}{l}\text { The preservation, collection, } \\
\text { or remembrance of things } \\
\text { works of art, and ideas both } \\
\text { tangible and intangible related } \\
\text { to industrial communities, } \\
\text { societies, production, and } \\
\text { transportation. }\end{array}$ & N/A & 1 \\
\hline G-Tradition & $\begin{array}{l}\text { Industrial Heritage is the } \\
\text { interpretation of tradition or } \\
\text { history of manufacturing, the } \\
\text { skills involved in making } \\
\text { things, the people \& } \\
\text { businesses that manufacture } \\
\text { items and the products } \\
\text { themselves. }\end{array}$ & N/A & 2 \\
\hline G-Transition & $\begin{array}{l}\text { Industrial heritage means } \\
\text { celebrating a once critical part } \\
\text { of the national economy that } \\
\text { has now been largely } \\
\text { outsourced to other countries } \\
\text { and overwhelmed by a white- } \\
\text { collar service economy. }\end{array}$ & N/A & 1 \\
\hline $\begin{array}{l}\text { G-Using past to } \\
\text { understand present }\end{array}$ & $\begin{array}{l}\text { Understanding what has been } \\
\text { done before to understand } \\
\text { where we are now. }\end{array}$ & N/A & 1 \\
\hline $\begin{array}{l}\text { G-Working } \\
\text { Environment }\end{array}$ & $\begin{array}{l}\text { ho lived before us, how they } \\
\text { lived and how they worked. }\end{array}$ & N/A & 1 \\
\hline General & N/A & $\begin{array}{l}\text { The "General" } \\
\text { code stands for } \\
\text { meanings } \\
\text { presented that } \\
\text { speak to } \\
\text { generalizations } \\
\text { or larger }\end{array}$ & 61 \\
\hline
\end{tabular}




\begin{tabular}{|c|c|c|c|}
\hline & & $\begin{array}{l}\text { concepts of } \\
\text { industrial } \\
\text { heritage } \\
\text { instead of } \\
\text { focusing on } \\
\text { one region, } \\
\text { industry, or } \\
\text { historical } \\
\text { period }\end{array}$ & \\
\hline Mixed & N/A & $\begin{array}{l}\text { The "Mixed" } \\
\text { code speaks to } \\
\text { the survey } \\
\text { question "what } \\
\text { does industrial } \\
\text { heritage mean } \\
\text { to you?" } \\
\text { where } \\
\text { responses } \\
\text { combine } \\
\text { specific and } \\
\text { personal } \\
\text { meanings on a } \\
\text { local scale, } \\
\text { while also } \\
\text { talking about } \\
\text { general } \\
\text { concepts } \\
\text { commonly } \\
\text { described by } \\
\text { scholarship on } \\
\text { the topic or } \\
\text { topics that } \\
\text { span } \\
\text { geographical } \\
\text { location, time, } \\
\text { and industry. }\end{array}$ & 14 \\
\hline S-Hubs of Industry & Lowell, Massachusetts & N/A & 1 \\
\hline S-Celebration & Celebrate & N/A & 1 \\
\hline
\end{tabular}




\begin{tabular}{|c|c|c|c|}
\hline S-Product & John Deere & N/A & 1 \\
\hline S-Industrialization & $\begin{array}{l}\text { I would relate Industrial } \\
\text { Heritage to the lumber mill } \\
\text { exhibit that talks about the } \\
\text { county's lumber boom in the } \\
\text { early 1900's; Alaska Gold } \\
\text { Mining Era }\end{array}$ & N/A & 2 \\
\hline $\begin{array}{l}\text { S-Hands on } \\
\text { Learning/Teaching }\end{array}$ & $\begin{array}{l}\text { our volunteers are engaged in } \\
\text { the saw room or small } \\
\text { engines because they want to } \\
\text { pass on this way of life }\end{array}$ & N/A & 5 \\
\hline S-Industrial Artifacts & $\begin{array}{l}\text { Restoring trains and train } \\
\text { related artifacts for the } \\
\text { present and future } \\
\text { generations. }\end{array}$ & N/A & 2 \\
\hline S-Innovations & $\begin{array}{l}\text { How did the invention } \\
\text { timeline go; the series of } \\
\text { changes that resulted in the } \\
\text { braille system; in Maine, use } \\
\text { of water-power and other } \\
\text { natural resources }\end{array}$ & N/A & 3 \\
\hline $\begin{array}{l}\text { S-Industrial } \\
\text { Methods/Operations }\end{array}$ & $\begin{array}{l}\text { historical industrial methods } \\
\text { (of wood and lumber } \\
\text { processing in the case of the } \\
\text { Ledyard mill) }\end{array}$ & N/A & 1 \\
\hline $\begin{array}{l}\text { S-Industry as affecting } \\
\text { local area }\end{array}$ & $\begin{array}{l}\text { To me it means the effect a } \\
\text { particular industry had on my } \\
\text { area. }\end{array}$ & N/A & 1 \\
\hline $\begin{array}{l}\text { S-Industry as Building } \\
\text { Town }\end{array}$ & $\begin{array}{l}\text { Bisbee, Arizona is a historical } \\
\text { copper mining community; a } \\
\text { town that copper built. }\end{array}$ & N/A & 1 \\
\hline $\begin{array}{l}\text { S-Industry as Shaping } \\
\text { City }\end{array}$ & $\begin{array}{l}\text { Growth of industry in } \\
\text { Chicago and its relationship } \\
\text { to Chicago waterways }\end{array}$ & N/A & 2 \\
\hline
\end{tabular}




\begin{tabular}{|c|c|c|c|}
\hline $\begin{array}{l}\text { S-Industry as Shaping } \\
\text { State }\end{array}$ & $\begin{array}{l}\text { he Pacific Locomotive } \\
\text { Association, Inc., operates } \\
\text { Niles Canyon Railway as a } \\
\text { living history museum } \\
\text { interpreting the importance of } \\
\text { our heritage railroads in the } \\
\text { development of California } \\
\text { and the nation. }\end{array}$ & N/A & 1 \\
\hline $\begin{array}{l}\text { S-Industry as Shaping } \\
\text { Nation }\end{array}$ & $\begin{array}{l}\text { he Pacific Locomotive } \\
\text { Association, Inc., operates } \\
\text { Niles Canyon Railway as a } \\
\text { living history museum } \\
\text { interpreting the importance of } \\
\text { our heritage railroads in the } \\
\text { development of California } \\
\text { and the nation. }\end{array}$ & N/A & 3 \\
\hline $\begin{array}{l}\text { S-Industry as Shaping } \\
\text { World }\end{array}$ & $\begin{array}{l}\text { At our museum we call it } \\
\text { agricultural heritage and it is } \\
\text { important to share. In this } \\
\text { increasingly technological } \\
\text { time, it is more important } \\
\text { than ever as people need to } \\
\text { know where their food comes } \\
\text { from and what is involved in } \\
\text { getting on your table. }\end{array}$ & N/A & 1 \\
\hline S-Infrastructure & $\begin{array}{l}\text { Often related to } \\
\text { infrastructure. }\end{array}$ & $\mathrm{N} / \mathrm{A}$ & 1 \\
\hline S-Legacy of Industry & $\begin{array}{l}\text { Industrial heritage has to do } \\
\text { with the history/legacy of } \\
\text { industries such as } \\
\text { manufacturing; The } \\
\text { preservation and restoration } \\
\text { of the Knight Foundry } \\
\text { provides an unparalleled } \\
\text { opportunity to protect the } \\
\text { history of industrial } \\
\text { technologies as they were } \\
\text { traditionally implemented, }\end{array}$ & N/A & 6 \\
\hline
\end{tabular}




\begin{tabular}{|c|c|c|c|}
\hline & $\begin{array}{l}\text { and to pass them on to future } \\
\text { generations; Restoring trains } \\
\text { and train related artifacts for } \\
\text { the present and future } \\
\text { generations. }\end{array}$ & & \\
\hline $\begin{array}{l}\text { S-Local Industrial } \\
\text { Boom }\end{array}$ & $\begin{array}{l}\text { I would relate Industrial } \\
\text { Heritage to the lumber mill } \\
\text { exhibit that talks about the } \\
\text { county's lumber boom in the } \\
\text { early 1900's }\end{array}$ & N/A & 2 \\
\hline $\begin{array}{l}\text { S-Local industry as } \\
\text { supplying nation }\end{array}$ & $\begin{array}{l}\text { Our story is that Bisbee } \\
\text { played a primary role in the } \\
\text { American Industrial } \\
\text { Revolution beginning in the } \\
1870 \text { s when everyone decided } \\
\text { they liked electric lighting } \\
\text { and telephones. }\end{array}$ & N/A & 1 \\
\hline S-Loss & $\begin{array}{l}\text { Gone; there are no industrial } \\
\text { heritage sites related to our } \\
\text { story }\end{array}$ & N/A & 1 \\
\hline S-Manufacturing & $\begin{array}{l}\text { manufacturing; Heritage from } \\
\text { the industrial period, i, e mills } \\
\text { etc. }\end{array}$ & N/A & 2 \\
\hline S-Mining & mining & N/A & 2 \\
\hline S-People & $\begin{array}{l}\text { The population rose from } \\
1400 \text { to } 15,000 \text { during that } \\
\text { early } 30 \text {-year span. }\end{array}$ & N/A & 3 \\
\hline S-Physical Remains & $\begin{array}{l}\text { Sites such as ours on an } \\
\text { actual mine yard }\end{array}$ & N/A & 1 \\
\hline S-Preservation & $\begin{array}{l}\text { Important as the history we } \\
\text { are seeking to preserve; The } \\
\text { mines closed in the mid- } \\
1970 \text { s, but the wealth of the } \\
\text { copper mines left a } \\
\text { wonderfully preserved, late }\end{array}$ & N/A & 10 \\
\hline
\end{tabular}




\begin{tabular}{|c|c|c|c|}
\hline & $\begin{array}{l}\text { 19th-century architectural } \\
\text { landscape. }\end{array}$ & & \\
\hline S-Remnants of the Past & $\begin{array}{l}\text { seeing the remnants of that } \\
\text { past; In addition to the } 11.5 \text { - } \\
\text { mile railroad that was built in } \\
\text { the } 1880 \text { 's to serve } 2 \text { granite } \\
\text { quarries we own one of the } \\
\text { finishing plants and several } \\
\text { other related buildings }\end{array}$ & N/A & 1 \\
\hline S-Restoration & $\begin{array}{l}\text { The preservation and } \\
\text { restoration of the Knight } \\
\text { Foundry provides an } \\
\text { unparalleled opportunity to } \\
\text { protect the history of } \\
\text { industrial technologies as they } \\
\text { were traditionally } \\
\text { implemented, and to pass } \\
\text { them on to future generations. }\end{array}$ & N/A & 2 \\
\hline S-State Industry & Alaska Gold Mining Era & N/A & 2 \\
\hline S-Innovation & $\begin{array}{l}\text { it means how life changed in } \\
\text { large and small ways, } \\
\text { anything from being able to } \\
\text { walk to a station and be } \\
\text { carried across the state in a } \\
\text { short time; The Cotton Gin } \\
\text { was one of the first } \\
\text { innovations to change the } \\
\text { hard work of de-seeding the } \\
\text { cotton lint. }\end{array}$ & N/A & 3 \\
\hline $\begin{array}{l}\text { S-Transportation } \\
\text { Network }\end{array}$ & $\begin{array}{l}\text { we try to focus on the impact } \\
\text { of the railroad on the local } \\
\text { area; and in this case, a } \\
\text { limited transportation hub; the } \\
\text { amount of work it took to } \\
\text { power an industrial port such } \\
\text { as this; }\end{array}$ & N/A & 8 \\
\hline
\end{tabular}




\begin{tabular}{|c|c|c|c|}
\hline $\begin{array}{l}\text { S-Unintended } \\
\text { Consequences }\end{array}$ & $\begin{array}{l}\text { to running outside to pull } \\
\text { laundry off the clothes lines } \\
\text { before a passing train spewed } \\
\text { its cinders all over the clean } \\
\text { sheets. }\end{array}$ & N/A & 1 \\
\hline $\begin{array}{l}\text { S-Working } \\
\text { Environment }\end{array}$ & $\begin{array}{l}\text { Same with a saw room: what } \\
\text { was the work pace, the sweat, } \\
\text { the skills needed, the } \\
\text { language and math }\end{array}$ & N/A & 1 \\
\hline Specific & & $\begin{array}{l}\text { The "Specific" } \\
\text { code stands in } \\
\text { for meanings } \\
\text { presented that } \\
\text { give specific } \\
\text { examples } \\
\text { only, talk } \\
\text { about their } \\
\text { museum } \\
\text { without } \\
\text { touching on a } \\
\text { general } \\
\text { scholarly } \\
\text { concepts of } \\
\text { industrial } \\
\text { heritage, and } \\
\text { primarily } \\
\text { discuss local } \\
\text { industry. }\end{array}$ & 23 \\
\hline
\end{tabular}

Online Survey Response Codes, Question \#26: What industries are represented in the collections and exhibits at your museum?

\begin{tabular}{|l|l|l|}
\hline Code & Examples from Survey & $\begin{array}{l}\text { Code } \\
\text { Frequency }\end{array}$ \\
\hline Agriculture & $\begin{array}{l}\text { General Forest Products; Animal Fur; Animal } \\
\text { Husbandry; Clamming; Commercial Fishing; } \\
\text { Cotton Farming; Dairy; Finishing; Fisheries; } \\
\text { Fishing; Food Production; Forest Management; }\end{array}$ & 38 \\
\hline
\end{tabular}




\begin{tabular}{|c|c|c|}
\hline & $\begin{array}{l}\text { General Agriculture; General Farming; Grist Mill; } \\
\text { Harvesting Marine Animals; Ice Harvesting; } \\
\text { Logging; Oysters; Ranching; Sugar; Sugar } \\
\text { Growing/Harvesting; Tobacco Farming; Whaling; } \\
\text { Wormseed }\end{array}$ & \\
\hline Communications & General Logistics; & 2 \\
\hline Construction & Construction & 2 \\
\hline Engineering & Mechanical Engineering; Military Engineering & 2 \\
\hline Extraction & $\begin{array}{l}\text { Bromine Extraction; Mercury Extraction; Oil } \\
\text { Extraction; Petroleum Extraction }\end{array}$ & 3 \\
\hline Infrastructure & Water Salination; Water Supply & 2 \\
\hline Manufacturing & $\begin{array}{l}\text { General Milling; Art; Automobiles; Blacksmith } \\
\text { Tools; Blacksmithing; Boatbuilding; Brass; Bricks; } \\
\text { Button Manufacturing; Cabinetry; Canning; } \\
\text { Carpentry; Chemical; Cider; Clock; Consumer } \\
\text { Goods; Covered Wagons; Cutlery; Dies; } \\
\text { Electronics; Eyelets; Firearms; Forging; Foundry; } \\
\text { Furniture; Gages; Garments; Glass Blowing; } \\
\text { Glassmaking; Hand Tools; Home and Personal } \\
\text { Care Products; Home-Textile; Horsepower Motors; } \\
\text { Hosiery; Internal Combustion Engine; Iron } \\
\text { Production; Lubricants; Lumber Milling; } \\
\text { Lumbering; Machine Manufacturing; machine } \\
\text { Tools; Machinery; Paper; Paper Mill; Precision } \\
\text { cutting tools; Precision Machines; Printing; } \\
\text { Recreation Products; Shingle Making; } \\
\text { Ropemaking; Saddletrees; Shipbuilding; Shipping; } \\
\text { Shoes; Silverware; Steel Stamps; Steelmaking; } \\
\text { Sugar Milling; Textile; Tool; Toys; Tractor } \\
\text { Assembly; Wooden Frames; Woodworking; } \\
\text { Woolen Mill }\end{array}$ & 53 \\
\hline Mining & $\begin{array}{l}\text { Cinnabar Mining; Coal Mining; Copper Mining; } \\
\text { General Mining; Gold Mining; Grain Milling; Iron } \\
\text { Mining; Iron Ore; Mica Spar }\end{array}$ & 23 \\
\hline
\end{tabular}




\begin{tabular}{|c|c|c|}
\hline $\begin{array}{l}\text { Power } \\
\text { Production }\end{array}$ & $\begin{array}{l}\text { Atomic Power; Electrical Power Generation; } \\
\text { Hydro Power; Hydro-Electric Power; Power } \\
\text { Generation; Steam Power }\end{array}$ & 7 \\
\hline Quarrying & Quarrying & 3 \\
\hline Recreation & Recreational Fishing & 5 \\
\hline Service & $\begin{array}{l}\text { Plumbing; Public Health; Tool and Equipment } \\
\text { Repair; Tourism }\end{array}$ & 2 \\
\hline Space & Aerospace; Space Exploration & 2 \\
\hline Technology & $\begin{array}{l}\text { Agriculture Technology; General Technology; } \\
\text { Medical Tech; Naval Warfare Technology; Steam } \\
\text { Technology }\end{array}$ & 6 \\
\hline Transportation & $\begin{array}{l}\text { General Maritime; Local Industry; Canals; General } \\
\text { Transportation; Locomotive; Rail Transportation; } \\
\text { Railroad; Roads; Steamboats; Trains }\end{array}$ & 37 \\
\hline
\end{tabular}

Online Survey Response Codes, Question \#34: If yes, how? (Hands-On Interaction)

\begin{tabular}{|l|l|l|}
\hline Code & Examples from Survey & $\begin{array}{l}\text { Code } \\
\text { Frequency }\end{array}$ \\
\hline Animals & $\begin{array}{l}\text { interacting with our heritage breed sheep; } \\
\text { fishing and clamming opportunities. }\end{array}$ & 2 \\
\hline Archaeology & $\begin{array}{l}\text { We have had volunteers help us with } \\
\text { preservation and archaeology of the site. }\end{array}$ & 1 \\
\hline Demonstrate Equipment & $\begin{array}{l}\text { Volunteers have the opportunity to run } \\
\text { physical demonstrations with mining } \\
\text { equipment and museum displays; Some } \\
\text { of our volunteers have done } \\
\text { demonstrations related to river industries, } \\
\text { such as creating crowfoot hooks which } \\
\text { were used to harvest mussels; } \\
\text { Demonstration cotton gin, interactive } \\
\text { auger system; Demonstration of mercury, }\end{array}$ & 18 \\
\hline
\end{tabular}




\begin{tabular}{|c|c|c|}
\hline & $\begin{array}{l}\text { demonstration of rotary furnace, } \\
\text { demonstration of mining artifacts to } \\
\text { visitors. }\end{array}$ & \\
\hline DNM & $\begin{array}{l}\text { No mining occurs at the museum. } \\
\text { Mining tools on display; Most of our } \\
\text { collection items stem from industrial } \\
\text { heritage }\end{array}$ & 2 \\
\hline Docenting & $\begin{array}{l}\text { volunteers are docents; We offer a } \\
\text { number of hands-on activities that our led } \\
\text { by our docents that are trained in the safe } \\
\text { operation of historic equipment; We also } \\
\text { have several other items the docents can } \\
\text { use to teach the public; }\end{array}$ & 5 \\
\hline Events & $\begin{array}{l}\text { Beyond restoration, our volunteers } \\
\text { operate equipment during events, and } \\
\text { those with trade skills hold classes using } \\
\text { our equipment and sell their crafts to } \\
\text { benefit the museum; We have also } \\
\text { recently added an Ice Harvest Festival to } \\
\text { our programming, which provides } \\
\text { additional interactive experiences; } \\
\text { Volunteers are eager and willing to share } \\
\text { their experiences and explain interesting } \\
\text { items they encounter in their work. } \\
\text { Community events are open to all, and } \\
\text { volunteers may also assist in planning and } \\
\text { preparing for events beyond their regular } \\
\text { projects. }\end{array}$ & 3 \\
\hline Exhibit Development & $\begin{array}{l}\text { Exhibit building; some work on exhibits; } \\
\text { work on displays }\end{array}$ & 3 \\
\hline Field Trips & $\begin{array}{l}\text { Offer our volunteers tours of the Copper } \\
\text { Queen Branch workings; We have a } \\
\text { presentation in our field trips that informs } \\
\text { on boat building history; We visit some } \\
\text { industrial sites still in operation and some } \\
\text { in the process of closing down }\end{array}$ & 2 \\
\hline
\end{tabular}




\begin{tabular}{|c|c|c|}
\hline Interact with Artifacts & $\begin{array}{l}\text { We have artifacts that are hands-on; } \\
\text { demonstration of mining artifacts to } \\
\text { visitors; sometimes work with objects; } \\
\text { permit limited handling of some of the } \\
\text { artifacts; }\end{array}$ & 9 \\
\hline Interact with Collections & $\begin{array}{l}\text { we are in the middle of a collections } \\
\text { audit, of all our items, by the volunteers; } \\
\text { working with the collection; Volunteering } \\
\text { with the collection; Our volunteers (and } \\
\text { the students working ere as well) work in } \\
\text { processing the collections }\end{array}$ & 2 \\
\hline Interact with Documents & $\begin{array}{l}\text { The sometimes work with old books; } \\
\text { Volunteers in our Rakow Library } \\
\text { contribute to the digitization of our } \\
\text { industrial heritage records; Our } \\
\text { volunteers (and the students working ere } \\
\text { as well) work in archives/library }\end{array}$ & 4 \\
\hline Interact with Workers & $\begin{array}{l}\text { We are located on an active cotton } \\
\text { plantation, so volunteers are able to } \\
\text { interact with the farmers; the experiences } \\
\text { of industry retirees; Volunteers assist } \\
\text { with museum's boat building shop; We } \\
\text { still operate our crane and some } \\
\text { volunteers actually work on the Brig } \\
\text { Niagara }\end{array}$ & 6 \\
\hline Interpretation & interpret the collection. & 1 \\
\hline Maintenance & $\begin{array}{l}\text { are restoring and maintaining vintage } \\
\text { railroad equipment and sites dating from } \\
\text { the } 1860 \text { s; they can work on maintenance } \\
\text { and restoration of locomotives and rolling } \\
\text { stock from a bygone era; They can work } \\
\text { on the trails right along the canal } \\
\text { waterway; maintenance and operation of } \\
\text { the campus and its demonstration railway, } \\
\text { streetcar line, and electric bus route. }\end{array}$ & 1 . \\
\hline
\end{tabular}




\begin{tabular}{|c|c|c|}
\hline Operate Equipment & $\begin{array}{l}\text { We operate historic } 10 \text { Stamp Mill from } \\
\text { the Golden Reef gold mine in our Cave } \\
\text { Creek Mining District; We run the mill } \\
\text { on steam power; During tours docents } \\
\text { operate all of the workstations }\end{array}$ & 23 \\
\hline Partnership & $\begin{array}{l}\text { We seek other organizations that offer } \\
\text { hands on or working historical processes. }\end{array}$ & 1 \\
\hline Physical Setting & $\begin{array}{l}\text { annually offer our volunteers tours of the } \\
\text { Copper Queen Branch workings; operate } \\
\text { historic } 10 \text { Stamp Mill; located on an } \\
\text { active cotton plantation; We have docents } \\
\text { at a life-saving station, a colonial house } \\
\text { involved in the bombardment of the town } \\
\text { in the War of 1812, and a menhaden } \\
\text { fishing net wheel; You can go on Old } \\
\text { Cabbage Head, the } 1913 \text { train }\end{array}$ & 8 \\
\hline Preservation/Conservation & $\begin{array}{l}\text { We have had volunteers help us with } \\
\text { preservation and archaeology of the site; } \\
\text { Research, demonstration, maintenance, } \\
\text { preservation, restoration; Research and } \\
\text { conservation work }\end{array}$ & 3 \\
\hline Research & $\begin{array}{l}\text { research \& writing; they are handling } \\
\text { artifacts and doing research }\end{array}$ & 6 \\
\hline Restoration & $\begin{array}{l}\text { restoring and maintaining vintage railroad } \\
\text { equipment and sites dating from the } \\
1860 \text { s; restoration of locomotives and } \\
\text { rolling stock from a bygone era; we do } \\
\text { restoration and building of new boats }\end{array}$ & 13 \\
\hline Sell Goods & $\begin{array}{l}\text { those with trade skills hold classes using } \\
\text { our equipment and sell their crafts to } \\
\text { benefit the museum. }\end{array}$ & 1 \\
\hline Teaching & $\begin{array}{l}\text { We have live action sawmill demos and } \\
\text { woodworking classes; As they teach and } \\
\text { work on displays; teaching local }\end{array}$ & 7 \\
\hline
\end{tabular}




\begin{tabular}{|l|l|l|}
\hline Tours & $\begin{array}{l}\text { elementary school students in old } \\
\text { classrooms with slate slabs to write on }\end{array}$ & $\begin{array}{l}\text { annually offer our volunteers tours of the } \\
\text { Copper Queen Branch workings; We } \\
\text { provide tours throughout the summer } \\
\text { months; We also provide enrichment } \\
\text { opportunities to our volunteers in the } \\
\text { form of periodic tours of local } \\
\text { manufacturers }\end{array}$ \\
\hline
\end{tabular}

Online Survey Response Codes, Question \#36: If yes, how? (Discuss Industrialization)

\begin{tabular}{|c|c|c|}
\hline Code & Code Meaning & $\begin{array}{l}\text { Code } \\
\text { Frequency }\end{array}$ \\
\hline $\begin{array}{l}\text { Anthropogenic } \\
\text { Landscape Change }\end{array}$ & $\begin{array}{l}\text { In the context of industrialization, the code } \\
\text { "Anthropogenic Landscape Change" pertains } \\
\text { to the alteration of the physical landscape by } \\
\text { humans for industrial purposes such as } \\
\text { farming, construction, waste retention and } \\
\text { removal, resource collection, etc. Respondents } \\
\text { to the survey mentioned pollution, } \\
\text { environmental destruction, deforestation, and } \\
\text { damage to environment through mining and } \\
\text { natural resource extraction. }\end{array}$ & 16 \\
\hline $\begin{array}{l}\text { Local/Regional } \\
\text { Economy }\end{array}$ & $\begin{array}{l}\text { In the context of industrialization, the code } \\
\text { "Local/Regional Economy" pertains to the } \\
\text { impact of industry on the local/regional } \\
\text { economy. Respondents to the survey } \\
\text { mentioned economic growth or a general } \\
\text { impact on their local/regional economic } \\
\text { health. }\end{array}$ & 3 \\
\hline $\begin{array}{l}\text { Introduction of } \\
\text { Technological } \\
\text { Innovations }\end{array}$ & $\begin{array}{l}\text { In the context of industrialization, the code } \\
\text { "Introduction of Technological Innovations" } \\
\text { pertains to the introduction and utilization of } \\
\text { new modes of production and labor } \\
\text { management, machinery, and transportation. }\end{array}$ & 28 \\
\hline
\end{tabular}




\begin{tabular}{|c|c|c|}
\hline & $\begin{array}{l}\text { Respondents to the survey mentioned the } \\
\text { introduction of the railroad, new labor } \\
\text { management practices, changing farming, } \\
\text { manufacturing, and lumbering technology that } \\
\text { in some cases replaced older technology and } \\
\text { methods. }\end{array}$ & \\
\hline Labor Issues & $\begin{array}{l}\text { In the context of industrialization, the code } \\
\text { "Labor Issues" pertains to child labor issues, } \\
\text { slavery and indentured servitude, employment } \\
\text { issues, the labor movement, strikes, union } \\
\text { disputed, and safety issues. }\end{array}$ & 6 \\
\hline Growth of Industry & $\begin{array}{l}\text { In the context of industrialization, the code } \\
\text { "Growth of Industry" pertains to the "Boom" } \\
\text { of industry or the increase in manufacturing, } \\
\text { natural resource mining, extraction, and } \\
\text { collection, an increase in jobs related to } \\
\text { specific industries, etc. }\end{array}$ & 14 \\
\hline $\begin{array}{l}\text { Community } \\
\text { Development }\end{array}$ & $\begin{array}{l}\text { In the context of industrialization, the code } \\
\text { "Community Development" pertains to the } \\
\text { development of communities through the } \\
\text { introduction of industry and/or an increase in } \\
\text { local/regional jobs and economic } \\
\text { opportunities. }\end{array}$ & 6 \\
\hline $\begin{array}{l}\text { Local/Regional } \\
\text { Populations }\end{array}$ & $\begin{array}{l}\text { In the context of industrialization, the code } \\
\text { "Local/Regional Populations" refers to the } \\
\text { mentioning of the daily life of industrialized } \\
\text { populations and the impacts of industry. } \\
\text { Respondents to the survey mentioned a change } \\
\text { in a community's daily life and the specific } \\
\text { impact of local and regional populations by } \\
\text { industrial activity. }\end{array}$ & 10 \\
\hline Economic Growth & $\begin{array}{l}\text { In the context of industrialization, the code } \\
\text { "Economic Growth" pertains to the success of } \\
\text { industry and companies whereby they } \\
\text { experience economic prosperity. Respondents } \\
\text { to the survey mentioned industry as leading to } \\
\text { an economic "golden age", economic growth }\end{array}$ & 3 \\
\hline
\end{tabular}




\begin{tabular}{|c|c|c|}
\hline & $\begin{array}{l}\text { and pollution, and the economic growth of } \\
\text { local businesses. }\end{array}$ & \\
\hline Decline in Industry & $\begin{array}{l}\text { In the context of industrialization, the code } \\
\text { "Decline in Industry" pertains to the decreased } \\
\text { success of local/regional industry and/or } \\
\text { companies. }\end{array}$ & 6 \\
\hline $\begin{array}{l}\text { Industrial } \\
\text { Diversification }\end{array}$ & $\begin{array}{l}\text { In the context of industrialization, the code } \\
\text { "Industrial Diversification" pertains to the } \\
\text { diversification of businesses/industries and/or } \\
\text { manufactured goods. Respondents to the } \\
\text { survey mentioned industrial decline leading to } \\
\text { diversification in businesses, an increase in } \\
\text { new needs (goods/services) due to an uptick in } \\
\text { industry, and new services and needs due to an } \\
\text { increase in trade and shipping. }\end{array}$ & 3 \\
\hline $\begin{array}{l}\text { Government } \\
\text { Involvement }\end{array}$ & $\begin{array}{l}\text { In the context of industrialization, the code } \\
\text { "Government Involvement" pertains to the } \\
\text { economic involvement of the government in } \\
\text { the development, regulation, and/or support of } \\
\text { specific industries. }\end{array}$ & 1 \\
\hline Disaster & $\begin{array}{l}\text { In the context of industrialization, the code } \\
\text { "Disaster" pertains to the physical destruction } \\
\text { of industrial property via human means, such } \\
\text { as a mine collapse or industrial accident. }\end{array}$ & 1 \\
\hline Creation of Jobs & $\begin{array}{l}\text { In the context of industrialization, the code } \\
\text { "Creation of Jobs" pertains to the influx of } \\
\text { industry and the subsequent need of employers } \\
\text { for employees. }\end{array}$ & 1 \\
\hline $\begin{array}{l}\text { Positive and } \\
\text { Negative Impacts }\end{array}$ & $\begin{array}{l}\text { In the context of industrialization, the code } \\
\text { "Positive and Negative Impacts" pertains to } \\
\text { the varying levels of impacts by } \\
\text { industrialization. }\end{array}$ & 1 \\
\hline $\begin{array}{l}\text { General Local } \\
\text { Industry }\end{array}$ & $\begin{array}{l}\text { In the context of industrialization, the code } \\
\text { "General Local Industry" pertains to the }\end{array}$ & 1 \\
\hline
\end{tabular}




\begin{tabular}{|c|c|c|}
\hline & $\begin{array}{l}\text { general and unspecified mentioning of local } \\
\text { industry by survey respondents. }\end{array}$ & \\
\hline Micro to Macro & $\begin{array}{l}\text { In the context of industrialization, the code } \\
\text { "Micro to Macro" pertains to the comparison } \\
\text { of industrialization in one context to that of a } \\
\text { larger one. }\end{array}$ & 2 \\
\hline Active Use & $\begin{array}{l}\text { In the context of industrialization, the code } \\
\text { "Active Use" pertains to industrial sites } \\
\text { continuing to be used for production or } \\
\text { habitation in a conventionally productive } \\
\text { manner, i.e., manufacturing, interpretation, } \\
\text { etc.. }\end{array}$ & 1 \\
\hline $\begin{array}{l}\text { General National } \\
\text { Industry }\end{array}$ & $\begin{array}{l}\text { In the context of industrialization, the code } \\
\text { "General National Industry" pertains to the } \\
\text { general and unspecified mentioning of national } \\
\text { industry by survey respondents. }\end{array}$ & 1 \\
\hline $\begin{array}{l}\text { Specific Local } \\
\text { Industry }\end{array}$ & $\begin{array}{l}\text { In the context of industrialization, the code } \\
\text { "Specific Local Industry" pertains to the } \\
\text { specific mentioning of a local industry by } \\
\text { survey respondents. }\end{array}$ & 23 \\
\hline $\begin{array}{l}\text { Specific National } \\
\text { Industry }\end{array}$ & $\begin{array}{l}\text { In the context of industrialization, the code } \\
\text { "Specific National Industry" pertains to the } \\
\text { specific mentioning of a national industry by } \\
\text { survey respondents. }\end{array}$ & 4 \\
\hline $\begin{array}{l}\text { Specific Regional } \\
\text { Industry }\end{array}$ & $\begin{array}{l}\text { In the context of industrialization, the code } \\
\text { "Specific Regional Industry" pertains to the } \\
\text { specific mentioning of a regional industry by } \\
\text { survey respondents. }\end{array}$ & 2 \\
\hline Exhibits & $\begin{array}{l}\text { Using exhibits to physically present the topic } \\
\text { of Industrialization }\end{array}$ & 9 \\
\hline Newsletter/Magazine & $\begin{array}{l}\text { Using newsletter/magazine(s) to physically } \\
\text { present the topic of Industrialization }\end{array}$ & 4 \\
\hline
\end{tabular}




\begin{tabular}{|l|l|l|}
\hline Talks/Speakers & $\begin{array}{l}\text { Using talks/speakers to physically present the } \\
\text { topic of Industrialization }\end{array}$ & 2 \\
\hline Videos & $\begin{array}{l}\text { Using videos to physically present the topic of } \\
\text { industrialization }\end{array}$ & 1 \\
\hline Tours & $\begin{array}{l}\text { Using tours to physically present the topic of } \\
\text { industrialization }\end{array}$ & 4 \\
\hline Meetings & $\begin{array}{l}\text { Using meetings to physically present the topic } \\
\text { of industrialization }\end{array}$ & 1 \\
\hline Programming & $\begin{array}{l}\text { Using programming to physically present the } \\
\text { topic of industrialization }\end{array}$ & 1 \\
\hline Social Media & $\begin{array}{l}\text { Using social media to present the topic of } \\
\text { industrialization }\end{array}$ & 2 \\
\hline Symposia & $\begin{array}{l}\text { Using symposia to present the topic of } \\
\text { industrialization }\end{array}$ & 1 \\
\hline Workshops & $\begin{array}{l}\text { Using workshops to present the topic of } \\
\text { industrialization }\end{array}$ & 1 \\
\hline Presentations & $\begin{array}{l}\text { Using presentations to present the topic of } \\
\text { industrialization }\end{array}$ & 2 \\
\hline Research & $\begin{array}{l}\text { Using research to present the topic of } \\
\text { industrialization }\end{array}$ & 1 \\
\hline Publications & $\begin{array}{l}\text { Using publications to present the topic of } \\
\text { industrialization }\end{array}$ & 1 \\
\hline
\end{tabular}

Online Survey Response Codes, Question \#38: If yes, how? (Discuss DeIndustrialization)

\begin{tabular}{|l|l|l|}
\hline Code & Code Meaning & $\begin{array}{l}\text { Code } \\
\text { Frequency }\end{array}$ \\
\hline $\begin{array}{l}\text { Economic } \\
\text { Changes }\end{array}$ & $\begin{array}{l}\text { In the context of de-industrialization, the code } \\
\text { "Economic Change" pertains to a change in the } \\
\text { economic standing of the industry, community, } \\
\text { nation, etc. Museums mentioning "Economic }\end{array}$ & 6 \\
\hline
\end{tabular}




\begin{tabular}{|c|c|c|}
\hline & $\begin{array}{l}\text { Change" discuss topics that include (but are not } \\
\text { limited to) economic health, industrial economy, } \\
\text { economic disparity, and the industries impact on } \\
\text { the local economy. }\end{array}$ & \\
\hline $\begin{array}{l}\text { Anthropogenic } \\
\text { Landscape } \\
\text { Change }\end{array}$ & $\begin{array}{l}\text { In the context of de-industrialization, the code } \\
\text { "Anthropogenic Landscape Change" pertains to } \\
\text { the human impact on the landscape. Respondents } \\
\text { to the survey mentioned deforestation and } \\
\text { pollution as part of their museum's discussion of } \\
\text { de-industrialization. }\end{array}$ & 3 \\
\hline Transition & $\begin{array}{l}\text { In the context of de-industrialization, the code } \\
\text { "Transition" pertains to a labor, social, industrial, } \\
\text { or environmental change. }\end{array}$ & 12 \\
\hline $\begin{array}{l}\text { Environmental } \\
\text { Reclamation }\end{array}$ & $\begin{array}{l}\text { In the context of de-industrialization, the code } \\
\text { "Environmental Reclamation" refers to } \\
\text { restoration, conservation, preservation, and } \\
\text { alteration of the environment. Museum } \\
\text { mentioning "Environmental Reclamation" discuss } \\
\text { how groups and organizations have worked to } \\
\text { improve the quality of the environment for safe } \\
\text { human and animal occupation. }\end{array}$ & 3 \\
\hline $\begin{array}{l}\text { Decline of } \\
\text { Industry }\end{array}$ & $\begin{array}{l}\text { In the context of de-industrialization, the code } \\
\text { "Decline of Industry" refers to the decline of a } \\
\text { local/regional/national industry. Museum } \\
\text { responses for this code mention the end of an } \\
\text { industry, its decline, destruction of industrial } \\
\text { sites, industrial downturn, etc. }\end{array}$ & 14 \\
\hline $\begin{array}{l}\text { Local/Regional } \\
\text { Populations }\end{array}$ & $\begin{array}{l}\text { In the context of de-industrialization, the code } \\
\text { "Local/Regional Populations" refers to a } \\
\text { responding museum mentioning workers and } \\
\text { populations. Museums using this code also } \\
\text { discussed population loss during migrations and } \\
\text { mechanization. }\end{array}$ & 6 \\
\hline $\begin{array}{l}\text { Introduction of } \\
\text { Technological } \\
\text { Innovations }\end{array}$ & $\begin{array}{l}\text { In the context of de-industrialization, the code } \\
\text { "Introduction of Technological Innovations" } \\
\text { refers to the mechanization of industry, the }\end{array}$ & 7 \\
\hline
\end{tabular}




\begin{tabular}{|c|c|c|}
\hline & $\begin{array}{l}\text { introduction of new forms of transportation, } \\
\text { manufacturing, and labor. Museums using this } \\
\text { code discussed why these innovations were } \\
\text { necessary, the loss of tactile knowledge relating } \\
\text { to an industrial process for manufacturing or } \\
\text { crafting products, or the change in labor values as } \\
\text { machines became increasingly present in } \\
\text { American factories. }\end{array}$ & \\
\hline $\begin{array}{l}\text { Adaptation and } \\
\text { Renewal }\end{array}$ & $\begin{array}{l}\text { In the context of de-industrialization, the code } \\
\text { "Adaptation and Renewal" refers to the ability of } \\
\text { nature to adapt to the industrial landscape and } \\
\text { renew itself. }\end{array}$ & 1 \\
\hline $\begin{array}{l}\text { Industrial } \\
\text { Diversification }\end{array}$ & $\begin{array}{l}\text { In the context of de-industrialization, the code } \\
\text { "Industrial Diversification" refers to a } \\
\text { community's change from long held industrial or } \\
\text { economic dependency to other markets or } \\
\text { industries due to industrial or economic decline. } \\
\text { Museums using this code discussed the } \\
\text { movement of communities to new markets, the } \\
\text { redevelopment of a community's economy, an } \\
\text { industries diversification in products and } \\
\text { manufactured goods, and a movement to new } \\
\text { forms of labor. }\end{array}$ & 5 \\
\hline Labor Issues & $\begin{array}{l}\text { In the context of de-industrialization, the code } \\
\text { "Labor Issues" refers to the mention of labor } \\
\text { movements, strikes, and economic issues that } \\
\text { occur because of the decline, maintenance, or } \\
\text { growth of industry. Museums using this code } \\
\text { discussed displaced labor, impacts on } \\
\text { employment due to industrial decline, and a } \\
\text { reduction in work value associated with factory } \\
\text { laborers. }\end{array}$ & 7 \\
\hline Industrial Sites & $\begin{array}{l}\text { In the context of de-industrialization, the code } \\
\text { "Industrial Sites" refers to the mention of } \\
\text { physical structures, such as the reuse of older } \\
\text { factory buildings, renewal of canals, and ghost } \\
\text { towns. }\end{array}$ & 3 \\
\hline
\end{tabular}




\begin{tabular}{|c|c|c|}
\hline Urban Renewal & $\begin{array}{l}\text { In the context of de-industrialization, the code } \\
\text { "Urban Renewal" refers to the act of } \\
\text { reconstruction and redevelopment of } \\
\text { economically blighted areas. }\end{array}$ & 1 \\
\hline $\begin{array}{l}\text { Community } \\
\text { Development }\end{array}$ & $\begin{array}{l}\text { In the context of de-industrialization, the code } \\
\text { "Community Development" refers to the } \\
\text { rebranding, coming together, and moving forward } \\
\text { of a community being impacted by industrial or } \\
\text { economic decline. }\end{array}$ & 1 \\
\hline Exhibits & $\begin{array}{l}\text { In the context of de-industrialization, the code } \\
\text { "Exhibits" refers to the museums method of } \\
\text { presenting the topic of de-industrialization } \\
\text { through exhibit content. }\end{array}$ & 5 \\
\hline Presentations & $\begin{array}{l}\text { In the context of de-industrialization, the code } \\
\text { "Presentations" refers to the respondent's } \\
\text { museums method of presenting the topic of de- } \\
\text { industrialization through event programming. }\end{array}$ & 3 \\
\hline Meetings & $\begin{array}{l}\text { In the context of de-industrialization, the code } \\
\text { "Meetings" refers to respondent's museums } \\
\text { method of presenting the topic of de- } \\
\text { industrialization through staff/volunteer meetings. }\end{array}$ & 1 \\
\hline Social Media & $\begin{array}{l}\text { In the context of de-industrialization, the code } \\
\text { "Social Media" refers to respondent's museums } \\
\text { method of presenting the topic of de- } \\
\text { industrialization through social media. }\end{array}$ & 2 \\
\hline Tours & $\begin{array}{l}\text { In the context of de-industrialization, the code } \\
\text { "Tours" refers to the respondent's museums } \\
\text { method of presenting the topic of de- } \\
\text { industrialization through tours and walkthroughs. }\end{array}$ & 3 \\
\hline Speakers/Lectures & $\begin{array}{l}\text { In the context of de-industrialization, the code } \\
\text { "Speakers/Lectures" refers to the respondent's } \\
\text { museums method of presenting the topic of de- } \\
\text { industrialization through speakers and lecturers. }\end{array}$ & 1 \\
\hline Symposia & $\begin{array}{l}\text { In the context of de-industrialization, the code } \\
\text { "Symposia" refers to the respondent's museums }\end{array}$ & 1 \\
\hline
\end{tabular}




\begin{tabular}{|l|l|l|}
\hline & $\begin{array}{l}\text { method of presenting the topic of de- } \\
\text { industrialization through symposiums. }\end{array}$ & \\
\hline Workshops & $\begin{array}{l}\text { In the context of de-industrialization, the code } \\
\text { "Workshops" refers to the respondent's museums } \\
\text { method of presenting the topic of de- } \\
\text { industrialization through workshops. }\end{array}$ & 1 \\
\hline Research & $\begin{array}{l}\text { In the context of de-industrialization, the code } \\
\text { "Research" refers to the respondent's museums } \\
\text { method of presenting the topic of de- } \\
\text { industrialization through research and academic } \\
\text { work. }\end{array}$ & 1 \\
\hline
\end{tabular}

Interviews with Trained Museum Professionals, Response Codes, Question \#12: How do you recruit volunteers?

\begin{tabular}{|l|l|l|}
\hline Code & Examples from Survey/Interviews & $\begin{array}{l}\text { Code } \\
\text { Frequency }\end{array}$ \\
\hline Word of Mouth & $\begin{array}{l}\text { In our small community, word-of-mouth; } \\
\text { contacts; Other Volunteers }\end{array}$ & 4 \\
\hline $\begin{array}{l}\text { Community } \\
\text { Outreach }\end{array}$ & $\begin{array}{l}\text { Well, we're doing some outreach to the } \\
\text { community }\end{array}$ & 2 \\
\hline Social Media & $\begin{array}{l}\text { we also have a Facebook page where were } \\
\text { always asking for volunteers }\end{array}$ & 3 \\
\hline AmeriCorps Member & $\begin{array}{l}\text { In the past, we've gone through AmeriCorps } \\
\text { and they basically assign a volunteer } \\
\text { coordinator to the museum }\end{array}$ & 1 \\
\hline $\begin{array}{l}\text { Reaching out to } \\
\text { other organizations }\end{array}$ & $\begin{array}{l}\text { Reaching out to other groups, like church } \\
\text { groups and youth groups. I think we've } \\
\text { reached out to the parent-teacher association } \\
\text { in the past }\end{array}$ & 2 \\
\hline $\begin{array}{l}\text { Visitor to the IHMO } \\
\text { become Interested }\end{array}$ & $\begin{array}{l}\text { Most are from tours; Visitor education; } \\
\text { respond to visitor inquiries; Respond to those } \\
\text { expressing interest. Directly asking people }\end{array}$ & 2 \\
\hline
\end{tabular}




\begin{tabular}{|l|l|l|}
\hline & $\begin{array}{l}\text { who come to the museum; We distribute } \\
\text { volunteer applications at our kiosk; Walk-ins }\end{array}$ & \\
\hline $\begin{array}{l}\text { IHMO's Staff } \\
\text { Attends Networking }\end{array}$ & networking & 1 \\
\hline $\begin{array}{l}\text { Posters, Flyers, } \\
\text { Signs, Newsletters, } \\
\text { and Ad Prints }\end{array}$ & $\begin{array}{l}\text { we often we'll put out a press release, we'll } \\
\text { often say we're looking for volunteers; }\end{array}$ & 1 \\
\hline Special Events & $\begin{array}{l}\text { it's usually likely folks just getting involved } \\
\text { through an event }\end{array}$ & 1 \\
\hline Third Party Website & $\begin{array}{l}\text { VolunteerMatch; online postings; Google } \\
\text { Ads; local volunteer consortium website }\end{array}$ & 1 \\
\hline $\begin{array}{l}\text { Contact Local } \\
\text { Universities }\end{array}$ & $\begin{array}{l}\text { work with the area colleges to recruit unpaid } \\
\text { college interns }\end{array}$ & 1 \\
\hline Emailing & $\begin{array}{l}\text { email; email blast } \\
\text { IhMOugh our website; application available on }\end{array}$ & 1 \\
\hline IHMebsite & $\begin{array}{l}\text { Througebsite; online postings } \\
\text { our we }\end{array}$ & 1 \\
\hline
\end{tabular}

Interviews with Trained Museum Professionals, Response Codes, Question \#13: What do volunteers do at your museum?

\begin{tabular}{|l|l|l|}
\hline Code & Examples from Interviews & $\begin{array}{l}\text { Code } \\
\text { Frequency }\end{array}$ \\
\hline Docenting & $\begin{array}{l}\text { we call docents that are essentially tour } \\
\text { guides for the different exhibits; being a } \\
\text { docent }\end{array}$ & 3 \\
\hline Exhibit Work & $\begin{array}{l}\text { program assistants, things like an intern } \\
\text { helping us put the exhibit together }\end{array}$ & 3 \\
\hline Fundraising & $\begin{array}{l}\text { grant writing as well, } \\
\text { Hospitality }\end{array}$ & $\begin{array}{l}\text { then they're also helpers at the information } \\
\text { desks; hey talk to people when they come } \\
\text { to the door when they come in }\end{array}$ \\
\hline
\end{tabular}




\begin{tabular}{|c|c|c|}
\hline Maintenance & $\begin{array}{l}\text { little baby tiny army of people who do } \\
\text { museum repair, window repair, or helping } \\
\text { you, plumbing repairs, the physical, } \\
\text { structural, taking care of the building that } \\
\text { way. }\end{array}$ & 4 \\
\hline IHMO Store Assistant & $\begin{array}{l}\text { take money to pay for something if people } \\
\text { buy anything, we have for sale }\end{array}$ & 1 \\
\hline Office Assistant & $\begin{array}{l}\text { developing and implementing policies and } \\
\text { procedures into everyday practice }\end{array}$ & 1 \\
\hline Research library & $\begin{array}{l}\text { volunteers and interns are either involved } \\
\text { in research or programming, so their either } \\
\text { conducting research or the supervision of } \\
\text { it by a curators or staff member }\end{array}$ & 4 \\
\hline Special Events/Programs & $\begin{array}{l}\text { volunteers and interns are involved in } \\
\text { programming, so their supervised by a } \\
\text { curator or staff member; working on a } \\
\text { program or helping to figure out how were } \\
\text { going to get a guest speaker somewhere to } \\
\text { talk; organizing a conference }\end{array}$ & 7 \\
\hline Tours & $\begin{array}{l}\text { we call docents that are essentially tour } \\
\text { guides for the different exhibits; they can } \\
\text { either be given tours to the general public } \\
\text { by staffing the exhibits for periods of time; } \\
\text { being a tour guide; guiding tour }\end{array}$ & 4 \\
\hline $\begin{array}{l}\text { Web Design and Social } \\
\text { Media }\end{array}$ & $\begin{array}{l}\text { promoting that on social media and } \\
\text { through constant contact. website } \\
\text { development, Facebook management, } \\
\text { press releases and event promotion }\end{array}$ & 3 \\
\hline Collections Management & $\begin{array}{l}\text { dealing with the collection, maintaining it, } \\
\text { figuring out what to do with it, how to } \\
\text { keep it safe; they check in any materials } \\
\text { that come in }\end{array}$ & 4 \\
\hline Administration & the board meetings, stuff like that, & 1 \\
\hline
\end{tabular}


Interviews with Trained Museum Professionals, Response Codes, Question \#19: What are they? (Volunteer Benefits/Rewards)

\begin{tabular}{|c|c|c|}
\hline Code & Examples from Interviews/Survey & $\begin{array}{l}\text { Code } \\
\text { Frequency }\end{array}$ \\
\hline $\begin{array}{l}\text { Volunteer Appreciation } \\
\text { Events }\end{array}$ & $\begin{array}{l}\text { Recognition during National Volunteer } \\
\text { Appreciation Week; Annual Meeting } \\
\text { Recognition; Annual Appreciation Lunch; } \\
\text { recognition at annual Volunteer Awards } \\
\text { Night; Weekly Volunteers get birthday } \\
\text { parties. }\end{array}$ & 2 \\
\hline $\begin{array}{l}\text { Free Admission to the } \\
\text { IHMO's } \\
\text { programs/events/special } \\
\text { events }\end{array}$ & $\begin{array}{l}\text { Free Admission to Member only events; } \\
\text { Free Admission to certain museum events; } \\
\text { Free Admission to special events based on } \\
\text { hours volunteered; invitations to member- } \\
\text { only events }\end{array}$ & 1 \\
\hline Free Parking & Free Parking & 1 \\
\hline $\begin{array}{l}\text { Free Family/Friends } \\
\text { Admission to nearby } \\
\text { Museums }\end{array}$ & Family pass to get into other museums & 1 \\
\hline $\begin{array}{l}\text { Volunteer only Social } \\
\text { Gathering }\end{array}$ & $\begin{array}{l}\text { End of the season get together; field trips; } \\
\text { Organized enrichment outings; volunteer- } \\
\text { only social functions; Weekly Fellowship; } \\
\text { any food left over from events; free water } \\
\text { and "snacks" while they are working their } \\
\text { shift driving the tractor over the causeway } \\
\text { or being a docent for the tug or the } \\
\text { museum; A couple lunches throughout the } \\
\text { year; annual dinner hosted by local } \\
\text { businessman; Complimentary seat at } \\
\text { Annual Fundraising Gala; Potlucks }\end{array}$ & 3 \\
\hline $\begin{array}{l}\text { Free Admission to } \\
\text { IHMO/Site }\end{array}$ & $\begin{array}{l}\text { entry into our historic sites; Free } \\
\text { admission; reciprocal pass privileges; free } \\
\text { admission for family and friends; free } \\
\text { museum admission to the volunteer and }\end{array}$ & 1 \\
\hline
\end{tabular}




\begin{tabular}{|c|c|c|}
\hline & $\begin{array}{l}\text { their immediate family; volunteers to bring } \\
24 \text { guests ( } 2 / \text { month) at no charge }\end{array}$ & \\
\hline $\begin{array}{l}\text { Non-Monetary } \\
\text { Volunteer Appreciation } \\
\text { Awards }\end{array}$ & $\begin{array}{l}\text { Event volunteers get 'bling'--a handmade } \\
\text { token.; Lots of hand-written thank you } \\
\text { notes (sometimes accompanied by candy).; } \\
\text { Name recognition on trail signs }\end{array}$ & 3 \\
\hline Gift Store Discount & Gift Store Discount & 2 \\
\hline $\begin{array}{l}\text { Discounts to the IHMO's } \\
\text { programs/events/special } \\
\text { events }\end{array}$ & $\begin{array}{l}\text { discounts to public programs and special } \\
\text { events; Program discounts; Stipend for } \\
\text { Tours }\end{array}$ & 1 \\
\hline Volunteer Name Tag & Volunteer Name Tag & 1 \\
\hline Free IHMO Membership & $\begin{array}{l}\text { free annual membership for } 50 \text { or more } \\
\text { volunteer hours in a year; free membership } \\
\text { after serving } 25 \text { hours each year. }\end{array}$ & 1 \\
\hline
\end{tabular}

Interviews with Trained Museum Professionals, Response Codes, Question \#20: How involved is the surrounding community with the museum and its administration?

\begin{tabular}{|l|l|l|}
\hline Code & Examples from Interviews & $\begin{array}{l}\text { Code } \\
\text { Frequency }\end{array}$ \\
\hline $\begin{array}{l}\text { Currently Actively } \\
\text { Involved }\end{array}$ & $\begin{array}{l}\text { We are well integrated in the community; } \\
\text { community is extremely interested in the } \\
\text { museum activities; Very involved; } \\
\text { community is very supportive of the } \\
\text { organization with a broad range of } \\
\text { members and financial backers; Getting } \\
\text { better all the time }\end{array}$ & 3 \\
\hline $\begin{array}{l}\text { Currently Moderately } \\
\text { Involved }\end{array}$ & $\begin{array}{l}\text { In a small rural community of less than } \\
5,000, \text { we have 80 volunteers, 1.6\% of } \\
\text { our community; Moderate; Not as much } \\
\text { with Administration aspects, but } \\
\text { definitely with support and interest in }\end{array}$ & \\
\hline
\end{tabular}




\begin{tabular}{|l|l|}
\hline $\begin{array}{l}\text { Currently Minimally } \\
\text { Involved }\end{array}$ & $\begin{array}{l}\text { bringing folks there from out of town, } \\
\text { etc. }\end{array}$ \\
\hline $\begin{array}{l}\text { Involvement has gone down } \\
\text { significantly; The community is not } \\
\text { involved a great deal; Hands off. We get } \\
\text { visitors, but they are not regulars; Almost } \\
\text { no involvement from surrounding } \\
\text { community; The immediate surrounding } \\
\text { neighborhood is uninvolved; The public's } \\
\text { awareness of our organization is not } \\
\text { good }\end{array}$ & 3 \\
\hline
\end{tabular}

Interviews with Trained Museum Professionals, Response Codes, Question \#21: What do you think are the motivations behind your volunteers to volunteer?

\begin{tabular}{|c|c|c|}
\hline Code & Examples from the Interviews/Survey & $\begin{array}{l}\text { Code } \\
\text { Frequency }\end{array}$ \\
\hline Experience/Learning & $\begin{array}{l}\text { Experience for Resume; seeking to learn; } \\
\text { learn skills; class credit; They are } \\
\text { lifelong learners; acquiring new } \\
\text { transferrable skills; Mental stimulation; } \\
\text { place with many opportunities to develop } \\
\text { new skills learn and research; fulfillment } \\
\text { of various community service } \\
\text { requirements }\end{array}$ & 4 \\
\hline Local Community Pride & Pride in Community; Local pride & 2 \\
\hline A Sense of Belonging & $\begin{array}{l}\text { a sense of belonging to our museum } \\
\text { family; sense of community with other } \\
\text { volunteers; Sense of community; social } \\
\text { activity; The society is a main pillar of } \\
\text { the community; socialize; Desire to be } \\
\text { involved; socialization; the friendships } \\
\text { that they have made with other } \\
\text { volunteers and staff over the years; } \\
\text { wanting a social experience; volunteers } \\
\text { love to restore machinery and have a } \\
\text { club; a desire to be a part of it; }\end{array}$ & 5 \\
\hline
\end{tabular}




\begin{tabular}{|c|c|c|}
\hline & $\begin{array}{l}\text { relationships with other volunteers, staff } \\
\text { and board; being involved in their local } \\
\text { community; Wanting to be involved in } \\
\text { community; social relationships; we are a } \\
\text { family; they like the fact that we have a } \\
\text { Volunteer Council with officers and } \\
\text { monthly meetings; a desire for social } \\
\text { engagement or peer pressure; } \\
\text { camaraderie; value the social aspects of } \\
\text { volunteering.; they like socializing with } \\
\text { each other and getting out of the house; } \\
\text { ant to be involved in something; }\end{array}$ & \\
\hline Help Local Community & $\begin{array}{l}\text { Volunteers want to help the local } \\
\text { community; the role of the museum } \\
\text { important in the life of the community; } \\
\text { Tourism is one of the last major } \\
\text { industries in the county; The society is a } \\
\text { main pillar of the community; Give back } \\
\text { to the community; Trying to promote the } \\
\text { area; being involved in their local } \\
\text { community }\end{array}$ & 2 \\
\hline Fulfilling Work & $\begin{array}{l}\text { They find their work fulfilling; } \\
\text { Interesting work; The personal } \\
\text { satisfaction resulting from volunteerism }\end{array}$ & 1 \\
\hline Interest in History & $\begin{array}{l}\text { interested in history; love of history; } \\
\text { Passion for history; deep colonial history; } \\
\text { They love history; enjoy history; A keen } \\
\text { interest in history; Passion for history }\end{array}$ & 4 \\
\hline Like the IHMO & $\begin{array}{l}\text { Like the Museum; Their love of the } \\
\text { museum; People really love the museum; } \\
\text { an institution they admire }\end{array}$ & 3 \\
\hline Interest in Local History & $\begin{array}{l}\text { Interest in local history; Interested in } \\
\text { local history; they want to get to know } \\
\text { the local history; Interest in history, } \\
\text { especial of local settlement life; love of } \\
\text { the area's history; engaging history of the } \\
\text { museum; they like to share stories about }\end{array}$ & 2 \\
\hline
\end{tabular}




\begin{tabular}{|c|c|c|}
\hline & $\begin{array}{l}\text { local history; enthusiasm for local } \\
\text { history; individuals who value the history } \\
\text { or our region }\end{array}$ & \\
\hline Personal Heritage & $\begin{array}{l}\text { volunteers often have a personal } \\
\text { connection to former employees; } \\
\text { Personal connection; They are proud of } \\
\text { their heritage; they have a personal } \\
\text { connection to the maritime world; A } \\
\text { personal connection to the industry and } \\
\text { related trades; their families part in it.; } \\
\text { volunteers usually have a connection to } \\
\text { the regions past }\end{array}$ & 1 \\
\hline Preservation & $\begin{array}{l}\text { feel like the museum is part of their } \\
\text { heritage that they want to preserve; } \\
\text { retired skilled craftsman who want to } \\
\text { help save a Historic Foundry; many also } \\
\text { are interested in our Historical } \\
\text { Preservation activities; Saving Important } \\
\text { History; preserving a significant part of } \\
\text { our nation's industrial heritage; desire to } \\
\text { preserve; An appreciation and interest in } \\
\text { industrial archeology; Keeping the old } \\
\text { ways new again. }\end{array}$ & 1 \\
\hline Looking for Purpose & $\begin{array}{l}\text { looking for something to do; to have } \\
\text { "something" to do; boredom; volunteers } \\
\text { who want to stay busy, active and } \\
\text { contribute; more time to spare for } \\
\text { volunteerism in retirement; Wanting to } \\
\text { be useful; wanting a purpose with their } \\
\text { free time; need to stay active and } \\
\text { engaged; people who are looking for } \\
\text { something to do to fill an hour or two a } \\
\text { week }\end{array}$ & 2 \\
\hline Previous experiences & $\begin{array}{l}\text { technical (professional) connection; } \\
\text { retired skilled craftsman who want to } \\
\text { help save a Historic Foundry; } \\
\text { professional interest; they have a } \\
\text { personal connection to the maritime }\end{array}$ & 1 \\
\hline
\end{tabular}




\begin{tabular}{|c|c|c|}
\hline & $\begin{array}{l}\text { world; previous experience related to } \\
\text { museum themes; personal connection to } \\
\text { the industry and related trades; nostalgia }\end{array}$ & \\
\hline Industrial Assets & $\begin{array}{l}\text { repairing tractors; Love of trains is } \\
\text { usually foremost; Love of trains; helping } \\
\text { animals; Most of them are looking to } \\
\text { participate in a largely extinct industrial } \\
\text { world; sharing their skills; building; } \\
\text { volunteers love to restore machinery; } \\
\text { interest in the collection; They're } \\
\text { interested in railroads; some like working } \\
\text { behind the scenes with primary source } \\
\text { documents and/or helping us digitize } \\
\text { these documents; volunteers first became } \\
\text { involved during construction of } \\
\text { schooners in our shipyard or the } \\
\text { adjoining shipyard; Interest in the } \\
\text { materials / project; Passion for trains; } \\
\text { Most get a lot of pleasure out of } \\
\text { watching children who frequently } \\
\text { experience their first train ride with us; } \\
\text { research about different artifact and } \\
\text { displays; learn how things were done in } \\
\text { the past.; fan of antiques or trains or } \\
\text { trolleys; exhibits (railroads, Civil War, } \\
\text { local history); fan of antiques or trains or } \\
\text { trolleys }\end{array}$ & 1 \\
\hline Training & $\begin{array}{l}\text { quick turn-around on answering and } \\
\text { training. }\end{array}$ & 1 \\
\hline General Support & $\begin{array}{l}\text { To make a better experience for others; } \\
\text { help the museum; desire to help; } \\
\text { opportunity to engage in something } \\
\text { they're really interested in; a desire to see } \\
\text { the museum succeed; contribute; want to } \\
\text { support the Museum; enjoy giving back; } \\
\text { Philanthropy; They want to be helpful to } \\
\text { an organization they care about; a desire }\end{array}$ & 4 \\
\hline
\end{tabular}




\begin{tabular}{|c|c|c|}
\hline & $\begin{array}{l}\text { to "give back" (especially in the case of } \\
\text { younger volunteers); fundraising }\end{array}$ & \\
\hline Teaching/Sharing & $\begin{array}{l}\text { educating visitors; working with kids; } \\
\text { sharing that passion with others; proud of } \\
\text { their heritage and want to share it; they } \\
\text { like to teach children; increase } \\
\text { accessibility to the information; the } \\
\text { ability to continue to use their vast } \\
\text { knowledge in a charitable way; enjoy } \\
\text { working with our visitors inc. school } \\
\text { children.; they enjoy meeting visitors } \\
\text { from around the world }\end{array}$ & 3 \\
\hline IHMO's Mission/Goals & $\begin{array}{l}\text { One is sharing in the goal of our } \\
\text { museum; care about our cause; Vision } \\
\text { for growth; They believe in what we do; } \\
\text { They like the mission of the museum; } \\
\text { find our mission important to share; are } \\
\text { motivated by the mission of the Museum }\end{array}$ & 2 \\
\hline $\begin{array}{l}\text { Interest in } \\
\text { Nature/Environment }\end{array}$ & $\begin{array}{l}\text { they're interested in nature, the } \\
\text { environment, and the combination of the } \\
\text { two }\end{array}$ & 1 \\
\hline Enthusiasts/Hobbyists & but they are hobbyists & 1 \\
\hline Employer Support & $\begin{array}{l}\text { it feels like an appropriate activity that } \\
\text { one's employer would find interesting and } \\
\text { would support }\end{array}$ & 1 \\
\hline Gardening & $\begin{array}{l}\text { there are people who love gardening and } \\
\text { we've got a huge garden so that's a way } \\
\text { they can help out }\end{array}$ & 1 \\
\hline
\end{tabular}

Interviews with Trained Museum Professionals, Response Codes, Question \#23: What does industrial heritage mean to you?

\begin{tabular}{|l|l|l|}
\hline Code & $\begin{array}{l}\text { Examples from } \\
\text { Interviews/Surveys }\end{array}$ & Code Meaning Code \\
& Frequency \\
\hline
\end{tabular}




\begin{tabular}{|c|c|c|c|}
\hline $\begin{array}{l}\text { G-Celebration of } \\
\text { Industrial Heritage }\end{array}$ & $\begin{array}{l}\text { The celebration of historic } \\
\text { enterprises; Industrial heritage } \\
\text { means celebrating a once } \\
\text { critical part of the national } \\
\text { economy that has now been } \\
\text { largely outsourced to other } \\
\text { countries and overwhelmed } \\
\text { by a white-collar service } \\
\text { economy.; Recognition and } \\
\text { exploration of the key role } \\
\text { that industry (and the people } \\
\text { who worked there) had in the } \\
\text { development of our } \\
\text { communities }\end{array}$ & N/A & 1 \\
\hline G-Industry & $\begin{array}{l}\text { A history of the following } \\
\text { commercial activities, } \\
\text { especially when they played a } \\
\text { significant role in a location's } \\
\text { economy: manufacturing new } \\
\text { goods; repairing damaged } \\
\text { goods (automotive repair), } \\
\text { transporting goods (shipping, } \\
\text { trucking), infrastructure } \\
\text { improvements, and/or natural } \\
\text { resource extraction and } \\
\text { refining (mining, quarrying, } \\
\text { lumber).; Manufacturing, } \\
\text { transportation, heavy } \\
\text { industry; The physical } \\
\text { remains of industrial sites, } \\
\text { whether mills, mining sites, } \\
\text { etc.; physical remains of the } \\
\text { history of technology and } \\
\text { industry, such as } \\
\text { manufacturing and mining } \\
\text { sites, as well as power and } \\
\text { transportation infrastructure; } \\
\text { The physical remains of } \\
\text { industrial sites, whether mills, } \\
\text { mining sites, etc.; History of }\end{array}$ & N/A & 2 \\
\hline
\end{tabular}




\begin{tabular}{|c|c|c|c|}
\hline & $\begin{array}{l}\text { local manufacturing?; } \\
\text { physical remains of the } \\
\text { history of technology and } \\
\text { industry, such as } \\
\text { manufacturing and mining } \\
\text { sites, as well as power and } \\
\text { transportation infrastructure; } \\
\text { How once worked in the US, } \\
\text { the products they made, how } \\
\text { that has changes and how the } \\
\text { industrial artifacts reveal } \\
\text { stories of the people who } \\
\text { owned them, made them, and } \\
\text { used them; produce products } \\
\text { that add value to raw } \\
\text { materials.; Manufacturing, } \\
\text { transportation, heavy } \\
\text { industry; the sites and } \\
\text { material culture that help to } \\
\text { tell the story of our } \\
\text { manufacturing past }\end{array}$ & & \\
\hline G-History of Industry & $\begin{array}{l}\text { The history of industry; } \\
\text { history of industrial } \\
\text { technology; History of past } \\
\text { industry; Physical remains of } \\
\text { the history of technology and } \\
\text { industry.; history of tech, } \\
\text { power, transportation, and } \\
\text { industry; The history of } \\
\text { industry in a town or } \\
\text { community; The history and } \\
\text { artifacts associated with } \\
\text { industry and work.; The } \\
\text { history of industry in America } \\
\text { in different sectors.; The } \\
\text { history of industry; It's } \\
\text { remembering where an } \\
\text { industry began and how that } \\
\text { affected the area.; History of } \\
\text { mining, factories and the }\end{array}$ & N/A & 1 \\
\hline
\end{tabular}




\begin{tabular}{|c|c|c|c|}
\hline & $\begin{array}{l}\text { people associated with them; } \\
\text { History of mining, factories } \\
\text { and the people associated } \\
\text { with them; history of mining, } \\
\text { economic decline, scale of } \\
\text { work; Industrial Heritage is } \\
\text { the interpretation of tradition } \\
\text { or history of manufacturing, } \\
\text { the skills involved in making } \\
\text { things, the people \& } \\
\text { businesses that manufacture } \\
\text { items and the products } \\
\text { themselves.; The preservation } \\
\text { and interpretation of artifacts, } \\
\text { stories, and places related to } \\
\text { the history of technology, } \\
\text { manufacturing, and } \\
\text { engineering. }\end{array}$ & & \\
\hline G-Workforce & $\begin{array}{l}\text { History of industry, including } \\
\text { entrepreneurship, innovation, } \\
\text { the workforce, immigration, } \\
\text { and organized labor. }\end{array}$ & N/A & 1 \\
\hline G-Industrial Artifacts & $\begin{array}{l}\text { artifacts from past industry.; } \\
\text { artifacts and memories from } \\
\text { the history of local industry } \\
\text { rise and fall; How once } \\
\text { worked in the US, the } \\
\text { products they made, how that } \\
\text { has changes and how the } \\
\text { industrial artifacts reveal } \\
\text { stories of the people who } \\
\text { owned them, made them, and } \\
\text { used them; The history and } \\
\text { artifacts associated with } \\
\text { industry and work.; The } \\
\text { preservation and } \\
\text { interpretation of artifacts, } \\
\text { stories, and places related to } \\
\text { the history of technology, }\end{array}$ & N/A & 2 \\
\hline
\end{tabular}




\begin{tabular}{|c|c|c|c|}
\hline & $\begin{array}{l}\text { manufacturing, and } \\
\text { engineering.; the sites and } \\
\text { material culture that help to } \\
\text { tell the story of our } \\
\text { manufacturing past; industrial } \\
\text { heritage includes all of the } \\
\text { social and material culture } \\
\text { directly or indirectly related } \\
\text { to the people engaged in the } \\
\text { creation of infrastructure and } \\
\text { the production and } \\
\text { distribution of raw materials, } \\
\text { objects, and energy }\end{array}$ & & \\
\hline $\begin{array}{l}\text { G-Industry as } \\
\text { Influencing Society }\end{array}$ & $\begin{array}{l}\text { The history of technology, the } \\
\text { machinery it produced, and its } \\
\text { effect on society. }\end{array}$ & N/A & 1 \\
\hline G-Trade/Commerce & $\begin{array}{l}\text { Our nation's heritage as it } \\
\text { relates to trade, } \\
\text { manufacturing, certain } \\
\text { industries including fish } \\
\text { culture, dairy, ranching, } \\
\text { farming, textiles, etc.; History } \\
\text { of industry, including } \\
\text { entrepreneurship, innovation, } \\
\text { the workforce, immigration, } \\
\text { and organized labor.; The } \\
\text { surviving memories, } \\
\text { knowledge, equipment and } \\
\text { sites of trades and processes }\end{array}$ & N/A & 1 \\
\hline G-Industrialization & $\begin{array}{l}\text { Heritage from the industrial } \\
\text { period, i, e mills etc.; } \\
\text { remaining built environment } \\
\text { from a previous era }\end{array}$ & N/A & 1 \\
\hline G-Social Culture & $\begin{array}{l}\text { industrial heritage includes all } \\
\text { of the social and material } \\
\text { culture directly or indirectly } \\
\text { related to the people engaged } \\
\text { in the creation of }\end{array}$ & N/A & 3 \\
\hline
\end{tabular}




\begin{tabular}{|c|c|c|c|}
\hline & $\begin{array}{l}\text { infrastructure and the } \\
\text { production and distribution of } \\
\text { raw materials, objects, and } \\
\text { energy }\end{array}$ & & \\
\hline $\begin{array}{l}\text { G-Industrial } \\
\text { Methods/Processes }\end{array}$ & $\begin{array}{l}\text { operations; about historical } \\
\text { industrial methods }\end{array}$ & N/A & 1 \\
\hline $\begin{array}{l}\text { G-Industry as Shaping } \\
\text { Community }\end{array}$ & $\begin{array}{l}\text { Recognition and exploration } \\
\text { of the key role that industry } \\
\text { (and the people who worked } \\
\text { there) had in the development } \\
\text { of our communities; impact } \\
\text { on the people, their lives, } \\
\text { their community, and the } \\
\text { world; The history of industry } \\
\text { in a town or community; } \\
\text { Industrial heritage is the root } \\
\text { of a community's identity. It } \\
\text { is the foundation of an } \\
\text { economy, a way of life, and a } \\
\text { common thread that binds } \\
\text { neighbors and community } \\
\text { together. }\end{array}$ & N/A & 2 \\
\hline $\begin{array}{l}\text { G-Industry as Impacting } \\
\text { Region }\end{array}$ & $\begin{array}{l}\text { It means acknowledgment of } \\
\text { the impact of local industry } \\
\text { on the development, } \\
\text { economy, and culture of a } \\
\text { region; It's remembering } \\
\text { where an industry began and } \\
\text { how that affected the area. }\end{array}$ & N/A & 1 \\
\hline $\begin{array}{l}\text { G-Industry as Shaping } \\
\text { Cultural Landscape }\end{array}$ & $\begin{array}{l}\text { A look into the historical } \\
\text { importance on how industries } \\
\text { shaped the cultural } \\
\text { landscape.; The type of } \\
\text { industry that defines a region } \\
\text { and shapes its current society } \\
\text { and landscape }\end{array}$ & N/A & 2 \\
\hline
\end{tabular}




\begin{tabular}{|c|c|c|c|}
\hline G-Machinery & $\begin{array}{l}\text { Something that is machine } \\
\text { related; study of the } \\
\text { mechanical devices } \\
\text { developed; The history of } \\
\text { technology, the machinery it } \\
\text { produced, and its effect on } \\
\text { society. }\end{array}$ & N/A & 2 \\
\hline G-Remembrance & $\begin{array}{l}\text { The preservation, collection, } \\
\text { or remembrance of things, } \\
\text { works of art, and ideas both } \\
\text { tangible and intangible related } \\
\text { to industrial communities, } \\
\text { societies, production, and } \\
\text { transportation.; Bring back } \\
\text { memories of bygone } \\
\text { business.; artifacts and } \\
\text { memories from the history of } \\
\text { local industry rise and fall; } \\
\text { The surviving memories, } \\
\text { knowledge, equipment and } \\
\text { sites of trades and processes }\end{array}$ & N/A & 2 \\
\hline G-People & $\begin{array}{l}\text { For industrial heritage, I get } \\
\text { more excited about the } \\
\text { people; lives of those who } \\
\text { lived before us, how they } \\
\text { lived; the stories of the people } \\
\text { who worked in and around } \\
\text { industry.; impact on the } \\
\text { people, their lives, their } \\
\text { community, and the world.; } \\
\text { Hard working folks that help } \\
\text { build our Country and } \\
\text { provides the work ethic to get } \\
\text { the job done; History of } \\
\text { mining, factories and the } \\
\text { people associated with them; } \\
\text { How once worked in the US, } \\
\text { the products they made, how } \\
\text { that has changes and how the }\end{array}$ & N/A & 3 \\
\hline
\end{tabular}




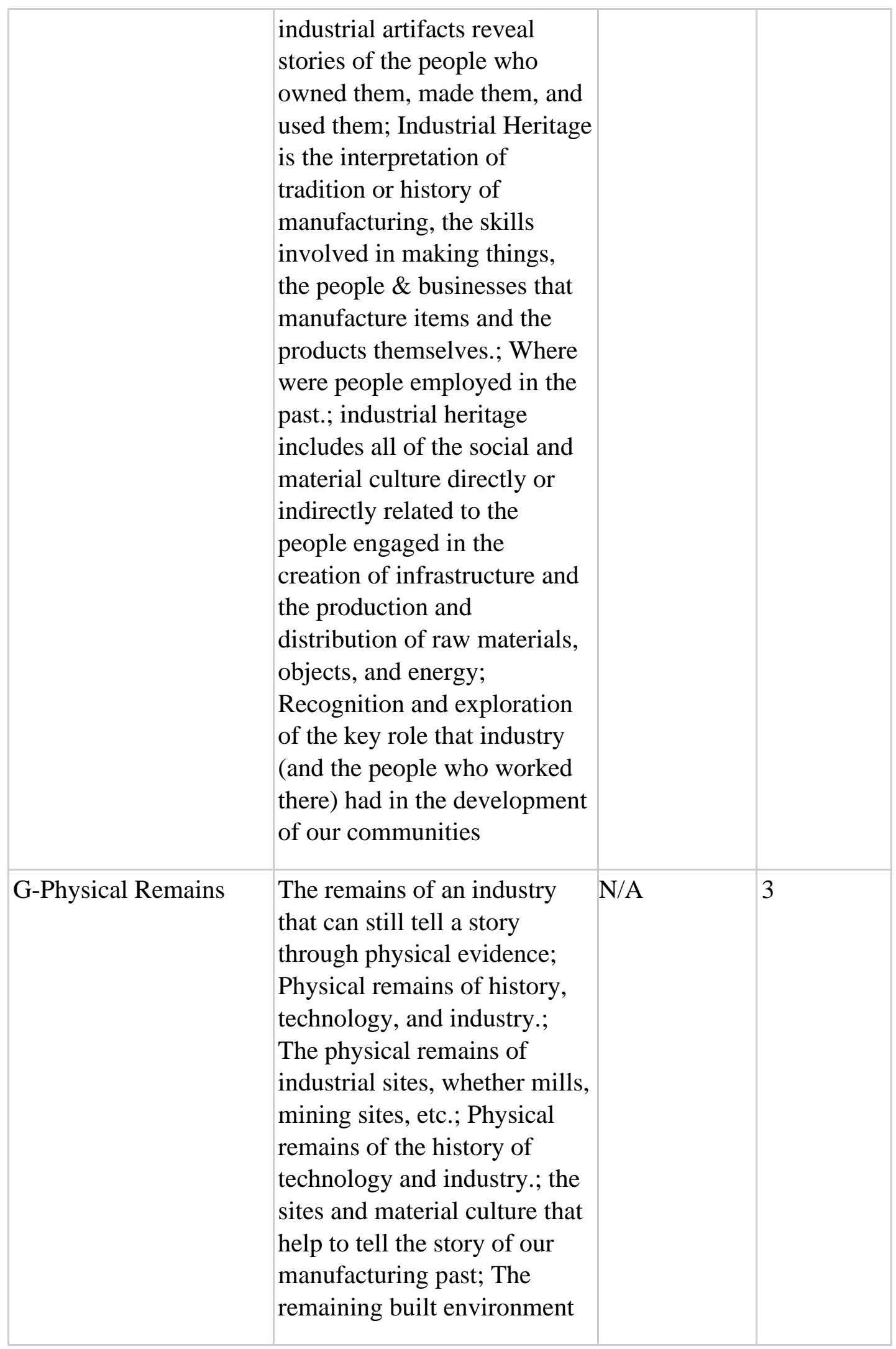




\begin{tabular}{|c|c|c|c|}
\hline G-Preservation & $\begin{array}{l}\text { Preserving the history of } \\
\text { previous industrial sites; } \\
\text { Preserving the history of } \\
\text { industrial technology, } \\
\text { operations, and the stories of } \\
\text { the people who worked in and } \\
\text { around industry; The } \\
\text { preservation of historic } \\
\text { enterprises; Preserving and } \\
\text { interpreting the legacy of } \\
\text { industry; Preserving the tools, } \\
\text { records, artifacts, structures, } \\
\text { and historic site of an } \\
\text { industry, and utilizing these } \\
\text { assets to educate visitors and } \\
\text { students about the industry } \\
\text { within its cultural context.; } \\
\text { The preservation and } \\
\text { interpretation of artifacts, } \\
\text { stories, and places related to } \\
\text { the history of technology, } \\
\text { manufacturing, and } \\
\text { engineering. }\end{array}$ & N/A & 1 \\
\hline G-Scale of Work & $\begin{array}{l}\text { history of mining, economic } \\
\text { decline, scale of work }\end{array}$ & N/A & 1 \\
\hline $\begin{array}{l}\text { G- } \\
\text { Tangibility/Intangibility }\end{array}$ & $\begin{array}{l}\text { The preservation, collection, } \\
\text { or remembrance of things } \\
\text { works of art, and ideas both } \\
\text { tangible and intangible related } \\
\text { to industrial communities, } \\
\text { societies, production, and } \\
\text { transportation. }\end{array}$ & N/A & 1 \\
\hline G-Tradition & $\begin{array}{l}\text { Industrial Heritage is the } \\
\text { interpretation of tradition or } \\
\text { history of manufacturing, the } \\
\text { skills involved in making } \\
\text { things, the people \& } \\
\text { businesses that manufacture }\end{array}$ & N/A & 2 \\
\hline
\end{tabular}




\begin{tabular}{|c|c|c|c|}
\hline & $\begin{array}{l}\text { items and the products } \\
\text { themselves. }\end{array}$ & & \\
\hline G-Uncertainty & $\begin{array}{l}\text { Understanding what has been } \\
\text { done before to understand } \\
\text { where we are now. }\end{array}$ & N/A & 1 \\
\hline $\begin{array}{l}\text { G-Working } \\
\text { Environment }\end{array}$ & $\begin{array}{l}\text { workers in large scale } \\
\text { industrial enterprises and } \\
\text { what were their lives like, } \\
\text { how did they impact the } \\
\text { place, and how they worked it } \\
\text { through in their own } \\
\text { generations }\end{array}$ & N/A & 3 \\
\hline General & & $\begin{array}{l}\text { The "General" } \\
\text { code stands for } \\
\text { meanings } \\
\text { presented that } \\
\text { speak to } \\
\text { generalizations } \\
\text { or larger } \\
\text { concepts of } \\
\text { industrial } \\
\text { heritage } \\
\text { instead of } \\
\text { focusing on } \\
\text { one region, } \\
\text { industry, or } \\
\text { historical } \\
\text { period }\end{array}$ & 2 \\
\hline Mixed & Lowell, Massachusetts & $\begin{array}{l}\text { The "Mixed" } \\
\text { code speaks to } \\
\text { the survey } \\
\text { question "what } \\
\text { does industrial } \\
\text { heritage mean } \\
\text { to you?" } \\
\text { where } \\
\text { responses } \\
\text { combine }\end{array}$ & 4 \\
\hline
\end{tabular}




\begin{tabular}{|c|c|c|c|}
\hline & & $\begin{array}{l}\text { specific and } \\
\text { personal } \\
\text { meanings on a } \\
\text { local scale, } \\
\text { while also } \\
\text { talking about } \\
\text { general } \\
\text { concepts } \\
\text { commonly } \\
\text { described by } \\
\text { scholarship on } \\
\text { the topic or } \\
\text { topics that } \\
\text { span } \\
\text { geographical } \\
\text { location, time, } \\
\text { and industry. }\end{array}$ & \\
\hline S-Hubs of Industry & $\begin{array}{l}\text { large scale industrial } \\
\text { enterprises }\end{array}$ & N/A & 1 \\
\hline S-Celebration & John Deere & N/A & 1 \\
\hline $\begin{array}{l}\text { S-Industry as } \\
\text { Influencing Region }\end{array}$ & $\begin{array}{l}\text { Growth of industry in } \\
\text { Chicago and its relationship } \\
\text { to Chicago waterways }\end{array}$ & N/A & 1 \\
\hline $\begin{array}{l}\text { S-Industry as Building } \\
\text { Town }\end{array}$ & $\begin{array}{l}\text { he Pacific Locomotive } \\
\text { Association, Inc., operates } \\
\text { Niles Canyon Railway as a } \\
\text { living history museum } \\
\text { interpreting the importance of } \\
\text { our heritage railroads in the } \\
\text { development of California } \\
\text { and the nation. }\end{array}$ & N/A & 1 \\
\hline $\begin{array}{l}\text { S-Industry as Shaping } \\
\text { Community }\end{array}$ & $\begin{array}{l}\text { I would relate Industrial } \\
\text { Heritage to the lumber mill } \\
\text { exhibit that talks about the } \\
\text { county's lumber boom in the } \\
\text { early 1900's }\end{array}$ & N/A & 1 \\
\hline
\end{tabular}




\begin{tabular}{|c|c|c|c|}
\hline S-Legacy of Industry & $\begin{array}{l}\text { Gone; there are no industrial } \\
\text { heritage sites related to our } \\
\text { story }\end{array}$ & N/A & 3 \\
\hline $\begin{array}{l}\text { S-Local Industrial } \\
\text { Boom }\end{array}$ & $\begin{array}{l}\text { manufacturing; Heritage from } \\
\text { the industrial period, i, e mills } \\
\text { etc. }\end{array}$ & N/A & 1 \\
\hline $\begin{array}{l}\text { S-Local industry as } \\
\text { supplying nation }\end{array}$ & mining & N/A & 1 \\
\hline S-People & $\begin{array}{l}\text { seeing the remnants of that } \\
\text { past; In addition to the } 11.5- \\
\text { mile railroad that was built in } \\
\text { the } 1880 \text { 's to serve } 2 \text { granite } \\
\text { quarries we own one of the } \\
\text { finishing plants and several } \\
\text { other related buildings }\end{array}$ & N/A & 1 \\
\hline S-Physical Remains & $\begin{array}{l}\text { The preservation and } \\
\text { restoration of the Knight } \\
\text { Foundry provides an } \\
\text { unparalleled opportunity to } \\
\text { protect the history of } \\
\text { industrial technologies as they } \\
\text { were traditionally } \\
\text { implemented, and to pass } \\
\text { them on to future generations. }\end{array}$ & N/A & 1 \\
\hline $\begin{array}{l}\text { S-Transportation } \\
\text { Network }\end{array}$ & $\begin{array}{l}\text { that we tell at the museum is } \\
\text { that when the railroad came } \\
\text { through in } 1881 \text { or } 1886\end{array}$ & N/A & 1 \\
\hline S-Workforce & workers in the foundry's & N/A & 1 \\
\hline Specific & & $\begin{array}{l}\text { The "Specific" } \\
\text { code stands in } \\
\text { for meanings } \\
\text { presented that } \\
\text { give specific } \\
\text { examples } \\
\text { only, talk }\end{array}$ & 2 \\
\hline
\end{tabular}




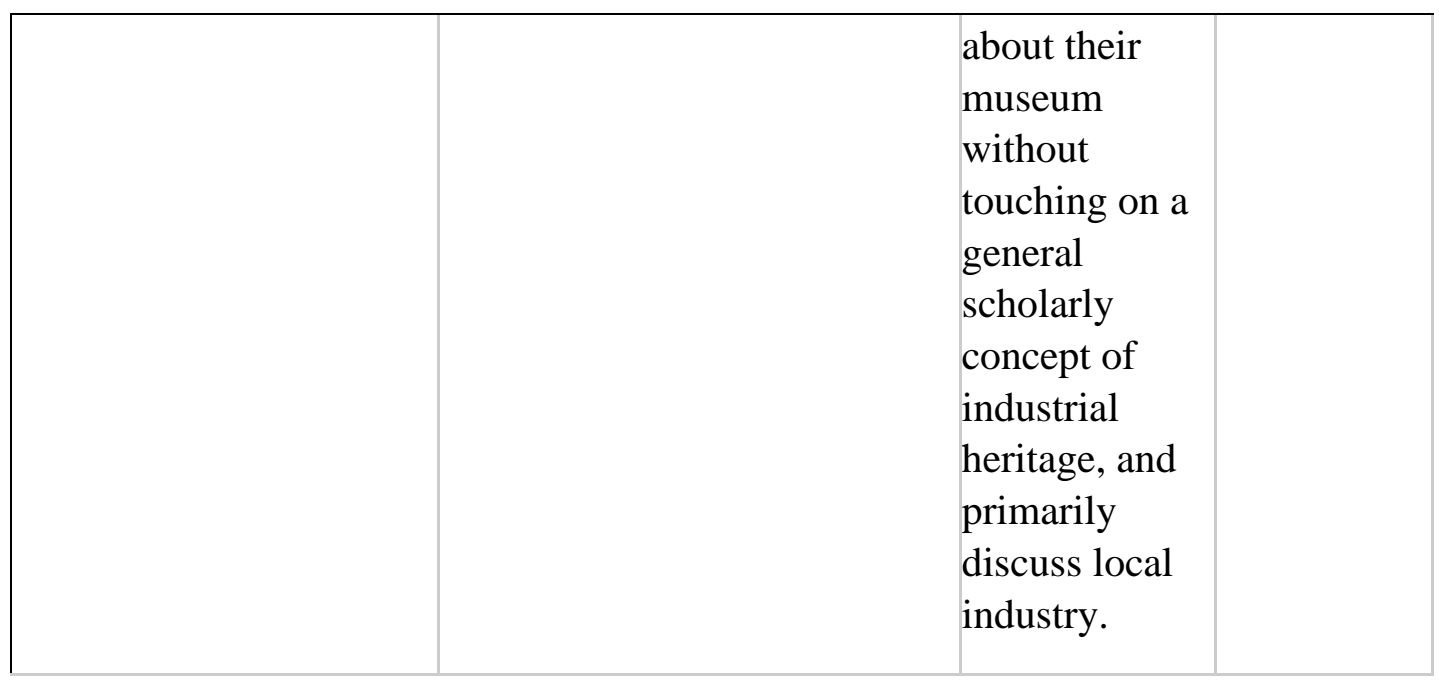

Interviews with Trained Museum Professionals, Response Codes, Question \#25: What industries are represented in the collections and exhibits at your museum?

\begin{tabular}{|l|l|l|}
\hline Code & Examples from Interviews/Survey & $\begin{array}{l}\text { Code } \\
\text { Frequency }\end{array}$ \\
\hline Transportation & $\begin{array}{l}\text { General Maritime; Local Industry; Canals; General } \\
\text { Transportation; Locomotive; Rail Transportation; } \\
\text { Railroad; Roads; Steamboats; Trains }\end{array}$ & 5 \\
& \multicolumn{1}{|l|}{$\begin{array}{l}\text { General Forest Products; Animal Fur; Animal } \\
\text { Husbandry; Clamming; Commercial Fishing; Cotton }\end{array}$} & \\
& $\begin{array}{l}\text { Farming; Dairy; Finishing; Fisheries; Fishing; Food } \\
\text { Production; Forest Management; General Agriculture; } \\
\text { General Farming; Grist Mill; Harvesting Marine } \\
\text { Animals; Ice Harvesting; Logging; Oysters; Ranching; } \\
\text { Sugar; Sugar Growing/Harvesting; Tobacco Farming; } \\
\text { Whaling; Wormseed }\end{array}$ & \\
\hline Manufacturing & $\begin{array}{l}\text { General Milling; Art; Automobiles; Blacksmith Tools; } \\
\text { Blacksmithing; Boatbuilding; Brass; Bricks; Button } \\
\text { Manufacturing; Cabinetry; Canning; Carpentry; } \\
\text { Chemical; Cider; Clock; Consumer Goods; Covered } \\
\text { Wagons; Cutlery; Dies; Electronics; Eyelets; Firearms; }\end{array}$ & \\
$\begin{array}{ll}\text { Forging; Foundry; Furniture; Gages; Garments; Glass } \\
\text { Blowing; Glassmaking; Hand Tools; Home and } \\
\text { Personal Care Products; Home-Textile; Horsepower } \\
\text { Motors; Hosiery; Internal Combustion Engine; Iron }\end{array}$ & \\
\hline
\end{tabular}




\begin{tabular}{|c|c|c|}
\hline & $\begin{array}{l}\text { Production; Lubricants; Lumber Milling; Lumbering; } \\
\text { Machine Manufacturing; machine Tools; Machinery; }\end{array}$ & \\
\hline & $\begin{array}{l}\text { Paper; Paper Mill; Precision cutting tools; Precision } \\
\text { Machines; Printing; Recreation Products; Shingle } \\
\text { Making; Ropemaking; Saddletrees; Shipbuilding; } \\
\text { Shipping; Shoes; Silverware; Steel Stamps; } \\
\text { Steelmaking; Sugar Milling; Textile; Tool; Toys; } \\
\text { Tractor Assembly; Wooden Frames; Woodworking; } \\
\text { Woolen Mill }\end{array}$ & \\
\hline Recreation & Recreational Fishing & 1 \\
\hline Quarrying & Quarrying & 2 \\
\hline Construction & Construction & 1 \\
\hline Mining & $\begin{array}{l}\text { Cinnabar Mining; Coal Mining; Copper Mining; } \\
\text { General Mining; Gold Mining; Grain Milling; Iron } \\
\text { Mining; Iron Ore; Mica Spar }\end{array}$ & 2 \\
\hline
\end{tabular}

Interviews with Trained Museum Professionals, Response Codes, Question \#33: If yes, how? (Hands-On Interaction)

\begin{tabular}{|l|l|l|}
\hline Code & Examples from Interviews/Survey & $\begin{array}{l}\text { Code } \\
\text { Frequency }\end{array}$ \\
\hline $\begin{array}{l}\text { Work with Industrial } \\
\text { Communities }\end{array}$ & $\begin{array}{l}\text { get out in the field and do projects with } \\
\text { the community organizations that work } \\
\text { on industrial heritage. }\end{array}$ & 1 \\
\hline Interact with Collections & $\begin{array}{l}\text { we are in the middle of a collections } \\
\text { audit, of all our items, by the } \\
\text { volunteers; working with the collection; } \\
\text { Volunteering with the collection; Our } \\
\text { volunteers (and the students working }\end{array}$ & \\
\hline
\end{tabular}




\begin{tabular}{|c|c|c|}
\hline & $\begin{array}{l}\text { ere as well) work in processing the } \\
\text { collections }\end{array}$ & \\
\hline Interact with Artifacts & $\begin{array}{l}\text { We have artifacts that are hands-on; } \\
\text { demonstration of mining artifacts to } \\
\text { visitors; sometimes work with objects; } \\
\text { permit limited handling of some of the } \\
\text { artifacts; }\end{array}$ & 1 \\
\hline Research & $\begin{array}{l}\text { research \& writing; they are handling } \\
\text { artifacts and doing research }\end{array}$ & 1 \\
\hline Exhibit Development & $\begin{array}{l}\text { Exhibit building; some work on } \\
\text { exhibits; work on displays }\end{array}$ & 1 \\
\hline Preservation/Conservation & $\begin{array}{l}\text { We have had volunteers help us with } \\
\text { preservation and archaeology of the } \\
\text { site; Research, demonstration, } \\
\text { maintenance, preservation, restoration; } \\
\text { Research and conservation work }\end{array}$ & 2 \\
\hline Demonstrate Equipment & $\begin{array}{l}\text { Volunteers have the opportunity to run } \\
\text { physical demonstrations with mining } \\
\text { equipment and museum displays; Some } \\
\text { of our volunteers have done } \\
\text { demonstrations related to river } \\
\text { industries, such as creating crowfoot } \\
\text { hooks which were used to harvest } \\
\text { mussels; Demonstration cotton gin, } \\
\text { interactive auger system; } \\
\text { Demonstration of mercury, } \\
\text { demonstration of rotary furnace, } \\
\text { demonstration of mining artifacts to } \\
\text { visitors. }\end{array}$ & 1 \\
\hline
\end{tabular}

Interviews with Trained Museum Professionals, Response Codes, Question \#35: If yes, how? (Discuss Industrialization)

\begin{tabular}{|l|l|l|}
\hline Code & Code Meaning & Code \\
& Frequency \\
\hline
\end{tabular}




\begin{tabular}{|c|c|c|}
\hline $\begin{array}{l}\text { Positive and Negative } \\
\text { Impacts }\end{array}$ & $\begin{array}{l}\text { In the context of industrialization, the } \\
\text { code "Positive and Negative Impacts" } \\
\text { pertains to the varying levels of impacts } \\
\text { by industrialization. }\end{array}$ & 1 \\
\hline Local/Regional Populations & $\begin{array}{l}\text { In the context of industrialization, the } \\
\text { code "Local/Regional Populations" } \\
\text { refers to the mentioning of the daily life } \\
\text { of industrialized populations and the } \\
\text { impacts of industry. Respondents to the } \\
\text { survey mentioned a change in a } \\
\text { community's daily life and the specific } \\
\text { impact of local and regional } \\
\text { populations by industrial activity. }\end{array}$ & 2 \\
\hline Labor Issues & $\begin{array}{l}\text { In the context of industrialization, the } \\
\text { code "Labor Issues" pertains to child } \\
\text { labor issues, slavery and indentured } \\
\text { servitude, employment issues, the labor } \\
\text { movement, strikes, union disputed, and } \\
\text { safety issues. }\end{array}$ & 1 \\
\hline \multirow[t]{2}{*}{$\begin{array}{l}\text { Anthropogenic Landscape } \\
\text { Change }\end{array}$} & $\begin{array}{l}\text { In the context of industrialization, the } \\
\text { code "Anthropogenic Landscape } \\
\text { Change" pertains to the alteration of the } \\
\text { physical landscape by humans for } \\
\text { industrial purposes such as farming, } \\
\text { construction, waste retention and } \\
\text { removal, resource collection, etc. } \\
\text { Respondents to the survey mentioned } \\
\text { pollution, environmental }\end{array}$ & 3 \\
\hline & $\begin{array}{l}\text { destruction, deforestation, and damage } \\
\text { to environment through mining and } \\
\text { natural resource extraction. }\end{array}$ & \\
\hline Specific Local Industry & $\begin{array}{l}\text { In the context of industrialization, the } \\
\text { code "Specific Local Industry" pertains } \\
\text { to the specific mentioning of a local } \\
\text { industry by survey respondents. }\end{array}$ & 2 \\
\hline
\end{tabular}




\begin{tabular}{|c|c|c|}
\hline Active Use & $\begin{array}{l}\text { In the context of industrialization, the } \\
\text { code "Active Use" pertains to industrial } \\
\text { sites continuing to be used for } \\
\text { production or habitation in a } \\
\text { conventionally productive manner, i.e., } \\
\text { manufacturing, interpretation, etc.. }\end{array}$ & 1 \\
\hline $\begin{array}{l}\text { Introduction of } \\
\text { Technological Innovations }\end{array}$ & $\begin{array}{l}\text { In the context of industrialization, the } \\
\text { code "Introduction of Technological } \\
\text { Innovations" pertains to the } \\
\text { introduction and utilization of new } \\
\text { modes of production and labor } \\
\text { management, machinery, and } \\
\text { transportation. Respondents to the } \\
\text { survey mentioned the introduction of } \\
\text { the railroad, new labor management } \\
\text { practices, changing farming, } \\
\text { manufacturing, and lumbering } \\
\text { technology that in some cases replaced } \\
\text { older technology and methods. }\end{array}$ & 1 \\
\hline
\end{tabular}

Interviews with Trained Museum Professionals, Response Codes, Question \#37: If yes, how? (Discuss De-Industrialization)

\begin{tabular}{|l|l|l|}
\hline Code & Examples from Interviews/Survey & $\begin{array}{l}\text { Code } \\
\text { Frequency }\end{array}$ \\
\hline $\begin{array}{l}\text { Technological Innovations } \\
\text { Frofion of }\end{array}$ & $\begin{array}{l}\text { In the context of de-industrialization, the } \\
\text { code "Introduction of Technological } \\
\text { Innovations" refers to the mechanization } \\
\text { of industry, the introduction of new } \\
\text { forms of transportation, manufacturing, } \\
\text { and labor. Museums using this code } \\
\text { discussed why these innovations were } \\
\text { necessary, the loss of tactile knowledge } \\
\text { relating to an industrial process for } \\
\text { manufacturing or crafting products, or } \\
\text { the change in labor values as machines } \\
\text { became increasingly present in } \\
\text { American factories. }\end{array}$ & \\
\hline
\end{tabular}




\begin{tabular}{|c|c|c|}
\hline Labor Issues & $\begin{array}{l}\text { In the context of de-industrialization, the } \\
\text { code "Labor Issues" refers to the } \\
\text { mention of labor movements, strikes, } \\
\text { and economic issues that occur because } \\
\text { of the decline, maintenance, or growth of } \\
\text { industry. Museums using this code } \\
\text { discussed displaced labor, impacts on } \\
\text { employment due to industrial decline, } \\
\text { and a reduction in work value associated } \\
\text { with factory laborers. }\end{array}$ & 1 \\
\hline Transition & $\begin{array}{l}\text { In the context of de-industrialization, the } \\
\text { code "Transition" pertains to a labor, } \\
\text { social, industrial, or environmental } \\
\text { change. }\end{array}$ & 1 \\
\hline Decline of Industry & $\begin{array}{l}\text { In the context of de-industrialization, the } \\
\text { code "Decline of Industry" refers to the } \\
\text { decline of a local/regional/national } \\
\text { industry. Museum responses for this } \\
\text { code mention the end of an industry, its } \\
\text { decline, destruction of industrial sites, } \\
\text { industrial downturn, etc. }\end{array}$ & 2 \\
\hline Winners and Losers & $\begin{array}{l}\text { In the context of de-industrialization, the } \\
\text { code "Winners and Losers " refers to } \\
\text { those who profited and those who were } \\
\text { subjugated or fell because of } \\
\text { competition. }\end{array}$ & 1 \\
\hline $\begin{array}{l}\text { Anthropogenic Landscape } \\
\text { Change }\end{array}$ & $\begin{array}{l}\text { In the context of de-industrialization, the } \\
\text { code "Anthropogenic Landscape } \\
\text { Change" pertains to the human impact } \\
\text { on the landscape. Respondents to the } \\
\text { survey mentioned deforestation and } \\
\text { pollution as part of their museum's } \\
\text { discussion of de-industrialization. }\end{array}$ & 1 \\
\hline Local/Regional Populations & $\begin{array}{l}\text { In the context of de-industrialization, the } \\
\text { code "Local/Regional Populations" } \\
\text { refers to a responding museum } \\
\text { mentioning workers and populations. }\end{array}$ & 1 \\
\hline
\end{tabular}


Museums using this code also discussed population loss during migrations and mechanization.

Interviews with Volunteers, Response Codes, Question \#8: Why did you begin volunteering at the museum?

\begin{tabular}{|l|l|l|}
\hline Code & Examples from Interviews/Survey & $\begin{array}{l}\text { Code } \\
\text { Frequency }\end{array}$ \\
\hline Help Local Community & $\begin{array}{l}\text { So, I said that I was willing to contribute time } \\
\text { and so that's how I started }\end{array}$ & 1 \\
\hline Interest in History & $\begin{array}{l}\text { mainly it was a history wheel, which was a } \\
\text { bus tour of the area, it was a historical bus } \\
\text { tour, and I was really impressed; I've always } \\
\text { had a passion for history }\end{array}$ & 3 \\
\hline Personal Project & $\begin{array}{l}\text { In order to transfer my photographs and } \\
\text { stories and history of granite carving to the } \\
\text { museum for posterity and safekeeping. }\end{array}$ & 1 \\
\hline Preservation & $\begin{array}{l}\text { In order to transfer my photographs and } \\
\text { stories and history of granite carving to the } \\
\text { museum for posterity and safekeeping. }\end{array}$ & 1 \\
\hline
\end{tabular}

Interviews with Volunteers, Response Codes, Question \#9: Why do you continue to do so? (Volunteering at IHMO)

\begin{tabular}{|l|l|l|}
\hline Code & Examples from Interviews/Survey & $\begin{array}{l}\text { Code } \\
\text { Frequency }\end{array}$ \\
\hline Experience/Learning & $\begin{array}{l}\text { I developed an interest in history and } \\
\text { everything that I learned through volunteering } \\
\text { it gets more and more exciting to me. I } \\
\text { learned a lot from it. }\end{array}$ & 2 \\
\hline Interest in History & $\begin{array}{l}\text { I developed an interest in history and } \\
\text { everything that I learned through volunteering } \\
\text { it gets more and more exciting to me }\end{array}$ & 2 \\
\hline
\end{tabular}




\begin{tabular}{|l|l|l|}
\hline $\begin{array}{l}\text { Interest in Local } \\
\text { History }\end{array}$ & $\begin{array}{l}\text { I still have a passion for history and also, I see } \\
\text { local history }\end{array}$ & 2 \\
\hline Personal Project & $\begin{array}{l}\text { Cause these photographs, and need to ah be } \\
\text { arranged }\end{array}$ & 1 \\
\hline Preservation & $\begin{array}{l}\text { I love American history, so we need to } \\
\text { preserve that as well. }\end{array}$ & 1 \\
\hline The IHM/O's Staff & I like working for \#\#\#\# & 1 \\
\hline
\end{tabular}

Interviews with Volunteers, Response Codes, Question \#10: What do you do at the museum?

\begin{tabular}{|l|l|l|}
\hline Code & Examples from Interviews/Survey & $\begin{array}{l}\text { Code } \\
\text { Frequency }\end{array}$ \\
\hline Maintenance & also, any other general work when I am available & 2 \\
\hline Research library & $\begin{array}{l}\text { I do a lot of the research and then \#\#\#\# sends me } \\
\text { requests from people which I do as well }\end{array}$ & 1 \\
\hline $\begin{array}{l}\text { Special } \\
\text { Events/Programs }\end{array}$ & $\begin{array}{l}\text { I coordinate the school tours and a lot of the } \\
\text { group tours and help out at the events }\end{array}$ & 1 \\
\hline Tours & $\begin{array}{l}\text { volunteer as a tour guide; I first started I started a } \\
\text { tour guide }\end{array}$ & 2 \\
\hline $\begin{array}{l}\text { Collections } \\
\text { Management }\end{array}$ & $\begin{array}{l}\text { I am organizing just my own materials and I am } \\
\text { bringing a few items that I think may have a } \\
\text { general interest here at the museum other than } \\
\text { being lost among my effects; gradually got into } \\
\text { doing more in the archives, when I started there } \\
\text { were no archives; }\end{array}$ & 3 \\
\hline Administration & I'm a board member and secretary right now. & 1 \\
\hline
\end{tabular}

Interviews with Volunteers, Response Codes, Question \#14: What are they? (Volunteer Benefits/Rewards)

\begin{tabular}{|l|l|l|}
\hline Code & $\begin{array}{l}\text { Examples from } \\
\text { Interviews/Survey }\end{array}$ & Code \\
& Frequency \\
\hline
\end{tabular}




\begin{tabular}{|c|c|c|}
\hline $\begin{array}{l}\text { Learning from Volunteers, Staff, and } \\
\text { Visitors }\end{array}$ & $\begin{array}{l}\text { As a benefit, I am learning to } \\
\text { allot, especially for giving } \\
\text { tours. People that come through } \\
\text { there's a lot that I learn from } \\
\text { them as well. }\end{array}$ & 2 \\
\hline $\begin{array}{l}\text { Free Admission to the IHM/O's } \\
\text { programs/events/special events }\end{array}$ & $\begin{array}{l}\text { Free Admission to Member } \\
\text { only events; Free Admission to } \\
\text { certain museum events; Free } \\
\text { Admission to special events } \\
\text { based on hours volunteered; } \\
\text { invitations to member-only } \\
\text { events }\end{array}$ & 1 \\
\hline Volunteer only Social Gathering & $\begin{array}{l}\text { End of the season get together; } \\
\text { field trips; Organized } \\
\text { enrichment outings; volunteer- } \\
\text { only social functions; Weekly } \\
\text { Fellowship; any food left over } \\
\text { from events; free water and } \\
\text { "snacks" while they are } \\
\text { working their shift driving the } \\
\text { tractor over the causeway or } \\
\text { being a docent for the tug or } \\
\text { the museum; A couple lunches } \\
\text { throughout the year; annual } \\
\text { dinner hosted by local } \\
\text { businessman; Complimentary } \\
\text { seat at Annual Fundraising } \\
\text { Gala; Potlucks }\end{array}$ & 2 \\
\hline Free Admission to IHM/O and/or Site & $\begin{array}{l}\text { entry into our historic sites; } \\
\text { Free admission; reciprocal pass } \\
\text { privileges; free admission for } \\
\text { family and friends; free } \\
\text { museum admission to the } \\
\text { volunteer and their immediate } \\
\text { family; volunteers to bring } 24 \\
\text { guests ( } 2 / \text { month) at no charge. }\end{array}$ & 1 \\
\hline Gift Store Discount & Gift Store Discount & 2 \\
\hline
\end{tabular}


Interviews with Volunteers, Response Codes, Question \#16: Why do you think other volunteers volunteer at the museum?

\begin{tabular}{|c|c|c|}
\hline Code & Examples from Interviews/Survey & $\begin{array}{l}\text { Code } \\
\text { Frequency }\end{array}$ \\
\hline A Sense of Belonging & $\begin{array}{l}\text { a sense of belonging to our museum family; } \\
\text { sense of community with other volunteers; } \\
\text { Sense of community; social activity; The } \\
\text { society is a main pillar of the community; } \\
\text { socialize; Desire to be involved; socialization; } \\
\text { the friendships that they have made with } \\
\text { other volunteers and staff over the years; } \\
\text { wanting a social experience; volunteers love } \\
\text { to restore machinery and have a club; a desire } \\
\text { to be a part of it; relationships with other } \\
\text { volunteers, staff and board; being involved in } \\
\text { their local community; Wanting to be } \\
\text { involved in community; social relationships; } \\
\text { we are a family; they like the fact that we } \\
\text { have a Volunteer Council with officers and } \\
\text { monthly meetings; a desire for social } \\
\text { engagement or peer pressure; camaraderie; } \\
\text { value the social aspects of volunteering.; they } \\
\text { like socializing with each other and getting } \\
\text { out of the house; ant to be involved in } \\
\text { something; }\end{array}$ & 1 \\
\hline Help Local Community & $\begin{array}{l}\text { Volunteers want to help the local community; } \\
\text { the role of the museum important in the life } \\
\text { of the community; Tourism is one of the last } \\
\text { major industries in the county; The society is } \\
\text { a main pillar of the community; Give back to } \\
\text { the community; Trying to promote the area; } \\
\text { being involved in their local community }\end{array}$ & 1 \\
\hline Fulfilling Work & $\begin{array}{l}\text { They find their work fulfilling; Interesting } \\
\text { work; The personal satisfaction resulting } \\
\text { from volunteerism }\end{array}$ & 1 \\
\hline
\end{tabular}




\begin{tabular}{|c|c|c|}
\hline Interest in History & $\begin{array}{l}\text { interested in history; love of history; Passion } \\
\text { for history; deep colonial history; They love } \\
\text { history; enjoy history; A keen interest in } \\
\text { history; Passion for history }\end{array}$ & 3 \\
\hline Like the IHM/O & $\begin{array}{l}\text { Like the Museum; Their love of the museum; } \\
\text { People really love the museum; an institution } \\
\text { they admire }\end{array}$ & 1 \\
\hline Personal Heritage & $\begin{array}{l}\text { volunteers often have a personal connection } \\
\text { to former employees; Personal connection; } \\
\text { They are proud of their heritage; they have a } \\
\text { personal connection to the maritime world; A } \\
\text { personal connection to the industry and } \\
\text { related trades; their families part in it.; } \\
\text { volunteers usually have a connection to the } \\
\text { regions past }\end{array}$ & 1 \\
\hline Preservation & $\begin{array}{l}\text { feel like the museum is part of their heritage } \\
\text { that they want to preserve; retired skilled } \\
\text { craftsman who want to help save a Historic } \\
\text { Foundry; many also are interested in our } \\
\text { Historical Preservation activities; Saving } \\
\text { Important History; preserving a significant } \\
\text { part of our nation's industrial heritage; desire } \\
\text { to preserve; An appreciation and interest in } \\
\text { industrial archeology; Keeping the old ways } \\
\text { new again. }\end{array}$ & 1 \\
\hline Looking for Purpose & $\begin{array}{l}\text { looking for something to do; to have } \\
\text { "something" to do; boredom; volunteers who } \\
\text { want to stay busy, active and contribute; more } \\
\text { time to spare for volunteerism in retirement; } \\
\text { Wanting to be useful; wanting a purpose with } \\
\text { their free time; need to stay active and } \\
\text { engaged; people who are looking for } \\
\text { something to do to fill an hour or two a week }\end{array}$ & 1 \\
\hline $\begin{array}{l}\text { Cross organizational } \\
\text { support }\end{array}$ & $\begin{array}{l}\text { most of our volunteers do so because it will } \\
\text { get the word out about their establishment }\end{array}$ & 1 \\
\hline
\end{tabular}




\begin{tabular}{|l|l|l|}
\hline & $\begin{array}{l}\text { and our staff will also volunteer at their } \\
\text { events }\end{array}$ & \\
\hline The IHM/O's Staff & $\begin{array}{l}\text { She comes in once every week and keeps } \\
\text { coming because she likes what \#\#\#\# asks her } \\
\text { to do. }\end{array}$ & 1 \\
\hline
\end{tabular}

Interviews with Volunteers, Response Codes, Question \#23: What does industrial heritage mean to you?

\begin{tabular}{|c|c|c|c|}
\hline Code & $\begin{array}{l}\text { Examples from } \\
\text { Interviews/Survey }\end{array}$ & Code Meaning & $\begin{array}{l}\text { Code } \\
\text { Frequency }\end{array}$ \\
\hline $\begin{array}{l}\text { G-History of } \\
\text { Engineering }\end{array}$ & $\begin{array}{l}\text { The preservation and } \\
\text { interpretation of artifacts, } \\
\text { stories, and places related to } \\
\text { the history of engineering }\end{array}$ & N/A & 1 \\
\hline $\begin{array}{l}\text { G-History of } \\
\text { Technology }\end{array}$ & $\begin{array}{l}\text { The history of technology; } \\
\text { history of industrial } \\
\text { technology; Physical remains } \\
\text { of the history of technology } \\
\text { and industry; history of tech, } \\
\text { power, transportation, and } \\
\text { industry; The cultural and } \\
\text { technological history of a } \\
\text { particular industry.; The } \\
\text { preservation and } \\
\text { interpretation of artifacts, } \\
\text { stories, and places related to } \\
\text { the history of technology, } \\
\text { manufacturing, and } \\
\text { engineering; The history of } \\
\text { technology, the machinery it } \\
\text { produced, and its effect on } \\
\text { society. }\end{array}$ & N/A & 1 \\
\hline G-History of Labor & $\begin{array}{l}\text { I am assuming the history of } \\
\text { the "working man". }\end{array}$ & N/A & 1 \\
\hline G-Social Culture & $\begin{array}{l}\text { industrial heritage includes } \\
\text { all of the social and material }\end{array}$ & N/A & 1 \\
\hline
\end{tabular}




\begin{tabular}{|c|c|c|c|}
\hline & $\begin{array}{l}\text { culture directly or indirectly } \\
\text { related to the people engaged } \\
\text { in the creation of } \\
\text { infrastructure and the } \\
\text { production and distribution of } \\
\text { raw materials, objects, and } \\
\text { energy }\end{array}$ & & \\
\hline $\begin{array}{l}\text { G-Industrial } \\
\text { Methods/Processes }\end{array}$ & $\begin{array}{l}\text { operations; about historical } \\
\text { industrial methods }\end{array}$ & N/A & 1 \\
\hline G-Machinery & $\begin{array}{l}\text { Something that is machine } \\
\text { related; study of the } \\
\text { mechanical devices } \\
\text { developed; The history of } \\
\text { technology, the machinery it } \\
\text { produced, and its effect on } \\
\text { society }\end{array}$ & N/A & 1 \\
\hline $\begin{array}{l}\text { G-Past Shapes } \\
\text { Present }\end{array}$ & $\begin{array}{l}\text { Understanding and } \\
\text { appreciating how } \\
\text { industrialization has shaped } \\
\text { our lives; Just what it says. } \\
\text { These are the things that } \\
\text { provided the physical support } \\
\text { for our way of life }\end{array}$ & N/A & 1 \\
\hline General & N/A & $\begin{array}{l}\text { The "General" code } \\
\text { stands for meanings } \\
\text { presented that speak } \\
\text { to generalizations or } \\
\text { larger concepts of } \\
\text { industrial heritage } \\
\text { instead of focusing } \\
\text { on one region, } \\
\text { industry, or } \\
\text { historical period }\end{array}$ & 1 \\
\hline Mixed & N/A & $\begin{array}{l}\text { The "Mixed" code } \\
\text { speaks to the survey } \\
\text { question "what does } \\
\text { industrial heritage }\end{array}$ & 4 \\
\hline
\end{tabular}




\begin{tabular}{|c|c|c|c|}
\hline & & $\begin{array}{l}\text { mean to you?" } \\
\text { where responses } \\
\text { combine specific } \\
\text { and personal } \\
\text { meanings on a local } \\
\text { scale, while also } \\
\text { talking about } \\
\text { general concepts } \\
\text { commonly } \\
\text { described by } \\
\text { scholarship on the } \\
\text { topic or topics that } \\
\text { span geographical } \\
\text { location, time, and } \\
\text { industry. }\end{array}$ & \\
\hline $\begin{array}{l}\text { S-Industrial } \\
\text { Methods/Operations }\end{array}$ & $\begin{array}{l}\text { culture has grown out of } \\
\text { agriculture, and the need to } \\
\text { farm and grow food has } \\
\text { grown out of a need to make } \\
\text { and use tools to make and use } \\
\text { all kinds of implements, so } \\
\text { industrial history interesting } \\
\text { to me because I like the } \\
\text { engineering aspects of it, I } \\
\text { like contemplating the use of } \\
\text { materials }\end{array}$ & N/A & 1 \\
\hline $\begin{array}{l}\text { S-Industry as } \\
\text { Influencing Region }\end{array}$ & $\begin{array}{l}\text { Industrial heritage has the } \\
\text { role of industry, how it plays } \\
\text { out like for example here in } \\
\text { our region, the calumet } \\
\text { region }\end{array}$ & N/A & 1 \\
\hline S-People & $\begin{array}{l}\text { Industrial heritage is what } \\
\text { we, what I, have gained from } \\
\text { the people before me }\end{array}$ & N/A & 1 \\
\hline S-Workforce & $\begin{array}{l}\text { Industrial heritage is what } \\
\text { we, what I, have gained from } \\
\text { the people before me, the }\end{array}$ & N/A & 2 \\
\hline
\end{tabular}


workers at the steel mills, the

workers in the foundry's

Interviews with Volunteers, Response Codes, Question \#25: What industries are represented in the collections and exhibits at the museum?

\begin{tabular}{|l|l|l|}
\hline Code & Examples from Interviews/Survey & $\begin{array}{l}\text { Code } \\
\text { Frequency }\end{array}$ \\
\hline Agriculture & $\begin{array}{l}\text { the ice cutting, ice harvesting; } \\
\text { Manufacturing }\end{array}$ & 1 \\
\hline $\begin{array}{l}\text { The handle factory; the farm equipment; machinery; } \\
\text { tool making for sure, course we have local tool makers } \\
\text { like granite city tools, but mostly at Trowe and Holden }\end{array}$ & 3 \\
\hline Quarrying & $\begin{array}{l}\text { most everything involves the granite industry; } \\
\text { Quarrying is the same industry, just different aspects of } \\
\text { it. }\end{array}$ & 2 \\
\hline
\end{tabular}

Interviews with Volunteers, Response Codes, Question \#36: If yes, how? (HandsOn Interaction)

\begin{tabular}{|l|l|l|}
\hline Code & Examples from Interviews/Survey & $\begin{array}{l}\text { Code } \\
\text { Frequency }\end{array}$ \\
\hline $\begin{array}{l}\text { Interact with } \\
\text { Collections }\end{array}$ & $\begin{array}{l}\text { I would assume that means, like we work in the } \\
\text { archives, we work with material, it may be just } \\
\text { scanning and putting things in order but that's a } \\
\text { big part of building a museum }\end{array}$ & 1 \\
\hline
\end{tabular}

Interviews with Volunteers, Response Codes, Question \#38: If yes, how? (Discuss Industrialization)

\begin{tabular}{|l|l|l|}
\hline Code & Examples from Interviews/Survey & $\begin{array}{l}\text { Code } \\
\text { Frequency }\end{array}$ \\
\hline $\begin{array}{l}\text { Past Influencing } \\
\text { Present }\end{array}$ & $\begin{array}{l}\text { There's a lot to be referred to from the past and } \\
\text { how it's affected our existence and where we are } \\
\text { now. }\end{array}$ & 1 \\
\hline
\end{tabular}




\begin{tabular}{|l|l|l|}
\hline & $\begin{array}{l}\text { We have that whole business of Barre exhibit, } \\
\text { the museum has taken that on and discussing } \\
\text { how the industry works, how it's affected by } \\
\text { change and really everything I would imagine; } \\
\text { guess it would in regards to the monument } \\
\text { demands }\end{array}$ & 2 \\
$\begin{array}{l}\text { Specific Local } \\
\text { Industry }\end{array}$ & $\begin{array}{l}\text { the museum has taken that on and discussing } \\
\text { how the industry works, how it's affected by } \\
\text { change and really everything I would imagine }\end{array}$ & 1 \\
\hline $\begin{array}{l}\text { Community } \\
\text { Development }\end{array}$ & & \\
\hline
\end{tabular}

Interviews with Volunteers, Response Codes, Question \#40: If yes, how? (Discuss De-Industrialization)

\begin{tabular}{|l|l|l|}
\hline Code & Examples from Interviews & $\begin{array}{l}\text { Code } \\
\text { Frequency }\end{array}$ \\
\hline $\begin{array}{l}\text { Decline of } \\
\text { Industry }\end{array}$ & $\begin{array}{l}\text { In the context of de-industrialization, the code } \\
\text { "Decline of Industry" refers to the decline of a } \\
\text { local/regional/national industry. Museum responses } \\
\text { for this code mention the end of an industry, its } \\
\text { decline, destruction of industrial sites, industrial } \\
\text { downturn, etc. }\end{array}$ & 2 \\
\hline
\end{tabular}




\section{Appendix D: Tables}

Table 1. The Age Range of a Majority of Volunteers in 8 Interviewed and 105 Surveyed IHMOs

\begin{tabular}{|l|l|l|}
\hline Age of Volunteers & \# of IHMOs & \% of IHMOs \\
\hline 13 - 20 years of age & 1 & $1 \%$ \\
\hline 21 - 39 years of age & 6 & $5 \%$ \\
\hline 40 - 59 years of age & 15 & $13 \%$ \\
\hline $60+$ years of age & 90 & $80 \%$ \\
\hline Uncertain & 1 & $1 \%$ \\
\hline
\end{tabular}

Table 2. Gender of a Majority of Volunteers in 8 Interviewed and 101/105 Surveyed IHMOs

\begin{tabular}{|l|l|l|}
\hline Gender of Volunteers & \# of IHMOs & \% of IHMOs \\
\hline Female & 44 & $39 \%$ \\
\hline Male & 57 & $50 \%$ \\
\hline Other & 6 & $5 \%$ \\
\hline Male/Female Split & 2 & $2 \%$ \\
\hline
\end{tabular}

Table 3. Race/Ethnicity of a Majority of Volunteers in 8 Interviewed and 103/105 Surveyed IHMOs

\begin{tabular}{|l|l|l|}
\hline Volunteer Race/Ethnicity & \# of IHMOs & \% of IHMOs \\
\hline Asian & 0 & $0 \%$ \\
\hline Black/African & 0 & $0 \%$ \\
\hline White & 108 & $97 \%$ \\
\hline Hispanic/Latinx & 0 & $0 \%$ \\
\hline Native American & 0 & $0 \%$ \\
\hline Pacific Islander & 0 & $0 \%$ \\
\hline Prefer Not to Answer & 3 & $3 \%$ \\
\hline
\end{tabular}


Table 4. Education level of a Majority of Volunteers in 8 Interviewed and 103/105 Surveyed IHMOs

\begin{tabular}{|l|l|l|}
\hline Education Level & \# of IHMOs & \% of IHMOs \\
\hline No schooling completed & 0 & $0 \%$ \\
\hline Nursery school to 8th grade & 0 & $0 \%$ \\
\hline Some high school, no diploma & 2 & $2 \%$ \\
\hline $\begin{array}{l}\text { High school graduate, diploma or the equivalent } \\
\text { (for example: GED) }\end{array}$ & 10 & $9 \%$ \\
\hline Trade/technical/vocational training & 7 & $6 \%$ \\
\hline Some college credit, no degree & 9 & $8 \%$ \\
\hline Associates Degree & 0 & $0 \%$ \\
\hline Bachelor's Degree & 62 & $55 \%$ \\
\hline Master's Degree & 10 & $9 \%$ \\
\hline Professional Degree & 2 & $2 \%$ \\
\hline Doctorate Degree & 0 & $0 \%$ \\
\hline Widely Varied & 9 & $8 \%$ \\
\hline
\end{tabular}

Table 5. Employment Status of a Majority of Volunteers in 7/8 Interviewed and 102/105 Surveyed IHMOs

\begin{tabular}{|l|l|l|}
\hline Employment Status & \# of IHMOs & $\%$ of IHMOs \\
\hline Employed for wages & 11 & $10 \%$ \\
\hline Self Employed & 0 & $0 \%$ \\
\hline $\begin{array}{l}\text { Out of work and looking for } \\
\text { work }\end{array}$ & 0 & $0 \%$ \\
\hline Homemaker & 0 & $0 \%$ \\
\hline Full-Time Student & 1 & $1 \%$ \\
\hline Part-Time Student & 1 & $1 \%$ \\
\hline Military & 0 & $0 \%$ \\
\hline Retired & 90 & $80 \%$ \\
\hline Unable to work & 1 & $1 \%$ \\
\hline Varied & 6 & $5 \%$ \\
\hline
\end{tabular}


Table 6. Marital Status of a Majority of Volunteers at 7/8 Interviewed and 95/105 Surveyed IHMOs

\begin{tabular}{|l|l|l|}
\hline Marital Status & \# of IHMOs & \% of IHMOs \\
\hline Married & 86 & $76 \%$ \\
\hline Single & 1 & $1 \%$ \\
\hline Divorced & 0 & $0 \%$ \\
\hline $\begin{array}{l}\text { Single, but cohabiting with a significant } \\
\text { other }\end{array}$ & 2 & $2 \%$ \\
\hline In a domestic partnership, or civil union & 0 & $0 \%$ \\
\hline Single, never married & 5 & $4 \%$ \\
\hline Widowed & 8 & $7 \%$ \\
\hline
\end{tabular}

Table 7. \# of Staff Members at 8 Interviewed and 103/105 Surveyed IHMOs

\begin{tabular}{|l|l|l|}
\hline \# of Staff Members & \# of IHMOs & \% of IHMOs \\
\hline 0 staff members & 26 & $23 \%$ \\
\hline $1-3$ staff members & 38 & $34 \%$ \\
\hline $4-9$ staff members & 31 & $27 \%$ \\
\hline $10+$ staff members & 17 & $15 \%$ \\
\hline
\end{tabular}

Table 8. \# of Volunteers at 8 Interviewed and 104/105 Surveyed IHMOs

\begin{tabular}{|l|l|l|}
\hline \# of Volunteers & \# of IHMOs & \% of IHMOs \\
\hline $1-10$ volunteers & 41 & $36 \%$ \\
\hline $11-25$ volunteers & 30 & $27 \%$ \\
\hline $26-49$ volunteers & 12 & $11 \%$ \\
\hline $50+$ volunteers & 29 & $26 \%$ \\
\hline
\end{tabular}

Table 9. Do the 8 Interviewed and 102/105 Surveyed IHMOs Recruit Volunteers?

\begin{tabular}{|l|l|l|}
\hline Recruitment (Y/N) & \# of IHMOs & \% of IHMOs \\
\hline Yes & 93 & $85 \%$ \\
\hline No & 17 & $15 \%$ \\
\hline
\end{tabular}


Table 10. Methods of Recruitment at 8 Interviewed and 85/105 Surveyed IHMOs

\begin{tabular}{|l|l|l|}
\hline Method of Recruitment & \# of IHMOs & \% of IHMOs \\
\hline Word-of-Mouth & 53 & $57 \%$ \\
\hline Posters, Flyers, Signs, Newsletters, and Ad Prints & 28 & $30 \%$ \\
\hline Social Media & 29 & $31 \%$ \\
\hline Museum's Website & 20 & $22 \%$ \\
\hline Visitor to Museum become Interested & 20 & $22 \%$ \\
\hline Ask current volunteers & 12 & $13 \%$ \\
\hline Hosts public program & 18 & $19 \%$ \\
\hline Third Party Website & 14 & $15 \%$ \\
\hline Museum reaches out to other organizations & 11 & $12 \%$ \\
\hline Emailing & 9 & $10 \%$ \\
\hline Contacts Local Educational Institutions & 7 & $8 \%$ \\
\hline Volunteer Fairs & 5 & $5 \%$ \\
\hline Community Events & 6 & $6 \%$ \\
\hline Museum professional notoriety & 4 & $4 \%$ \\
\hline Hosts Public Meeting & 4 & $4 \%$ \\
\hline Public Service Announcements & 2 & $2 \%$ \\
\hline Community Outreach & 7 & $8 \%$ \\
\hline Recruitment Drives & 1 & $1 \%$ \\
\hline Museum's Staff Attends Networking & 1 & $1 \%$ \\
\hline Special Events & 1 & $1 \%$ \\
\hline AmeriCorps Member & 1 & $1 \%$ \\
\hline
\end{tabular}

Table 11. Decades 8 Interviewed and 104/105 Surveyed IHMOs began their Volunteering Programs

\begin{tabular}{|l|l|l|}
\hline Decades & \# of IHMOs & \% of IHMOs \\
\hline $1900 \mathrm{~s}$ & 6 & $5 \%$ \\
\hline $1910 \mathrm{~s}$ & 0 & $0 \%$ \\
\hline
\end{tabular}




\begin{tabular}{|l|l|l|}
\hline $1920 \mathrm{~s}$ & 0 & $0 \%$ \\
\hline $1930 \mathrm{~s}$ & 2 & $2 \%$ \\
\hline $1940 \mathrm{~s}$ & 2 & $2 \%$ \\
\hline $1950 \mathrm{~s}$ & 2 & $2 \%$ \\
\hline $1960 \mathrm{~s}$ & 16 & $14 \%$ \\
\hline $1970 \mathrm{~s}$ & 25 & $22 \%$ \\
\hline $1980 \mathrm{~s}$ & 18 & $16 \%$ \\
\hline $1990 \mathrm{~s}$ & 14 & $12 \%$ \\
\hline $2000 \mathrm{~s}$ & 15 & $13 \%$ \\
\hline $2010 \mathrm{~s}$ & 12 & $11 \%$ \\
\hline Unanswered & 1 & $1 \%$ \\
\hline
\end{tabular}

Table 12. Common Tasks for Volunteers at 8 Interviewed and 104/105 Surveyed IHMOS

\begin{tabular}{|l|l|l|}
\hline Volunteer Tasks & \# of Museums & \% of IHMOs \\
\hline Docenting & 88 & $79 \%$ \\
\hline Exhibit Work & 65 & $58 \%$ \\
\hline Fundraising & 58 & $52 \%$ \\
\hline Hospitality & 60 & $54 \%$ \\
\hline Maintenance & 71 & $63 \%$ \\
\hline Marketing & 33 & $29 \%$ \\
\hline Membership & 37 & $33 \%$ \\
\hline Museum Store Assistant & 47 & $42 \%$ \\
\hline Newsletter & 39 & $35 \%$ \\
\hline Office Assistant & 35 & $31 \%$ \\
\hline Public Relations & 41 & $37 \%$ \\
\hline Research library & 53 & $47 \%$ \\
\hline Special Events/Programs & 89 & $79 \%$ \\
\hline Tours & 86 & $77 \%$ \\
\hline Volunteer Management & 41 & $37 \%$ \\
\hline Web Design and Social Media & 41 & $37 \%$ \\
\hline Collections Management & 76 & $68 \%$ \\
\hline
\end{tabular}




\begin{tabular}{|l|l|l|}
\hline Finances & 2 & $2 \%$ \\
\hline Administration & 4 & $4 \%$ \\
\hline
\end{tabular}

Table 13. Do 8 Interviewed and 103/105 Surveyed IHMOs have a volunteer manager?

\begin{tabular}{|l|l|l|}
\hline Volunteer Manager (Y/N) & \# of IHMOs & \% of IHMOs \\
\hline Yes & 72 & $65 \%$ \\
\hline No & 39 & $35 \%$ \\
\hline
\end{tabular}

Table 14. Who is the Volunteer Manager at the 8 Interviewed and 103/105

Surveyed IHMOs?

\begin{tabular}{|l|l|l|}
\hline Volunteer Manager & \# of IHMOs & \% of IHMOs \\
\hline Paid Employee & 57 & $69 \%$ \\
\hline Volunteer & 24 & $29 \%$ \\
\hline Mixed & 2 & $2 \%$ \\
\hline
\end{tabular}

Table 15. Do the 8 Interviewed and 103/105 Surveyed IHMOs Offer Training to New Volunteers?

\begin{tabular}{|l|l|l|}
\hline Training (Y/S) & \# of IHMOs & \% of IHMOs \\
\hline Yes & 100 & $90 \%$ \\
\hline No & 11 & $10 \%$ \\
\hline
\end{tabular}

Table 16. Who Conducts Training at the Interviewed and Surveyed IHMOs?

\begin{tabular}{|l|l|l|}
\hline Position & \# of IHMOs & \% of IHMOs \\
\hline Paid Employee & 57 & $50 \%$ \\
\hline Volunteer & 33 & $29 \%$ \\
\hline Both & 13 & $12 \%$ \\
\hline None & 10 & $9 \%$ \\
\hline
\end{tabular}


Table 17. Are there Benefits for Volunteers at 8 Interviewed and 104/105 Surveyed IHMOs?

\begin{tabular}{|l|l|l|}
\hline Benefits (Y/N) & \# of IHMOs & \% of IHMOs \\
\hline Yes & 67 & $60 \%$ \\
\hline No & 45 & $40 \%$ \\
\hline
\end{tabular}

Table 18. Benefits/Rewards Given to Volunteers at 6/8 Interviewed and 63/105 Surveyed IHMOs

\begin{tabular}{|l|l|l|}
\hline Benefits/Rewards & \# of IHMOs & \% of IHMOs \\
\hline Volunteer only Social Gathering & 34 & $49 \%$ \\
\hline Volunteer Appreciation Events & 27 & $39 \%$ \\
\hline Free admission to IHMO programs/events/special events & 20 & $29 \%$ \\
\hline Gift Store Discount & 18 & $26 \%$ \\
\hline Non-Monetary Volunteer Appreciation Awards & 14 & $20 \%$ \\
\hline Free Admission to IHMO/Site & 11 & $16 \%$ \\
\hline Volunteer Involvement Trinket from IHMO & 9 & $13 \%$ \\
\hline Free IHMO Membership & 8 & $12 \%$ \\
\hline Free Use of IHMO Assets & 5 & $7 \%$ \\
\hline Discounts to IHMO programs/events/special events & 5 & $7 \%$ \\
\hline Discounted IHMO Membership & 3 & $4 \%$ \\
\hline Use of IHMO Venues & 3 & $4 \%$ \\
\hline Free Parking & 3 & $4 \%$ \\
\hline Involvement in IHMO Administration & 2 & $3 \%$ \\
\hline Monetary Volunteer Appreciation Award & 2 & $3 \%$ \\
\hline Ability to Volunteer & 1 & $1 \%$ \\
\hline Discounts to local restaurants and attractions & 1 & $1 \%$ \\
\hline Free Family/Friends Admission to other Museums & 2 & $3 \%$ \\
\hline IHMO Volunteer and Member Newsletter & 1 & $1 \%$ \\
\hline Travel Stipend & 1 & $1 \%$ \\
\hline Learning from Volunteers, Staff, and Visitors & 1 & $1 \%$ \\
\hline Volunteer Name Tag & 2 & $3 \%$ \\
\hline
\end{tabular}


Table 19. Level of Community Involvement at 8 Interviewed and 98/105 Surveyed IHMOS

\begin{tabular}{|l|l|l|}
\hline Level of Involvement & \# of IHMOs & \% of IHMOs \\
\hline Community is Actively Involved & 39 & $37 \%$ \\
\hline Community is Moderately Involved & 23 & $22 \%$ \\
\hline Community is Minimally Involved & 33 & $31 \%$ \\
\hline
\end{tabular}

Table 20. Motivations of Volunteers to Volunteer in 8 Interviewed and 103/105 Surveyed IHMOs

\begin{tabular}{|l|l|l|}
\hline Volunteer Motivations & \# of IHMOs & \% of IHMOs \\
\hline A Sense of Belonging & $26 \%$ & $26 \%$ \\
\hline Industrial Assets & $22 \%$ & $22 \%$ \\
\hline Interest in History & $23 \%$ & $23 \%$ \\
\hline General Support & $19 \%$ & $19 \%$ \\
\hline Interest in Local History & $15 \%$ & $15 \%$ \\
\hline Teaching/Sharing & $15 \%$ & $15 \%$ \\
\hline Industry & $11 \%$ & $11 \%$ \\
\hline Looking for Purpose & $13 \%$ & $13 \%$ \\
\hline Preservation & $11 \%$ & $11 \%$ \\
\hline Museum Mission/Goals & $10 \%$ & $10 \%$ \\
\hline Personal Heritage & $8 \%$ & $8 \%$ \\
\hline Help Local Community & $10 \%$ & $10 \%$ \\
\hline Like the Museum & $10 \%$ & $10 \%$ \\
\hline Previous experiences & $7 \%$ & $7 \%$ \\
\hline Experience/Learning & $12 \%$ & $12 \%$ \\
\hline Pride in Museum & $5 \%$ & $5 \%$ \\
\hline Fulfilling Work & $5 \%$ & $5 \%$ \\
\hline Museum Events & $4 \%$ & $4 \%$ \\
\hline Local Community Pride & $5 \%$ & $5 \%$ \\
\hline Beneficial to Health & $1 \%$ & $1 \%$ \\
\hline Local Heritage Pride & $2 \%$ & $2 \%$ \\
\hline Location & $2 \%$ & $2 \%$ \\
\hline
\end{tabular}




\begin{tabular}{|l|l|l|}
\hline Cross organizational support & $1 \%$ & $1 \%$ \\
\hline Personal Pride & $1 \%$ & $1 \%$ \\
\hline Personal Projects & $1 \%$ & $1 \%$ \\
\hline Training & $2 \%$ & $2 \%$ \\
\hline $\begin{array}{l}\text { Interest in } \\
\text { Nature/Environment }\end{array}$ & $1 \%$ & $1 \%$ \\
\hline Enthusiasts/Hobbyists & $1 \%$ & $1 \%$ \\
\hline Employer Support & $1 \%$ & $1 \%$ \\
\hline Gardening & $1 \%$ & $1 \%$ \\
\hline
\end{tabular}

Table 21. How Interviewed and Surveyed IHMOs understand the Concept of Industrial Heritage

\begin{tabular}{|l|l|l|}
\hline Viewpoint & \# of IHMOs & $\%$ of IHMOs \\
\hline $\begin{array}{l}\text { G-Bridge Between the Past and } \\
\text { Present }\end{array}$ & 1 & $1 \%$ \\
\hline G-Artwork & 1 & $1 \%$ \\
\hline $\begin{array}{l}\text { G-Celebration of Industrial } \\
\text { Heritage }\end{array}$ & 1 & $1 \%$ \\
\hline G-Cultural History of Industry & 1 & $1 \%$ \\
\hline G-Economic Decline & 1 & $1 \%$ \\
\hline G-Industry & 14 & $13 \%$ \\
\hline G-Equipment & 1 & $1 \%$ \\
\hline G-Hands on Learning/Teaching & 3 & $3 \%$ \\
\hline G-History of Engineering & 1 & $1 \%$ \\
\hline G-History of Invention & 1 & $1 \%$ \\
\hline G-History of Industry & 19 & $18 \%$ \\
\hline G-History of Power & 1 & $1 \%$ \\
\hline G-History of Technology & 11 & $10 \%$ \\
\hline G-History of Transportation & 1 & $1 \%$ \\
\hline G-History of Labor & 1 & $1 \%$ \\
\hline G-Immigration & 1 & $1 \%$ \\
\hline G-Organized Labor & 1 & $1 \%$ \\
\hline G-Workforce & 2 & $2 \%$ \\
\hline & & \\
\hline
\end{tabular}




\begin{tabular}{|c|c|c|}
\hline G-Industrial Artifacts & 9 & $8 \%$ \\
\hline G-Industry as Influencing Society & 2 & $2 \%$ \\
\hline G-Trade/Commerce & 4 & $4 \%$ \\
\hline G-Industrialization & 3 & $3 \%$ \\
\hline G-Social Culture & 4 & $4 \%$ \\
\hline G-Industry as World Shaping & 2 & $2 \%$ \\
\hline G-Industrial Methods/Processes & 3 & $3 \%$ \\
\hline G-Industry as Shaping Community & 8 & $8 \%$ \\
\hline G-Industry as Defining Region & 1 & $1 \%$ \\
\hline G-Industry as Impacting Region & 3 & $3 \%$ \\
\hline G-Industry as Nation Altering & 1 & $1 \%$ \\
\hline G-Industry as Nation Shaping & 5 & $5 \%$ \\
\hline $\begin{array}{l}\text { G-Industry as Shaping Cultural } \\
\text { Landscape }\end{array}$ & 4 & $4 \%$ \\
\hline G-Infrastructure & 4 & $4 \%$ \\
\hline G-Interpretation & 4 & $4 \%$ \\
\hline G-Local Industry & 7 & $7 \%$ \\
\hline G-Machinery & 6 & $6 \%$ \\
\hline G-Remembrance & 3 & $3 \%$ \\
\hline G-Past Creates Present & 1 & $1 \%$ \\
\hline G-Past Shapes Present & 5 & $5 \%$ \\
\hline G-Past Influence the Future & 2 & $2 \%$ \\
\hline G-People & 14 & $13 \%$ \\
\hline G-Physical Remains & 12 & $11 \%$ \\
\hline G-Preservation & 8 & $8 \%$ \\
\hline G-Repairing Goods & 1 & $1 \%$ \\
\hline G-Salvation & 1 & $1 \%$ \\
\hline G-Scale of Work & 2 & $2 \%$ \\
\hline G-Tangibility/Intangibility & 2 & $2 \%$ \\
\hline G-Tradition & 4 & $4 \%$ \\
\hline G-Transition & 1 & $1 \%$ \\
\hline G-Uncertainty & 1 & $1 \%$ \\
\hline
\end{tabular}




\begin{tabular}{|c|c|c|}
\hline G-Using past to understand present & 1 & $1 \%$ \\
\hline G-Working Environment & 4 & $4 \%$ \\
\hline General & 62 & $58 \%$ \\
\hline Mixed & 18 & $17 \%$ \\
\hline S-Hubs of Industry & 2 & $2 \%$ \\
\hline S-Celebration & 2 & $2 \%$ \\
\hline S-Product & 1 & $1 \%$ \\
\hline S-Industrialization & 6 & $6 \%$ \\
\hline S-Hands on Learning/Teaching & 5 & $5 \%$ \\
\hline S-Industrial Artifacts & 2 & $2 \%$ \\
\hline S-Innovations & 5 & $5 \%$ \\
\hline S-Industrial Methods/Operations & 1 & $1 \%$ \\
\hline S-Industry as affecting local area & 1 & $1 \%$ \\
\hline S-Industry as Influencing Region & 1 & $1 \%$ \\
\hline S-Industry as Building Town & 2 & $2 \%$ \\
\hline S-Industry as Shaping City & 2 & $2 \%$ \\
\hline S-Industry as Shaping State & 2 & $2 \%$ \\
\hline S-Industry as Shaping Nation & 3 & $3 \%$ \\
\hline S-Industry as Shaping World & 1 & $1 \%$ \\
\hline S-Industry as Shaping Community & 1 & $1 \%$ \\
\hline S-Infrastructure & 1 & $1 \%$ \\
\hline S-Legacy of Industry & 9 & $8 \%$ \\
\hline S-Local Industrial Boom & 3 & $3 \%$ \\
\hline $\begin{array}{l}\text { S-Local industry as supplying } \\
\text { nation }\end{array}$ & 2 & $2 \%$ \\
\hline S-Loss & 1 & $1 \%$ \\
\hline S-Manufacturing & 2 & $2 \%$ \\
\hline S-Mining & 2 & $2 \%$ \\
\hline S-People & 4 & $4 \%$ \\
\hline S-Physical Remains & 2 & $2 \%$ \\
\hline S-Preservation & 11 & $10 \%$ \\
\hline S-Remnants of the Past & 1 & $1 \%$ \\
\hline
\end{tabular}




\begin{tabular}{|l|l|l|}
\hline S-Restoration & 2 & $2 \%$ \\
\hline S-State Industry & 2 & $2 \%$ \\
\hline S-Innovation & 5 & $5 \%$ \\
\hline S-Transportation Network & 9 & $8 \%$ \\
\hline S-Unintended Consequences & 1 & $1 \%$ \\
\hline S-Workforce & 1 & $1 \%$ \\
\hline S-Working Environment & 1 & $1 \%$ \\
\hline Specific & 25 & $24 \%$ \\
\hline
\end{tabular}

Table 22. Industries Represented in the 8 Interviewed and 102/105 Surveyed IHMOS

\begin{tabular}{|l|l|l|}
\hline Represented Industries & \# of IHMOs & \% of IHMOs \\
\hline Agriculture & 42 & $38 \%$ \\
\hline Communications & 2 & $2 \%$ \\
\hline Construction & 3 & $3 \%$ \\
\hline Engineering & 2 & $2 \%$ \\
\hline Extraction & 3 & $3 \%$ \\
\hline Infrastructure & 2 & $2 \%$ \\
\hline Manufacturing & 61 & $55 \%$ \\
\hline Mining & 25 & $23 \%$ \\
\hline Power Production & 7 & $6 \%$ \\
\hline Quarrying & 5 & $5 \%$ \\
\hline Recreation & 6 & $5 \%$ \\
\hline Service & 2 & $2 \%$ \\
\hline Space & 2 & $2 \%$ \\
\hline Technology & 6 & $5 \%$ \\
\hline Transportation & 42 & $38 \%$ \\
\hline
\end{tabular}

Table 23. Narrative of Surveyed IHMOs

\begin{tabular}{|l|l|l|}
\hline Museum Narrative & \# of IHMOs & \% of IHMOs \\
\hline Single Industry Centered Narrative Museums & 50 & $48 \%$ \\
\hline
\end{tabular}




\begin{tabular}{|l|l|l|}
\hline Single Industry Inclusive Narrative Museums & 14 & $13 \%$ \\
\hline Multi-Industry Centered Narrative Museums & 16 & $15 \%$ \\
\hline Multi-Industry Inclusive Narrative Museums & 25 & $24 \%$ \\
\hline
\end{tabular}

Table 24. Are the 8 Interviewed and 100/105 Surveyed Industry(s) Represented in the IHMO still Operating?

\begin{tabular}{|l|l|l|}
\hline Operating (Y/N) & \# of IHMOs & \% of IHMOs \\
\hline Yes & 75 & $69 \%$ \\
\hline No & 33 & $31 \%$ \\
\hline
\end{tabular}

Table 25. \# of Volunteers who Worked in the Industry(s) Represented in 8 Interviewed and 102/105 Surveyed IHMOs

\begin{tabular}{|l|l|l|}
\hline \# of Volunteers & \# of IHMOs & \% of IHMOs \\
\hline 0 volunteers & 24 & $21 \%$ \\
\hline $1-3$ volunteers & 36 & $32 \%$ \\
\hline $4-9$ volunteers & 20 & $18 \%$ \\
\hline $10+$ volunteers & 29 & $26 \%$ \\
\hline
\end{tabular}

Table 26. \# of Volunteers Currently in the Industry(s) Represented in 8 Interviewed and 102/105 Surveyed IHMOs

\begin{tabular}{|l|l|l|}
\hline \# of Volunteers & \# of IHMOs & \% of IHMOs \\
\hline 0 volunteers & 71 & $63 \%$ \\
\hline $1-3$ volunteers & 19 & $17 \%$ \\
\hline $4-9$ volunteers & 12 & $11 \%$ \\
\hline $10+$ volunteers & 8 & $7 \%$ \\
\hline
\end{tabular}

Table 27. \# of Volunteers that have Familial Connections to the Industry(s) Represented in 7/8 Interviewed and 99/105 Surveyed IHMOs

\begin{tabular}{|l|l|l|}
\hline \# of Volunteers & \# of IHMOs & \% of IHMOs \\
\hline 0 volunteers & 12 & $11 \%$ \\
\hline $1-3$ volunteers & 25 & $22 \%$ \\
\hline
\end{tabular}




\begin{tabular}{|l|l|l|}
\hline $4-9$ volunteers & 27 & $24 \%$ \\
\hline $10+$ volunteers & 40 & $35 \%$ \\
\hline
\end{tabular}

Table 28. Perceptions of Urbanity and Rurality from 8 Interviewed and 103/105 Surveyed IHMOs

\begin{tabular}{|l|l|l|}
\hline Urbanity/Rurality Classification & \# of IHMOs & $\%$ of IHMOs \\
\hline Rural & 34 & $31 \%$ \\
\hline Somewhere In-Between & 52 & $47 \%$ \\
\hline Urban & 24 & $22 \%$ \\
\hline All of the Above & 1 & $1 \%$ \\
\hline
\end{tabular}

Table 29. What is the urbanity or rurality of the surveyed IHMOs?

\begin{tabular}{|l|l|l|}
\hline Rurality or Urbanity & \# of Museums & $\%$ of IHMOs \\
\hline Rural Area & 48 & $46 \%$ \\
\hline Rural Space & 18 & $17 \%$ \\
\hline Urban Cluster & 9 & $9 \%$ \\
\hline Urban Area & 30 & $29 \%$ \\
\hline
\end{tabular}

Table 30. Do 8 Interviewed and 101/105 Surveyed IHMOs offer their Volunteers Hands-On Interactions with Industrial Heritage?

\begin{tabular}{|l|l|l|}
\hline Interaction (Y/N) & \# of IHMOs & $\%$ of IHMOs \\
\hline Yes & 85 & $78 \%$ \\
\hline No & 24 & $22 \%$ \\
\hline
\end{tabular}

Table 31. Hands-On Opportunities for Volunteers to Interact with Industrial Heritage at 7/8 Interviewed and 80/105 Surveyed IHMOs

\begin{tabular}{|l|l|l|}
\hline Opportunity & \# of IHMOs & $\%$ of IHMOs \\
\hline Operate Equipment & 22 & $25 \%$ \\
\hline Demonstrate Equipment & 19 & $22 \%$ \\
\hline Maintenance & 13 & $15 \%$ \\
\hline
\end{tabular}




\begin{tabular}{|l|l|l|}
\hline Restoration & 13 & $15 \%$ \\
\hline Interact with Artifacts & 8 & $9 \%$ \\
\hline Physical Setting & 13 & $15 \%$ \\
\hline Teaching & 7 & $8 \%$ \\
\hline Interact with Workers & 6 & $7 \%$ \\
\hline Research & 7 & $8 \%$ \\
\hline Docenting & 5 & $6 \%$ \\
\hline Interact with Documents & 4 & $5 \%$ \\
\hline Tours & 3 & $3 \%$ \\
\hline Events & 3 & $3 \%$ \\
\hline Exhibit Development & 4 & $5 \%$ \\
\hline Preservation/Conservation & 5 & $6 \%$ \\
\hline Animals & 2 & $2 \%$ \\
\hline DNM & 2 & $2 \%$ \\
\hline Field Trips & 3 & $3 \%$ \\
\hline Interact with Collections & 10 & $11 \%$ \\
\hline Archaeology & 1 & $1 \%$ \\
\hline Interpretation & 1 & $1 \%$ \\
\hline Partnership & 1 & $1 \%$ \\
\hline Sell Goods & 1 & $1 \%$ \\
\hline Work with Industrial & 1 & $1 \%$ \\
\hline Communities & & \\
\hline
\end{tabular}

Table 32. Do 8 Interviewed and 99/105 Surveyed IHMOs discuss industrialization?

\begin{tabular}{|l|l|l|}
\hline Industrialization (Y/N) & \# of IHMOs & \% of IHMOs \\
\hline Yes & 88 & $82 \%$ \\
\hline No & 19 & $18 \%$ \\
\hline
\end{tabular}


Table 33. Method of Discussion about Industrialization by 5/8 Interviewed and 81/105 Surveyed IHMOs

\begin{tabular}{|l|l|l|}
\hline Methods of Discussion & \# of Museums & \% of IHMOs \\
\hline Introduction of Technological Innovations & 28 & $33 \%$ \\
\hline Specific Local Industry & 24 & $28 \%$ \\
\hline General Local Industry & 17 & $20 \%$ \\
\hline Anthropogenic Landscape Change & 18 & $21 \%$ \\
\hline Growth of Industry & 14 & $16 \%$ \\
\hline Local/Regional Populations & 11 & $13 \%$ \\
\hline Labor Issues & 7 & $8 \%$ \\
\hline Community Development & 5 & $6 \%$ \\
\hline Decline in Industry & 6 & $7 \%$ \\
\hline Specific National Industry & 4 & $5 \%$ \\
\hline Local/Regional Economy & 3 & $3 \%$ \\
\hline Economic Growth & 3 & $3 \%$ \\
\hline Industrial Diversification & 3 & $3 \%$ \\
\hline Micro to Macro & 2 & $2 \%$ \\
\hline Specific Regional Industry & 2 & $2 \%$ \\
\hline Government Involvement & 1 & $1 \%$ \\
\hline Disaster & 2 & $2 \%$ \\
\hline Creation of Jobs & 2 & $1 \%$ \\
\hline Positive and Negative Impacts & 1 & \\
\hline Active Use & $2 \%$ & \\
\hline General National Industry & $2 \%$ & \\
\hline
\end{tabular}


Table 34. Do 8 Interviewed and 101/105 Surveyed IHMOs discuss De-

Industrialization?

\begin{tabular}{|l|l|l|}
\hline De-Industrialization (Y/N) & \# of IHMOs & \% of IHMOs \\
\hline Yes & 50 & $46 \%$ \\
\hline No & 59 & $54 \%$ \\
\hline
\end{tabular}

Table 35. Method of Discussion about De-Industrialization by 4/8 Interviewed and 46/105 Surveyed IHMOs

\begin{tabular}{|l|l|l|}
\hline Methods of Discussion & \# of IHMOs & \% of IHMOs \\
\hline Decline of Industry & 16 & $32 \%$ \\
\hline Transition & 12 & $24 \%$ \\
\hline $\begin{array}{l}\text { Introduction of Technological } \\
\text { Innovations }\end{array}$ & 7 & $14 \%$ \\
\hline Labor Issues & 8 & $16 \%$ \\
\hline Economic Changes & 6 & $12 \%$ \\
\hline Local/Regional Populations & 7 & $14 \%$ \\
\hline Industrial Diversification & 5 & $10 \%$ \\
\hline Anthropogenic Landscape Change & 4 & $8 \%$ \\
\hline Environmental Reclamation & 3 & $6 \%$ \\
\hline Industrial Sites & 3 & $6 \%$ \\
\hline Adaptation and Renewal & 1 & $2 \%$ \\
\hline Urban Renewal & 1 & $2 \%$ \\
\hline Community Development & 1 & $2 \%$ \\
\hline Winners and Losers & 1 & $2 \%$ \\
\hline & & \\
\hline
\end{tabular}


Table 36. \# of Interviewed or Surveyed IHMOs (by State)

\begin{tabular}{|l|l|l|}
\hline State & \# IHMOs & $\%$ of IHMOs \\
\hline Alabama - AL & 1 & $1 \%$ \\
\hline Alaska - AK & 1 & $1 \%$ \\
\hline Arizona - AZ & 4 & $4 \%$ \\
\hline Arkansas - AR & 6 & $5 \%$ \\
\hline California - CA & 5 & $4 \%$ \\
\hline Colorado - CO & 2 & $2 \%$ \\
\hline Connecticut - CT & 2 & $2 \%$ \\
\hline Delaware - DE & 3 & $3 \%$ \\
\hline Florida - FL & 2 & $2 \%$ \\
\hline Georgia - GA & 1 & $1 \%$ \\
\hline Hawaii - HI & 1 & $1 \%$ \\
\hline Idaho - ID & 0 & $0 \%$ \\
\hline Illinois - IL & 7 & $6 \%$ \\
\hline Indiana - IN & 5 & $4 \%$ \\
\hline Iowa - IA & 3 & $3 \%$ \\
\hline Kansas - KS & 1 & $1 \%$ \\
\hline Kentucky - KY & 3 & $3 \%$ \\
\hline Louisiana - LA & 2 & $2 \%$ \\
\hline Maine - ME & 5 & $4 \%$ \\
\hline Maryland - MD & 5 & $4 \%$ \\
\hline Massachusetts - MA & 7 & $6 \%$ \\
\hline Michigan - MI & 2 & $2 \%$ \\
\hline Minnesota - MN & 1 & $1 \%$ \\
\hline Mississippi - MS & 1 & $2 \%$ \\
\hline Missouri - MO & 0 & \\
\hline Montana - MT & 2 & 2 \\
\hline Nebraska - NE & 2 & \\
\hline & & \\
\hline
\end{tabular}




\begin{tabular}{|l|l|l|}
\hline Nevada - NV & 0 & $0 \%$ \\
\hline New Hampshire - NH & 2 & $2 \%$ \\
\hline New Jersey - NJ & 4 & $4 \%$ \\
\hline New Mexico - NM & 1 & $1 \%$ \\
\hline New York - NY & 4 & $4 \%$ \\
\hline North Carolina - NC & 2 & $2 \%$ \\
\hline North Dakota - ND & 0 & $0 \%$ \\
\hline Ohio - OH & 1 & $1 \%$ \\
\hline Oklahoma - OK & 1 & $1 \%$ \\
\hline Oregon - OR & 1 & $1 \%$ \\
\hline Pennsylvania - PA & 6 & $5 \%$ \\
\hline Rhode Island - RI & 0 & $0 \%$ \\
\hline South Carolina - SC & 1 & $1 \%$ \\
\hline South Dakota - SD & 1 & $1 \%$ \\
\hline Tennessee - TN & 0 & $0 \%$ \\
\hline Texas - TX & 2 & $2 \%$ \\
\hline Utah - UT & 1 & $1 \%$ \\
\hline Vermont - VT & 4 & $4 \%$ \\
\hline Virginia - VA & 3 & $3 \%$ \\
\hline Washington - WA & 1 & $1 \%$ \\
\hline West Virginia - WV & 1 & $1 \%$ \\
\hline Wisconsin - WI & 2 & $2 \%$ \\
\hline Wyoming - WY & 1 & $1 \%$ \\
\hline
\end{tabular}

Table 37. Common Social Media Platforms Used by 105 Surveyed IHMOs?

\begin{tabular}{|l|l|l|}
\hline Social Media Platform & \# of IHMOs & \% of IHMOs \\
\hline Facebook & 100 & $95 \%$ \\
\hline Twitter & 66 & $63 \%$ \\
\hline Instagram & 44 & $42 \%$ \\
\hline
\end{tabular}




\begin{tabular}{|l|l|l|}
\hline YouTube & 21 & $20 \%$ \\
\hline FlickR & 14 & $13 \%$ \\
\hline Pinterest & 17 & $16 \%$ \\
\hline Blog & 12 & $11 \%$ \\
\hline Snapchat & 0 & $0 \%$ \\
\hline LinkedIn & 19 & $18 \%$ \\
\hline Tumblr & 4 & $4 \%$ \\
\hline
\end{tabular}

Table 38. Volunteer Tasks at Forty-four Interviewed/Surveyed IHMOs with a Majority of their Volunteers being Female

\begin{tabular}{|l|l|l|}
\hline Volunteer Tasks & \# of IHMOs & \% of IHMOs \\
\hline Docenting & 32 & $73 \%$ \\
\hline Exhibit Work & 23 & $52 \%$ \\
\hline Fundraising & 21 & $48 \%$ \\
\hline Hospitality & 28 & $64 \%$ \\
\hline Maintenance & 20 & $45 \%$ \\
\hline Marketing & 9 & $20 \%$ \\
\hline Membership & 14 & $32 \%$ \\
\hline Museum Store Assistant & 18 & $41 \%$ \\
\hline Newsletter & 12 & $27 \%$ \\
\hline Office Assistant & 12 & $27 \%$ \\
\hline Public Relations & 16 & $36 \%$ \\
\hline Research library & 29 & $66 \%$ \\
\hline Special Events/Programs & 37 & $84 \%$ \\
\hline Tours & 30 & $68 \%$ \\
\hline Volunteer Management & 10 & $23 \%$ \\
\hline Web Design and Social Media & 11 & $25 \%$ \\
\hline Collections Management & 28 & $64 \%$ \\
\hline Finances & 0 & $0 \%$ \\
\hline Administration & 1 & $2 \%$ \\
\hline
\end{tabular}


Table 39. Volunteer Tasks at Fifty-seven Interviewed/Surveyed IHMOs with a Majority of their Volunteers being Male

\begin{tabular}{|l|l|l|}
\hline Volunteer Tasks & \# of IHMOs & \% of IHMOs \\
\hline Docenting & 49 & $86 \%$ \\
\hline Exhibit Work & 37 & $65 \%$ \\
\hline Fundraising & 31 & $54 \%$ \\
\hline Hospitality & 28 & $49 \%$ \\
\hline Maintenance & 44 & $77 \%$ \\
\hline Marketing & 21 & $37 \%$ \\
\hline Membership & 19 & $33 \%$ \\
\hline Museum Store Assistant & 24 & $42 \%$ \\
\hline Newsletter & 23 & $40 \%$ \\
\hline Office Assistant & 18 & $32 \%$ \\
\hline Public Relations & 22 & $39 \%$ \\
\hline Research library & 22 & $39 \%$ \\
\hline Special Events/Programs & 43 & $75 \%$ \\
\hline Tours & 49 & $86 \%$ \\
\hline Volunteer Management & 15 & $26 \%$ \\
\hline Web Design and Social Media & 25 & $44 \%$ \\
\hline Collections Management & 41 & $72 \%$ \\
\hline Finances & 1 & $2 \%$ \\
\hline Administration & 2 & $4 \%$ \\
\hline
\end{tabular}

Table 40. Community Involvement at Forty Interviewed/Surveyed IHMOs with a Majority of their Volunteers being Female

\begin{tabular}{|l|l|l|}
\hline Level of Involvement & \# of IHMOs & \% of Total \\
\hline Community is Actively Involved & 17 & $43 \%$ \\
\hline Community is Moderately Involved & 9 & $23 \%$ \\
\hline Community is Minimally Involved & 12 & $30 \%$ \\
\hline
\end{tabular}

Table 41. Community Involvement at Fifty-six Interviewed/Surveyed IHMOs with a Majority of their Volunteers being Male

\begin{tabular}{|l|l|l|}
\hline Level of Involvement & \# of IHMOs & \% of Total \\
\hline Community is Actively Involved & 17 & $30 \%$ \\
\hline Community is Moderately Involved & 12 & $21 \%$ \\
\hline Community is Minimally Involved & 19 & $34 \%$ \\
\hline
\end{tabular}


Table 42. Volunteer Motivations at Forty-three Interviewed/Surveyed IHMOs with a Majority of their Volunteers being Female

\begin{tabular}{|l|l|l|}
\hline Volunteer Motivation & \# of IHMOs & \% of IHMOs \\
\hline A Sense of Belonging & 15 & $35 \%$ \\
\hline Industrial Assets & 4 & $9 \%$ \\
\hline Interest in History & 14 & $33 \%$ \\
\hline General Support & 8 & $19 \%$ \\
\hline Interest in Local History & 10 & $23 \%$ \\
\hline Teaching/Sharing & 5 & $12 \%$ \\
\hline Industry & 3 & $7 \%$ \\
\hline Looking for Purpose & 6 & $14 \%$ \\
\hline Preservation & 4 & $9 \%$ \\
\hline Museum Mission/Goals & 4 & $9 \%$ \\
\hline Personal Heritage & 3 & $7 \%$ \\
\hline Help Local Community & 5 & $12 \%$ \\
\hline Like the Museum & 4 & $9 \%$ \\
\hline Previous experiences & 1 & $2 \%$ \\
\hline Experience/Learning & 7 & $16 \%$ \\
\hline Pride in Museum & 3 & $7 \%$ \\
\hline Fulfilling Work & 2 & $5 \%$ \\
\hline Museum Events & 1 & $2 \%$ \\
\hline Local Community Pride & 2 & $5 \%$ \\
\hline Beneficial to Health & 1 & $2 \%$ \\
\hline Local Heritage Pride & 1 & $2 \%$ \\
\hline Location & 1 & $2 \%$ \\
\hline Cross organizational support & 1 & $2 \%$ \\
\hline Personal Pride & 0 & $0 \%$ \\
\hline Personal Projects & 0 & $0 \%$ \\
\hline Training & 2 & $5 \%$ \\
\hline Interest in Nature/Environment & 0 & $0 \%$ \\
\hline Enthusiasts/Hobbyists & 0 & $0 \%$ \\
\hline Employer Support & 0 & $0 \%$ \\
\hline Gardening & 1 & $2 \%$ \\
\hline
\end{tabular}


Table 42. Volunteer Motivations at Fifty-seven Interviewed/Surveyed IHMOs with a Majority of their Volunteers being Male

\begin{tabular}{|l|l|l|}
\hline Volunteer Motivations & \# of IHMOs & \% of IHMOs \\
\hline A Sense of Belonging & 10 & $18 \%$ \\
\hline Industrial Assets & 15 & $26 \%$ \\
\hline Interest in History & 11 & $19 \%$ \\
\hline General Support & 8 & $14 \%$ \\
\hline Interest in Local History & 5 & $9 \%$ \\
\hline Teaching/Sharing & 9 & $16 \%$ \\
\hline Industry & 8 & $14 \%$ \\
\hline Looking for Purpose & 7 & $12 \%$ \\
\hline Preservation & 7 & $12 \%$ \\
\hline Museum Mission/Goals & 6 & $11 \%$ \\
\hline Personal Heritage & 5 & $9 \%$ \\
\hline Help Local Community & 5 & $9 \%$ \\
\hline Like the Museum & 5 & $9 \%$ \\
\hline Previous experiences & 6 & $11 \%$ \\
\hline Experience/Learning & 4 & $7 \%$ \\
\hline Pride in Museum & 2 & $4 \%$ \\
\hline Fulfilling Work & 2 & $4 \%$ \\
\hline Museum Events & 1 & $2 \%$ \\
\hline Local Community Pride & 1 & $2 \%$ \\
\hline Beneficial to Health & 1 & $2 \%$ \\
\hline Local Heritage Pride & 1 & $2 \%$ \\
\hline Location & 0 & $0 \%$ \\
\hline Cross organizational support & 0 & $0 \%$ \\
\hline Personal Pride & 1 & $2 \%$ \\
\hline Personal Projects & 1 & $2 \%$ \\
\hline Training & 0 & $0 \%$ \\
\hline Interest in Nature/Environment & 1 & $2 \%$ \\
\hline Enthusiasts/Hobbyists & 1 & $2 \%$ \\
\hline Employer Support & 1 & $2 \%$ \\
\hline Gardening & 1 & $2 \%$ \\
\hline & & \\
\hline
\end{tabular}


Table 43. Perceptions of Industrial Heritage from Eight Interviewed/Surveyed IHMOs with a Majority of their Volunteers between Thirteen and Thirty-nine years old

\begin{tabular}{|l|l|l|}
\hline Perceptions of Industrial Heritage & \# of IHMOs & \% of IHMOs \\
\hline G-Industry & 2 & $25 \%$ \\
\hline G-History of Industry & 2 & $25 \%$ \\
\hline G-History of Technology & 1 & $13 \%$ \\
\hline G-Industrial Artifacts & 0 & $0 \%$ \\
\hline G-Industry as Shaping Community & 0 & $0 \%$ \\
\hline G-People & 1 & $13 \%$ \\
\hline G-Physical Remains & 3 & $38 \%$ \\
\hline G-Preservation & 1 & $13 \%$ \\
\hline General & 7 & $88 \%$ \\
\hline Mixed & 0 & $0 \%$ \\
\hline S-Preservation & 1 & $13 \%$ \\
\hline S-Transportation Network & 0 & $0 \%$ \\
\hline Specific & 1 & $13 \%$ \\
\hline
\end{tabular}

Table 44. Perceptions of Industrial Heritage from Eighty-five

Interviewed/Surveyed IHMOs with a Majority of their Volunteers being Sixty years or older

\begin{tabular}{|l|l|l|}
\hline Perceptions of Industrial Heritage & \# of IHMOs & \% of IHMOs \\
\hline G-Industry & 10 & $12 \%$ \\
\hline G-History of Industry & 14 & $16 \%$ \\
\hline G-History of Technology & 8 & $9 \%$ \\
\hline G-Industrial Artifacts & 6 & $7 \%$ \\
\hline G-Industry as Shaping Community & 6 & $7 \%$ \\
\hline G-People & 8 & $9 \%$ \\
\hline G-Physical Remains & 7 & $8 \%$ \\
\hline G-Preservation & 2 & $2 \%$ \\
\hline General & 47 & $55 \%$ \\
\hline Mixed & 16 & $19 \%$ \\
\hline S-Preservation & 9 & $11 \%$ \\
\hline S-Transportation Network & 9 & $11 \%$ \\
\hline Specific & 22 & $26 \%$ \\
\hline
\end{tabular}


Table 45. A Comparison of Thirty-two Interviewed/Surveyed IHMOs with Minimal Community Involvement and the Population Density around their IHMO

\begin{tabular}{|l|l|l|}
\hline Population Densities & \# of IHMOs & \% of IHMOs \\
\hline Rural & 14 & $44 \%$ \\
\hline Somewhere-in-Between & 11 & $34 \%$ \\
\hline Urban & 7 & $22 \%$ \\
\hline
\end{tabular}

Table 46. A Comparison of Twenty-seven Interviewed/Surveyed IHMOs with no Staff Members and the Population Density around their IHMO

\begin{tabular}{|l|l|l|}
\hline Community Involvement & \# of IHMOs & \% of IHMOs \\
\hline Actively Involved Community & 7 & $26 \%$ \\
\hline Moderately Involved Community & 3 & $11 \%$ \\
\hline Minimally Involved Community & 12 & $44 \%$ \\
\hline
\end{tabular}

Table 47. A Comparison of Thirty-eight Interviewed/Surveyed IHMOs with between One to Three Staff Members and the Level of Community Involvement around their IHMO

\begin{tabular}{|l|l|l|}
\hline Community Involvement & \# of IHMOs & \% of IHMOs \\
\hline Actively Involved Community & 10 & $26 \%$ \\
\hline Moderately Involved Community & 9 & $24 \%$ \\
\hline Minimally Involved Community & 13 & $34 \%$ \\
\hline
\end{tabular}

Table 48. A Comparison of Thirty-one Interviewed/Surveyed IHMOs with between Four to Nine Staff Members and the Level of Community Involvement around their IHMO

\begin{tabular}{|l|l|l|}
\hline Community Involvement & \# of IHMOs & \% of IHMOs \\
\hline Actively Involved Community & 13 & $42 \%$ \\
\hline Moderately Involved Community & 9 & $29 \%$ \\
\hline Minimally Involved Community & 7 & $23 \%$ \\
\hline
\end{tabular}

Table 49. A Comparison of Seventeen Interviewed/Surveyed IHMOs with Ten or more Staff Members and the Level of Community Involvement around their IHMO

\begin{tabular}{|l|l|l|}
\hline Community Involvement & \# of IHMOs & \% of IHMOs \\
\hline Actively Involved Community & 9 & $53 \%$ \\
\hline Moderately Involved Community & 2 & $12 \%$ \\
\hline Minimally Involved Community & 1 & $6 \%$ \\
\hline
\end{tabular}


Table 50. A Comparison of Thirty-nine Interviewed/Surveyed IHMOs with Active Community Involvement and the Population Density around their IHMO

\begin{tabular}{|l|l|l|}
\hline Population Densities & \# of IHMOs & \% of IHMOs \\
\hline Rural & 9 & $23 \%$ \\
\hline Somewhere-in-Between & 21 & $54 \%$ \\
\hline Urban & 9 & $23 \%$ \\
\hline
\end{tabular}

Table 51. How Sixty-three Interviewed/Surveyed IHMOs discuss Industrialization when the Industries Represented in their Collections/Exhibits are still in Operation

\begin{tabular}{|l|l|l|}
\hline Methods of discussion & \# of IHMOs & \% of Total \\
\hline $\begin{array}{l}\text { Introduction of Technological } \\
\text { Innovations }\end{array}$ & 21 & $33 \%$ \\
\hline Specific Local Industry & 16 & $25 \%$ \\
\hline General Local Industry & 11 & $17 \%$ \\
\hline Anthropogenic Landscape Change & 10 & $16 \%$ \\
\hline Growth of Industry & 12 & $19 \%$ \\
\hline Local/Regional Populations & 7 & $11 \%$ \\
\hline Labor Issues & 5 & $8 \%$ \\
\hline Community Development & 3 & $5 \%$ \\
\hline Decline in Industry & 0 & $0 \%$ \\
\hline Specific National Industry & 3 & $5 \%$ \\
\hline Local/Regional Economy & 1 & $2 \%$ \\
\hline Economic Growth & 3 & $5 \%$ \\
\hline Industrial Diversification & 3 & $5 \%$ \\
\hline Micro to Macro & 2 & $3 \%$ \\
\hline Specific Regional Industry & 2 & $3 \%$ \\
\hline Government Involvement & 1 & $2 \%$ \\
\hline Disaster & 1 & $2 \%$ \\
\hline Creation of Jobs & 0 & $0 \%$ \\
\hline Positive and Negative Impacts & 2 & $3 \%$ \\
\hline Active Use & 1 & $2 \%$ \\
\hline General National Industry & 2 & $3 \%$ \\
\hline
\end{tabular}


Table 52. How Twenty-two Interviewed/Surveyed IHMOs discuss Industrialization when the Industries Represented in their Collections/Exhibits are no-longer in Operation

\begin{tabular}{|l|l|l|}
\hline Methods of discussion & \# of IHMOs & \% of Total \\
\hline Introduction of Technological Innovations & 7 & $32 \%$ \\
\hline Specific Local Industry & 8 & $36 \%$ \\
\hline General Local Industry & 6 & $27 \%$ \\
\hline Anthropogenic Landscape Change & 8 & $36 \%$ \\
\hline Growth of Industry & 2 & $9 \%$ \\
\hline Local/Regional Populations & 4 & $18 \%$ \\
\hline Labor Issues & 2 & $9 \%$ \\
\hline Community Development & 2 & $9 \%$ \\
\hline Decline in Industry & 0 & $0 \%$ \\
\hline Specific National Industry & 1 & $5 \%$ \\
\hline Local/Regional Economy & 2 & $9 \%$ \\
\hline Economic Growth & 0 & $0 \%$ \\
\hline Industrial Diversification & 0 & $0 \%$ \\
\hline Micro to Macro & 0 & $0 \%$ \\
\hline Specific Regional Industry & 0 & $0 \%$ \\
\hline Government Involvement & 0 & $0 \%$ \\
\hline Disaster & 0 & $0 \%$ \\
\hline Creation of Jobs & 1 & $5 \%$ \\
\hline Positive and Negative Impacts & 0 & $0 \%$ \\
\hline Active Use & 1 & $5 \%$ \\
\hline General National Industry & 0 & $0 \%$ \\
\hline
\end{tabular}

Table 53. How Interviewed/Surveyed Thirty-two IHMOs discuss Deindustrialization when the Industries Represented in their Collections/Exhibits are still in Operation

\begin{tabular}{|l|l|l|}
\hline Methods of Discussion & \# of IHMOs & \% of IHMOs \\
\hline Decline of Industry & 11 & $34 \%$ \\
\hline Transition & 10 & $31 \%$ \\
\hline
\end{tabular}

Table 54. How Fourteen Interviewed/Surveyed IHMOs discuss Deindustrialization when the Industries Represented in their Collections/Exhibits are no-longer in Operation

\begin{tabular}{|l|l|l|}
\hline Methods of Discussion & \# of IHMOs & \% of IHMO \\
\hline Decline of Industry & 5 & $36 \%$ \\
\hline Transition & 2 & $14 \%$ \\
\hline
\end{tabular}


Table 55. An Alternative Breakdown of the Demographic Groups of Volunteers in One Hundred and Thirteen Interviewed/Surveyed IHMOs

\begin{tabular}{|c|c|c|c|c|c|c|}
\hline Age & Gender & Ethnicity & Education & Employment & $\begin{array}{l}\text { \# of } \\
\text { IHMOs }\end{array}$ & $\begin{array}{l}\text { \% of } \\
\text { IHMOs }\end{array}$ \\
\hline $60+$ & Male & White & Bachelor's & Retired & 21 & $19 \%$ \\
\hline $60+$ & Male & White & Bachelor's & Mixed/Unsure & 1 & $1 \%$ \\
\hline $60+$ & Male & White & $\begin{array}{l}\text { High School } \\
\text { GED }\end{array}$ & Retired & 3 & $3 \%$ \\
\hline $60+$ & Male & White & Master's & Retired & 4 & $4 \%$ \\
\hline $60+$ & Male & White & Professional & Retired & 2 & $2 \%$ \\
\hline $60+$ & Male & White & $\begin{array}{l}\text { College but no } \\
\text { degree }\end{array}$ & Retired & 5 & $4 \%$ \\
\hline $60+$ & Male & White & $\begin{array}{l}\text { College but no } \\
\text { degree }\end{array}$ & $\begin{array}{l}\text { Employed for } \\
\text { Wages }\end{array}$ & 1 & $1 \%$ \\
\hline $60+$ & Male & White & Trade School & Retired & 5 & $4 \%$ \\
\hline $60+$ & Male & White & $\begin{array}{l}\text { Widely } \\
\text { Varied/Unsure }\end{array}$ & Retired & 3 & $3 \%$ \\
\hline $60+$ & Other & White & Bachelor's & Retired & 2 & $2 \%$ \\
\hline $60+$ & Other & $\begin{array}{l}\text { Prefer } \\
\text { Not To } \\
\text { Answer }\end{array}$ & $\begin{array}{l}\text { Widely } \\
\text { Varied/Unsure }\end{array}$ & Retired & 1 & $1 \%$ \\
\hline $60+$ & Other & White & Master's & Retired & 1 & $1 \%$ \\
\hline $60+$ & N/A & N/A & Mixed/Unsure & Mixed/Unsure & 1 & $1 \%$ \\
\hline $60+$ & N/A & N/A & N/A & N/A & 1 & $1 \%$ \\
\hline $60+$ & N/A & White & Trade School & $\begin{array}{l}\text { Employed for } \\
\text { Wages }\end{array}$ & 1 & $1 \%$ \\
\hline $60+$ & N/A & White & Master's & Retired & 1 & $1 \%$ \\
\hline $60+$ & N/A & White & Bachelor's & Retired & 1 & $1 \%$ \\
\hline $60+$ & Female & $\begin{array}{l}\text { Prefer } \\
\text { Not To } \\
\text { Answer }\end{array}$ & Bachelor's & Retired & 2 & $2 \%$ \\
\hline $60+$ & Female & White & Bachelor's & $\begin{array}{l}\text { Employed for } \\
\text { Wages }\end{array}$ & 1 & $1 \%$ \\
\hline $60+$ & Female & White & $\begin{array}{l}\text { High School } \\
\text { GED }\end{array}$ & Retired & 4 & $4 \%$ \\
\hline $60+$ & Female & White & Master's & Retired & 2 & $2 \%$ \\
\hline $60+$ & Female & White & N/A & Retired & 1 & $1 \%$ \\
\hline $60+$ & Female & White & $\begin{array}{l}\text { Some College, } \\
\text { No Degree }\end{array}$ & Retired & 2 & $2 \%$ \\
\hline
\end{tabular}




\begin{tabular}{|c|c|c|c|c|c|c|}
\hline $60+$ & Female & White & Bachelor's & Retired & 22 & $19 \%$ \\
\hline $60+$ & Female & White & Mixed/Unsure & Retired & 2 & $2 \%$ \\
\hline $40-59$ & Male & White & Bachelor's & Retired & 2 & $2 \%$ \\
\hline $40-59$ & Male & White & Bachelor's & $\begin{array}{l}\text { Employed for } \\
\text { Wages }\end{array}$ & 3 & $3 \%$ \\
\hline $40-59$ & Male & White & Master's & Retired & 1 & $1 \%$ \\
\hline $40-59$ & Male & White & $\begin{array}{l}\text { Widely } \\
\text { Varied/Unsure }\end{array}$ & Mixed/Unsure & 1 & $1 \%$ \\
\hline $40-59$ & Male & White & N/A & $\mathrm{N} / \mathrm{A}$ & 1 & $1 \%$ \\
\hline $40-59$ & Other & White & Bachelor's & Retired & 2 & $2 \%$ \\
\hline $40-59$ & N/A & White & Bachelor's & $\mathrm{N} / \mathrm{A}$ & 1 & $1 \%$ \\
\hline $40-59$ & Female & White & $\begin{array}{l}\text { High School } \\
\text { GED }\end{array}$ & Mixed/Unsure & 1 & $1 \%$ \\
\hline $40-59$ & Female & White & Trade School & $\begin{array}{l}\text { Employed for } \\
\text { wages }\end{array}$ & 1 & $1 \%$ \\
\hline $40-59$ & Female & White & $\begin{array}{l}\text { Bachelor's } \\
\text { degree }\end{array}$ & Retired & 1 & $1 \%$ \\
\hline $40-59$ & Female & White & $\begin{array}{l}\text { Some College, } \\
\text { No Degree }\end{array}$ & $\begin{array}{l}\text { Employed for } \\
\text { wages }\end{array}$ & 1 & $1 \%$ \\
\hline $21-39$ & Male & White & $\begin{array}{l}\text { Some high } \\
\text { school, no } \\
\text { diploma }\end{array}$ & $\begin{array}{l}\text { Unable to } \\
\text { work }\end{array}$ & 1 & $1 \%$ \\
\hline $21-39$ & Male & White & $\begin{array}{l}\text { High School } \\
\text { GED }\end{array}$ & Mixed/Unsure & 1 & $1 \%$ \\
\hline $21-39$ & Male & White & $\begin{array}{l}\text { Bachelor's } \\
\text { degree }\end{array}$ & $\begin{array}{l}\text { Employed for } \\
\text { wages }\end{array}$ & 2 & $2 \%$ \\
\hline $21-39$ & Female & White & $\begin{array}{l}\text { Master's } \\
\text { degree }\end{array}$ & $\begin{array}{l}\text { Employed for } \\
\text { wages }\end{array}$ & 1 & $1 \%$ \\
\hline $21-39$ & Female & White & $\begin{array}{l}\text { Bachelor's } \\
\text { degree }\end{array}$ & $\begin{array}{l}\text { Part-Time } \\
\text { Student }\end{array}$ & 1 & $1 \%$ \\
\hline $13-20$ & Female & White & $\begin{array}{l}\text { Some high } \\
\text { school, no } \\
\text { diploma }\end{array}$ & $\begin{array}{l}\text { Full-Time } \\
\text { Student }\end{array}$ & 1 & $1 \%$ \\
\hline $\begin{array}{l}\text { Mixed/ } \\
\text { Unsure }\end{array}$ & Female & White & $\begin{array}{l}\text { High School } \\
\text { GED }\end{array}$ & Mixed/Unsure & 1 & $1 \%$ \\
\hline
\end{tabular}




\section{Bibliography}

Alexander, M. \& Herring, D. (2020). Beyond Binary. American Alliance of Museums. Retrieved October 13, 2020 from https://www.aam-us.org/2020/02/27/beyond-binary/ American Association of Museums. (2010). Demographic Changes and the Future of Museums. Retrieved October 14, 2020, from https://www.aam-us.org/wpcontent/uploads/2017/12/Demographic-Change-and-the-Future-of-Museums.pdf

Amichai-Hamburger, Y. (2008). Potential and promise of online volunteering. Computers in Human Behavior, 24(2): 544-562.

Baldwin, J. (2019). Museums as a Pink Collar Profession. American Alliance of Museums. Retrieved October 12, 2020, from https://www.aamus.org/2019/03/25/museums-as-a-pink-collar-profession/

Baldwin, J. \& Ackerson, A. (2017). Women in the Museum: Lessons from the Workplace. New York: Routledge.

Battle-Baptiste, W. (2011). Black Feminist Archaeology. New York: Routledge. Retrieved October 13, 2020, from https://colmtu.primo.exlibrisgroup.com/permalink/01COL_MTU/13nj5id/alma999151971904769

Benjamin, P. L. (1932). The Family Society and the Depression. The Annals of the American Academy of Political and Social Science, 160: 135-143.

Berger, H. \& Burger, S. (2019). (De-) Industrial Heritage: An Introduction. Labor, 16 (1): $1-27$.

Bishop, S. (1902). The New Movement in Charity. American Journal of Sociology, 7(5): 595-610.

Bogardus, E. (1923). The Concept of Unselfish Service. The Journal of Social Forces 1(2): 100-102.

Brandt, L. (2016). First in the Homes of His Countrymen: George Washington's Mount Vernon in the American Imagination. University of Virginia Press.

Brindle, D. (2015). A history of the volunteer: how active citizenship became the big society. The Guardian. Retrieved December 18, 2019, from https://www.theguardian.com/voluntary-sector-network/2015/jun/01/a-history-of-thevolunteer-how-active-citizenship-became-the-big-society

Bronski, M. (2011). A Queer History of the United States. Boston, MA: Beacon Press. 
Brown et al. (2011). Becoming an Older Volunteer: A Grounded Theory Study. Nursing Research and Practices.

Brugge, D. \& Goble, R. (2002). The History of Uranium Mining and the Navajo People. American Journal of Public Health, 92(9): 1410-1419. Retrieved December 28, 2020, from https://www.ncbi.nlm.nih.gov/pmc/articles/PMC3222290/

Burns, A. T. (1932). Community Responsibility for the Relief and Prevention of Unemployment. Proceedings of the Academy of Political Science, 14(4): 5-10.

Carson, E. D. (1999). Comment: On Defining and Measuring Volunteering in the United States and Abroad. Law and Contemporary Problems, 52(4), Amateurs in Public Service: Volunteering, Service-Learning, and Community Service: 67-71.

Carter et al. (2011). Defetishizing the Plantation: African American's in the Memorialized South. Historical Geography, 39: 128-146.

Charmaz, K. (1996). The Search for Meanings - Grounded Theory. In. (Ed. J. A. Smith, R Harre, \& L. Van Langenhove (Eds.), Rethinking Methods in Psychology (pp.22-49). London: Sage Publishing.

Charmaz, K. (2014). Constructing Grounded Theory: A Practical Guide Through Qualitative Analysis. Thousand Oaks, CA: SAGE Publications, Ltd.

Csikszentmihalyi, M. \& Hermanson, K. (1996). Intrinsic Motivation in Museums: Why Does One Want to Learn?. In (Ed. J. H. Falk and L. D. Dierking) Public Institutions for Personal Learning (pp. 67-75). American Association of Museums. Retrieved September 22, 2020, from https://arts.berkeley.edu/wp-content/uploads/2016/01/CsikszentmihalyiHermanson-1995_Intrinsic-Motivation-in-Museums.pdf

Corbin, J.M., \& Strauss, A. (2008). Basics of qualitative research: Techniques and procedures for developing grounded theory. Thousand Oaks: Sage Publications.

Corporation for National and Community Service. (n.a). Demographics. Retrieved September 30, 2020, from https://www.nationalservice.gov/serve/via/demographics

Curly, A. (2019). T'áá hwó ají t'éego and the Moral Economy of Navajo Coal Workers. Annals of the American Association of Geographers, 109(1): 71-86.

Dillman et al. (2009). Internet, mail, and mixed-mode surveys: the tailored design method. Ed. $3^{\text {rd }}$. New Yok. John Wiley \& Sons, Inc.

DiMaggio, P. (1986). Cultural Entrepreneurship in the $19^{\text {th }}$ Century Boston. In Nonprofit enterprises in the arts. New York: Oxford University Press.

Devine, E. T. (1913). Social Ideals Implied in Present American Programs of Voluntary Philanthropy. American Journal of Sociology, 18(6): 784-795. 
Donovan, S. \& Shimabukuro, J. (2016). The Fair Labor Standards Act (FLSA) Child Labor Provisions. Congressional Research Service. Retrieved December 22, 2020, from https://fas.org/sgp/crs/misc/R44548.pdf.

Funk, M. \& Pashkevich, A. (2020). Representations of industrial heritage in tourism materials: Analysing androcentric discourse in textual and visual content. Dos Algarves: A Multidisciplinary e-Journal, 36: 41-58. Retrieved August 29, 2020 from https://www.researchgate.net/publication/341874381_Representations_of_industrial_heri tage_in_tourism_marketing_materials_Analysing_androcentric_discourse_in_textual_an d_visual_content.

Eichstedt, J. \& Small, S. (2002). Representations of Slavery: Race and Ideology in Southern Plantation Museums. Washington, DC: Smithsonian Institution Press.

Farmer, G. \& Piotrkowski, C. (2009) African and European American Women's Volunteerism and Activism: Similarities in Volunteering and Differences in Activism. Journal of Human Behavior in the Social Environment, 19(2): 196-212. Retrieved December 31, 2020, from https://www.tandfonline.com/doi/full/10.1080/10911350802687182?scroll=top\&needAc cess $=$ true

Gender Equity in Museums Movement. (2018). Survey Reveals Extent of Gender Inequity in Museum Workplace. Retrieved December 31, 2020, from https://www.genderequitymuseums.com/single-post/2018-survey-reveals-extent-ofgender-inequity-in-museum-workplace

Goddin, G. (2002). Whose Heritage Railway is It? - A Study of Volunteer Motivation. Japan Railway \& Transport Review, 32: 46-49.

Goodland, S. \& McIvor, S. (1998). Museum Volunteers: Good Practice in the Management of Volunteers. New York: Routledge.

Google Books Ngram Viewer. (2020). Volunteerism. Retrieved October 22, 2020, from https://books.google.com/ngrams/graph?content=volunteerism\&year_start=1800\&year_e $\mathrm{nd}=2010 \&$ corpus $=0 \&$ smoothing $=3 \&$ direct_url $=\mathrm{t} 1 \% 3 \mathrm{~B} \% 2 \mathrm{Cvolunteerism} \% 3 \mathrm{~B} \% 2 \mathrm{Cc} 0$

Groen et al. (2017). An Introduction to Grounded Theory: Choosing and Implementing an Emergent Method. American Society for Engineering Education.

Gurock, J. S. (1981). Jacob A. Riis: Christian Friend or Missionary Foe? Two Jewish Views. American Jewish History, 71(1): 29-47.

Haigney, S. (2020). Museums Have A Docent Problem. Slate. Retrieved October 13, 2020, from https://slate.com/culture/2020/08/museums-train-white -docents-talk-raceart.html 
Hochbaum, A. (2015). The History Of Volunteering At A Glance. Givingway. Retrieved October 18, 2020, from https://www.givingway.com/blog/the-history-of-volunteering-ata-glance

Holmes, K. (2006). Experiential learning or exploitation? Volunteering for work experience in the UK museums sector. Museum Management and Curatorship, 21: 240253.

Holmes et al. (2010). Developing the Dimensions of Tourism Volunteering. Leisure Sciences, 32: 255-269.

Holmes, K. (1999). Changing Times: Volunteering in the Heritage Sector 1984-1998. Voluntary Action, 1(2): 21-35.

Holmes, K. \& Smith, K. (2009). Managing Volunteers in Tourism: Attractions, Destinations and Events. New York: Elsevier Ltd.

Hoelscher, S. (2003). Making Place, Making Race: Performances of Whiteness in the Jim Crow South. Annals of the Association of American Geographers, 93(3): 657-686.

Ihm, J. (2017). Classifying and Relating Different Types of Online and Offline Volunteering. Voluntas, 28: 400-419.

Industrial Heritage. (n.d). European Heritage Volunteers. Retrieved November 12, 2019, from https://www.heritagevolunteers.eu/en/ProjectsBySites/IndustrialHeritage?.

Jacob, S. \& Furgerson, S. (2012). Writing Interview Protocols and Conducting Interviews: Tips for Students New to the Field of Qualitative Research. The Qualitative Report, 17(42): 1-10.

Kaufman, N. (2004). Historic Places and the Diversity Deficit in Heritage Preservation. National Park Service. Retrieved October 2, 2020, from https://home1.nps.gov/CRMJournal/summer2004/article3.html

Kessier-Harris, A. (2018). Women Have Always Worked: A Concise History. $2^{\text {nd }}$ Ed. Chicago: University of Illinois Press.

Konadu, K. (2010). The Akan Diaspora in the Americas. Oxford: Oxford University Press.

Lander, H. (2006). Maintaining a viable volunteer organization: The Sydney Heritage Fleet. Australian Journal of Multi-disciplinary Engineering, 4(1): 31-36.

Langton, S. (1982). The New Voluntarism. In J. D. Harman (Ed.), Volunteerism in the Eighties: Fundamental Issues in Voluntary Action (pp. 3-21). New York: University Press of America.

Lee, Albert. (1980). Henry Ford and the Jews. New York: Stein and Day. 
Marsh, P. A. (2015). A Black Logger's Journey: Jackson Parish, Louisiana, to Wallowa County, Oregon. Oregon Historical Quarterly, 116 (4), 500-521. Retrieved October 13, 2020, from https://www.jstor.org/stable/10.5403/oregonhistq.116.4.0500

Martin, E. S. (1925). A Double Barreled Social Agency: The Boy Scouts of America. Social Forces, 4(1): 94-97.

Marx, K., Engels, F., Mandel, E., \& Fowkes, B. (1990). Capital: A critique of political economy. London: Penguin in association with New Left Review.

Mattingly, J. (1993). Volunteers in Museums and Art Galleries: The Report of a Survey into the Work of Volunteers in Museums and Galleries in the United Kingdom. The Volunteer Centre UK.

Mattis, J. et al. (2004). Who Will Volunteer? Religiosity, Everyday Racism, and Social Participation Among African American Men. Journal of Adult Development, 11: 261272.

Merritt, E. (2016). Volunteers and Museum Labor. American Alliance of Museums. Retrieved September 30, 2020, from https://www.aam-us.org/2016/10/18/volunteers-andmuseum-labor/

Merritt, E. (2019). Museums and Equity: Volunteers. American Alliance of Museums. Retrieved September 30, 2020, from https://www.aam-us.org/2019/07/22/museums-andequity-volunteers/

Middleton, M. \& Morgan-Hubbard, S. (2018). Woman/Trans/Femme in the Museum. Journal of Museum Education, 43(3): 174-178.

Miles, M., Huberman, A., \& Saldaña, J. (2013). Qualitative Data Analysis: A Methods Sourcebook. Ed. $3^{\text {rd }}$. New York: Sage Publications.

Sorensen, L. (n.d.). "Mongan, Agnes." Dictionary of Art Historians. Retrieved December 31, 2020, from http://www.arthistorians.info/mongana.

Morse, J. \& Maddox, L. (2014). Analytic integration in qualitatively driven (QUAL) mixed and multiple methods designs. In Flick, U. The SAGE handbook of qualitative data analysis (pp. 524-539). London: SAGE Publications Ltd.

National Park Service. (2019). What is a National Heritage Area? National Park Service. Retrieved October 31, 2020 from https://www.nps.gov/articles/what-is-a-nationalheritage-

area.htm\#: :text=Benefits\%20of\%20NHAs\&text=Improved $\% 20$ Quality $\% 20$ of $\% 20 \mathrm{Life}$ $\% 20 \%$ E2\%80\%93Through,improve\%20local\%20quality\%20of\%20life.

Parker, S. R. (1997). Volunteering - Altruism, Markets, Causes and Leisure. World Leisure \& Recreation, 39(3): 4-5. 
Pearce, J. (1993). The Organizational Behavior of Unpaid Workers. New York: Routledge.

Petrzelka, P. \& Mannon, S. E. (2006). Keepin’ This Little Town Going: Gender and Volunteerism in Rural America. Gender \& Society, 20(2): 236-258.

Prestwich, P. (1983). Museums, Friends and Volunteers - A Delicate Relationship. The International Journal of Museum Management and Curatorship, 2: 171-176.

Public Broadcasting Service. (2004). Slavery and the Making of America Timeline. Public Broadcasting Service. Retrieved December 27, 2020, from https://www.thirteen.org/wnet/slavery/timeline/1739.html

Ratcliffe et al. (2016). Defining Rural at the US Census Bureau. United States Census Bureau. Retrieved October 26, 2020, from https://www2.census.gov/geo/pdfs/reference/ua/Defining_Rural.pdf

Rhoden, S., Inseon, E. M., \& Ralston R. (2009). Volunteer motivation in heritage railways: a study of the West Somerset Railway volunteers. Journal of Heritage Tourism, 4(1): 19-36.

Rochester, C., Paine, A. E., \& Howlett, S. (2010). Making Sense of Volunteering: Perspectives, principles and definitions. In C. Rochester, A. E. Paine, and S. Howlett (Eds.), Volunteering and Society in the 21st Century (pp. 9-23). England: Palgrave Macmillian.

Romano, R. \& Papastefanaki, L. (2020). Women and Gender in the Mines: Challenging Masculinity Through History: An Introduction. International Review of Public History, 65 (2), 191-230. Retrieved September 29, 2020, from https://www.cambridge.org/core/journals/international-review-of-socialhistory/article/women-and-gender-in-the-mines-challenging-masculinity-through-historyan-introduction/6BBA9A00B8A0BC11DF01919C33EA210D

Rosenburg, S. (2013). Volunteering: History of an American value. Volunteer Match. Retrieved October 18, 2020, from http://blogs.volunteermatch.org/engagingvolunteers/2013/04/18/volunteeringhistory-ofan-american-value/

Rowley, J. \& Fullwood, R. (2017). Knowledge Sharing in Context: The Case of Volunteer Development at a Heritage Site. Presented at the European Conference on Knowledge Management. Barcelona, Spain. Retrieved November 24, 2019, from https://e-space.mmu.ac.uk/619717/.

Ryan, R., \& Deci, E. (2000). Intrinsic and Extrinsic Motivations: Classic Definitions and New Directions. Contemporary Educational Psychology, (25): 54-67. 
Schuermann, D. (2016). Millennial College Students and Volunteering: Their Motivations and Perceived Obstacles. Graduate School of the University of MissouriColumbia, Master of Arts, Master's Thesis.

Schwartz, D. F. (2005). Dude, Where's My Museum? Inviting Teens to Transform Museums. American Alliance of Museums. Retrieved October 13, 2020, from https://www.mercermuseum.org/wp-content/uploads/2014/10/Dude-Wheres-MyMuseum..pdf

Scott, C. and Medaugh, M. (2017). Axial Coding. In J. Matthes, C.S. Davis and R.F. Potter (Eds.). The International Encyclopedia of Communication Research Methods. Thousand Oaks: John Wiley \& Sons, Inc.

Smith, D. H. (1994). Determinants of Voluntary Association Participation and Volunteering: A Literature Review. Nonprofit and Voluntary Sector Quarterly, 23(3): 243-263.

Smith, L. (2006). Use Of Heritage. New York: Routledge.

Spera et al. (2013). Volunteering as a Pathway to Employment: Does Volunteering Increase Odds of Finding a Job for the Out of Work? Corporation for National and Community Service. Retrieved October 28, 2020, from https://www.nationalservice.gov/sites/default/files/upload/employment_research_report.p df

Stebbins, R. A. (1996). Volunteering: A Serious Leisure Perspective. Nonprofit and Voluntary Sector Quarterly, 12(2): 211-224.

Stukas, A. A., Snyer, M., \& Clary, E. G. (1999). The Effects of "Mandatory Volunteerism" on Intentions to Volunteer. American Psychological Society, 10(1): 59-64.

Sweetland, M. (1943). The New Democracy in Social Welfare. The Antioch Review, 3(3): 418-424.

Swienty, T. (2008). The other half: the life of Jacob Riis and the world of immigrant America. New York: W. W. Norton \& Company.

Taksa, L. (2019). 'Hidden In Plain Sight': Uncovering the gendered heritage of an industrial landscape. In N. S. De, H. Orange, S. High, \& E. Koskinen-Koivisto (Eds.), The Routledge handbook of memory and place (pp. 203-213). New York: Routledge.

Tnnenbaum, N. \& Reisch, M. (2001). From Charitable Volunteers to Architects of Social Welfare: A Brief History of Social Work. School of Social Work at the University of Michigan. Retrieved November 23, 2019, from https://ssw.umich.edu/about/history/briefhistory-of-social-work. 
Trotter, J. W. Jr. (2000). African Americans and the Industrial Revolution. $O A H$ Magazine of History, 15(1), 19-23. Retrieved October 14, 2020, from https://www.jstor.org/stable/25163396

Tschirhart, M. (2005). Employee Volunteer Program. In J. L. Brudney (Ed.) Emerging Areas of Volunteering ( $2^{\text {nd }}$ ed.). ARNOVA Occasiona Paper Series, 1(2): 15-32.

Union Pacific. (2017). Move Over Sir: Women Working on the Railroad. Retrieved October 1, 2020, from https://www.up.com/aboutup/community/inside_track/firstfemale-engineers-05-05-2017

US Bureau of Labor Statistics. (2015). Volunteering in the United States, 2015. Retrieved October 1, 2020, from https://www.bls.gov/news.release/volun.nr0.htm\#: :text=By\%20age\%2C\%2035\%2D\%2 0to $\% 2044, \% 2$ Dolds $\% 20(18.4 \% 20$ percent).\&text=Over\%20the $\% 20$ year $\% 2 \mathrm{C} \% 20$ the $\% 20$ volunteer,64\%2Dyear\%2Dolds\%20declined

U. S. Volunteerism. (n.d.a). Volunteerism In Colonial America, Volunteerism In The Early Republic, Volunteerism During And After The Civil War. Retrieved November 28, 2019, from https://science.jrank.org/pages/8148/Volunteerism-U-S.html.

U. S. Volunteerism. (n.d.b). Volunteerism in Colonial America. Retrieved November 28, 2019, from https://science.jrank.org/pages/11592/Volunteerism-U-S-Volunteerism-inColonial-America.html.

U. S. Volunteerism. (n.d.d). Volunteerism During And After The Civil War. Retrieved November 28, 2019, from https://science.jrank.org/pages/11594/Volunteerism-U-SVolunteerism-during-after-Civil-War.html.

Vanderpool, T. (2020). After the Local Coal Mine Shuts Down, These Navajo and Hopi Communities Seek a Just Transition. The Natural Resource Defense Council. Retrieved December 28, 2020, from https://www.nrdc.org/stories/after-local-coal-mine-shuts-downthese-navajo-and-hopi-communities-seek-just-transition

Willis, M. (2016). Henry Ford's Anti-Semitism. JSTOR Daily. Retrieved December 28, 2020, from https://daily.jstor.org/henry-fords-anti-semitism/

Wines, F. H. (1898). "Sociology and Philanthropy." The Annals of the American Academy of Political and Social Science, 12, 49-57.

Wood, B. (2020). Introduction. In (Ed. Betsy Wood) Upon the Altar of Work: Child Labor and the Rise of a New American Sectionalism. Chicago: University of Illinois Press.

York, H. (2012). Do Children Harvest Your Food?. The Atlantic, March 26, 2012. Retrieved December 22, 2020, from 
https://www.theatlantic.com/health/archive/2012/03/do-children-harvest-yourfood/254853/

Zhang et al. (2018). Motivations of Volunteers in the Transcribe Sheng Project: A Grounded Theory Approach. 81st Annual Meeting of the Association for Information Science \& Technology. 